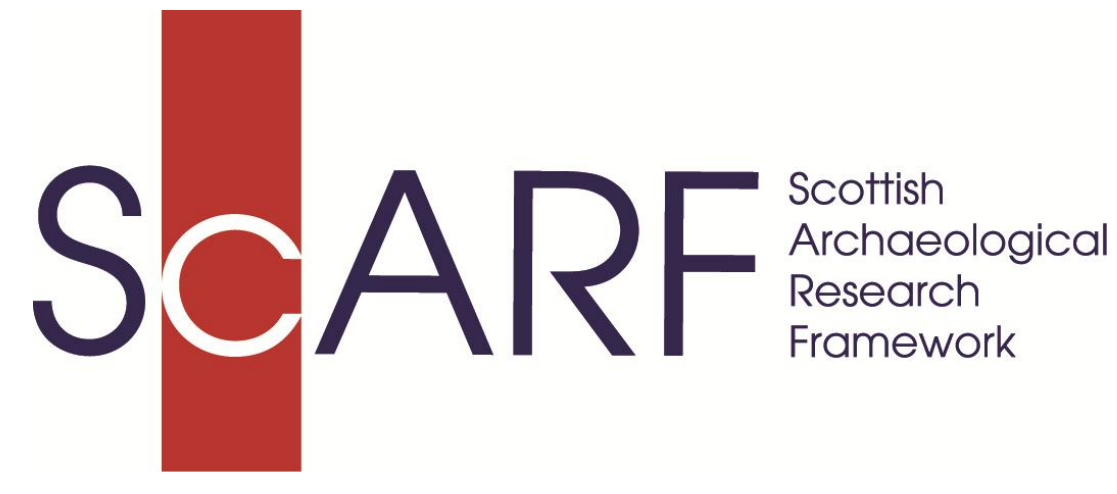

\title{
Science in Scottish Archaeology: ScARF Panel Report
}

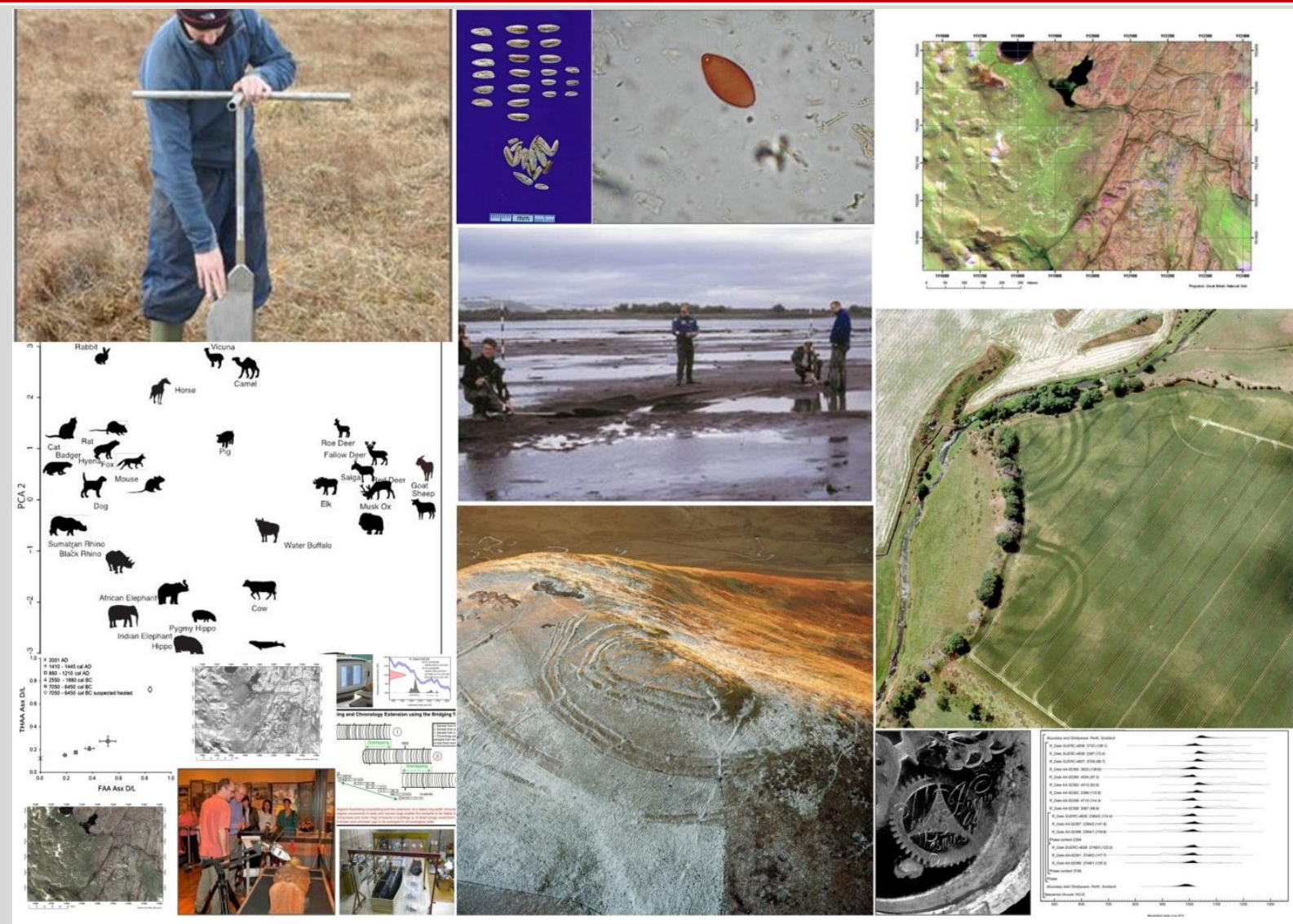

Images $(\subset$ as noted in the text

ScARF Summary Science Panel Document 


\title{
SCARF $=$
}

\section{ScARF Science in Scottish Archaeology Panel}

Karen Milek and Richard Jones (eds)

With contributions from: Richard Bates, Paul Bishop, Kate Britton, Graeme Cavers, Ruby Ceron-Carrasco, Matthew Collins, Gordon Cook, Dave Cowley, Anne Crone, Alastair Dawson, Sue Dawson, Ian J. Fairchild, Oliver Craig, Andy Dugmore, Richard Jones, Peter Langdon, Roderick McCullagh, Kathleen McSweeney, Ingrid Mainland, Karen Milek, Anthony Newton, Sue Ovenden, Eva Panagiotakopulu, Ed Schofield, Marian Scott, Finlay Stuart, Scott Timpany, Richard Tipping, Lyn Wilson, Rob Wilson

\author{
Abbreviations \\ ED-XRF Energy-dispersive XRF \\ FT IR Fourier Transform Infra Red spectrometry \\ ICP-ES (MS) Inductively coupled emission spectrometry (mass spectrometry) \\ NAA Neutron activation analysis \\ ORA Organic residue analysis \\ SAGES Scottish Alliance for Geosciences and Society \\ SEM Scanning electron microscope \\ SEM-EDAX SEM with energy-dispersive $\mathrm{X}$-ray analysis \\ XRD X-ray diffraction \\ XRF X-ray fluorescence spectrometry
}




\section{Contents}

\section{Executive Summary}

Introduction

1. Chronology

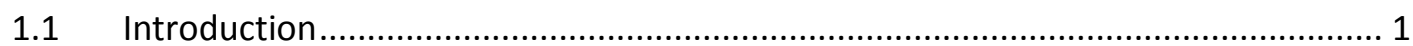

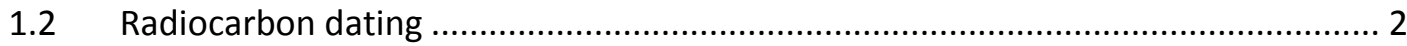

1.3 Cosmogenic nuclide and $\mathrm{Ar} / \mathrm{Ar}$ dating techniques and facilities in Scotland ............ 7

1.4 Luminescence dating in archaeology ............................................................... 10

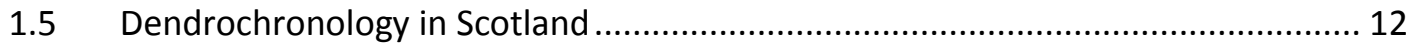

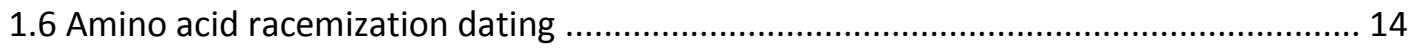

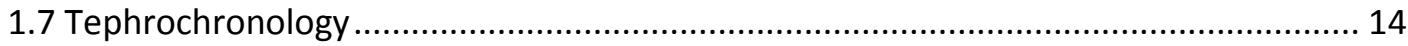

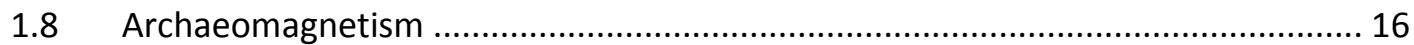

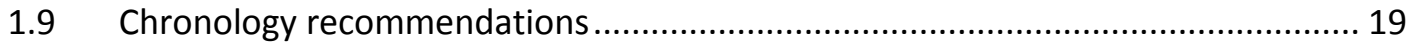

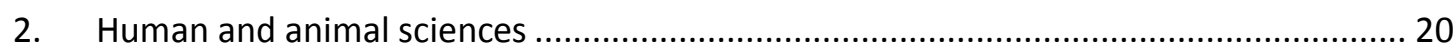

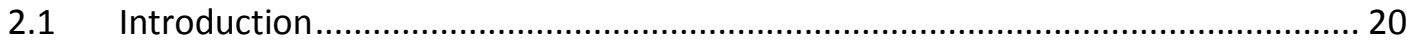

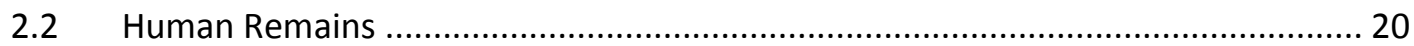

$2.3 \quad$ DNA

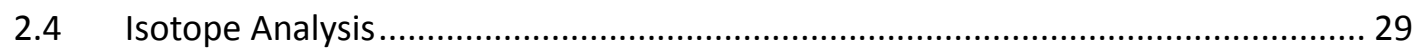

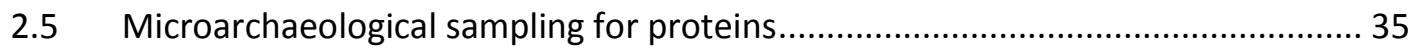

2.6 Human and animal sciences recommendations .................................................. 37

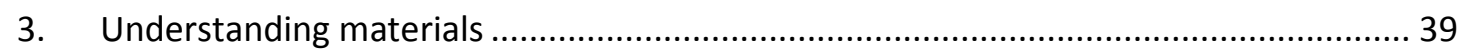

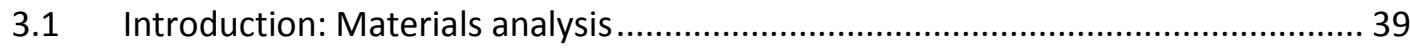

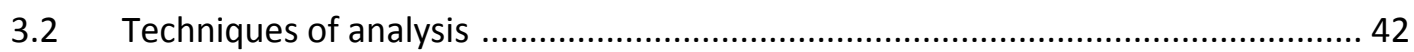

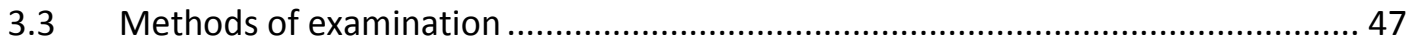

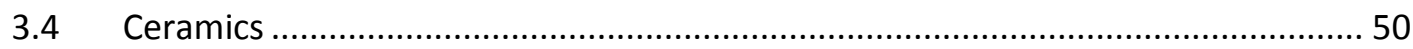

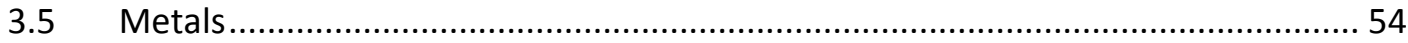

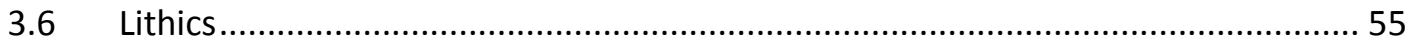

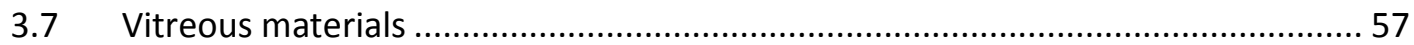

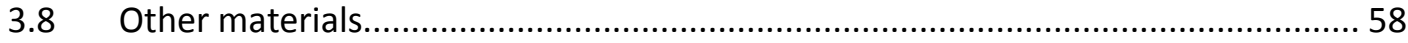


Science in Scottish Archaeology

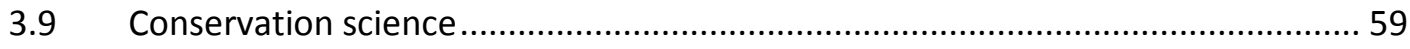

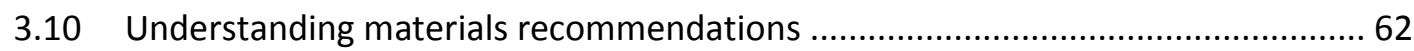

In addition, the following comprise potential opportunities....................................... 62

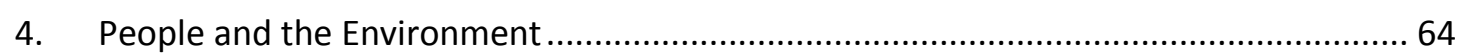

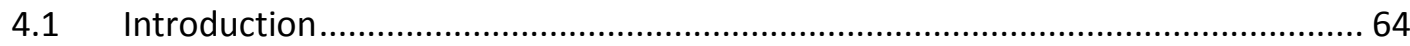

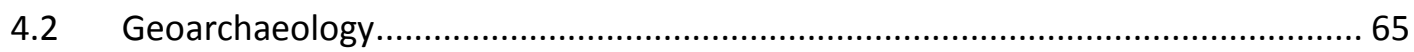

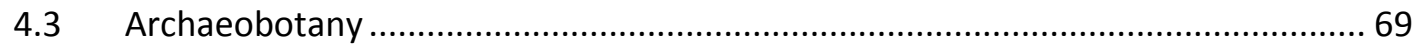

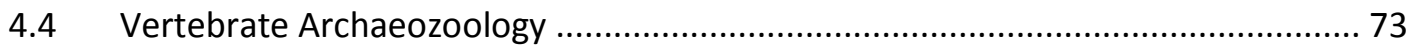

4.5 Archaeoentomology in Scotland: Background and Potential ............................... 82

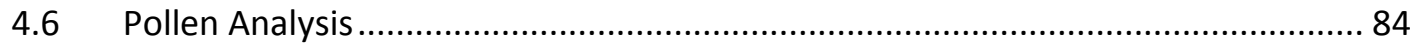

4.7 Landscape-scale Geomorphology and Sedimentology ................................... 87

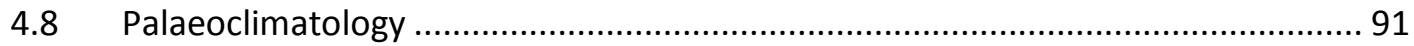

4.9 People and the environment recommendations ........................................... 98

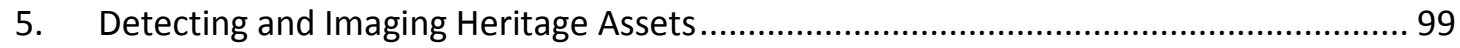

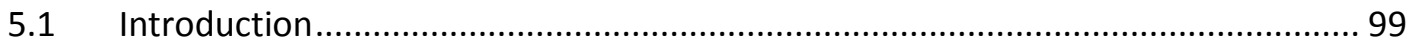

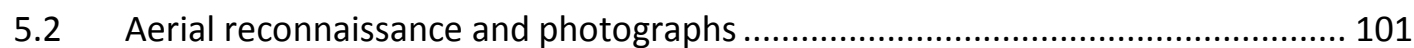

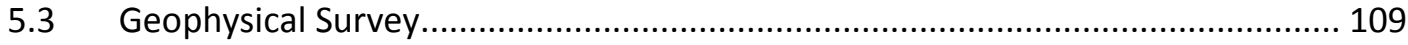

U.4 Underwater Surface Mapping .............................................................. 117

$5.5 \quad$ Laser Scanning ................................................................................ 119

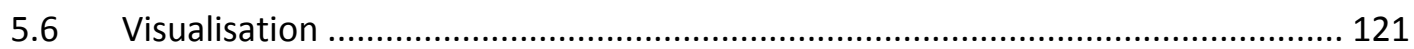

5.7 Detecting and imaging heritage assets recommendations ............................ 122

6. Statistical modelling in archaeological applications .......................................... 123

7. The Vision for Science in Scottish Archaeology ................................................ 127

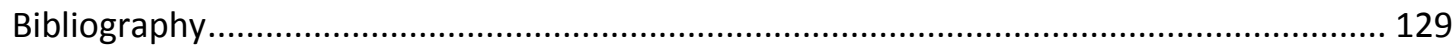




\section{List of Figures}

Figure 1: Graphical representation of the calibration of radiocarbon results for carbonised residues from Perth, Scotland in Hall et al. (2007)..

Figure 2: Sampling underway in the roof of the Mansion House, Drum Castle, Aberdeenshire, (C) AOC Archaeology Group.

Figure 3: The distribution of the archaeomagnetic dates produced on Scottish material, CCathy Batt.

Figure 4: Body of thoracic vertebra with depression in the bone surface , (c) K McSweeney 23

Figure 5: The chapel in Ensay @ Wikimedia commons.

Figure 6: Free amino acids (FAA) vs Total hydrolysable amino acids (THAA) from Demarchi et al.(2010)

Figure 7: ZooMS discrimination of animals from bone collagen peptides. Data replotted from Buckley et al. 2009.

Figure 8: Selection of the Lewis chessmen, CNMS. 39

Figure 9: pXRF of Egyptian sarcophagus, (C) Glasgow Museums 43

Figure 10: 16thc Asian bronze buddah @Glasgow Museums

Figure 11: FTIR microscope in use at NMS Collection Centre, Edinburgh CNMS

Figure 12: CT Image of 17th century pocket watch from shipwreck, revealing maker's signature CNMS

Figure 13: PC plot showing the classification of ICP-ES compositions of ceramic material .... 49

Figure 14: Four chemical chemically-defined groups, each of them in this case representing likely production sites of medieval White Gritty ware.

Figure 15: Map of the vicinity of Barnhouse showing locations of igneous dykes and Grooved Ware vessel

Figure 16: Photomicrographs of thin sections of Grooved Ware at Barnhouse 52

Figure 17: The Carpow longboat during excavation and undergoing treatment in the large objects facility at the National Museums Scotland Collection Centre (CRCAHMS and (C) Strachan, D Carpow in Context.

Figure 18: Charred grain before and after sorting of a flotation sample into species, including here oats, barley and wheats, together with wild taxa. CScott Timpany 69

Figure 19: Charred fruit stones, CScott Timpany. 70

Figure 20: Otoliths of $2^{\text {nd }}-3^{\text {rd }}$ year saithe (Pollachius virens) recovered at the Iron Age settlement of Bostadh Beach, Lewis, Western Isles, (C Cerón-Carrasco 2005 
Figure 21: Core samples for pollen analysis taken from natural peatland contexts, (C) J Schofield.

Figure 22: Pollen-based studies which consider the impact of people, (C) J Schofield.

Figure 23: Cereals pollen grains, (C) J Schofield.

Figure 24: Schematic representation of crossdating in dendrochronology, (CR Wilson 93

Figure 25: A preliminary mean July-August temperature reconstruction for the Cairngorms (C) Wilson.

Figure 26: Differential crop growth revealing a complex of plough-levelled sites at Aytonlaw in Berwickshire, CRCAHMS. 102

Figure 27: Oblique aerial view centred on the remains of Woden Law Fort in the Cheviots, C) RCAHMS

Figure 28: Multi-spectral survey of an area on the Isle of Coll showing an enclosure in the centre of the image, (C) Dawson/Winterbottom/NERC. 107

Figure 29: False colour composite using the 9, 7, 3 bands in the red, green and blue display respectively i.e. the inferred light range, (C) Dawson/Winterbottom/NERC. 108

Figure 30: Daytime thermal image using band 11 of the spectrum i.e. infrared, (C) Dawson/Winterbottom/NERC. 108

Figure 31: Radiocarbon calibration, (C) ORAU. 124

\section{List of Tables}

Table 1: Previous studies of human remains in Scotland

Table 2: Ceramics: a selection of recent fabric, technological and functional (organic residue) analyses

Table 3: Metals: a selection of recent investigations 55

Table 4: Lithics: provenance determinations 57

Table 5: Work on Scottish vitreous materials 58

Table 6: selected work on other materials 59

Table 7: Selected examples of conservation science 60

Table 8: Dates for Neolithic cultivation from sites across Scotland; an example of collated data.

Table 9: Summary of Geophysical Techniques and their application 110

Table 10: A summary of the suitable application of various techniques 115

Table 11: Nearshore marine survey methods 118 


\section{Executive Summary}

\section{The Importance of Science in Scottish Archaeology}

Scotland has the potential to be a world leader in the development and application of archaeological science and builds on a long and distinctive tradition of both scientific and archaeological innovation. A variety of peoples have met, interacted and lived in Scotland over many thousands of years and archaeological science is fundamental to understanding their life stories: from establishing when and where they lived, to the objects they produced, and the material remains of the individuals themselves. The Scottish environment itself offers a unique blend of characteristics within a relatively small geographical area that preserve a range of information on past peoples and landscapes. The body of evidence is large enough to be encompassing, though small enough to be comprehensible. Understanding the past is also wholly relevant to the present day, contributing to current understandings of how peoples and individuals interact with one another and with the world around them, as well as enriching current life through understanding and presenting this rich heritage in contemporary terms to modern people.

In Science, Scotland excels in a number of fields and can draw upon a range of resources and skills distributed across the country. Archaeologically, Scotland offers a diverse set of contexts in which to apply and improve techniques of analysis in order to understand past lives. Partnerships between these diverse (and often overlapping) communities provides the opportunity to combine both, exploring the past through landscapes, site, artefacts and people, both in the field and in the laboratory.

\section{Panel Task and Remit}

The task that faced the ScARF Science in Scottish Archaeology Panel was to provide a critical review of the application of scientific techniques within archaeological research and to identify improvements for future research. To this end, the panel undertook to summarise the current state of knowledge, divided into five study themes: Chronology, Human and animal sciences, Understanding materials, People and the environment, and Detecting and imaging heritage assets. The panel report is aimed at both archaeologists and natural scientists, hopefully making both communities better aware of the data, techniques and resources that the other can provide, and promoting the benefits of collaboration.

\section{Future Research}

The main recommendations of the panel report can be summarised under four key headings:

- High quality, high impact research: the importance of archaeological science is reflected in work that explores issues connected to important contemporary topics, including: the demography of, the nature of movement of, and contact between peoples; societal resilience; living on the Atlantic edge of Europe; and coping with environmental and climatic change. A series of large-scale and integrated archaeological science projects are required to stimulate research into these important topics. To engage fully with 


\section{Science in Scottish Archaeology}

these questions data of sufficient richness is required that is accessible, both within Scotland and internationally. The RCAHMS' database Canmore provides a model for digital dissemination that should be built on.

- Integration: Archaeological science should be involved early in the process of archaeological investigation and as a matter of routine. Resultant data needs to be securely stored, made accessible and the research results widely disseminated. Sources of advice and its communication must be developed and promoted to support work in the commercial, academic, research, governmental and $3^{\text {rd }}$ sectors.

- Knowledge exchange and transfer: knowledge, data and skills need to be routinely transferred and embedded across the archaeological sector. This will enable the archaeological science community to better work together, establishing routes of communication and improving infrastructure. Improvements should be made to communication between different groups including peers, press and the wider public. Mechanisms exist to enable the wider community to engage with, and to feed into, the development of the archaeological and scientific database and to engage with current debates. Projects involving the wider community in data generation should be encouraged and opportunities for public engagement should be pursued through, for example, National Science Week and Scottish Archaeology Month.

- Networks and forums: A network of specialists should be promoted to aid collaboration, provide access to the best advice, and raise awareness of current work. This would be complemented by creating a series inter-disciplinary working groups, to discuss and articulate archaeological science issues. An online service to match people (i.e. specialist or student) to material (whether e.g. environmental sample, artefactual assemblage, or skeletal assemblage) is also recommended. An annual meeting should also be held at which researchers would be able to promote current and future work, and draw attention to materials available for analysis, and to specialists/students looking to work on particular assemblages or projects. Such meetings could be rolled into a suitable public outreach event. 


\section{Introduction}

Scotland has a rich history of archaeological science, building on a strong tradition of research in both archaeology and the natural sciences. A range of scientific techniques are routinely employed within archaeological work, from radiocarbon dating to palynology. Scotland also has a long history of reconnaissance for sites through survey on the ground, in the air, and increasingly, underwater. Artefacts analysis, another traditional strength in Scotland, is now being supplemented by new non-destructive technologies. Research conducted in fields such as genetics has the potential to provide a new window into the past through the remains of people and animals. Technologies are increasingly mobile, allowing the laboratory to be brought to the field, while new techniques can profitably be applied to the archaeological archive, whether through physical investigation or through the statistical analysis of existing data.

The Scottish environment itself offers a unique blend of characteristics within a relatively small geographical area, including peat formation, wetlands, indented coastlines and a range of low to high energy environments that preserve a variety of information on past peoples and landscapes. The evidence is big enough to be substantial, though small enough to be achievable, with the retreat of the ice sheets providing a well-defined starting point for the presence of human societies. The diverse and distinctive set of environmental archives provides a wealth of data on how people lived in the Atlantic zone.

Techniques and approaches are continually developing, and it is essential that capacity and expertise are built up in tandem. Engaging scientists with archaeological questions, while highlighting the potential of archaeological data to drive research is an important consideration. This can be developed through research projects tackling fundamental questions regarding human society in the past, as well as by making collaboration an integral and routine part of archaeological practice, involving archaeological scientists early in project planning.

Archaeological science research in Scotland has broader implications relevant to contemporary issues and for science in archaeology all periods are interesting and of value, from deep time until the recent past. Analysis of the remains of humans and animals, for example, provides data of relevance to the history of disease and other demographic questions. Research into past human responses to environmental change is also of great relevance to understanding processes in the present, as studies of past societies provide 'completed experiments.' A key challenge is to be able to untangle the range of causes for change in past society, some driven by climate and the environment, others driven by cultural choices and historical events. How societies developed and why some appear more durable than others are questions that a combination of archaeological and scientific techniques can begin to answer.

These issues are all explored through a number of different themes, and following an introduction to each, there is a survey of Scottish applications, a statement on current scientific facilities available in Scotland and reflection on emerging opportunities. Building on sound archaeological and scientific principles in these areas allows a greater understanding, and therefore appreciation, of the past, helping to unleash its knowledge and heritage value through research, preservation, promotion and engagement. 


\section{Chronology}

\subsection{Introduction}

Chronology is a fundamental part of archaeology. All of the questions we have about the past require an accurate knowledge of chronology in order to answer them satisfactorily. Establishing the timing and sequence of events is central to integrating the rich and diverse strands of material evidence available to archaeology. Scientific techniques have revolutionised chronological estimations for archaeologists, and are increasingly able to provide chronological resolution on the scale of single human generations, allowing the understanding of change on the level of a human lifespan.

In addition to refinements of established techniques (including greater precision, smaller sample sizes, less destructive techniques, and faster and more economical processing), new approaches are continually being developed. The range of different dating techniques available represents considerable research potential for archaeology in Scotland. In order to harness this potential, however, and to decide the best application of each technique, there is a need to understand the information that it can (and cannot) provide, as well as the approach (or combination of approaches) that should be utilised. The infrastructure and knowledge base for different dating techniques differs across Scotland with different expert practitioners, centres of excellence and facilities relevant to different aspects of chronology.

Relatively established techniques are briefly listed below. The most extensively utilised technique within Scottish archaeology - radiocarbon dating- can be used to date organic remains and inorganic carbon-containing materials such as shell. Luminescence dating can be used to date minerals such as quartz or feldspar within ceramics, lithics and sedimentary materials according to their last exposure to light or heat. Dendrochronology uses tree-rings to date wooden material according to when it lived or was felled, and long-term dendrochronological sequences are now being constructed for Scottish material. Tephrochronology is based on the identification and correlation of volcanic deposits. Cosmogenic nuclide dating has been widely utilised within earth and environmental sciences to date exposure of surfaces through analysis of radionuclides formed in surface rocks and soils (including $10 \mathrm{Be},{ }^{26} \mathrm{Al}$ and ${ }^{36} \mathrm{Cl}$ ) and has now been developed to explore timescales relevant to archaeological analysis; cosmogenic nuclide analysis can also be used to determine ancient rates of erosion, an issue that is potentially useful in understanding human impact in the archaeological record. Amino acid racemisation dates marine molluscs and archaeomagnetic dating is used to date fired structures, such as hearths or kilns.

The selection of a particular technique will depend upon the circumstances of any given archaeological research. This requires consideration of the likely age and type of material available and the levels of precision and accuracy required, and should be reflected in suitable dating strategies. The limitations of each technique should be considered (bearing in mind that these may change depending on context), as well as the need for relating scientifically-derived information from specific samples to contextual information from the site, building, artefact or landscape.

Dating strategies should be fully considered at the start of a project and consistently re-evaluated as new evidence comes to light. This not only helps to ensure that a dating opportunity is not 
missed in the field, as optically stimulated luminescence and archaeomagnetic sampling must occur with in situ deposits, but it also encourages an on-going dialogue between the archaeologist and dating specialist that will only serve to increase the reliability of any dating undertaken. This is especially important since the statistical modelling and analysis of data, where applicable, should also form a component of further analysis. If the dating programme is developed and undertaken using a Bayesian framework, the results will be robust and a greater precision will almost certainly be achieved.

Building on established techniques - as well as developing both new approaches and novel applications of existing techniques - offers to archaeology an increasingly powerful set of tools. Archaeology in turn can provide a driver for developing and improving techniques. The relationship between the sciences and archaeology in terms of chronology is therefore mutually beneficial, and absolutely essential for answering questions about people in the past.

\subsection{Radiocarbon dating}

${ }^{14} \mathrm{C}$ is a cosmogenic radionuclide that is formed continuously but not quite at a constant rate by the reaction of thermal neutrons with atmospheric nitrogen:

$$
{ }_{7}^{14} N+n \rightarrow{ }_{6}^{14} C+p
$$

It was the work of Willard Libby and his co-workers at the Institute for Nuclear Studies and Department of Chemistry at the University of Chicago that led to the development of the radiocarbon dating technique (e.g. Libby 1946; Anderson et al. 1947; Libby et al. 1949; Anderson and Libby, 1951).
The ${ }^{14} \mathrm{C}$ that is produced in the upper atmosphere by the ${ }^{14} \mathrm{~N}(n, p){ }^{14} \mathrm{C}$ reaction is rapidly oxidised to ${ }^{14} \mathrm{CO}_{2}$ and mixes with the stable isotope forms $\left({ }^{13} \mathrm{CO}_{2}\right.$ and ${ }^{14}\left(\mathrm{CO}_{2}\right)$, giving a final atom ratio of approximately $10^{12}: 10^{10}: 1$ of ${ }^{12} \mathrm{C}:{ }^{13} \mathrm{C}$ : ${ }^{14} \mathrm{C}$. The $\mathrm{CO}_{2}$ is taken up by green plants in the terrestrial biosphere and converted to carbohydrates by the process of photosynthesis. Subsequent consumption of plants by animals (and animals by other animals) transfers the ${ }^{14} \mathrm{C}$ throughout the entire terrestrial food chain and it is now well established that there is global uniformity in natural ${ }^{14} \mathrm{C} /{ }^{12} \mathrm{C}$ enrichment between the well mixed atmosphere and the terrestrial flora and fauna that atmospheric carbon supports, provided that due corrections are made for the degree of isotopic fractionation that takes place during the initial uptake and subsequent metabolic fixation of atmospheric carbon by the primary producers (plant life) and thereafter, any isotopic fractionation that occurs during subsequent transport through the food chain. In contrast, however, the oceans and the life that they support represent a rather heterogeneous reservoir that is not in equilibrium with the atmosphere.

The four fundamental assumptions in the conventional radiocarbon dating method are that:

1. The rate of formation of ${ }^{14} \mathrm{C}$ in the upper atmosphere has been constant over the entire applied ${ }^{14} \mathrm{C}$ dating time-scale (approximately the last 50,000 years).

2. The activity of the atmosphere and the biosphere with which it is in equilibrium has been constant over the applied time-scale.

3. The rate of transfer of ${ }^{14} \mathrm{C}$ between different reservoirs of the carbon cycle is rapid with respect to the average lifetime of ${ }^{14} \mathrm{C}$ (approximately 8300 years). 


\section{The half-life is accurately known}

On the basis of the above assumptions, all living organisms, throughout the entire applied ${ }^{14} \mathrm{C}$ dating time-scale, would have been labelled to the same extent with ${ }^{14} \mathrm{C}$ during life, however, on death, ${ }^{14} \mathrm{C}$ uptake ceases and only radioactive decay (which follows first order kinetics) then occurs.

The current internationally-accepted value for living, terrestrial carbonaceous matter was determined from tree rings formed in the year 1890 and is quoted as $0.226 \mathrm{~Bq} \mathrm{~g}^{-1}$ of carbon. The year 1890 was chosen as the last time that the ${ }^{14} \mathrm{C}$ record was undisturbed. After this time, a significant dilution of the atmospheric ${ }^{14} \mathrm{CO}_{2}$ was observed due to the burning of fossil fuels (Suess, 1953; 1955), often termed the Suess effect. Then, during the 1950s and early 1960s, the atmospheric testing of nuclear weapons increased the atmospheric ${ }^{14} \mathrm{C}$ activity. In the northern hemisphere, the atmospheric activity almost doubled by the early 1960s, however, following the partial test ban treaty in 1963, the activity has declined exponentially as the excess ${ }^{14} \mathrm{C}$ has entered the oceans and the terrestrial biosphere.

\section{Age Ranges and Calculations}

The entire applied radiocarbon dating time-scale extends from about 300 years BP to about 50,000 years BP. Samples more recent than $300 \mathrm{BP}$ are indistinguishable from late $19^{\text {th }}$ and early $20^{\text {th }}$ samples because of the Suess effect while at 50,000 BP; measurements are approaching the limit of detection.

A radiocarbon age is calculated from a rearranged form of the first order decay equation as follows:

$$
\mathrm{t}=\frac{1}{\lambda} \ln \left[\frac{\mathrm{Ao}}{\mathrm{At}}\right]
$$

where $t=$ the time that has elapsed since removal of the carbonaceous material from the carbon cycle (ie. death of the organism), $\lambda=$ decay constant $\left(\ln 2 / t_{1 / 2}\right)=$ $1.2449 \times 10^{-4}$ where $t_{1 / 2}=$ Libby half-life $=$ 5568 years, $A_{t}=$ the activity of the carbonaceous material $t$ years after death as measured in the radiocarbon laboratory and $A_{0}=$ equilibrium living activity of 1890 wood $\left(0.226 \mathrm{~Bq} \mathrm{~g} \mathrm{~g}^{-1} \mathrm{C}\right)$, again as measured in the radiocarbon laboratory. Because 1890 wood, which can be considered to be the primary standard, is limited in supply, a secondary standard whose activity can be linked to that of the primary standard is typically measured. The current internationallyaccepted standard is SRM-4990C, which is oxalic acid manufactured from the 1977 harvests of French sugar beet molasses. It is commonly known as Oxalic acid II and is distributed by the National Institute of Standards and Technology, Maryland, USA. SRM-4990, often termed Oxalic acid I, was the original standard but supplies of this material were largely exhausted some time ago.

Because samples have to be corrected for fractionation, the equation is more correctly written as:

$$
\mathrm{t}=\frac{1}{\lambda} \ln \left[\frac{\mathrm{AON}}{\mathrm{ASN}}\right]
$$

where $A_{O N}$ is the activity of the Oxalic acid II standard normalised for fractionation and $A_{S N}$ is the normalised sample activity.

It is now well established that none of the four assumptions quoted above are strictly correct. For example:

1. It is now well known that there are both long term and shortterm variations in the ${ }^{14} \mathrm{C}$ production rate (Elsasser et al. 1956; Stuiver 1961; Damon et al. 1989; Sternberg 1992). 
2. It follows that if the ${ }^{14} \mathrm{C}$ production rate has not been constant, it is unlikely that the activity in the atmosphere and biosphere could have remained constant, in particular as reservoir sizes have also changed through time in response to climatic change.

3. It is now well established that contemporaneous terrestrial and marine organisms will give different radiocarbon ages due to the long residence times of carbon in the deep oceans (approximately 2000-3000 years) and the fact that the surface oceans are a mix of 'old' carbon from the deep oceans and 'new' carbon from the atmosphere, resulting in organisms that are supported by surface ocean carbon having an age offset of about 400 years (marine reservoir effect). This is further complicated by the fact that thermohaline circulation and upwelling patterns mean that the oceanic environment and the plant and animal life that it supports represents a rather heterogeneous environment with respect to ${ }^{14} \mathrm{C}$ activities, irrespective of corrections for fractionation. Therefore, a standard correction cannot be applied to ages derived from the marine environment to bring them into line with terrestrial ${ }^{14} \mathrm{C}$ ages. However, calibration curves that are models based on the atmospheric ${ }^{14} \mathrm{C}$ record are available for marine samples (Stuiver et al. 1998). The modelled marine calibration curve (Marine09) accounts for the global average surface water offset $\mathrm{R}(\mathrm{t})$; however, temporal and spatial deviations from this offset, known as $\Delta R$, are evident.
In the absence of suitable terrestrial material, accurate and precise quantification of $\Delta R$ is imperative for accurate calculation of calendar age ranges based on samples containing marine-derived carbon. This is a critical factor in Scottish archaeology where, owing to our island location, prehistoric communities typically exploited a large coastal resource base. Consequently, marine-derived material makes a considerable contribution to the national archaeological assemblages. Therefore, if ${ }^{14} \mathrm{C}$ dating has to rely on marine-derived material from any of these sites, it is of paramount importance that variations in $\Delta R$ are well documented in order to ensure good chronological control. Previous SUERC studies within the British Isles to determine $\Delta \mathrm{R}$ have been carried out by Ascough et al. (2004, 2005a, 2005b. 2006, 2007, 2009) and Russell et al. (2010, 2011a, 2011b), and further research is on-going

4. The Libby half-life, which is significantly different from the true physical half-life, is still used in ${ }^{14} \mathrm{C}$ age calculations.

In the case of samples derived from the terrestrial environment, assumption 3 does not really apply and the other three have been overcome by correlating the radiocarbon dating technique with dendrochronology. The latter has provided a continuous sequence of tree ring material of absolute known age, which covers the entire Holocene. Radiocarbon dating of decadal sequences of this material has provided a plot of true calendar age versus radiocarbon age, i.e. a calibration curve. This calibration curve has now been extended back to the upper limit of detection using paired $14 \mathrm{C}$ and $\mathrm{U}$ - 
series age measurements on coral sequences, 14C dated high-resolution marine varves, etc.

\section{Available Radiocarbon Technology in Scotland}

In terms of radiocarbon dating, Scotland is extremely fortunate to have 2 AMS instruments at the Scottish Universities Environmental Research Center (SUERC) and the combined AMS $/{ }^{14} \mathrm{C}$ expertise that exists within SUERC puts Scotland at the forefront of ${ }^{14} \mathrm{C}$ research. The $5 \mathrm{MV}$ tandem AMS (National Electrostatics Corporation) is a multi-purpose instrument used for ${ }^{10} \mathrm{Be},{ }^{26} \mathrm{Al}$ and ${ }^{36} \mathrm{Cl}$ as well as ${ }^{14} \mathrm{C}$ analysis. The second instrument is a $250 \mathrm{kV}$ single stage AMS (SSAMS) (again National Electrostatics Corporation) which is dedicated to ${ }^{14} \mathrm{C}$ analysis. The former satisfies the requirements of the Glasgow University, Edinburgh University and NERC cosmogenic isotope preparation facilities as well as the SUERC Radiocarbon Dating Laboratory and the Natural Environment Research Council (NERC) Radiocarbon Facility (Environment). The SSAMS is dedicated to making measurements for the two radiocarbon laboratories. For clarity, both radiocarbon laboratories are managed by SUERC. The NERC Radiocarbon Facility (Environment) was established to meet the need within the UK for radiocarbon analyses in NERCsupported areas of environmental and Earth sciences. The SUERC laboratory undertakes collaborative research within the university sector as well as its own inhouse research and has received research funding from a variety of bodies including the UK Research Councils, the Leverhulme Trust, the UK Nuclear Industry, the Commission of European Communities, International Atomic Energy Agency, Historic Scotland and English Heritage. The commercial wing of the laboratory undertakes radiocarbon analyses in a number of fields but the main focus is archaeology. The laboratory currently has the capacity to produce around 5000 AMS targets per annum, of which approximately 3500 would be unknown age samples and 1500 would be standards. Currently a total of around 3500 targets are measured. The standard target size is $1.5 \mathrm{mg}$ carbon for routine analyses but for research purposes samples of a few tens of micrograms have been measured. For standard-sized targets, routine precision for samples of Holocene age is \pm 30 - 35 years at 1 sigma.

\section{Emerging Opportunities}

There are a number of opportunities arising from the on-going research at SUERC. These include the following:

- High precision AMS analysis: the capability to measure unknown ${ }^{14} \mathrm{C}$ samples to a precision of between 1 and $2 \%$ (i.e. 8-16 years) has been demonstrated (Cook et al. 2010). These results were backed up by quality assesment data that confirmed both the accuracy and precision of the measurements on the unknowns. This capability will be used in an application currently being prepared that will include the dating of Early Iron Age crannogs whose construction phase falls on the socalled 'Hallstat Plateau'. There are many other potential applications that would benefit from high precision data, particularly if used in combination with Bayesian statistics (see section 6).

- Maximisation of Impact of dating information: There is a need for people in Scotland with a good background in Bayesian statistics (and archaeology) who can help archaeologists to design their ${ }^{14} \mathrm{C}$ dating programs to achieve the maximum amount of information. In particular, someone with a good grasp of calibration programs such as OxCal 
that use Bayesian techniques. $\mathrm{Dr}$ Derek Hamilton is a recent appointment to SUERC staff and has that expertise (Hamilton and Haselgrove 2009; Hall et al. 2010).

- Compound Specific ${ }^{14} \mathrm{C}$ dating: $\mathrm{Dr}$ Gillian Mackinnon is a SAGES appointment whose remit is partly to develop compound specific ${ }^{14} \mathrm{C}$ dating. This presents an opportunity for research grant applications on such topics as food residues in pottery, etc.

- Enhanced understanding of marine and freshwater reservoir effects: There is a definite requirement for archaeologists to understand the effects of non terrestrial food resources in the human diet on calibration of ${ }^{14} \mathrm{C}$ ages of human remains. There are potential opportunities for research in this area. The SUERC lab. has been researching both marine and freshwater reservoir effects for around a decade (Cook et al. 2001, 2002; Ascough et al. 2004, 2005, 2006; Russell et al. 2010).

More generally, there is an opportunity for archaeologists in Scotland (in professional, academic and private sectors) to formulate and submit research grant applications with SUERC staff and to achieve meaningful collaborations on a range of archaeological problems requiring ${ }^{14} \mathrm{C}$ and/or stable isotope measurements.
Historic Scotland (HS) has funded the development of an on-line system to handle archaeologists' applications for HS funded radiocarbon dating. The system is based on a database, linked to the Online AccesS to the Index of archaeological investigations (OASIS), which will provide the applicant with an on-screen application form and will permit the submission of the form electronically to the HS programme supervisor for consideration. The programme supervisor's decision will be transmitted directly back to the applicant and forwarded to the ${ }^{14} \mathrm{C}$ laboratory. If approved, the applicant will then be instructed to dispatch the samples and the lab will be forewarned of their imminent arrival. The system will allow applicant and supervisor to communicate to resolve problems. Once the analysis is complete, the system will then transmit the radiocarbon result certificate to both the supervisor and applicant. At the time of writing (April 2011), the system is undergoing further bench-testing. Some minor faults remains to be ironed out but HS hope to see the system running by late summer 2012.

HS also hope that once the system is up and running well they will be able to upload all the existing ${ }^{14} \mathrm{C}$ results funded through HS or its predecessor bodies. These data will be available through the same on-line database system and will be supplemented as each new batch of result certificates is issued. The system has the facility of not moving results into the public domain if some compelling reason exists for confidentiality. 


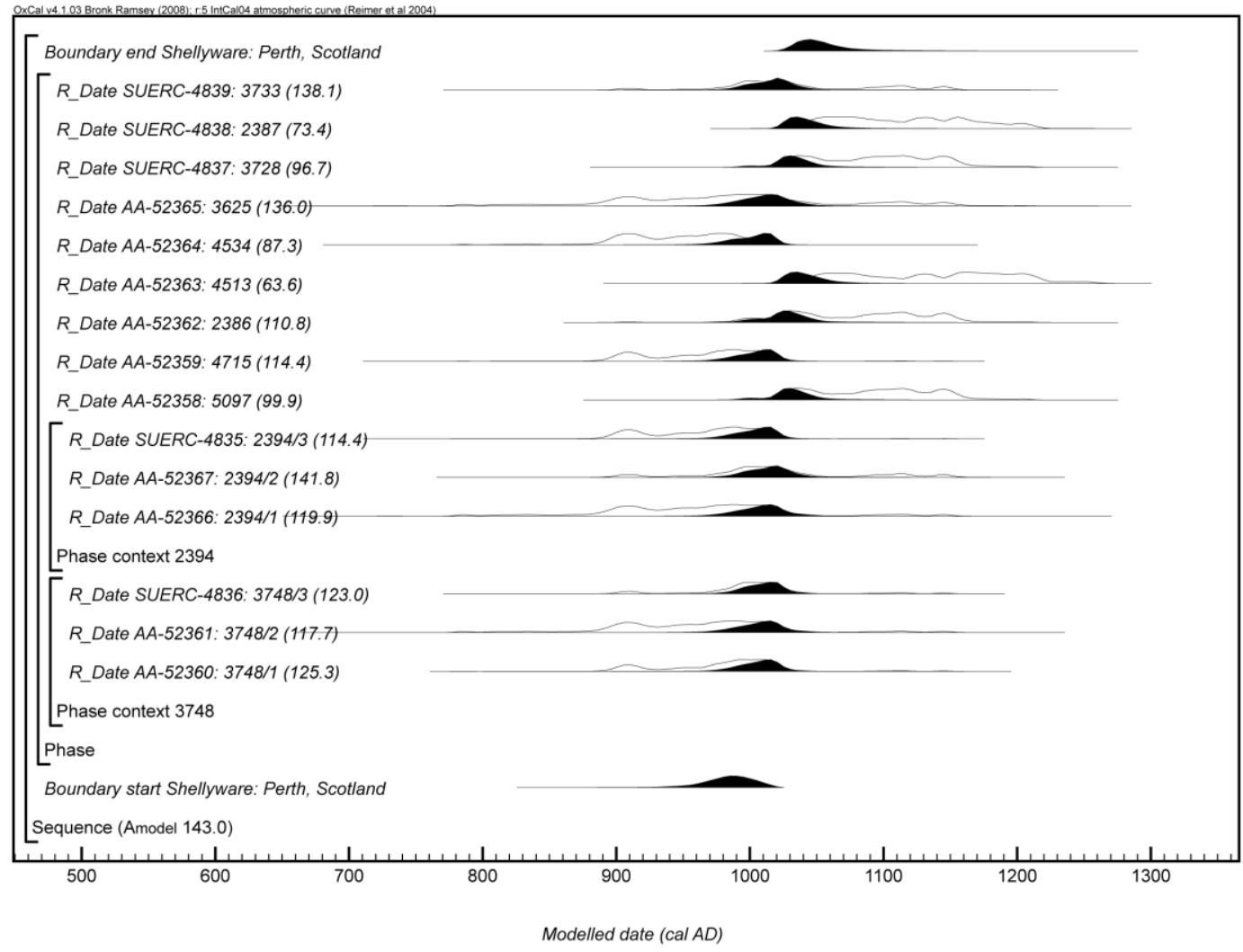

Figure 1: Graphical representation of the calibration of radiocarbon results for carbonised residues from Perth, Scotland. The chronological model for Shelly Ware in Perth is as previously described in Hall et al. (2007). It is composed of the ${ }^{14} \mathrm{C}$ measurements on 15 carbonized residues from 11 different archaeological contexts. The measurements are in agreement with the model assumption that they belong to a single phase of activity. This activity dates the introduction of Shelly Ware in Perth to cal AD 930-1020 (95\% probability; start Shellyware: Perth, Scotland) [cal AD 960-1000 (68\% probability)]. Shelly Ware fell out of use in Perth in cal AD 1020-1120 (95\% probability; end Shellyware: Perth, Scotland) [cal AD 1030-1070 (68\% probability)]. (N.B. These results vary very slightly from those analysed using OxCal 3.10 and reported in Hall et al. (2007)).

\subsection{Cosmogenic nuclide and Ar/Ar} dating techniques and facilities in Scotland ${ }^{1}$

Introduction and explanation of the technique

The terrestrial cosmogenic nuclide (TCN) and ${ }^{40} \mathrm{Ar} /{ }^{39} \mathrm{Ar}$ chronometric techniques

${ }^{1} \mathrm{Ar}=$ Argon, $\mathrm{K}=$ Potassium, $\mathrm{Be}=$ Beryllium, $\mathrm{Al}=$ Aluminium, $\mathrm{Cl}=$ Chlorine, $\mathrm{Ca}=$ Calcium, $\mathrm{He}=$ Helium, $\mathrm{Ne}=\mathrm{Neon}, \mathrm{Sr}=$ Strontium are widely used in Earth and environmental sciences. TCN techniques rely on the ingrowth of nuclides within the mineral lattice (hence, in situ TCNs) as a result of the interactions between secondary cosmic radiation and minerals in that lattice, and the Ar-Ar technique is a development of the technique that relies on the decay of $\mathrm{K}$ to $\mathrm{Ar}$ to date volcanic rocks and weathering products. Recent technical advances in both fields now allow the techniques to be used on timescales that are relevant to archaeology, and although technically challenging, both techniques are now capable of measuring sub-1,000 year ages. TCNs accumulate at the Earth's 
surface and so provide a chronology of exposure (Siame et al. 2006; Dunai 2010).

Recent archaeological applications include the dating of flint artefacts and building structures (Akçar et al. 2008). TCNs can also be used to determine rates of erosion, and multiple nuclides with different half-lives can be used to date the deep burial of materials (e.g., in caves where the materials are cut off from cosmic radiation). Such burial dating isbest suited to older settings, however, such as Palaeolithic stone artefacts that have been buried for hundreds of thousands of years, and so is not likely to be useful in the currently understood Scottish context.

A blog of Dr Greg Balco of the Berkeley Geochronology Center in California has a very useful and up-to-date discussion of the issues associated with burial dating and its application ${ }^{2}$. Novel applications of multiple nuclides with different half-lives are also being developed for determining ages of timing and amounts of soil erosion in the past, with potential applications to archaeological settings (see below).

$\mathrm{Ar} / \mathrm{Ar}$ dating is limited to $\mathrm{K}$-rich minerals, such as sanidine, from volcanic ashes and is primarily used to bracket the timing of site occupation. The SUERC $\mathrm{Ar} / \mathrm{Ar}$ laboratory has three magnetic sector mass spectrometers which it operates for the NERC-funded national facility.

\section{A survey of the Scottish application and a brief literature review}

As far as is currently known, TCNs have not yet been exploited directly in Scottish archaeological contexts, but there is great

2

(http://cosmognosis.wordpress.com/2010/11/ 03/exotic-burial-dating-methods/; accessed 15 July 2011) potential for their application, given the research capacity and analytical capability that are available in Scotland (see below). In Israel, for example, Verri et al. (2005) interpreted the differing ${ }^{10} \mathrm{Be}$ contents of independently dated chert tools in a cave. They argued that the chert for artefacts with very low ${ }^{10} \mathrm{Be}$ concentrations must have been obtained from mines or pits deeper than a few metres (i.e., below the depth of production of $\left.{ }^{10} \mathrm{Be}\right)$, whereas others artefacts had measurable but variable ${ }^{10} \mathrm{Be}$ contents, indicating that the chert for these artefacts had been obtained from either deposits of varying depths (i.e., varying degrees of exposure to cosmic radiation) or from surface materials that had had varying durations of exposure at the ground surface. In other words, TCN analysis in this context is a valuable tool for provenance studies and other specific applications may yet be developed.

\section{Research capacity within Scotland}

There are two types of TCNs, radioactive ('radio-nuclides') and stable. The radionuclides, primarily ${ }^{10} \mathrm{Be},{ }^{26} \mathrm{Al}$ and ${ }^{36} \mathrm{Cl}$, with ${ }^{14} \mathrm{C}$ currently in development, are extracted from exposed rocks and minerals, at several dedicated laboratories in Scotland.

Note that consideration here is of in situ ${ }^{14} \mathrm{C}$ that is formed in the crystal lattice of quartz by spallation of oxygen by secondary cosmic radiation, and not the ${ }^{14} \mathrm{C}$ that is formed in the upper atmosphere by spallation of nitrogen. The ${ }^{14} \mathrm{C}$ formed by spallation of $\mathrm{N}$ is oxidised to $\mathrm{CO}_{2}$ that is taken up in photosynthesis and forms the basis of 'conventional' radiocarbon dating. That ${ }^{14} \mathrm{C}$ can be thought of as 'meteoric' ${ }^{14} \mathrm{C}$ (formed in the atmosphere) and there is likewise meteoric ${ }^{10} \mathrm{Be}$ that was used in the $1980 \mathrm{~s}$ and 1990s but fell into disuse once the theory and practice of in situ ${ }^{10} \mathrm{Be}$ had been formulated by Lal (1988). The use of meteoric ${ }^{10} \mathrm{Be}$ is currently being revived for landscape evolution studies (Graley et 
al. 2010; Willenbring and von Blanckenburg, 2010).

SUERC hosts the joint Glasgow-SUERC laboratory and, on behalf of NERC, the Cosmogenic Isotope Analysis Facility (CIAF) dedicated to UK scientists. The University of Edinburgh laboratory is in the School of GeoSciences. ${ }^{10} \mathrm{Be},{ }^{26} \mathrm{Al}$ and ${ }^{14} \mathrm{C}$ are extracted from quartz, involving two processes: (i) the preparation of ultrapure quartz from the sample rock, and (ii) the extraction of the relevant nuclide from that quartz, by chemical means in the case of ${ }^{10} \mathrm{Be}$ and ${ }^{26} \mathrm{Al}$, and by heating in the case of in situ ${ }^{14} \mathrm{C} .{ }^{10} \mathrm{Be}$ and ${ }^{26} \mathrm{Al}$ is extracted and prepared for measurement at all three Scottish facilities, whereas Edinburgh is the only facility in Scotland that has historically had capability for extracting cosmogenic ${ }^{36} \mathrm{Cl}$ (generally from $\mathrm{CaCO}_{3}$-bearing rocks, in which the ${ }^{36} \mathrm{Cl}$ is formed from Ca). SUERC hosts a developmental line for the extraction and graphitization of in situ ${ }^{14} \mathrm{C}$ from quartz, being currently one of probably only three laboratories world-wide that is producing repeatable measurements of in situ ${ }^{14} \mathrm{C}$ in 'unknown' samples (Fülöp et al. 2010a). All radio-nuclides are measured using the $5 \mathrm{MV}$ tandem accelerator mass spectrometer (AMS) at SUERC, the only AMS for cosmogenic nuclide measurements in the UK and the only AMS world-wide dedicated solely to geosciences applications.

The stable TCN, ${ }^{3} \mathrm{He}$ and ${ }^{21} \mathrm{Ne}$, are measured at the SUERC noble gas isotope laboratory. It is equipped with a new HELIX-SFT multiple-collector mass spectrometer capable of highly precise cosmogenic $\mathrm{He}$ and $\mathrm{Ne}$ isotope determinations.

\section{Emerging opportunities, future research areas, and future needs}

The foregoing highlights the fact that Scotland hosts virtually all of the UK's expertise and preparation facilities for TCN analysis, and certainly all of
Scotland's analytical capability, presenting an unparalleled opportunity for Scottish archaeology.

It has been noted above that there are two principal routine uses of TCN analysis, namely, surface exposure dating and the determination of catchment-averaged rates of erosion. Surface exposure dating is widely used to provide ages of deglaciation for Scotland (e.g. Stroeven et al. 2010) and for the ages of particular landforms (e.g., Fabel et al. (2010) for the famous Parallel Roads of Glen Roy; Stone et al. (1996) for the raised rock platforms of Lismore). There is obvious potential here for dating the emergence of Scottish coastal landscapes from below sea-level for subsequent occupation. Unpublished TCN surface exposure dating of raised beaches on Jura, for example, confirms their Late Pleistocene emergence and the extreme rates of glacio-isostatic surface uplift immediately after deglaciation (Fabel et al.in prep), and many glacial landforms are amenable to the same type of analysis in an archaeological context.

TCNs can also be used to determine catchment-averaged rates of erosion, provided certain conditions can be met (Dunai 2010, 122). Thus, geoarchaeological investigations could in principle include determination of catchment-averaged erosion rates, but it must be remembered that the rates so determined integrate the erosion rate for the time period it takes the material to get from $2 \mathrm{~m}$ depth in the regolith/soil to the ground surface, where it is detached. New work using nuclide pairs, one of which is in situ ${ }^{14} \mathrm{C}$, has the potential to quantify the timing and amount of at-apoint Holocene soil erosion (as opposed to the catchment-averaged rates provided by TCNs or, indeed, by sediment flux/mass balance studies). This new work utilises depth profiles of in situ ${ }^{10} \mathrm{Be}$ and ${ }^{14} \mathrm{C}$ in sediments/soils of known age and exploits the different production rates and half-lives of the two nuclides to the timing and amount of Holocene soil 
erosion (e.g., Fülöp et al. 2009, 2010b). At

this stage, the work is laborious, expensive and developmental, but virtually all analytical geochronological techniques are thus as they are developed but ultimately become more affordable as they become more routine.

It is worth recalling here that the application of all geochronological techniques is never fully routine, though some are more widely understood than others and their assumptions (and the associated potential pitfalls) are part of the 'working toolkit' of many archaeologists. TCN analysis is still overall in a developmental phase, although it is reasonable to state that its application is becoming more routine. The assumptions and necessary 'pre-requisites' for the technique are probably less likely to be routinely well understood by archaeologists. For that reason, it is essential that anyone seeking to employ TCN analysis link up with a practising TCN analyst (or, at least, an experienced user). The wealth of capability and experience in Scotland where by far and away the bulk of UK expertise in TCN analysis resides should make that relatively easy for anyone interested in TCN analysis.

\subsection{Luminescence dating in archaeology}

Luminescence dating utilises energy deposited in mineral lattices by naturally occurring ionising radiation to record information encoding chronology, depositional process information, and thermal history records in ceramics, lithics, and sedimentary materials. The information is stored through charge trapping processes in populations of point defects in common minerals, and can be reset by heating (for ceramics and heated lithic materials) and/or exposure to light (for sediments and exposed rock surfaces). Luminescence dating quantifies the radiation exposure experienced by target minerals (usually quartzes or feldspars) from the sample as an "equivalent dose", measured in Grays (Gy), and representing the mean radiation dose which would reproduce the observed natural signal levels of the sample as prepared in the laboratory. The "dose rate", measured in mGy/a, is determined by combining field and laboratory analyses of the levels of naturally occurring radionuclides and cosmic radiation with an appropriate microdosimetric model for the mineral phase in question. The luminescence age is estimated from the quotient of "stored dose" over "dose rate".

The age range of luminescence dating extends from modern samples ( $<10$ years) to $10^{5}-10^{6}$ years, thus covering all periods of known human occupation of Scotland, and much of the Palaeolithic elsewhere. Precision of dating varies from sample to sample, and from context to context, depending on individual sample characteristics (mineralogy, luminescence sensitivity, stability and homogeneity of the radiation environment, and the quality of initial zeroing). Typically precisions of $\pm 2-10 \%$ of age can be achieved with $5 \%$ dating precision representing a reasonable target for general purposes. A well calibrated laboratory can produce accuracy at the lower end of the precision scale. For high quality work it is important that the environmental gamma dose rates are recorded in-situ at time of excavation, which is most readily facilitated by involving the dating laboratory in fieldwork.

The key importance of luminescence dating within Scottish Archaeology lies in the nature of the events represented by the various dating materials. In this respect, and in extending the range of dating materials and questions available, there have significant developments in recent years, and more can be anticipated. 
Science in Scottish Archaeology

For heated materials both thermoluminescence (TL) and Optically Stimulated Luminescence (OSL) can be applied. TL analysis has the advantage that it can also reveal thermal history information - enabling the thermal exposures of early ceramics, and heated stones to be estimated as a by product of dating. This has provided evidence for fuel poverty in prehistoric island communities in Scotland, and also in a contemporary setting has been used to assist civil engineers with assessing fire damage of modern concrete structures (notably the Storebaelt and Channel Tunnel fires). In addition to ceramics the application of TL/OSL dating to hearthstones provides a direct indication of abandonment, since the last heating of a hearth relates directly to the end of an occupation phase in a domestic structure. This has been applied to prehistoric settlements in Orkney, where there is evidence of abandonment of marginal settlements at times of environmental stress, and to Iron Age hut circles in the Scottish Borders, where abandonment coincides with the Roman occupation of the region. Other fire damaged structures, including spectacularly vitrified forts, can be dated by $\mathrm{TL}$, as can burnt stone mounds which remain an abundant and enigmatic resource within the landscape.

In the sedimentary field there have also been important developments. The recognition in the early 1980's that luminescence signals could be zeroed by light exposure has led to the development of photostimulated luminescence (PSL) or Optically Stimulated Luminescence (OSL) methods and associated instrumentation which have dramatically enhanced the potential chronometers for studying archaeological sites and landscapes. A wide range of aeolian, fluvial, alluvial and colluvial materials have been studied worldwide for mainly quaternary research purposes. Archaeological applications are also increasingly prominent in the literature. The ability to date clean wind- blown sand layers in archaeological landscapes and sequences provide important opportunities to examine human-environment interactions, and in particular the impact of past storminess on early communities. This has external links to the North Atlantic climate system, and also to the development of greater understanding of the environmental factors which accompany changes in settlement pattern, and population movements. Within sites the recognition that some constructional activities can also reset the luminescence age system for underlying sedimentary substrates has profound implications for dating incised features and certain built structures. Within Scotland this has been used to date, for example the re-setting of the Hilton of Cadboll stone, and other monuments in Orkney including the ditchfills of the Ring of Brodgar within the World Heritage Site in Orkney. On the international scene, researchers based in Scotland have used these methods to provide the first dates for ancient canals in the early rice cultivating empires of SE Asia, and to understand the dynamics of incised features within Neolithic sites in the Mediterranean and Southern Italy. Importance aspects of OSL dating of sediments within complex sites relate to establishing whether individual samples have been effectively zeroed at time of final enclosure within the site formation processes, and whether they have been subject to post-depositional disturbances resulting in mixed-age materials. Two significant developments have greatly assisted the task of resolving such complexity. One is the development of rapid OSL profiling methods, originally using series of small samples analysed in the laboratory to map sedimentary stratigraphy, and more recently with the development, at SUERC, of field portable instrumentation which can be used to detect inversions, age-discontinuities, and redepositional sequences during excavation and sampling. The other is the development of small-aliquot and single- 
grain OSL methods which can generate dose-distributional information using automated equipment in the laboratory, and thus provide a means of monitoring and accounting for mixed-age and partially zeroed materials within sediment samples.

Finally there has been recent recognition of the potential for surface bleaching of luminescence signals in rock surfaces and worked stone objects to generate dating opportunities for these classes of materials. Further methodological research is required to refine physical models for these processes and to develop robust means of extracting dating information from them. But these approaches may hold new opportunities for dating lithic monuments such as standing stones, chambered tombs or other built monuments which can currently only be placed into their cultural and chronological contexts using indirect means. They may also provide a means of enhancing understanding of the duration of use of portable stone objects (including handaxes) prior to deposition within archaeological sites and landscapes.

Scotland is well placed to contribute to high quality research, development and application of luminescence dating, having the combination of a good science base with well established and developed expertise in this area, and a wide range of monuments, landscapes and materials covering the last 8000 years to which these methods could be applied. Critical to such work is developing and sustaining effective collaborative working arrangements between archaeological units and the research laboratories, since provision for luminescence dating and its associated sampling needs to be embedded into excavation planning and operation from the outset to achieve effective results.

\subsection{Dendrochronology in Scotland}

Dendrochronology is the technique of dating wooden structures and objects through the measurement and analysis of the growth-patterns of the parent tree. It is the most precise dating technique available to building historians and archaeologists because, given a complete sample with bark edge, the calendar year in which the tree was felled can be identified. The statistical correlations on which the dating method is based also enables the source of the wood to be provenanced. Other growth-ring parameters (Blue Intensity - see Wilson et al 2011) are being developed but all the dating work reported below is based on ring-width measurement.

In Scotland there is a commercial dendrochronological laboratory at $A O C$ Archaeology Group where Anne Crone specialises in the analysis of standing buildings and archaeological materials. In the School of Geography and Geosciences at the University of St Andrews Rob Wilson and a team of postgraduates is working on the development of a native pine network based on living trees and sub-fossil data. Coralie Mills is a research fellow at St Andrews and provides freelance dendrochronological services for both the cultural and natural heritage sectors.

As in the rest of the UK dendrochronological studies in Scotland have focused primarily on oak (Quercus sp.), because this is the species most commonly used in construction from the Neolithic until the post-medieval period. Chronological and geographical coverage in Scotland is patchy and the existence of robust local chronologies influences the likelihood of successful dating. The bulk of the oak data for Scotland has come from the sampling of standing buildings, with only small amounts coming from archaeological and other sources. Consequently, there is more data for the medieval and post-medieval periods than for earlier periods. From the medieval period one issue dominates cultural dendrochronology in Scotland and that is the distinction between native-grown and 
imported timber, and the implications this has for woodland history and the timber trade. Until the late $15^{\text {th }}$ century longlived native oak was widely available and has been found on many urban medieval sites (Crone 2000a) and in buildings such as Glasgow Cathedral, Caerlaverock Castle (Baillie 1977) and Darnaway Castle (Stell \& Baillie 1993). Many of the native oak chronologies begin growth as early as the mid- $9^{\text {th }}$ century AD (Crone 2006). Native oak has been identified in only a few later buildings, all late $16^{\text {th }} /$ early $17^{\text {th }}$ century in date, and this timber tended to be young, poorly-grown oak; consequently the dating of native oak in these later periods remains problematic.

From the late $15^{\text {th }}$ century imported oak was used almost exclusively in building, presumably because native-grown oak was in short supply. There is now an extensive network of oak chronologies throughout Europe and this has facilitated the identification and dating of imported oak in Scotland. Oak boards from the eastern Baltic and beams from Scandinavia have been identified by dendrochronology in many buildings dating from the late $15^{\text {th }}$ century to the late $17^{\text {th }}$ century (ie Crone 2008; Crone \& Gallagher 2008). Consequently, a sizeable corpus of Scottish 'import' data now exists which makes it relatively straightforward to date and provenance imported oak.

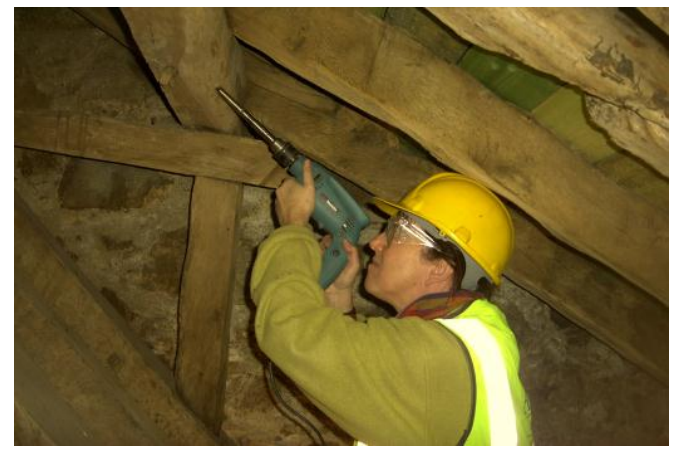

Figure 2: Sampling underway in the roof of the Mansion House, Drum Castle, Aberdeenshire. Native oak timber, felled over a period of years from AD 1603 to at least AD 1612 was used in the construction of this roof. This is one of a very few buildings of this date which was built with native oak, which probably came from the nearby Forest of Drum. The timber was small in crosssection and knotty, with wavy, irregular grain and compressed growth, probably signalling poor management of the Forest in the previous century, (C) AOC Archaeology Group.

Considerable progress has been made in the analysis of Scots pine (Pinus sylvestris) in recent years. As with oak it is necessary to be able to distinguish between nativegrown and imported pine. By the $17^{\text {th }}$ century European sources of oak were also dwindling and pine imported from Scandinavia and the eastern Baltic replaced oak as the main building timber in Scotland. Although there are still only a relatively small number of dated pine assemblages from Scotland the growing network of master pine chronologies throughout Europe means that dating imported pine in post-medieval and early modern buildings is becoming more routine (Crone \& Sproat 2011).

This is not the case with native-grown pine. A programme is underway to develop a continuous reference chronology for the last millennium, primarily for climatic reconstruction, but it may also have applications for the dating of cultural material (Wilson et al 2011). Commercial exploitation of Scotland's pinewoods began in the $17^{\text {th }}$ century the timber was intended for both shipbuilding and construction. However, at present the tree-ring data comes mainly from the isolated remnant pine woodlands in the Highlands and may not be representative of the timber used in construction. Nonetheless, two vernacular buildings in Upper Deeside have now been successfully dated against local reference chronologies (Mills \& Crone 2012).

There is very little chronological coverage earlier than the mid- $9^{\text {th }}$ century $A D$, when many of the medieval chronologies begin. Attempts have been made to date numerous prehistoric and early historic sites which have produced oak timbers 
but these have been unsuccessful (ie Crone 1998a; 1998b; 2002), largely because the sites are geographically remote from all the reference chronologies available for the these periods but also because they have not produced timbers in sufficient numbers to construct robust site chronologies with strong climatic signals. All the sites that have been successfully dated lie in southwest Scotland, and their dating has relied on their proximity to northern Ireland or northern England, where there are regional reference chronologies constructed from trees which probably grew in similar environmental conditions to those in SW Scotland.

Currently, only two prehistoric sites have been dendro-dated; oak timbers from two crannogs, Cults Loch and Dorman's Island, Whitefield Loch, both in Wigtonshire, have been successfully dated indicating building activity in the $5^{\text {th }}$ centuries and $2^{\text {nd }}$ centuries BC (Cavers et al 2011). Buiston crannog, Ayrshire produced one of the largest assemblages of oak timbers retrieved from an archaeological site in Scotland and consequently, a robust site chronology was constructed, covering the years $A D 250$ - 615, and indicating building activity on the crannog in the late $6^{\text {th }}$ century and into the $7^{\text {th }}$ century $A D$ (Crone 2000b). Structural timbers from the Northumbrian monastic settlement at Whithorn have also been successfully dated, producing a site chronology covering the years AD 278- 752 (Crone 1997).

The only other species which has been used in dendrochronological studies in Scotland is alder (Alnus glutinosa), mainly because it has been used extensively in the construction of crannogs. There are no master reference chronologies for alder so it cannot be used directly to obtain calendrical dates, its greatest value lying in its potential to provide sitespecific chronological relationships. However, it was used successfully at Buiston crannog where the alder chronology could be indirectly linked to the dated oak chronology through stratigraphic connection, thus providing calendrical dates for some of the structures. Work on alder from other crannogs has highlighted problems relating to sequence length, tree structure and growing conditions.

\section{Future directions}

Much of the dendro-dating of medieval and early modern Scottish material is now relatively routine and improvements in provenancing is dependent to a large extent on the continuing work of European colleagues. Work is still needed on strengthening the later sections of the native oak chronologies, particularly the $16^{\text {th }}$ and $17^{\text {th }}$ centuries, while the development of the native pine network is critical if we are to date much of the vernacular building stock. Efforts should focus on the development of a continuous tree-ring chronology for the $1^{\text {st }}$ millennium $B C$, based on crannog timbers, which would help to resolve many chronological issues for this period.

\subsection{Amino acid racemization dating}

Demarchi et al. (2010) has reported the application of Intra-crystalline protein degradation (ICPD) to analyse Scottish shell midden sequences, and the results suggest it is a plausible (albeit relatively imprecise) dating method (Figure 6). See also section 2.5 .

\subsection{Tephrochronology}

Tephrochronology is a dating technique based on the identification and correlation of deposits of volcanic ejecta, (volcanic ash or pumice, all known as tephra) (Thórarinsson, 1944, 1981). In practice in Scotland this means either atmospheric fallout of particles $<200$ microns in size, or cobble-grade piece of pumice dispersed over the ocean by wind and waves; virtually all Scottish tephra deposits originate in Iceland (Dugmore, 1991; Dugmore et al. 1995b). Dating does not take place on the tephra itself, but on 
the eruption that produced it. As a result it is the correlation of a tephra to its source eruption enables the dating of that event to be applied to tephra wherever it is found (Dugmore and Newton, 2009). Dating may be derived from a number of sources such as written records, ice core dates, sediment accumulation rates and radiocarbon. Correlation of tephra deposits generally relies on accurate grain specific chemical analysis of major and minor elements.

Firmly identified tephra deposits have the potential to define an isochron, or horizon of equal age. This may be very precisely defined even if the absolute age of the tephra is unknown. The best isochrons in Scotland are formed by in situ deposits from atmospheric fallout that were originally deposited within a matter of few hours or days (Dugmore et al. 1995a). Pumice in Scotland is rarely found in situ in natural contexts partly due to sea level changes, but it does occur in a range of archaeological contexts that are not contemporaneous with the original, pumice-forming eruptions. Since the first discovery and identification of Icelandic volcanic ash in microscopic amounts (cryptotephras) in Scotland (Dugmore, 1989), tephrochronology (Lowe, 2010) has become a standard palaeoenvironmental tool in Scotland. Tephra layers have been identified in Scotland's peat deposits and lake sediments dating from the late glacial until the eruption of Hekla in 1947 (Dugmore et al. 1995b; Turney et al. 1997; Lowe et al. 2008; Housely et al. 2010). Recent events, such as the 2010 eruption of Eyjafjallajökull, have highlighted the importance of understanding the distribution of volcanic ash deposits, but the tephra preserved in Scotland's peat and lake deposits contributes directly to science-based archaeology. The presence of unambiguously identified and dated tephra layers can provide a crucial test of other chronological methods (e.g. Dugmore et al. $1995 \mathrm{a}$ and b), as well as providing otherwise unobtainable precise dating of palaeoenvironmental and proxy climate records (e.g. Langdon and Barker, 2004). This allows precise correlations to be made between high resolution palaeoenvironmental records within Scotland, across Greenland, the North Atlantic and north-west Europe.

Scotland also has excellent facilities to geochemically analyse volcanic ash. The Natural Environmental Research Council Tephra Analytical Unit ${ }^{3}$ (electron and ion microprobes) is based in the School of GeoSciences at the University of Edinburgh (School of GeoSciences, 2010).

It is through the definition of isochrons and the precise correlation of environmental records and chronology that tephra allows, that the greatest potential contribution to Scottish archaeology by this means can be expected. While the presence of more than a dozen tephras can add spot dates of great utility to long-term records (such as $1510 \mathrm{AD})$, it is the use of preciselydefined isochrons that lie across most of Scotland that holds the greatest future potential. Spatial patterns and their changes through time are crucially important to our understanding of the past, particular during periods of rapid cultural or environmental change and tephrochronology can enable correlations to be made to within a year. This can add a spatial dimension of great utility to other very precise records such as dendrochronology.

${ }^{3}$ http://www.geos.ed.ac.uk/facilities/tephra/ 


\subsection{Archaeomagnetism}

\section{Introduction}

Archaeomagnetism is a method for dating fired materials and sediments from archaeological sites, based on changes of the Earth's magnetic field in the past. The principles of the method are well established; see Linford (2006) and Zananiri et al. (2007). It has been used in Scotland from 1967 (Aitken and Hawley 1967) and is increasingly part of multimethod site chronologies. The strengths of archaeomagnetic dating are that it dates fired clay and stone, for example hearths, kilns, ovens and furnaces, which occur frequently on archaeological sites; it dates the last use of features, providing a clear link to human activity; it is cost effective and is potentially most precise in periods where other dating methods, e.g. radiocarbon dating, are problematic.

\section{Principles and practicalities of the method}

Archaeomagnetic dating is based on a comparison of the ancient geomagnetic field, as recorded by archaeological materials, with a dated record of changes in the Earth's field over time in a particular geographical area, referred to as a secular variation curve. The geomagnetic field changes both in direction (declination and inclination) and in strength (intensity) and archaeomagnetic dating can be based on either changes in direction or intensity or a combination of the two. Dating by direction requires the exact position of the archaeological material in relation to the present geomagnetic field to be recorded, and so the material must be undisturbed and sampled in situ. Dating by intensity does not require in situ samples but is less precise and experimentally more difficult. The vast majority of UK studies are dating by direction, as intensity dating is not commercially viable at present
For archaeological material to be suitable for dating using magnetic direction it must contain sufficient magnetised particles, and an event must have caused these particles to record the Earth's magnetic field. Many geologically derived materials e.g. soils, sediments, clays, contain sufficient magnetic minerals. There are primarily two types of archaeological events which may result in the Earth's magnetic at a particular moment being recorded by archaeological material: heating and deposition in air or water. If materials have been heated to a sufficiently high temperature $\left(>400^{\circ} \mathrm{C}\right)$ they may retain a thermoremament magnetisation, which reflects the Earth's magnetic field at the time of last cooling. Suitable archaeological features would include hearths, kilns and other fired structures. Sediments may acquire a datable detrital remanent magnetisation from the alignment of their magnetic grains by the ambient field during deposition. Such an effect allows deposits in wells, ditches and streams to be dated. However, factors such as bioturbation and diagenesis of sediments can cause postdepositional disturbance of the magnetisation. In the UK archaeomagnetic dating can be applied to features expected to date from 1000BC to the present day, as this is the period covered by the secular variation curve. However, as discussed below the precision of the date obtained will vary according to the period.

Samples of robust fired materials are usually taken by attaching a $25 \mathrm{~mm}$ flanged plastic reference button to a cleaned stable area of the feature using a fast setting epoxy resin or encasing part of the feature in plaster of Paris (Clark et al. 1988). Sediments and friable fired materials are sampled by insertion of $25 \mathrm{~mm}$ diameter plastic cylinders. Magnetometers used are sufficiently sensitive for only small samples (c. $1 \mathrm{~cm}^{3}$ ) to be required; approximately 15 samples are needed from each feature and it may 
be possible to select sampling location to minimise the visual impact if the feature is to be preserved. In the laboratory the remanent magnetisation of each sample is measured in a magnetometer and the stability of this magnetisation evaluated by alternating magnetic fields or thermal demagnetisation (Linford 2006).

Once a stable magnetic direction has been obtained, this is dated by comparing it with the secular variation curve showing changes in the Earth's field over time (Clark et al. 1988; Zananiri et al. 2007). The secular variation curve is compiled from direct measurements of the field which extend back to AD1576 in Britain, and, prior to that, from archaeomagnetic measurements from features dated by other methods. There are a number of factors that will influence the precision of the dates obtained:

1. Differential recording of the field by different parts of the feature

2. Disturbance of the material after firing/deposition

3. Uncertainties in sampling and laboratory measurements

4. Precision of the secular variation curve itself

5. Uncertainties in the comparison of the magnetic direction with the secular variation curve

6. Spatial variation of the geomagnetic field

The precision of the secular variation curve varies with time and so the precision of the date obtained will depend on the archaeological period. As the geomagnetic field has occasionally had the same direction at two different times, it is also possible to obtain two or more alternative dates for a single archaeological event. In most case the archaeological evidence can be used to select the most likely of these. Given the number of contributing factors it is not possible to define the general precision of archaeomagnetic dates but there will be an error margin of at least \pm 50 years. It is important to note that, since the methods relies on the reliability of previously dated sites, the secular variation curve improves as more measurements become available. Features that cannot be dated or give broad age ranges now, may be datable in the future.

\section{Applications of archaeomagnetic dating in Scotland}

There have been a significant number of archaeomagnetic studies in Scotland (Figure 3), with 27 sites producing 103 dates. There are concentrated in the Iron Age, mainly reflecting the use of archaeomagnetic dating in the investigation of vitrified hillforts (Gentles 1989) and within long-running research projects. Such investigations have the advantage of being able to integrate archaeomagnetic studies with other methods to produce significant advances in archaeological understanding (e.g. Outram and Batt 2010). However, there is a dearth of archaeomagnetic dates from commercial archaeological investigations when compared with England. This may partly be due to lack of awareness of the method, but the main issue is the distribution of archaeomagnetic laboratories. There are no laboratories in Scotland; the English laboratories are currently based in Bradford, Liverpool, Lancaster, Isle of Man, Plymouth and Portsmouth. Because archaeomagnetic dating usually requires laboratory personnel to collect samples on site, the lack of Scottish laboratories makes the method both expensive and unable to respond rapidly, except within the framework of planned research excavations.

\section{Emerging opportunities}

It is clearly advantageous to raise the profile of archaeomagnetic dating in Scotland. The method has been shown to provide valuable archaeological information and supplement the suite of chronological tools available. In addition, 
the development of archaeomagnetic dating as a method, and the wider understanding of the Earth's magnetic field, is hindered by the lack of data from Scotland. The main opportunities for progress are:

1. Increasing the level of awareness of the potential of archaeomagnetic dating within Scottish excavations.

2. The consideration of archaeomagnetic dating at the planning stages of major archaeological projects.

3. Targeting key periods and locations for intensive sampling of

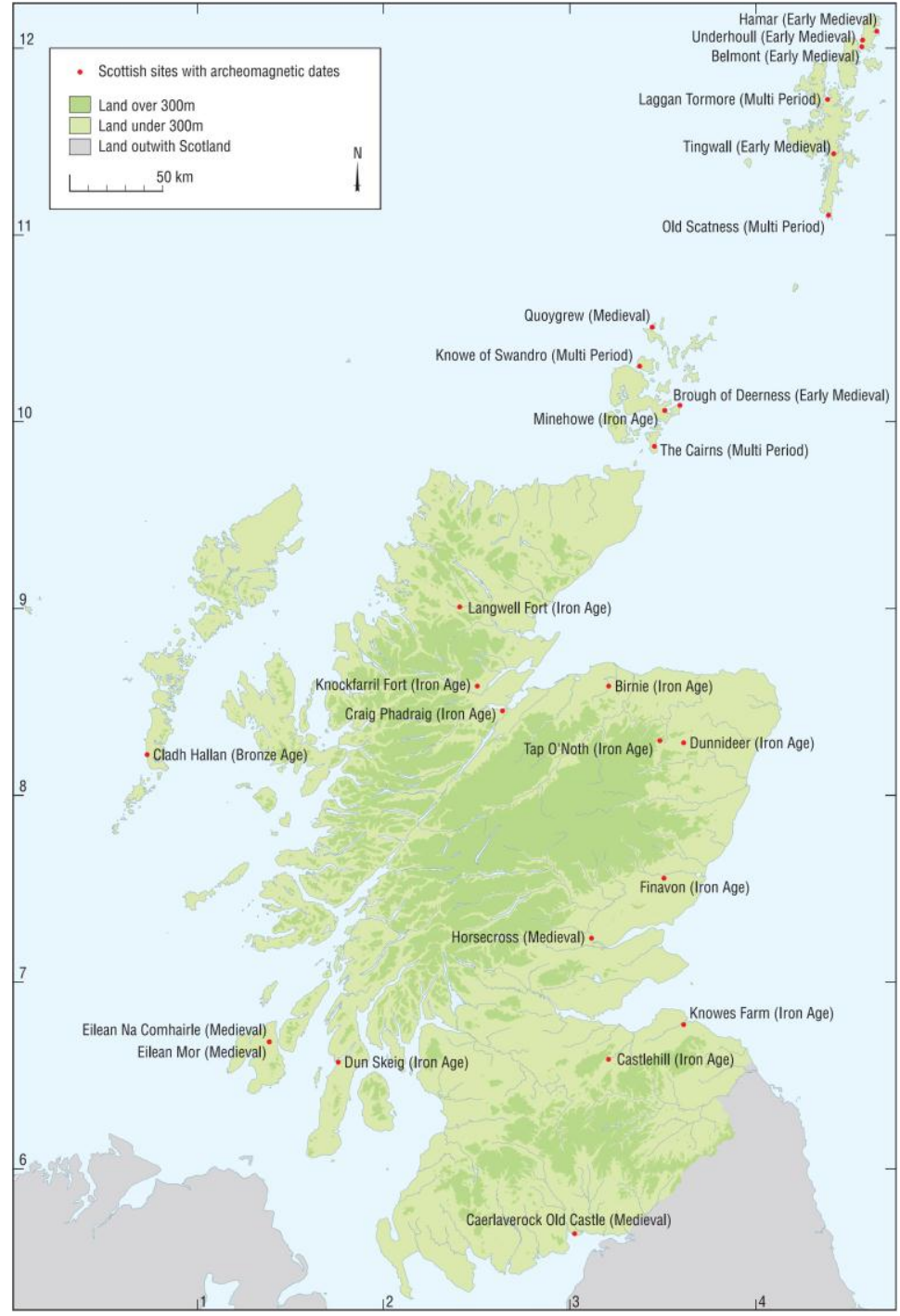

Figure 3: The distribution of the archaeomagnetic dates produced on Scottish material. Key to placemark colours: Orange-Bronze Age; Green-Iron Age; White-Early Medieval; Yellow-Medieval; Pink-multiperiod sites. CCathy Batt. Full details are available from http://www.brad.ac.uk/archaeomagnetism/ suitable material, most notably the Bronze Age, Medieval and Post-Medieval periods. Scotland to undertake sampling, increasing the availability of the method and decreasing costs.

5. Establishment of an archaeomagnetic dating facility within Scotland, ideally in association with other dating methods or within geophysics research laboratories with appropriate equipment.
4. Training of personnel within 


\subsection{Chronology recommendations}

Most of the seven sections above on dating techniques include specific recommendations for future work. More general recommendations are:

- Notwithstanding the primacy of radiocarbon dating in Scottish archaeology, create more dialogue between specialists in other dating techniques and the archaeological community.

- Encourage the deployment of combinations of dating techniques.

- Establish databases that incorporate dates obtained from different techniques, and ensure those databases are freely available. 


\section{Human and animal sciences}

\subsection{Introduction}

The human and animal sciences play a pivotal role in archaeological science and are at the forefront of exciting new directions in modern archaeological research. The study of human and animal remains - from the microanalysis of individual proteins to the investigation of large burial assemblages - provides direct evidence for ancient human life ways, including diet and subsistence, health, living conditions, mobility, demography and even modes of occupation and interpersonal violence.

'Bioarchaeology' draws on biological science methods in order to elucidate aspects of the lives of past individuals and populations, from the microscopic to macroscopic level. The discipline incorporates a large number of different technical approaches and analytical tools, including field archaeology and anthropology, osteoarchaeology and palaeopathology, biomolecular and geochemical techniques for dietary reconstruction and mobility studies, palaeodemographic studies, palaeoepidemiology, biological distance studies and biomechanical approaches for understanding patterns of activity. As well as drawing on bioscience methods, bioarchaeological data in turn has potential implications for the modern biological sciences, including studies of health, nutrition, demographics and epidemiology. Archaeological case studies have the potential to deliver diachronic data on the scale of millennia, rather than decades, and study across archaeological time-scales provides models of human subsistence choices, health, gene-flow and adaptability in the face of broad-scale climatic, ecological or demographic shifts - adding vital time depth which modern studies can rarely provide.
The study of animal and human remains is a rapidly progressing field, as new technologies and new analytical techniques emerge. These methods offer new opportunities, not only in the study of new materials and new questions, but also in the re-evaluation of previously studied materials and long-standing archaeological problems. Along with this emerging expertise, a new awareness of the field is surfacing, with issues such as ethics in the study of human remains becoming ever more pertinent. With reburial of human remains becoming an increasing public expectation, and retention for re-study being an academic prerogative, adaptability to these changing states is key to the future of bioarchaeology as a discipline. As threats of climate change, resource depletion and global pandemics shape policy making, the need to make provision for the study of the human past becomes ever clearer. In addition to providing the infra-structure and cross-disciplinary access to state-ofthe-art technologies, there is also a responsibility to ensure the development and retention of a skill base and range of expertise within Scotland. As with many fields, national and international collaborations will also be pivotal to ensuring that there is the expertise, infrastructure and oversight to approach future challenges and opportunities.

\subsection{Human Remains}

The scientific analysis of human skeletal remains from the archaeological contexts in which they were found is termed human osteoarchaeology, or 'bioarchaeology'. [NB: the term 'bioarchaeology', while considered among the archaeological community in the UK to refer to both animal and human remains, is used by human osteologists within and outside the UK (primarily the US) to refer exclusively to human remains 
(see for example, Buikstra \& Beck 2006; Larsen 1997; Roberts \& Cox 2003).]

Skeletal remains constitute the most direct evidence to enable the reconstruction of biology, health, diet, social structure and violence and trauma within past populations. Integrated with historical and archaeological information, osteological analysis can provide a more thorough understanding of ancient populations. Traditional methods of studying human remains include visual inspection and metrical analysis, although more modern applications, such as medical imaging techniques are gradually supplementing these traditional methods, giving additional tools for the study of archaeological and fossil specimens.

Basic analyses, including assessments of age at death, sex in adults, stature (Bass 2005; Schaefer et al 2009; White \& Folkens 2005) and palaeopathology (Ortner 2003; Roberts \& Manchester 2005; Waldron 2009), can be used to reconstruct the lifestyle of the individual. Collated information can provide evidence of population biodistance (Larsen 1997), palaeodemography (Chamberlain 2006) and palaeoepidemiology (Waldron 2007) in ancient communities. Human bone analysis can also provide additional information to the archaeologist on burial practices, cremation technology and taphonomic processes. For example, missing skeletal elements may indicate secondary burial (Mays 2010), the colour of cremated bone can indicate the temperature and efficiency of burning (Walker et al 2008) and the condition of the remains can indicate the taphonomic history of a skeletal assemblage (Buikstra \& Ubelaker 1994).

\section{Previous studies of human remains in Scotland}

In the past, with some few exceptions, studies in archaeological human remains in Scotland have largely been carried out on a case by case basis, driven mainly, as with archaeology in general, by developer-funded excavation (for example O'Sullivan 1994; Rees 2004). Many of these were cremation burials (e.g. Mercer et al 1997; Neighbour et al 2005). Some larger studies have also been carried out. Table 2 gives examples of published previous research (only sites with several individuals are mentioned).

Table 1: Previous studies of human remains in Scotland

\begin{tabular}{|c|c|c|c|}
\hline PERIOD & SITE & $\begin{array}{l}\text { NO. OF } \\
\text { INDIV. }\end{array}$ & REFERENCE \\
\hline Neolithic & Quanterness, Orkney & 157 & Chesterman 1979 \\
\hline Neolithic & Isbister, Orkney & 341 & Chesterman 1983 \\
\hline Neolithic & $\begin{array}{l}\text { Quoyness, Sanday, } \\
\text { Orkney }\end{array}$ & 14 & Wells 1951-2 \\
\hline Bronze Age & $\begin{array}{l}\text { Barns Farm, Dalgety } \\
\text { Bay, Fife }\end{array}$ & 24 & Lunt and Barnetson 1982 \\
\hline Bronze Age & Various, N.E. Scotland & 60 & Shepherd \& Bruce 1982 \\
\hline Bronze Age & $\begin{array}{l}\text { Sketewan, Balnaguard, } \\
\text { Perth \& Kinross }\end{array}$ & 21 & McSweeney 1997 \\
\hline Iron Age & Dunbar, East Lothian & 21 & $\begin{array}{l}\text { Brothwell \& Powers } \\
\text { 1964-6 }\end{array}$ \\
\hline Early Medieval & $\begin{array}{l}\text { Kneep, Uig, Isle of } \\
\text { Lewis }\end{array}$ & 7 & Harman 1967 \\
\hline
\end{tabular}


Science in Scottish Archaeology

\begin{tabular}{|c|c|c|c|}
\hline Early Medieval & $\begin{array}{l}\text { Four Winds, } \\
\text { Longniddry, East } \\
\text { Lothian }\end{array}$ & 8 & Lorimer 1992 \\
\hline Early Medieval & $\begin{array}{l}\text { Hallow Hill, St } \\
\text { Andrews, Fife }\end{array}$ & 93 & Lunt 1996; Young 1996 \\
\hline Late Medieval & $\begin{array}{l}\text { Isle of Ensay, Outer } \\
\text { Hebrides }\end{array}$ & 316 & Miles, 1989 \\
\hline Late Medieval & $\begin{array}{l}\text { Whithorn, } \\
\text { Wigtonshire }\end{array}$ & 1092 & Cardy, 1997 \\
\hline Late Medieval & $\begin{array}{l}\text { St Marys Kirk Hill, St } \\
\text { Andrews, Fife }\end{array}$ & 330 & Bruce et al 1997 \\
\hline Late Medieval & $\begin{array}{l}\text { Holy Trinity, St } \\
\text { Andrews, Fife }\end{array}$ & 27 & McSweeney 2008 \\
\hline Late Medieval & $\begin{array}{l}\text { Linlithgow, Perth, } \\
\text { Aberdeen }\end{array}$ & c. 343 & Cross \& Bruce 1989 \\
\hline $\begin{array}{l}\text { Neolithic to } \\
\text { Medieval }\end{array}$ & Scotland & 322 & Lunt 1974 \\
\hline
\end{tabular}

\section{Standardised traditional methodology}

The traditional methods for examining human skeletal remains have been largely based on macroscopic, i.e., visual, and metrical analyses. Methodologies have developed rather idiosyncratically and piecemeal, and some recent publications have sought to address the previous lack of standardised methodology (e.g., Buikstra \& Ubelaker, 1994, Brickley \& McKinley, 2004) and professional organisations now strive to promote professional and ethical standards ${ }^{4}$.

\section{Sexing and Age at Death}

Accurate assessments of sex and estimations of age at death are crucial for an understanding of both past societies and for identification in forensic cases.

4 e.g. The British Association of Biological Anthropology and Osteoarchaeology [BABAO] http://www.babao.org.uk/; Paleopathology Association http://www.paleopathology.org/
However, it is not always possible to accurately assess sex in some individuals, or to assign a true age to skeletal remains. In the absence of aDNA, or histological analyses, the best that can be done is to try to link biological age (based on skeletal development and degeneration) with chronological age (Cox 2000; Schaefer et al. 2009). This is done largely by comparing standards generated from modern materials of known sex and age. Both skeletal development and degeneration varies between populations and individuals; the degree of accuracy can therefore vary and standards used may not be relevant to the individual or population being examined. Multivariate systems are recommended for the greatest accuracy (Brickley and McKinley 2004). However, research into new methods of population specific sexing and ageing techniques continue to be developed, especially in the field of forensic anthropology (Charisi et al. 2011; Matt et al. 2006). 


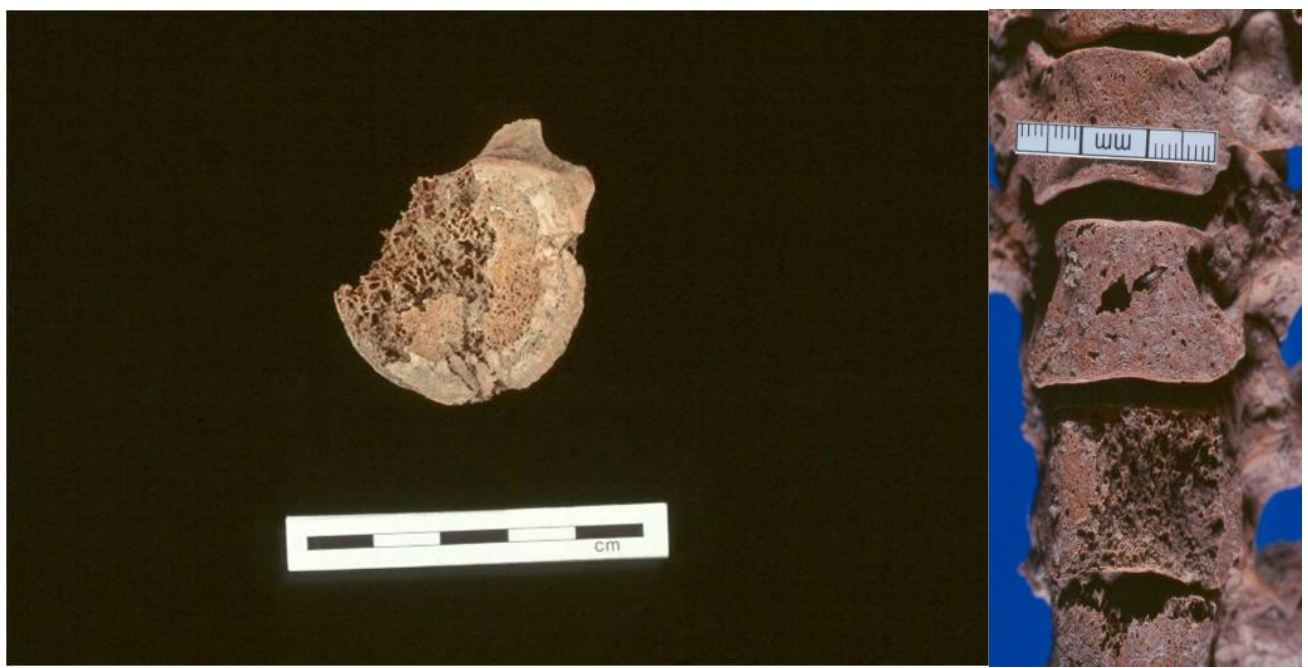

Figure 4: (left) Body of thoracic vertebra with depression in the bone surface, indicating that a bone projectile had penetrated the intervertebral disc space. (Late Mesolithic, Schela Cladovei, Romania), (C) K McSweeney

(right) Evidence of a projectile injury in the upper thoracic vertebra with a tiny fragment of flint embedded in the bone(Late Mesolithic, Schela Cladovei, Romania). Experiments with fresh animal bone have shown that flint projectiles often do not fully embed in bone, but leave only minute traces that are often only visible microscopically (Smith et al. 2007), @ K McSweeney

The importance of understanding taphonomic processes and burial practices in the interpretation of human osteological analysis

For the proper interpretation of human skeletal remains, it is of primary importance to understand the taphonomic processes and burial practices that can occur both before and after burial. For example, a current research project on infant jar burials is providing new information on burial practices in Early Bronze Age Bulgaria (Bacarov et al. 2011; Bacarov and McSweeney 2011). Previous osteological analyses of some of the infant remains provided only demographic data. A recent opportunity to micro-excavate an intact jar burial has revealed evidence of excarnation, partial decomposition at the time of deposition in the jar, and dismemberment (McSweeney, forthcoming). This demonstrates the importance of taking into account the archaeological context in which human remains are found.

\section{Biocultural approach}

In the past skeletal analysis tended to concentrate on the individual; today the thrust of osteological analysis is largely on populations as seen within their cultural environment. While there may be variations in approach according to geographical location, the general emphasis today in osteology is to consider the 'biocultural approach'. This term was first used in 1977 by Blakely:

$$
\begin{aligned}
& \text { "Humans survive not through } \\
& \text { cultural adaptation nor } \\
& \text { through biological adaptation } \\
& \text { but through biocultural } \\
& \text { adaptation". }
\end{aligned}
$$

Because culture is such an important component of human society, population groups must be understood within the context of their associated culture, which brings a far richer understanding of biological data.

The holistic biocultural approach has specific goals: 
1. To document specific ways in which biological anthropologists can contribute to studies of cultural processes.

2. To illustrate the interrelationship between the biological, cultural and environmental variables that affect the adaptedness, or maladaptedness of prehistoric populations.

3. To demonstrate the need for cooperation among biological anthropologists, archaeologists, ethnologists and other expert investigators toward problemsolving in behavioural anthropology (Blakely, 1977).

The biocultural approach has led to a number of interdisciplinary studies, including:

- Bone chemistry for dietary reconstruction

- Palaeodemographic studies

- Palaeoepidemiology

- Field anthropology

- Biological distance studies

- Biomechanical approaches for understanding patterns of activity

- Stable isotope ratios (strontium) for establishing mobility.

\section{Palaeopathology}

The identification and recording of pathological lesions are an important part of human bone analysis and can provide much information of the lifestyle of an individual, or the health of a population group. It should be appreciated, however, that there are numerous limitations to assessments of health and disease and the analysis of pathological lesions will only provide a partial representation. Firstly, not all diseases will affect the skeleton. Only those diseases and conditions that are chronic tend to affect the skeleton; acute infectious diseases, or those confined to soft tissue, will leave no trace. Thus, in the majority of cases, the cause of death cannot be established.

Even when pathological lesions are present on the bone, it may not be possible to diagnose the disease process that caused the lesions. Bone responds to disease processes in a limited number of ways and many diseases will have similar effects on the skeleton. Thus, it is more important to describe the nature, location and distribution of bony change, rather than to feel obliged to attempt a diagnosis (Ortner 2003). One can suggest differential diagnoses, however.

The difficulties in diagnosing diseases from human skeletal remains have been recognised. Waldron (2009) has suggested 'Operational Definitions' for some of the most common diseases affecting bone, for example osteoarthritis and tuberculosis. As the distribution of lesions throughout the skeleton is important to the accuracy of diagnosis, good preservation and completeness of skeletal remains can be crucial. For example, the numerous types of joint disease can have different distributions of joints affected (Rogers and Waldron 1995). In the case of incomplete remains the diagnosis of a specific joint disease may not be possible.

The future of the accurate diagnosis and the history of disease may lie in biomolecular analyses, such as aDNA. For example a current project, headed by Prof. Charlotte Roberts of the University of Durham, is researching the aetiology 
and development of tuberculosis in Britain and Europe ${ }^{5}$

\section{New imaging techniques}

Traditional metrical analysis is being replaced by new imaging techniques. Geometric morphometrics uses anatomical landmarks and imaging software to explore size and shape variation in individuals (see, for example, Wilson et al. 2008b, 2011b; Franklin et al. 2008). Much of the work on this new tool is being progressed by the European Virtual Anthropology Network (EVAN), a multidisciplinary project, which combines 'anatomical imaging, 3D digitisation, display, modelling, programming, and leading edge expertise in the quantitative analysis of anatomical variability' to study 'anatomical variability in humans, their ancestors, and their close relatives' ${ }^{\prime}$.

Geomorphic morphometrics has a number of applications that can be utilised in the study of archaeological skeletal populations, from comparing variability within and between groups, assessing sex in sub-adults (previously problematic) and for assessing sex in sexually indeterminate or incomplete skeletal remains. Such computergenerated analyses eliminate the user error that can occur in normal metrical analysis. It can also be used to create a digital archive of skeletal populations, trauma or disease. The University of Edinburgh Archaeology department has purchased the necessary software and hardware to conduct such analyses and is creating a digital library that contains several digital archives of trauma and

5

http://www.dur.ac.uk/archaeology/research/ projects/?mode=project\&id=353

${ }^{6}$ See: http://www.evan.at/ morphological variation, which is being extensively used for teaching purposes.

Virtual Anthropology allows the study of specimens in three dimensions through the use of medical imaging techniques, such as CT (Computed Tomography) scans. This approach is ideal for application to the study of fragile and precious archaeological skeletal material, and enables the study of internal features without damaging the specimens. Because of these properties, virtual anthropology methods have become the standard in the reconstruction and study of highly valuable and fragile fossil skeletal material, and, increasingly, also in more recent skeletal remains. Both coordinate 3-D data, such as those used in geometric morphometric analyses, and standard linear measurements, such as those used in more traditional craniometric analyses, as well as additional useful measurements such as volumes and surfaces, can be obtained non-invasively from CT scan data. Moreover, special characteristics of the skeleton such as hard tissue thicknesses, trabecular patterns, or particular traumatic patterns, only visible in the endocranial surface are now available for observation via a 3D virtual reconstruction from the $\mathrm{CT}$ scan data.

\section{Research capacity}

Until fairly recently the analysis of human skeletal remains was conducted rather piecemeal in the UK by amateur osteologists, many of whom had medical and not archaeological backgrounds (for example, Chesterman 1979, 1983; Young 1996). The last few decades has seen a mushrooming of the field of osteoarchaeology; the important difference being that osteological remains are viewed within their archaeological context. Seven universities in the UK now offer taught postgraduate degrees in this discipline and the number of universities with staff and students conducting relevant research is in double figures. The 
University of Edinburgh has been offering taught postgraduate programmes in osteoarchaeology since 2005 and each year since their inception has seen an increase in student intake, both at taught MSc and PhD levels. In 2010/11, this total had reached 45 . The level of research currently conducted in the UK has therefore proliferated and the resulting research potential is massive.

Several research students are currently undertaking research in Scotland, including the treatment and use of human remains in the Atlantic Scottish Iron Age (University of Bradford), and at the University of Edinburgh, cremation technology and ritual in Bronze Age Scotland, the osteological examination of the human skeletal remains from Berst Ness, Westray, and health status in Medieval Scotland.

There are numerous collections of archaeological skeletal assemblages within Scotland that could potentially be utilised for research. The University of Edinburgh holds three Scottish skeletal populations, all of medieval or postmedieval date. Other large collections are held at the University of Aberdeen, Marischal Museum, the National Museum of Scotland and at various other museums in Scotland. There is no existing record of exactly what is held and a clear need for a national skeletal database to establish exactly what is available for study.

The Department of Archaeology at the University of Edinburgh has established collaborations with medical centres such as the Medical Imaging Centre at the Royal Infirmary of Edinburgh and the Heraklion Medical Centre, Greece, in order to acquire CT-scan data for several different studies. One of the studies involves the creation of an examination protocol for evaluating trauma through 3$D$ reconstructions from $C T$ scans in archaeological and modern skeletal remains. The goal of this project is to establish objective criteria for the assessment of perimortem and postmortem trauma, including extent and severity. This project seeks to build on the success of recent studies using 3-D CT imaging in the evaluation of trauma patterning and the development of a qualitative method of assigning trauma. The protocol could be extended and could have applications in forensic cases, as well as fragile archaeological specimens and to the valuable fossil record.

Collaboration on trauma simulation is also currently being progressed between the Archaeology department at the University of Edinburgh and the Royal Veterinary College of London.

\section{Opportunities for Further Research}

Notwithstanding the above examples, there have been few thematic, temporal or geographic studies carried out and there are huge opportunities for research frameworks with such foci.

Modern medical image technology and the use of CT scans offers the possibility of creating virtual models (e.g. Finite Element Analysis models) in order to simulate impacts that created a fracture or activities such as mastication or locomotion that would add essential information on the habits and welfare of past populations.

Current research collaborations with the Royal Infirmary of Edinburgh and the Royal Veterinary College of London indicate the potential for joint research projects with medical researchers. A recent study by a University of Edinburgh PhD student has revealed a very early case of prostate cancer, a child with advanced tuberculosis and a potential case of pre-Columbian syphilis. These examples have sparked the interest of epidemiologists, historians and medical specialists and indicate the possibility on future collaboration with such professionals.

\section{Forensic Anthropology}




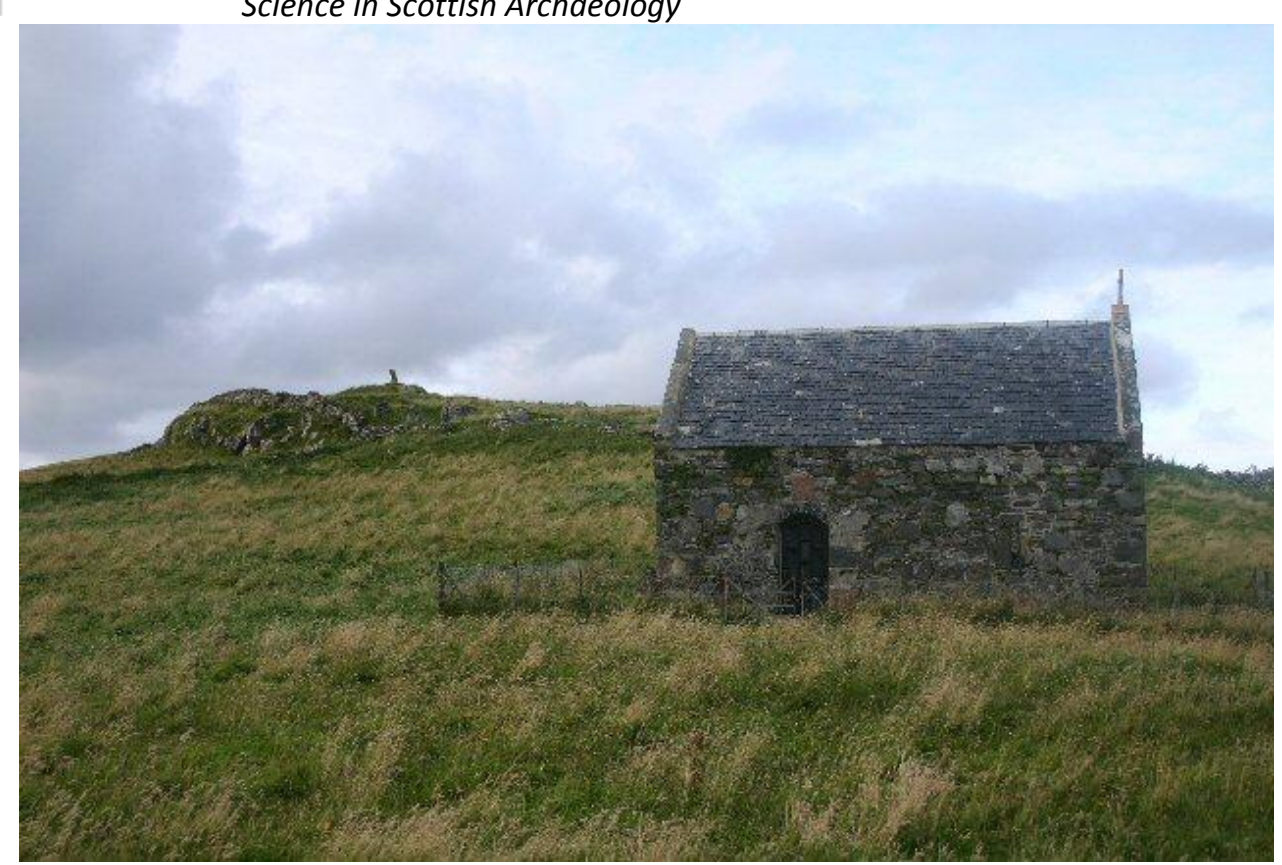

Figure 5: The chapel in Ensay associated with the excavated human remains that was the subject of osteological analysis by Miles $(1989,1994,1995)$. The remains have now been reburied. While Miles report was extremely comprehensive and provides an important published resource, had the remains been retained for future research, more modern osteological techniques, such as imaging, bone chemistry and histological analysis, could have been applied, making the resource even more valuable $(c)$ Wikimedia commons.

Together with osteoarchaeology, the field of forensic anthropology has also developed considerably in the last two decades. This discipline, which focuses on human skeletal remains recovered from crime scenes, war graves and humanitarian crises, has a great overlap with osteoarchaeology. Similar methodological techniques are applied to osteological analysis and archaeological excavation methods are often applied to the recovery of forensic human remains (see, for example, Hunter 1996).

Much recent osteological research has been conducted by forensic specialists working on archaeological skeletal populations. The two disciplines therefore have much to learn from each other.

\section{Ethics}

By virtue of their status as the remains of once living people, the analysis and treatment of human remains requires ethical considerations over and above those that pertain to other classes of archaeological materials. Human remains should always be treated with dignity and respect regardless of age or provenance.

The Vermillion Accord on Human Remains in 1989 at World Archaeological Congress Inter-Congress, Vermillion, South Dakota, USA adopted the following principles ${ }^{7}$ :

1. Respect for the mortal remains of the dead shall be accorded to all, irrespective of origin, race, religion, nationality, custom and tradition.

Respect for the wishes of the dead concerning disposition shall be accorded whenever possible, reasonable and lawful, when they

${ }^{7}$ Vermillion Accord on Human Remains, 1990: http://www.worldarchaeologicalcongress.org/ site/about ethi.php 
are known or can be reasonably inferred.

2. Respect for the wishes of the local community and of relatives or guardians of the dead shall be accorded whenever possible, reasonable and lawful. Respect for the scientific research value of skeletal, mummified and other human remains (including fossil hominids) shall be accorded when such value is demonstrated to exist.

3. Agreement on the disposition of fossil, skeletal, mummified and other remains shall be reached by negotiation on the basis of mutual respect for the legitimate concerns of communities for the proper disposition of their ancestors, as well as the legitimate concerns of science and education.

The express recognition that the concerns of various ethnic groups, as well as those of science are legitimate and to be respected, will permit acceptable agreements to be reached and honoured.Under Scots law all human remains have 'the right of sepulchre' and to violate a burial deliberately is a criminal act. While it is not an offence in every case to disturb or disinter human remains, the right of sepulchre is strongly defended under the law and an offence is considered to have been committed if the treatment of human remains is deemed to have offended public decency $^{89}$.

8 Historic Scotland, 1997 The treatment of human remains in archaeology Historic
Further information on the treatment of human remains can be found in MarquezGrant \& Fibiger (2011) and Brickley \& McKinley (2004). $\begin{array}{lrr}\text { Scotland } & \text { Operational Policy } & \text { Paper } \\ \text { 5.Edinburgh: } & \text { Historic } & \text { Scotland. }\end{array}$ http://www.historic-scotland.gov.uk/humanremains.pdf

${ }^{9}$ Also see: British Association for Biological Anthropology and Osteoarchaeology. http://www.babao.org.uk/index/ethics-andstandards 


\subsection{DNA}

There is much potential in the use of DNA analytical techniques in archaeology. These methods include the analysis of both modern and ancient nuclear and mitochondrial DNA, chromosomal studies and new genomics approaches. New applications outside of Scotland have included modern and ancient humans; extinct and extant animals; the detection of DNA on artefacts to establish use, and in soils and sediments (so called 'geogenetics'); the sampling of pathogen genetic material (e.g. Mycobacterium tuberculosis) in archaeological samples; and even the analysis of plant DNA in order to study domestication.

To date, very little human DNA work has been undertaken on either Scottish archaeological materials, or on modern materials to address archaeological questions. There are some notable exceptions, such as the ancestry work undertaken by Dr. Jim Wilson and colleagues at Edinburgh University/Western General Hospital in Edinburgh. Dr Wilson is involved in media output and commercial enterprise (with the founding of his own company EthnoAncestry, offering genetic ancestry profiling), and has received substantial press coverage for his work using $Y$ chromosome genetic markers to establish the ancestry of modern populations in the Western Isles, and the north of Scotland, and the contribution of Gael, Pict and Norse DNA to modern populations.

The analysis of animal DNA has been incorporation into a limited number of archaeological investigations in Scotland to date. Notably, this includes a recent AHRC-funded project investigating the phylogeography of the Orkney vole (e.g. Cucchi, et al. 2009a). Scottish material has also been incorporated into other phylogeographical studies, including that of the house mouse (e.g. Jones, et al. 2010) and the wild boar (Larson, et al. 2005).
Areas for development:

- Movements and diasporas (population origins)

- Population history (including demography, bottle-necks, etc)

- Phylogeography of consumal species

- Domestication of plants and animals

\subsection{Isotope Analysis}

Stable isotope techniques are based on the principle that human and animal body tissues will reflect the isotopic composition of food and water ingested during their lifetimes - 'You are what you eat'. Isotopes are different versions of the same elements, and characteristic patterns or isotope signatures can be useful in determining dietary habits, and the location or environment in which a human or animal inhabited during life. In archaeological case studies, analysis most commonly involves the samples of preserved hard tissues including bone, tooth enamel and dentine, but can also include soft tissues such as hair or fingernails in certain instances of good preservation. Analysis involves both the inorganic components of hard tissues (also known as bioapatite) but also preserved proteins such as collagen which may be preserved in bone or tooth dentine and can be extracted through the removal of the mineral component (demineralisation) and gelatinisation.

Carbon and nitrogen analysis of collagen (bone and dentine)

The most frequently used technique in archaeology involves the analysis of ratios of carbon and nitrogen isotopes in bone collagen $\left(\delta^{13} \mathrm{C}\right.$ and $\left.\delta^{15} \mathrm{~N}\right)$. Data from controlled feeding studies and field experiments have confirmed that bone collagen and other body tissues, such as hair (keratin), reflect dietary inputs and that these techniques can provide a direct 
measurement of diet (Ambrose 1993). Bone remodels during life and therefore bone collagen can be used to determine long-term dietary trends prior to death ( 5-10years) (Hedges et al. 2007). Tooth dentinal collagen can be used to assess short-term changes that occurred during childhood, as these tissues form in early life and undergo little remodelling (Gage et al. 1989). The relative abundance of the stable isotopes of carbon, ${ }^{13} \mathrm{C}$ and ${ }^{12} \mathrm{C}$ $\left(\delta^{13} \mathrm{C}\right)$, vary between different habitats, for example, between plants of different photosynthetic pathway such as C4 plants (tropical grasses including maize and sorghum) and C3 plants (including all trees, bushes and temperate grasses) (Smith \& Epstein 1971; DeNiro \& Epstein 1978). Carbon isotope ratios also vary between terrestrial and marine ecosystems (Schoeninger et al. 1983).

The stable isotope ratio of ${ }^{15} \mathrm{~N}$ and ${ }^{14} \mathrm{~N}$ $\left(\delta^{15} \mathrm{~N}\right)$ increases by $3-5 \%$ with each step up the foodchain, and is therefore most commonly used to indicate the trophic level of protein consumed (Bocherens \& Drucker 2003). Given that aquatic food chains are often far longer than terrestrial ones, nitrogen isotope data can also be used to distinguish between marine/freshwater and terrestrial diets (Richards et al. 2001). Nitrogen isotope values of animals at the same trophic level are also influenced by a range of other variables, and are often related to local environmental conditions (e.g. water availability, temperature, use of fertilisers, stocking rate, salinity, coastal proximity, biome) as well as physiology (see reviews in Hedges and Reynard 2007, Britton et al. 2008).

The analysis of the carbon and nitrogen isotope ratios in bone collagen involves the sampling of a small amount of bone or tooth dentine $(<1 \mathrm{~g})$, sample cleaning and demineralisation to remove the mineral matrix. The sample is then gelatinised and purified through filtration. The gelatinised protein is dried, weighed into tin capsules (0.5-1mg in weight), and are analysed using mass spectrometry.

\section{Strontium and oxygen analysis of bioapatite}

Although less common than the analysis of bone collagen, the other most frequently used type of stable isotope analysis in bioarchaeology is the strontium and oxygen isotope analysis of dental enamel. Enamel, like bone, is formed of a material known as bioapatite, however, unlike bone, the densely packed crystalline structure of enamel makes it preferential for this type of isotope analysis as it less resistant to undergoing chemical changes in the burial environment (known as diagenesis) (Hoppe et al. 2003). Unlike bone, tooth enamel is not remodeled during life, and therefore the isotopic composition of tooth enamel is directly related to environment and diet during dental formation (i.e. during childhood). Therefore, isotope data determined from dental enamel can be compared to the local environmental and geological parameters, identifying indigenes and potential immigrants. The strontium $\left.{ }^{\left({ }^{87} \mathrm{Sr} /\right.} /{ }^{86} \mathrm{Sr}\right)$ isotope ratio of enamel is directly related to the ${ }^{87} \mathrm{Sr} /{ }^{86} \mathrm{Sr}$ ratio of ingested plants and, ultimately, that of the soils and water available to the plants. This has been demonstrated to correlate with underlying geology and been used to explore human and animal mobility in the past (see review in Bentley 2006). ${ }^{87} \mathrm{Sr} /{ }^{86} \mathrm{Sr}$ analysis involves the sampling and dissolving of small section of tooth enamel $(<20 \mathrm{mg})$ in a strong nitric acid in a high-grade clean laboratory. A series of steps are then undertaken in order to isolate and extract dissolved strontium from the sample solutions. Samples are analysed using mass spectrometry. Another method, utilising laser ablation techniques, can be used on intact samples without the need to dissolve samples prior to analysis. This is virtually nondestructive, although measurements may 
not be as precise as with 'traditional' solution methods.

Oxygen $\left({ }^{18} \mathrm{O}\right.$ and ${ }^{16} \mathrm{O}$, or $\left.\delta^{18} \mathrm{O}\right)$ isotope ratios of tooth enamel can also be used to help identify the place of origin of individuals, as the oxygen isotopic composition $\left(\delta^{18} \mathrm{O}\right)$ of body water is directly related to meteoric water consumed during life (D'Angela and Longinelli 1990), which is in itself closely related to local temperature (Dansgaard 1964). Therefore, when used in tandem, these methods can help to pinpoint likely areas of geographical (geological) and climatic origin of individuals. Given that teeth form incrementally, analysis of subsamples of enamel for either oxygen or strontium isotopes can be used to gain time-series information (e.g. Balasse et al. 2005, Britton et al. 2009) Oxygen isotope ratios are commonly determined through the analysis of dental enamel, including the powdering of a sub-sample of enamel (<20mg) and subsequent reaction with ortho-phosphoric acid. This $\mathrm{CO}_{2}$ produced is then analysed for carbon and oxygen isotope ratios using mass spectrometry, measuring the bulk oxygen in a sample. However, another method, in which the phosphate-only component of the bioapatite crystal is first isolated (through the formation of silver phosphate) and then analysed, may also be used. This method is sometimes favoured on the reasoning that the phosphate component of the bioapatite crystal is better protected against diagenetic alteration.

\section{Archaeological applications}

Isotope analysis is now playing a routine role in many archaeological projects and is a key method utilized for investigating human diets and subsistence strategies, animal husbandry practices, movements and migrations, and individual life histories (through the analysis of incrementally developed tissues). By far the most common application of isotope analysis to archaeological case studies is the analysis of the ratios of the stable isotopes of carbon $\left(d^{13} \mathrm{C}\right)$ and nitrogen $\left(d^{15} N\right)$ to archaeological bone collagen to reconstruct long-term dietary history of individuals. In other areas of the United Kingdom, this has been applied to human remains from the Palaeolithic (e.g. Richards et al. 2000, Schulting et al. 2005, Stevens et al. 2010), through to the Mesolithic (e.g. Schulting and Richards 2002a, Schulting and Richards 2002b), Neolithic (e.g. Richards and Hedges 1999, Richards 2000, Richards et al. 2003) and later Prehistoric periods through to the Roman (e.g. Chenery et al. 2010, Fuller et al. 2005, Jay et al. 2008, Redfern et al. 2010, Richards et al. 1998) and Medieval periods (e.g. Fuller et al. 2003, Muldner and Richards 2005, Muldner and Richards 2007b, Richards et al. 2002, Roberts et al. 2010). There have also been a small number of published diachronic studies, assessing dietary change at the same location through time (e.g. The City of York, Muldner and Richards 2007a). A small number of studies have also utilized these techniques to investigate other aspects of human life histories and population demography, such as the age of weaning in the late Medieval period (Fuller et al. 2003, Richards et al. 2002).

Although applications are growing, a far smaller number of studies have incorporated strontium isotope analysis $\left({ }^{87} \mathrm{Sr} /{ }^{86} \mathrm{Sr}\right)$ of bioapatite (normally tooth enamel) - a method utilized to explore geographical origins of individuals and movements they may have undertaken during their lifetimes (e.g. Chenery et al. 2010, Eckardt et al. 2009, Evans et al. 2006a, Evans et al. 2006b, Montgomery 2002). The reasons for the smaller number of such studies (compared to other isotope approaches) largely relates to analytical costs. Strontium isotope studies are often conducted alongside stable oxygen isotope analyses $\left(d^{18} \mathrm{O}\right)$, in order to provide complimentary climatic or palaeotemperature proxies to ${ }^{87} \mathrm{Sr} /{ }^{86} \mathrm{Sr}$ data to better establish geographical 
Science in Scottish Archaeology origins of individuals (e.g. Eckardt et al. 2009).

In addition to applications of isotope analyses to human remains, these techniques have also been applied to zooarchaeological materials in order investigate the palaeoecology and biogeography of archaeological-important prey species (Britton et al. 2009), as well as foddering and other husbandry practices employed by human populations while raising domesticates. This has included the successful identification of animal husbandry practices rarely found in modern contexts such as salt-marsh grazing (Britton et al. 2008) and the seasonal movements of animals between different types of pasture (Evans et al. 2007). Animal isotope data - whether wild or domesticate - is also a vital component of any human isotope study in order to establish a suitable 'baseline'.

\section{Previous Isotope Archaeology Studies in Scotland}

In comparison to other areas of the UK, there are have been relatively few published stable isotope studies conducted on Scottish archaeological material, and even fewer that have been led by archaeological research groups within Scotland. Although there are some obvious issues with the availability of material from certain time-periods (e.g. the scarcity of skeletal material from the Palaeolithic and Mesolithic), and issues of preservation (due to often acidic soils), the amount of work conducted in Scotland is certainly not representative of the quantity of archaeological material excavated or adequately addressing the key issues of modern Scottish archaeological investigation. Much work to date has focused on the Islands, including Orkney and the Hebrides.

e.g.

- Mesolithic-Neolithic dietary transitions in Orkney (Mieklejohn et al. 2005, Richards 2004, Schulting and Richards 2002c)

- Seaweed foddering in Neolithic (and modern) sheep the Orkney Isles (Balasse et al. 2005, Balasse et al. 2006, Balasse et al. 2009)

- A single diachronic dietary study (Iron Age, Viking and Late Medieval) in Newark Bay, Orkney (Richards et al. 2006)

- Hebridean migrations including origins of Norse communities (Montgomery et al. 2003, Montgomery and Evans 2006)

- Strontium isotope mapping of the Isle of Skye (Evans et al. 2009)

- Isotope analysis of archaeological faunal material on South Uist (Mulville et al. 2009)

There has been a limited amount of published isotope work conducted on archaeological material from the Scottish mainland, including a study of the diets and origins of the Bishops at Medieval Whithorn (Muldner et al. 2009).

A recent project funded by the US National Science Foundation, headed by T. Douglas Price, involving Janet Montgomery (Bradford) amongst others, is utilizing Scottish material in a larger project looking at Viking migration in the North Atlantic. Some of this material (e.g. that from the Hebrides) has already been published, along with that from other areas of the North Atlantic (e.g. Iceland, Price and Gestsdóttir, 2006).

Another recent large-scale AHRC-funded project, The Beaker Isotope Project, assessing mobility, migration and diet in the early Bronze Age, also incorporated a limited amount of Scottish material. To date, much of this material is being prepared for publication. 
Future Areas of Focus

\section{More studies}

Given the potential of isotope methods to explore ancient life-ways, there is a clear need for more isotope studies on Scottish material. General awareness of the potential of isotope analysis of animal or human remains should be promoted, and there inclusion in bioarchaeological studies should be endorsed. Although it should be noted that such studies be conducted by specialists (i.e. isotope archaeologists), or in collaboration with those specialists, it is essential not only that scientific analytical techniques are robust, but also that data are interpreted within in a robust archaeological framework by those who thoroughly understand the limitations of isotope archaeology, understand the processes of archaeological investigation and appreciate the archaeological relevance/setting of the material under investigation.

\section{Growth of isotope archaeology research groups, laboratories and collaborations within Scotland}

England now hosts several isotope archaeology research groups with dedicated in-house analytical facilities at a number of universities (e.g. Oxford, Cambridge, Reading, Bradford). These, along with other global research centers such as those at Harvard University, University of British Columbia and the Max Planck Institute for Evolutionary Anthropology, Leipzig, are also testament to how successfully dedicated isotope archaeology facilities can produce research of international significance. No such research groups currently exist in Scotland. This is highlighted as an area of potential development, alongside further effective integration with isotope work at environmental science (SUERC) ${ }^{10}$ and agronomic research centers (e.g. University of Dundee), and the forging of international collaborations.

To date, of the published isotopic archaeology studies conducted on Scottish material, it is notable that few of these studies were undertaken by Scottish research teams or in Scottish laboratories.

\section{Identification of key issues and research frameworks}

In additional to the above, it is also clear that there are numerous aspects of Scottish archaeology that would be particularly benefit from isotopic investigations and areas for future focus, including:

Movements: The fundamental research carried out by Jane Evans (NERC Isotope Geoscience Laboratoty, Keyworth) and others, has produced a general map of 'bioavailble' strontium for the British Isles and more detailed maps of certain regions of Scotland (Evans et al. 2009, Evans et al. 2010). These studies go beyond traditional geological mapping, and provide the framework in which archaeological investigations can take place. There is much potential in Scotland to utilize geographically/geologicallyvarying isotope systems $\left({ }^{87} \mathrm{Sr} /{ }^{86} \mathrm{Sr}, \mathrm{d}^{18} \mathrm{O}\right.$, $d^{34} S$ ) to explore human and animal mobility. Given that bulk and incremental tooth samples can be taken, there is the potential for research to take place at a variety of scales, from within lifetime

${ }^{10}$ At SUERC, analysis of $\delta^{2} \mathrm{H}, \delta^{13} \mathrm{C}, \delta^{15} \mathrm{~N}, \delta^{18} \mathrm{O}$, ${ }^{87} \mathrm{Sr} /{ }^{86} \mathrm{Sr} .{ }^{206} \mathrm{~Pb} /{ }^{207} \mathrm{~Pb} /{ }^{208} \mathrm{~Pb}$ isotopes for topics such as climate, diet, population movement, and source provenance is available. Analysis of $\delta^{34} \mathrm{~S}$ for dietary work is currently being developed and should be available by autumn 2012 
movements, landscape use (exploring aspects of animal husbandry and transhumance) and general population mobility to larger issues such as colonisation, and modern and ancient diasporas.

Diachronic changes in diet and health: In addition to site-specific dietary studies, there is a need for multi-period dietary studies in Scotland. Diachronic stable isotope studies (carbon and nitrogen) are very effective ways of assessing changes in diets and subsistence strategies through time, especially when combined with osteological and zooarchaeological approaches. Unlike other approaches, long-term (e.g. bone collagen) and shortterm (e.g. dentine collagen) bulk dietary trends can be established using isotopic methods - in both individuals and on population levels. These methods lead to directly comparable geographically and temporally comparable data sets, and are an effective way of looking at population level changes through time - changes that can be correlated with larger scale social and political changes (e.g. mass population movements, land clearance, etc)

Animal husbandry and subsistence strategies: One growing area of isotope

\section{The medieval Bishops of Whithorn}

When applied to human remains, stable isotope analysis can offer both population level and individual data, revealing details of the lives of individual people, and also informing on broader societal trends. To date, very few studies have focused on material from Scotland, although the handful of research projects undertaken to date reveal the true potential of these methods to the key themes of Scottish Archaeology, from Prehistory to the Postmedieval period.

A recent study, published in Antiquity (Müldner et al. 2009) demonstrates the power of stable isotopes to inform on individual life histories, and through this, reveal important information about past societies. In combination with traditional archaeological approaches used to assess the burials, this study undertook isotope analysis on human remains at Whithorn Cathedral Priory (Dumfries and Galloway), in order to assess diet, status $\left(\delta^{13} \mathrm{C}, \delta\right.$ $\left.{ }^{15} \mathrm{~N}\right)$, and mobility $\left(\delta^{18} \mathrm{O},{ }^{87} \mathrm{Sr} /{ }^{86} \mathrm{Sr}\right.$ ) between different individuals and groups. The study revealed differences between the lay-community, high-ranking clergy and the Bishops buried in the medieval cemetery, concluding that the Bishops consumed significantly more fish than the meat-eating populus and were also - for the most part - likely to have moved to the area from further east in Scotland. The consumption of fish - a spiritually-significant 
fasting food - provides direct evidence for this religious practice in the lives of medieval clergy men. In contrast to the Bishops, the lay-community were largely identified as having local upbringings, implying that - within Medieval society - mobility itself was statusdependant. Whilst revealing the life-histories of individuals, the isotope data attest to the expression of contemporary social, religious and status differences within medieval society (Müldner et al. 2009: 1131).

\subsection{Microarchaeological sampling for proteins}

\section{Recovery of proteins}

Almost certainly more is known about the persistence of proteins than any other biomolecule in the archaeological record, as a result of both the recovery of collagen for ${ }^{14} \mathrm{C}$ dating and $\delta{ }^{13} \mathrm{C}, \delta{ }^{5} \mathrm{~N}$ analysis and by virtue of the measures of decay for dating (recently rejuvenated in the UK by North East Amino Acid Racemization (NEaar)), using the so-called
'Intra-crystalline protein degradation' approach' (ICPD).

As a consequence of these methods it is known that proteins will display measurable levels of deterioration in post-Roman samples even if protected from microbial decay. However it is also known that proteins in protected environments, such as bone collagen, have the potential to persist in all archaeological samples recovered from Scotland.

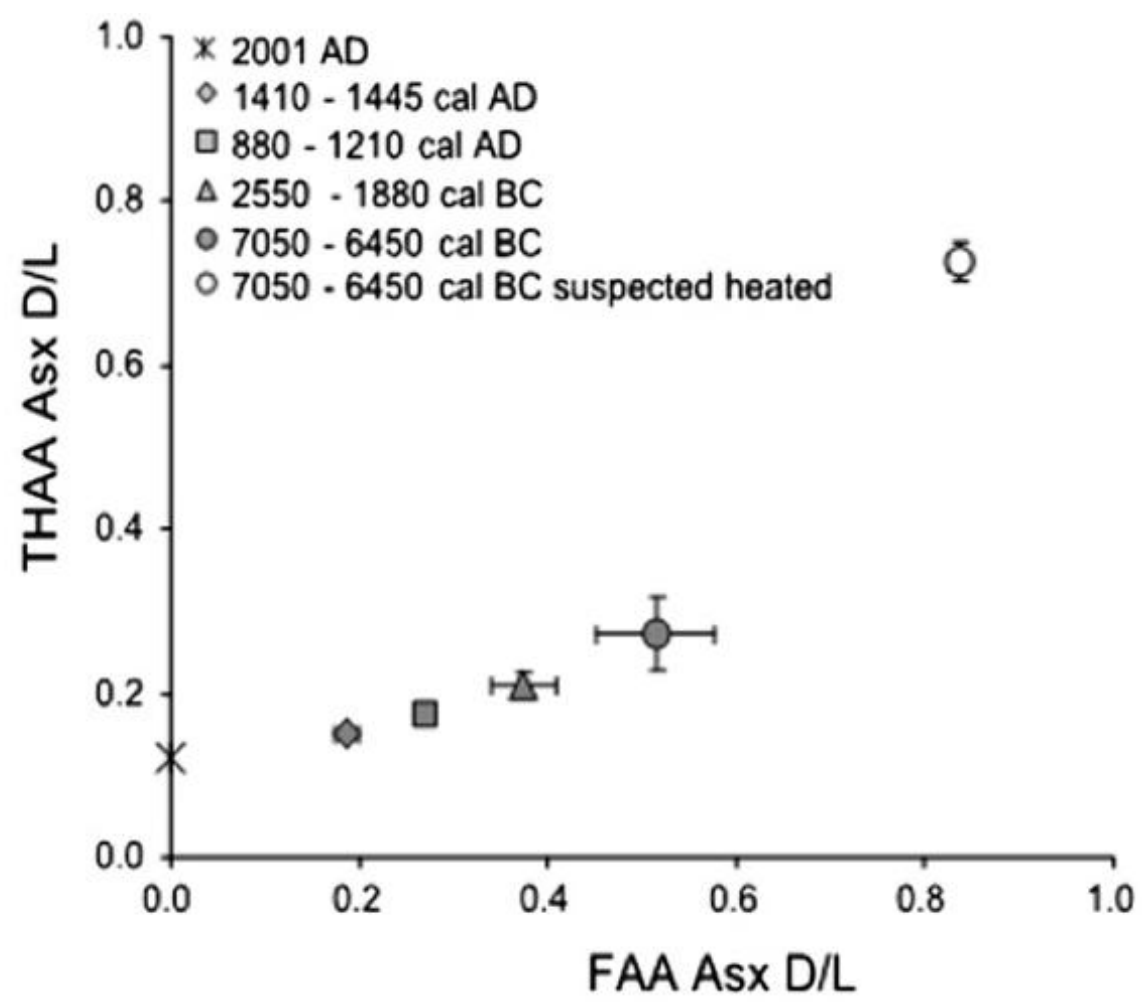

Figure 6: Free amino acids (FAA) vs Total hydrolysable amino acids (THAA) plot for Asx D/L measured in Scottish archaeological Patella; error bars represent one standard deviation around the mean for each site. Modern (collected in 2001 AD) Patella D/L values are also plotted for comparison (from Demarchi et al. 2010) 


\section{New directions}

\section{Stable isotope analysis}

Improvements in amino acid analysis, specifically single compound amino acids $\delta^{13} \mathrm{C}$ and $\delta{ }^{5} \mathrm{~N}$ hold promise of a more subtle interrogation of bone proteins. As an example it would be possible to obtain greater understanding of the reliance of humans on coastal resources and of the key dietary transitions in Scottish pre- and proto-history.

\section{Proteins in ceramics}

Interface samples (such as pottery crusts) represent an intermediate type of survival, and we do not know what information will be preserved in them. However there is encouraging research from Solazzo et al.(2008) and Stevens et al. (2010) suggest that it may be possible to identify proteins in some ceramics. This would be potentially useful in order to investigate dietary change, because specific animal and plant proteins (e.g. gadoid myoglobin, albumin, sheep casein) may be identifiable from sherds.

\section{ZooMS (Zooarchaeology by Mass Spectrometry)}

Protein is present as collagen in almost all Scottish archaeological bone (as well as dentine, ivory and antler). The development of a new high-throughput screening technique using soft-ionisation mass spectrometry to fingerprint collagen peptides has potential for protecting morphologically valuable remains from destructive analysis. ZooMS can discriminate small particles of bone to genus level, offering a new approach to rapidly characterise unidentifiable bone fragments (such as cetaceans) routinely and at low cost. One potential application would be to identify additional human material in Mesolithic shell middens, which have been the focus of intense interest in order to understand the dating of the arrival of Neolithic populations, the use of middens as burial sites, and the different approaches to marine exploitation.

ZooMS also appears to be able to recover sufficient collagen from some cremated remains for identification. A new direction is the detection of proteins in eggshells. The recent colonisation of fulmar in the $20^{\text {th }}$ century has been attributed to the increased access to bycatch. However claims for the detection of fulmar in Viking levels at Freswick Links, suggest a more complex pattern of dispersal. 


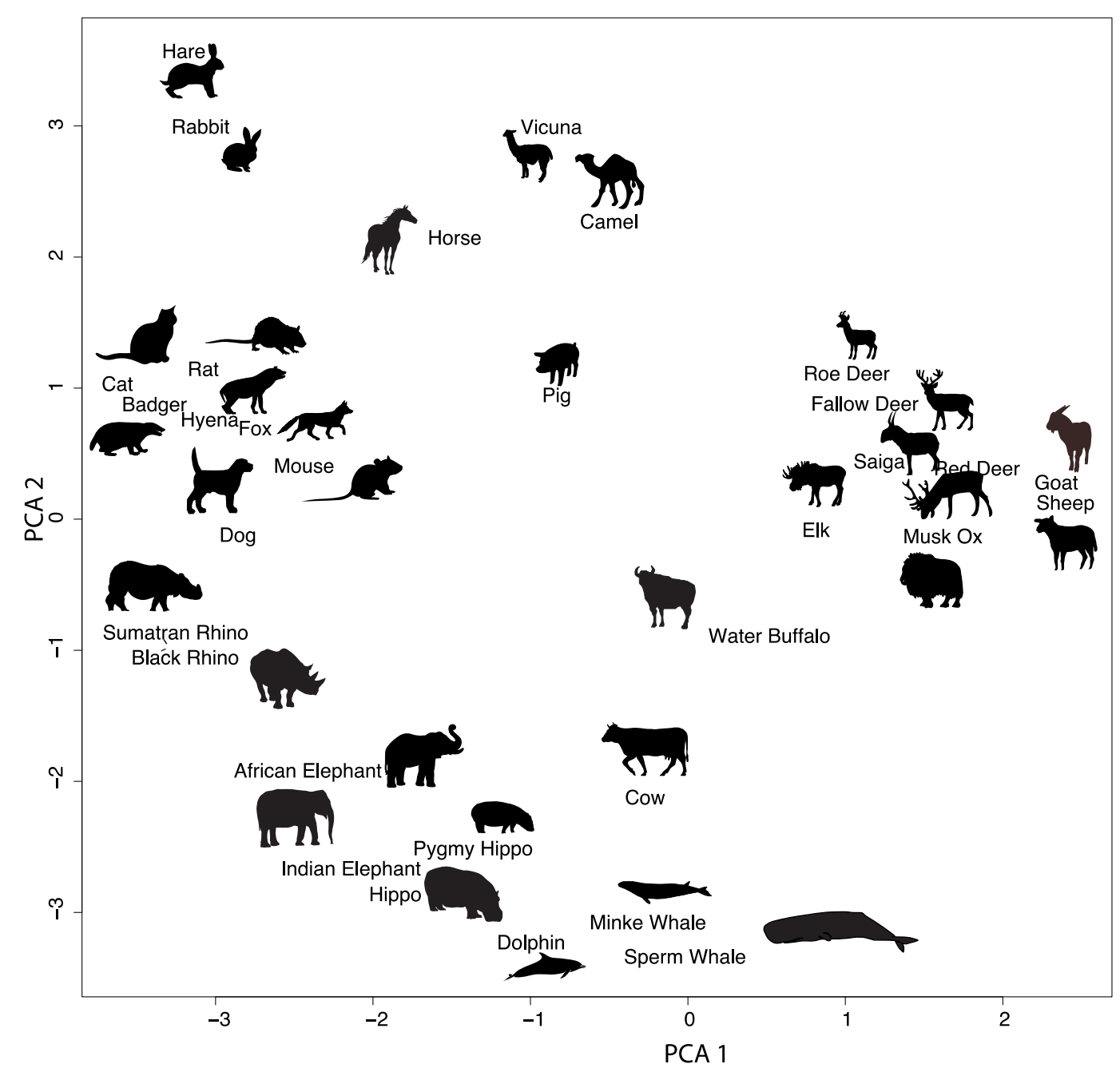

Figure 7: ZooMS discrimination of animals from bone collagen peptides. Data replotted from Buckley et al. 2009.

\subsection{Human and animal sciences recommendations}

- Establishment of a national online database of human skeletal material from Scottish archaeological sites, which would enable researchers to easily locate specimens appropriate for specific research projects and facilitate new thematic, temporal and geographical studies of the DNA, diet, health, mobility and demography of past populations in Scotland.

- Active promotion of new collaborative research between the existing DNA, isotope, biomolecule, epidemiology and medical imaging facilities and expertise in Scotland and archaeologists and bioarchaeologists working on Scottish remains through a series of symposia and workshops aimed at the development of new project proposals. 
- Wide publicization of Scotland's outstanding potential to provide a focus for research on past human and animal adaptation, flexibility and mobility patterns due to the highly contrasting environments and ecosystems within a relatively small geographical area, in order to attract cutting-edge scientific research on these issues using Scottish archaeological material.

- Targeted research on sites of all periods in the areas of Scotland where local soil conditions permit the preservation of human and animal skeletal material, in order to address the current gaps in the human and animal bone records. 


\section{Understanding materials}

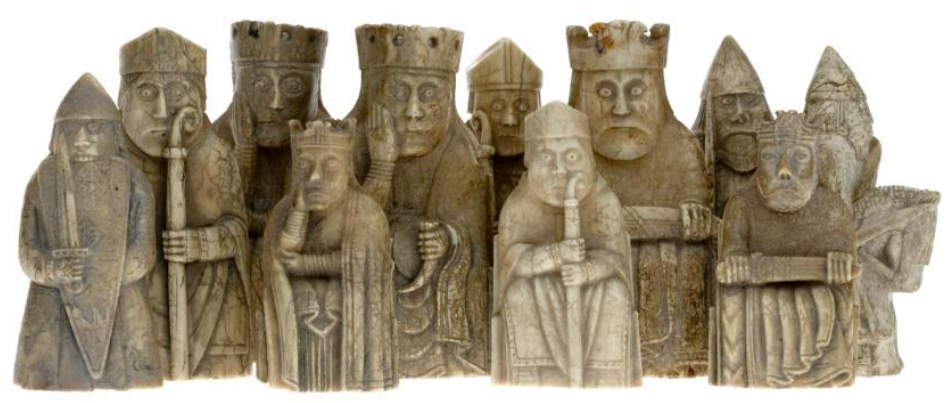

Figure 8: Selection of the Lewis chessmen. Analysis of the chessmen has revealed that they were carved from walrus ivory, probably the work of five different craftsmen, most likely in the $12^{\text {th }}$ or $13^{\text {th }}$ centuries AD in Trondheim, Norway, ONMS

\subsection{Introduction: Materials analysis}

This large theme can be classified according to investigations into Technology, Provenance and Function. The theme also relates to issues in conservation science such as decay, stabilization and maintenance.

The following questions about materials are relevant to an understanding:

- Identity of the material(s) from which the artefact was made?

- Technology of fabrication of the artefact?

- What was the source of the artefact or the raw materials?

- What was the function and use of the artefact?
- How has the condition of the artefact altered, or been altered, since antiquity?

- What is the material condition and how can it be stabilised and preserved?

These questions are crucial because they concern such fundamental aspects of the past as technology, use, trade and exchange. Understanding materials also leads to more abstract but no less valuable insights into the past which are bound up with the issues of ideology, choice and value: was a particular material or production method used over another for social, practical or a combination of reasons?

Chronologically and typologically, artefacts are enormously wide ranging, from Neolithic pots to Iron Age torcs to Viking steatite bowls to silver coins, 
reflecting the spectrum of inorganic raw materials available in Scotland from the well-known metal ores, clays and building stones to more unusual ones such as Arran pitchstone. Artefacts of organic nature have very often been lost from the archaeological record, but materials such as bone, walrus ivory and whales' teeth (as in the Lewis chessmen), amber and jet are well known, and there are materials that are neither raw material nor artefact, for example cramp, a vitreous seaweed cremation 'waste' of prehistoric Orkney.

Equally, the scope and scale of investigations, adopting an array of science-based techniques and approaches, is very wide ranging. The age of the artefact or material of course holds no barrier to its examination. Some investigations are site-based, focusing on artefacts/materials deriving from recent archaeological excavation which pose questions of immediate concern and interest, sometimes in a conservation context, (e.g. the Viking boat burial on Sanday [Owen and Dalland 1999]). Other investigations may be concerned with an individual museum object, such as the Monymusk reliquary, or examples of a particular artefact type, such as brooches. Drawing on artefacts from several sites which are now housed in museum collections, other investigations have a wider remit, often extending beyond Scotland to a European or world-wide context (e.g. faience). There are enquiries that in going beyond the laboratory examination demand an experimental approach, for example pottery making, metal working and vitrified fort construction and firing.

Of equal relevance are items that are less archaeological in their status but instead are products of the visual and decorative arts, originally made to decorate a church, a palace or a home, such as paintings, textiles, furniture, metal and glassware, and now commonly exhibited in a museum or gallery. Here the enquiry may be more conservation based, but its outcome can have equal technological interest as well as providing information about the biography of the piece and the source of its raw materials. Into this category may belong sculpted stone, such as Pictish crosses.

The fundamental importance of analysis to many aspects of the conservation and long-term preservation of artefacts deserves further attention. Clearly it is important to know what the material being conserved is, while the identification of corrosion products and the understanding of degradation processes inform both conservation treatment and knowledge of the object history and past environments. In some cases the treatment has to be developed and monitored using scientific methods which may themselves be applied in a novel way to meet the particular demands of archaeological materials; the preservation of waterlogged wood being a good example of this. Conservation science is a specialist part of the application of science to heritage materials, but is often inextricably mixed with characterisation and study of fabrication technology; examples include the Forteviot Early Bronze Age dagger burial $^{11}$, the radiography of corroded ironwork to define preservation strategies, and understanding the effects of light damage on pigments or organic dyes.

Almost alone among the themes presented in this document, Understanding Materials usually operates within a context of specialisms that combine the traditional with sciencebased. One scenario sees the finds

11 http://www.aocarchaeology.com/keyprojects/conservation-services-keyprojects/conserving-the-forteviot-daggerburial 
Science in Scottish Archaeology specialist, having identified questions that only a science-based analysis or examination can resolve, setting up a collaboration with one or more analysts. The success of that collaboration is as much a function of effective communication between specialists in optimising the interpretation of the scientific data as it is of the scientific data alone. In any case, the science-based analysis/examination is likely to involve more than one technique, beginning probably with one of the non-destructive techniques outlined below and leading to more detailed analyses requiring a sample to be taken. The same remarks apply to the the reverse situation where the initiative is taken by the scientist/analyst leading to discussion with the museum curator or finds specialist on the historical or archaeological interpretation of the analysis/examination.

The techniques of analysis are numerous, reflecting the various purposes of investigations, as well as the likelihood that a given investigation will lead to the application of complimentary techniques to reveal further information. The three broad categories outlined below encompass the main techniques found to be applicable in Scottish work.

Non-destructive techniques:

- Optical, scanning electron microscopy and other surface visualisation and characterisation methods.

- Radiographic methods using Xrays, neutrons and other penetrating radiation to reveal internal structures and compositional differences.

- Elemental and chemical analysis using spectroscopic methods with infra red, visible and shorter wavelength light, synchrotron, $\mathrm{X}$ rays and partical excitation.
Techniques requiring samples to be taken and preserved:

- Spectroscopic and microscopic methods for petrographic, mineral and metallurgical analysis revealing crystalline structure and phase compositions, and technological examination of paint and other layers. Elemental analysis where sampling, for example, to fit into vacuum chamber.

Requiring samples or micro-samples to be taken and destroyed

- Spectroscopic and mass spectroscopic methods where molecular and isotopic information is obtained by dissolving or dissociating the sample in solution, vapour or plasma.

- Chromatographic and combination methods to determine molecular structure and composition.

Petrographic analysis has a long history in identifying and sourcing stone types from historical and archaeological contexts in Scotland, but it is since the 1970s that the science-based component of understanding materials has accelerated. Mention should be made here of the early and pioneering analytical work on artefacts by Hugh McKerrell at the laboratory of the National Museum of Antiquities of Scotland (McKerrell 1974). Since then there have been many major advances in analytical methods, with equipment and techniques now available which can provide a wide range of analytical information on microscopic sized samples. The developments of analysis using synchrotron radiation and adaption of methods arising from the expansion in forensic science means that heritage science now has an often bewildering array of analytical methods 
potentially available, while at the same time the complexity of establishing, operating and maintaining such equipment means that it can only be supported and used in expensive and specialist centres. In the face of such opportunities it becomes increasingly important to ensure that the questions being asked/data being sought are well defined so that the most relevant and diagnostic outcome is obtained.

Methods of physical examination, some of which are set out in Table $1 b$, are therefore numerous and rapidly changing as new methods and combinations of examination and analysis are developed; one important consequence of improved detectors and instrument design is the reduction in sample size. Many of these are well known techniques where the generation of results can almost be guaranteed. New methods and techniques are, however, constantly emerging where the success in, or relevance to, any enquiry is less certain. To implement these may have an element of risk to the object or require precautionary sampling. The discipline needs to be open to this process, for example, in certain DNA and isotopic studies. Both Tables $1 a$ and $b$ include the facilities which are located in Scotland and beyond (in brackets). Following these Tables is a box feature on data treatment of analytical data (see also section 6).

The UK National Heritage Science Strategy identified many of the issues relating to the discipline and illustrated the actual and potential public benefits arising from the understanding, preservation and enjoyment of heritage that it brings. The key strategic aims which the report draws together are as relevant to Scotland as to the rest of the UK. The examination of ancient materials and Conservation Science feature regularly in such public events as the Edinburgh Science Festiva, but there are many more opportunities to engage with the public and increase recognition and support.
Partnerships are strong across the community in Scotland, but there remains plenty of scope to strengthen existing links and build new partnerships which will, it is to be hoped, lead to the fuller availability of resources. There is a need to ensure that, through partnerships, collaborations, training and, where possible enhanced funding, there is built a secure future capacity to match the growing demand for an adequate science based infrastructure to support archaeology and historical studies and to preserve material for the future.

\subsection{Techniques of analysis ${ }^{12}$}

\subsubsection{Spectroscopic}

\section{$\mathrm{X}$-ray Fluorescence (XRF)}

Energy-dispersive XRF

This technique uses an X-ray beam to excite fluorescent $X$-rays from the surface of a sample. These are detected by a solid state detector (usually liquid nitrogencooled $\mathrm{Si}(\mathrm{Li})$, although room temperature detectors are becoming more common) which measures their energy and quantity. Elements are identified from their unique set of fluorescent X-ray energies and composition can be deduced from their relative abundance in the XRF spectrum under the experimental condition.

XRF has the advantage of being completely non-destructive and very

\footnotetext{
${ }^{12}$ For further reading on analytical techniques see, for example Pollard AM, C Batt and B Stern, 2007, Analytical Chemistry in Archaeology, CUP, which covers most techniques and Potts PJ and West M. 2008. Portable X-ray fluorescence spectrometry: capabilities for in-situ analysis. Cambridge: RSC publishing.
} 
quick. An air-path system can be used directly on complete objects.

The main limitation of the technique is that it is only able to analyse the surface layer (typically up to the first hundred microns, but the depth depends on the material composition). This means that if surface enrichment has taken place, for example on a metal artefact, the results may not represent initial bulk composition (Tate 1986). XRF can only detect light elements such as sodium if the sample is maintained in a vacuum chamber, a system with reduced suitability for much archaeological material or complete artefacts.

XRF has been used to characterise archaeological metals, such as copper alloys and silver, and is also highly suited as first-line identification technique for a wide range of other inorganic materials and to characterise surface gilding or decoration, Micro-XRF systems are now well established where the analysed area is of micron dimensions and may be used to build up a compositional maps across small areas of an artefact's surface.

\section{Used at: NMS, University of St Andrews}

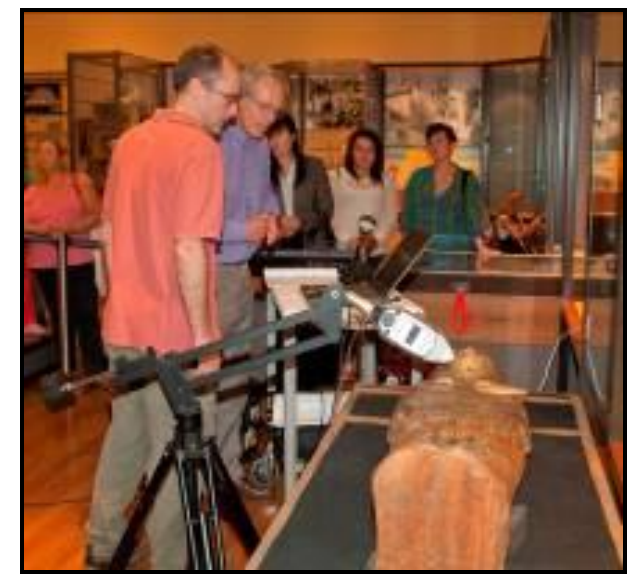

Figure 9: pXRF of Egyptian sarcophagus 1895 167a, Kelvingrove Museum, Glasgow (photo:@ Glasgow Museums)

\section{$\underline{\mathrm{HH} X R F}$}

Portable or hand-held X-ray fluorescence has been used intermittently in archaeological science for the last couple of decades, however recent advances in detector technology, specifically the introduction of the silicon drift detector (SDD) means that it is becoming more popular not only across a range of material types but also as an ideal in-situ 'screening' technique, for example on artefacts in museums. Various techniques (partial vacuum, He flush) allow systems to detect elements as light as Al.

Used at: HS, Scottish Analytical Services for Art \& Archaeology (Glasgow)

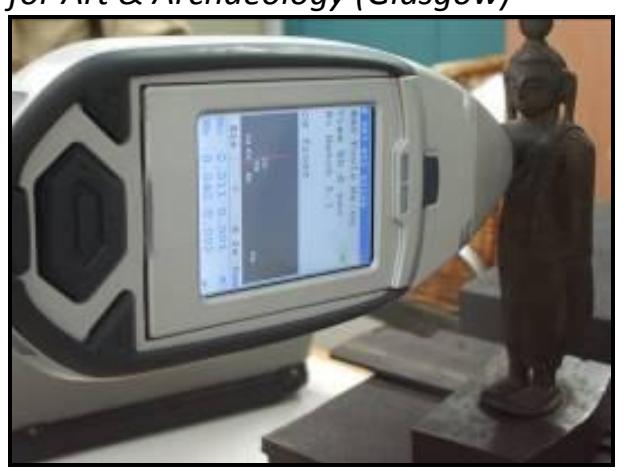

Figure 10: 16thc Asian bronze buddah (CGlasgow Museums 1929.64.ca)

\section{Wavelength-dispersive XRF}

A different method of determining the energy of the fluorescent X-rays (see XRD below) can lead to higher sensitivity. The method is often used for bulk sample analysis of stone, soil and ceramics. Detects a wide range of elements, and as the sample is normally contained in a vacuum chamber, includes light elements.

Used at: Edinburgh Geosciences,

\section{$\underline{\text { X-ray diffraction (XRD) }}$}

X-ray diffraction provides information about the structure of a material, rather than its chemical composition. X-ray diffraction depends on the $X$-ray wavelength and the lattice spacing of the sample material, by measuring the angles at which diffraction lines occur the crystalline structure of the sample can be deduced. This technique is used to 
identify minerals and geological materials, to characterise corrosion products of metals and deterioration products of stone and in any aspect of archaeological science where knowing the structure as well the composition of a material is required.

Used at: Edinburgh Geosciences, Historic Scotland, NMS, Glasgow Earth Sciences, Charleston Consultants (Scottish Lime Centre, Fife), University of St Andrew.

Electron Microprobe analysis (EPMA) and Scanning Electron Microscopy (SEM) with Energy or Wavelength Dispersive analysis (EDS or WDS)

In each of these methods the sample, normally as a small polished specimen mounted in a plastic block and carbon coated, is irradiated with a beam of electrons. Fluorescent $\mathrm{X}$-rays are generated by the electron-sample interaction and can be detected as in XRF, using energy dispersive or wavelength dispersive spectroscopy. The electron microprobe uses a highly focused and intense electron beam to analyse all but the lightest elements (>Be) with a spatial resolution of about 1 micron and good analytical precision. The scanning electron microscope (see below) allows similar analysis but with lower sensitivity in favour of improved image resolution. EPMA has been applied mostly to glass, whereas SEM-EDS is commonly used for a wide range of metals and vitreous materials.

Used at: NMS (SEM-EDS) Edinburgh Geosciences ((EMPA/SEM-WDS) where it forms part of the NERC Tephrochronology Service)

Particle induced X-ray emission (PIXE) and Gamma spectroscopy (PIGE)

This technique uses a finely focused ion beam, normally protons, to excite $\mathrm{X}$-rays from the sample. Like XRF, the energy of these $\mathrm{X}$-rays is diagnostic of each element present. PIXE allows quantitative analysis with very low detection limits for many elements (ppm) and has been applied to the trace element characterisation of metals, ceramics and lithics. The proton interaction also causes gamma emission from some elements: this emission is not just from the surface of the sample and thus gamma spectroscopy can give information about the bulk, as well as surface composition of a sample. Various other techniques such as Rutherford backscattering analysis can be combined with this methodology.

Used at: Department of Materials at Oxford, CNRS Louvre Paris

\section{Analysis using Synchrotron radiation}

At the high-tech end of analytical methods is the national synchrotron science facility, Diamond Light Source, based at Harwell. The unique characteristics of synchrotron radiation particularly the ability to produce a high intensity and tightly focused excitation beam of electromagnetic radiation - are ideal for analytical problems requiring high spatial or temporal resolution or problems that are intractable using conventional instruments. Cultural heritage work exploits analytical techniques from infrared to hard X-ray wavelengths. Imaging from $X$-ray to micro-CT scanning is also possible.

http://www.diamond.ac.uk/Home/Scienc e/Culture.html

\section{Fourier Transform Infra-red Spectroscopy (FTIR)}

This technique identifies materials based on their absorption of infra-red light. The absorption spectrum depends on the molecular species present since they have different vibrational frequencies. It is most commonly used in the identification of organic materials such as waxes, resins 
and pigments, which, in a conservation context, are helpful in determining previous treatments on objects. Modern materials including plastics can also be routinely identified with FTIR. FTIR can be used in bench mode or with various microscope configurations for the examination of micro-samples. Interest is now focused on hand-held instruments for in-situ analysis.

Used at: NMS, Textile Conservation Centre Glasgow, Strathclyde, Napier (Forensics)

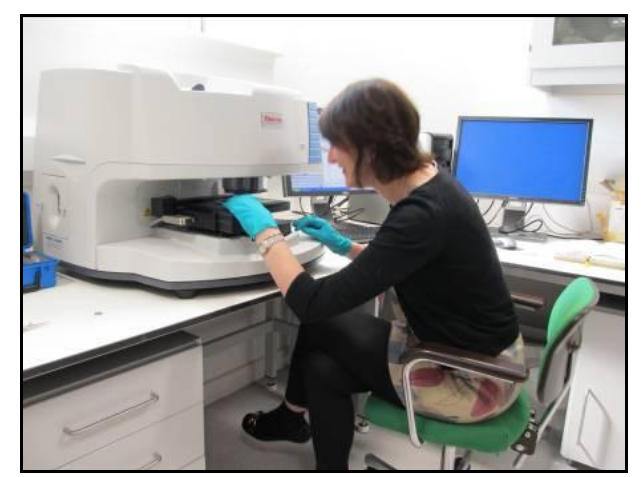

Figure 11: FTIR microscope in use at NMS Collection Centre, Edinburgh CNMS

Raman spectroscopy, Fourier Transform Raman spectroscopy, Surface Enhanced Raman Spectroscopy.

Like FTIR, but using a visible laser rather than infra-red, Raman spectroscopy provides information about the molecular species present in a sample and their charge state. This technique has been extensively applied to a wide range of materials. It has been applied routinely to pigment identification and has also been used to look at the corrosion of glass and other materials in a museum setting.. In materials which have transparent upper layers the area beneath can be analyses, allowing examination of, for example, pigment layers beneath glass, while significant improvements in detection limits can be obtained with SIMS. In recent years the use of surface enhanced Raman scattering (SERS) has greatly enhanced the capabilities of Raman as a technique, significantly reducing the size of sample required.

Used at: Glasgow Earth Sciences (Renishaw inVia), Strathclyde, Napier

\subsubsection{Inductively-coupled Plasma techniques (ICP)}

Inductively Coupled Plasma Spectroscopy (ICPS) Plasma Spectroscopy covers a family of techniques used for the analysis of a wide range of elements, particularly trace elements. All the techniques initially require the transformation of the sample from a solid sample into a plasma, effectively its vaporisation into positive and negative ions, electrons and molecular fragments. The composition of the plasma can then be measured by several methods.

\begin{tabular}{ll} 
Inductively-coupled Plasma & Atomic \\
\hline Emission Spectroscopy (ICP-AES) &
\end{tabular}

Atomic emission spectroscopy measures spectral emission arising from energy changes within an atom to determine which elements are present, and in what concentration, within the sample. Detection limits are or can be very low, down to parts per million (ppm) and even parts per billion (ppb), depending on the element. Conventional AAS requires samples to be in solution prior to analysis. This technique has been extensively used in archaeological science for provenance studies, characterising trace element compositions of ceramics, metals, vitreous materials, lithics and soils.

Used at: SUERC, Stirling (Environmental \& Biological Sciences), Edinburgh Geosciences

Inductively-coupled Plasma Mass Spectrometry (ICP-MS)

Mass spectrometry uses the mass and charge of ions (charged particles) to separate the component constituents form the plasma which can then be 
Science in Scottish Archaeology quantitatively detected to determine each element present. This is a highly sensitive technique with detection limits in the parts per billion ( $p p b)$ range for some elements. It has been employed in provenance studies as for ICP-AES.

\section{Used at: SUERC, Edinburgh Geosciences}

Laser Ablation Inductively-coupled Plasma Mass Spectrometry (LA-ICP-MS)

Here a laser is used to ablate a tiny amount of material from the sample/object into the plasma; a mass spectrometer then identifies and quantifies the elements present as in the technique above. This technique is particularly useful in archaeological science as it is minimally destructive and so can be used on entire objects (albeit with considerable limitations due to the size of the required vacuum chamber). It is extremely sensitive for trace and rare earth elements with detection limits in the ppb range. This technique is increasingly being used in provenance studies of a range of materials but has significant potential for more. With a multi-collector (LA-MC-ICPMS) it can also be used to characterise radiogenic isotope ratios such as lead, which can be used to provenance metals.

Used at: Aberdeen Geosciences, St Andrews

\section{Thermal ionization mass spectrometry (TIMS)}

TIMS is another mass spectrometry technique which utilises a heated filament to ionize a sample prior to separation in the mass spectrometer. While radiogenic isotopic ratio analysis has been extensively applied to geological materials, the archaeological applications of TIMS have used lead isotope ratios to source metals, glasses and pigments. It requires the removal and dissolution of small samples (usually in hydrofluoric acid), as well as knowledge of the sample's bulk chemistry.

Used at: SUERC

\section{Secondary ion mass spectrometry (SIMS)}

By subjecting the sample to a focused beam of high energy ions SIMS can be used to examine the composition and charge state of materials. It is the most sensitive technique available for the analysis of surfaces, determining the elemental, isotopic, or molecular composition of the surface, and used for example for the examination of depletion layers in historical glass .

Used at: Department of Materials at Oxford and Imperial College London

\subsubsection{Chromatographic methods}

High Performance Liquid Chromatography (HPLC-PDA) and combined techniques with mass spectroscopy.

HPLC is used with a variety of detection methods, photodiode array (PDA), ultraviolet (UV), refractive index (RI) and mass spectroscopy (MS). It is a chromatographic technique, and since its early development in the late 1960s it has become one of the most commonly used techniques for both qualitative and quantitative analysis. It makes use of the interactions of molecule(s) with the mobile liquid phase and solid column phase. This allows separation of complex mixtures based on their retention time in the column. Identification of the molecules and derivatives can then be achieved, based on retention time, molecular weight etc. Frequently software packages contain extensive libraries which greatly assist in identification. Increasingly improved detectors allow for successful identification of samples in the nano, pico and even femto-scale range. In archaeological and other heritage science it has been used for the analysis of a number of materials, for example to 
identify wine residues in ceramics, identification of dyes in textiles and pigments in paintings.

Used at: NMS

Gas Chromatography Mass Spectrometry (GC/MS)

GC is an extensively used chromatographic technique which was developed in the 1950's. It is used for the qualitative and quantitative analysis of organic materials. A liquid sample is injected into a port, which is held at a high temperature $\left(150-250^{\circ} \mathrm{C}\right.$ ) $)$ the sample is then vaporized and moved by the inert carrier gas across a solid column phase. Like HPLC, components within a mixture are interact and then are eluted from the column with differing retention times, these then flow into the mass spectrometer detector. Compounds and derivatives can be identified by using a spectral library as each compound has an unique fragmentation pattern. Successful GC/MS depends on samples having suitable vapour pressures and thermally stabilities. It is an extremely sensitive technique and is therefore able to identify the constituents of very small amounts of sample material. The major archaeological applications of this technique are in organic residue analysis, but it is also used for the identification of organic materials such as bog butter, waxes, resins and adhesives either used in the construction of an object or later conservation treatments, particularly in paintings.

Used at: Glasgow University Chemistry and Earth Sciences Departments, Bristol (Chemistry), Bradford (Archaeological Sciences) and York (Archaeology)

\subsection{Methods of examination}

In practice many of the methods outlined above provide an element of visual examination as well as analytical data. The most common direct observation methods are:

\section{Optical microscopy}

The use of binocular, metallographic and polarising light microscopes in archaeological science is extremely common. Microscopy can provide a great deal of information about objects from finding details of their construction to looking at the preservation of surfaces. Advances in image processing mean that greater focal depth can be achieved in the examination and visualisation of surface detail.

The metallography of cross sections from archaeological objects can provide much information about the manufacture of metal objects, including working, annealing, temperature of melting etc (Scott 1991). Polarizing microscopes which have an adjustable polarising filter have been extensively used in petrographic thin-section analysis of archaeological ceramics, while fluorescence microscopes allow the visualisation of pigments excited by wavelengths outwith the visible spectrum.

\section{Scanning electron microscopy (SEM)}

In scanning electron microscopy a beam of electrons is rastered across the sample causing scattering and electron and $\mathrm{x}$-ray interactions which are used to generate a visual image in a number of different ways. The detection of secondary electrons depends strongly on the topographical structure of the sample and thus can be used to examine surface detail. Backscattered electrons also reveal compositional differences since their number, and hence the brightness of the image, depends on the atomic number of the area of the sample they interact with. Various other detectors can be used, eg to measure absorbed current, and produce images of different quality dependent upon the conductivity and fragility of the sample.

Used at: NMS, Glasgow Earth Sciences, SUERC, Edinburgh Geosciences 


\section{$X$-radiography, Gamma and Neutron radiography}

Conventional radiography produces twodimensional images of the object, the intensity of the image depending on the amount to which incident $\mathrm{X}$-rays penetrate or are absorbed by the different thicknesses and densities of the material(s) being $\mathrm{x}$-rayed. $\mathrm{X}$-radiography is extensively used to image archaeological materials of all kinds, particularly archaeological iron where very often the shape of the object is hidden by encrustations of corrosion and even when the iron itself is lost the form remains visible within the corrosion mass. Currently the change is from conventional film-bases systems to ones using various forms of digital recording. Medium and low-energy cabinet systems exist, while for large items or the technological investigation of artefacts made from dense metals such as silver or bronze higher X-ray energies are required with appropriate radiation enclosures. Gamma radiography is undertaken industrially using radioactive sources and may have applications for particularly large or inaccessible objects, while neutron radiography is a specialist alternative with advantages for some very $\mathrm{X}$-ray dense materials.

\section{Used at: NMS, AOC Archaeology}

\section{Computed Tomography (CT and micro CT scanning)}

This technique uses $\mathrm{X}$-rays to produce detailed 3-D images of objects. By rotating the X-ray source and detectors a crosssectional "slice" of the object can be obtained while the object is moved through the array to generate a complete series of slices which can then be combined to create a virtual 3D image. Medical CT equipment has been suited to the imaging of mummies, including the production of facial reconstructions, while micro $\mathrm{CT}$, using similar technology but on a smaller scale that allows more penetrating X-rays and higher spatial resolution, has been applied to complex objects.

Used at: Glasgow Western Infirmary, Edinburgh Royal Infirmary, Natural History Museum.

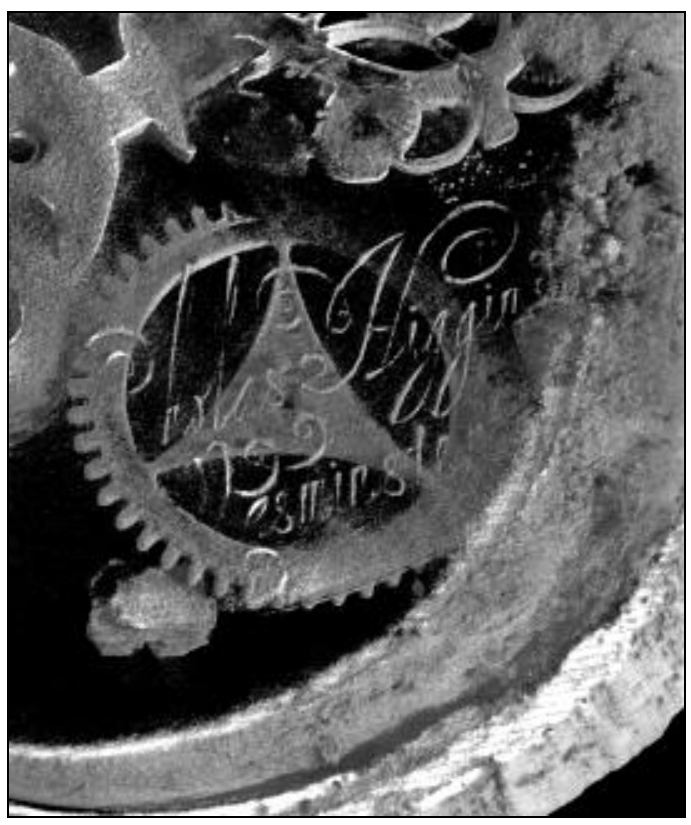

Figure 12: CT Image of 17th century pocket watch from shipwreck, revealing maker's signature CNMS 


\section{Data treatment and interpretation}

Cluster analysis and principal components analysis (PCA) are exploratory tools which are able to look for structure within the data set (Baxter 1994, 2001); in the present context they are able to identify chemical groupings within the data set. Those groupings can then be examined for their potential significance in terms of the origin of the raw material, technology of production or other factor. At a practical level, multivariate techniques should not normally be applied to small datasets, that is less than 20 samples. Of the many methods of cluster analysis, the average linkage (or between groups linkage) method is the most commonly used. Cluster analysis is often carried out in conjunction with PCA; the principal clusters in the dendrogram can then be superimposed on the plot of the first and second (or other) principal components. The importance of PCA lies in the way it quantifies what proportion of the overall variance in composition each principal component gives and furthermore identifies which combination of elements dominates each principal component.

Figure 13 shows a typical PC plot showing the classification of ICP-ES compositions of ceramic material from site $\mathrm{CN}$. There are two groupings, $\mathrm{A}$ and $\mathrm{B}$, which separate along PC2 which is dominated by $\mathrm{Ca}, \mathrm{Cr}$ and $\mathrm{Y}$ contents. The PC plot has identified some outliers CN690, 1270, 1280, 2012 and 1172 - most of which have high scores on PC1. The variance and main elements loading each of the two PCs are indicated. PCA could if necessary be repeated in the absence of those outliers.

Turning to discriminant analysis, Figure 14Error! Reference source not found. four chemical chemically-defined groups, each of them in this case representing likely production sites of medieval White Gritty ware. Ceres, Colstoun, Kelso Abbey and Elgin are very well differentiated along discriminant function 1, but Colstoun can only be differentiated from Kelso Abbey with respect to discriminant function 2. If we have composition data for pottery samples from another findspot and have reason to believe that pottery could have come from one or other of these four centres, discriminant analysis can assign each sample, on the basis of its composition, to one of those centres with a given probability. However, its success depends critically on the confidence that those four centres are indeed the candidate centres of production.

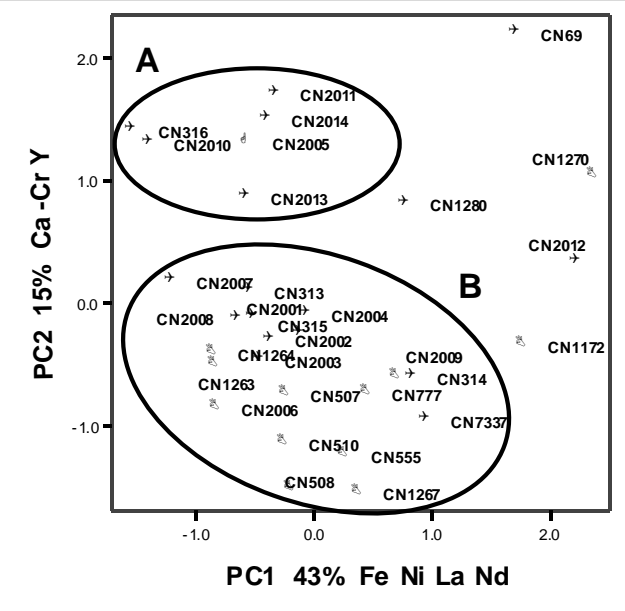

Figure 13: PC plot showing the classification of ICP-ES compositions of ceramic material from site CN 


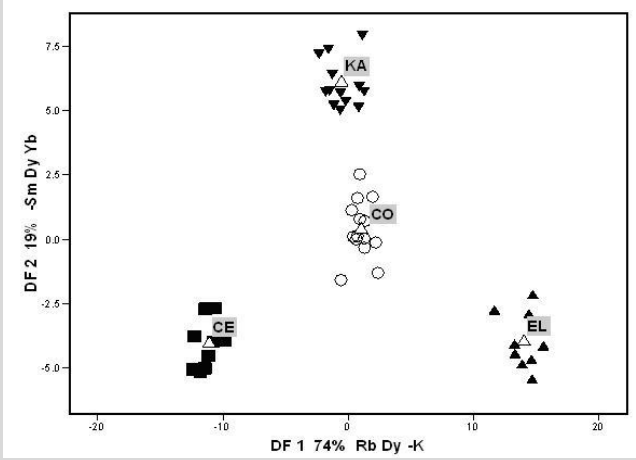

Figure 14: Four chemical chemically-defined groups, each of them in this case representing likely production sites of medieval White Gritty ware.

\subsection{Ceramics}

Three areas can be highlighted here fabric and organic residue analyses and experimental work - all of which were reviewed at a meeting in Glasgow in $2010^{13}$.

\section{Fabric analysis}

Petrographic analysis has been most suited to the study of coarse-textured pottery, in particular the identification of fabric groups. This approach has been applied notably to Neolithic pottery to define the main inclusions which often represent the tempering material. Where the site lies in a region of some geological diversity, results have been very encouraging; for example, the presence in Late Neolithic pottery at Barnhouse on Orkney of different igneous rocks occurring in the site's vicinity has been exploited to reveal detailed information on the dynamics of intra-site potting practices at this settlement (see the Case Study on Grooved ware below and Table 2).

The accumulated experience is that pottery of later date is best examined by a

13

http://www.gla.ac.uk/departments/archaeolo gy/newslinks/ceramicviews combination of petrographic and chemical analysis. The focus of Roman Antonine Wall pottery studies has been on determining what classes were made locally; there is surely room to exploit this potential. Chemical analysis has been able to determine that medieval White Gritty ware was produced at many different locations in Scotland, the corresponding petrographic analysis providing supporting characterisation as well as more technological information. Medieval pottery from the Forth valley analysed by neutron activation analysis showed compositional grouping of ceramics from Throsk (Caldwell et al. 1992). The later Red wares of Scotland have proved to be very amenable to chemical characterisation. Furthermore, the chemical data for both these wares are being considered within a north European context.

As regards databases, some Scottish pottery has been entered into the UK ceramic thin-section database, now partly or wholly hosted by the AHDS, but this has not been updated comprehensively during the last fifteen years. Morris and Woodward (2003) address this issue as it affects prehistory pottery. There is no chemical database for Scottish pottery although in the 1980s SURRC (now SUERC) prepared with NMS an 'E4' ceramic standard (Topping and Mackenzie 1988). 


\section{Organic residue analysis (ORA)}

This has been an active area of research in the last decade. In its earlier phase it concentrated on the lipid content in pottery on the basis of the relatively good survival of lipids over time and during burial; this approach was adopted in the study of residues in Grooved ware at Barnhouse on Orkney (see the case study below and Table 2) and has worked to quite good effect elsewhere in Scotland. However, it has become increasingly recognised that more refined, more species-specific information is necessary. To that end, the group at Bristol led by Richard Evershed has pioneered the incorporation of the carbon isotope analysis of the $\mathrm{C} 16$ and $\mathrm{C} 18$ fatty acids into the analytical sequence. This has allowed the discrimination of sheep, pig and cow fats as residues in Grooved ware pottery. The welcome and complementary approach has been to look at the protein residue in prehistoric pots associated with dairying in the Western Isles (Craig et al 2005; see here 4.4). Almost all organic residue analyses to date have been on prehistoric pottery, although there has been analysis of samples of bog butter from the NMS collection (Berstan et al. 2004).

Concerning facilities, organic residue analysis has been undertaken on an adhoc basis in only a few laboratories/institutions in Scotland.

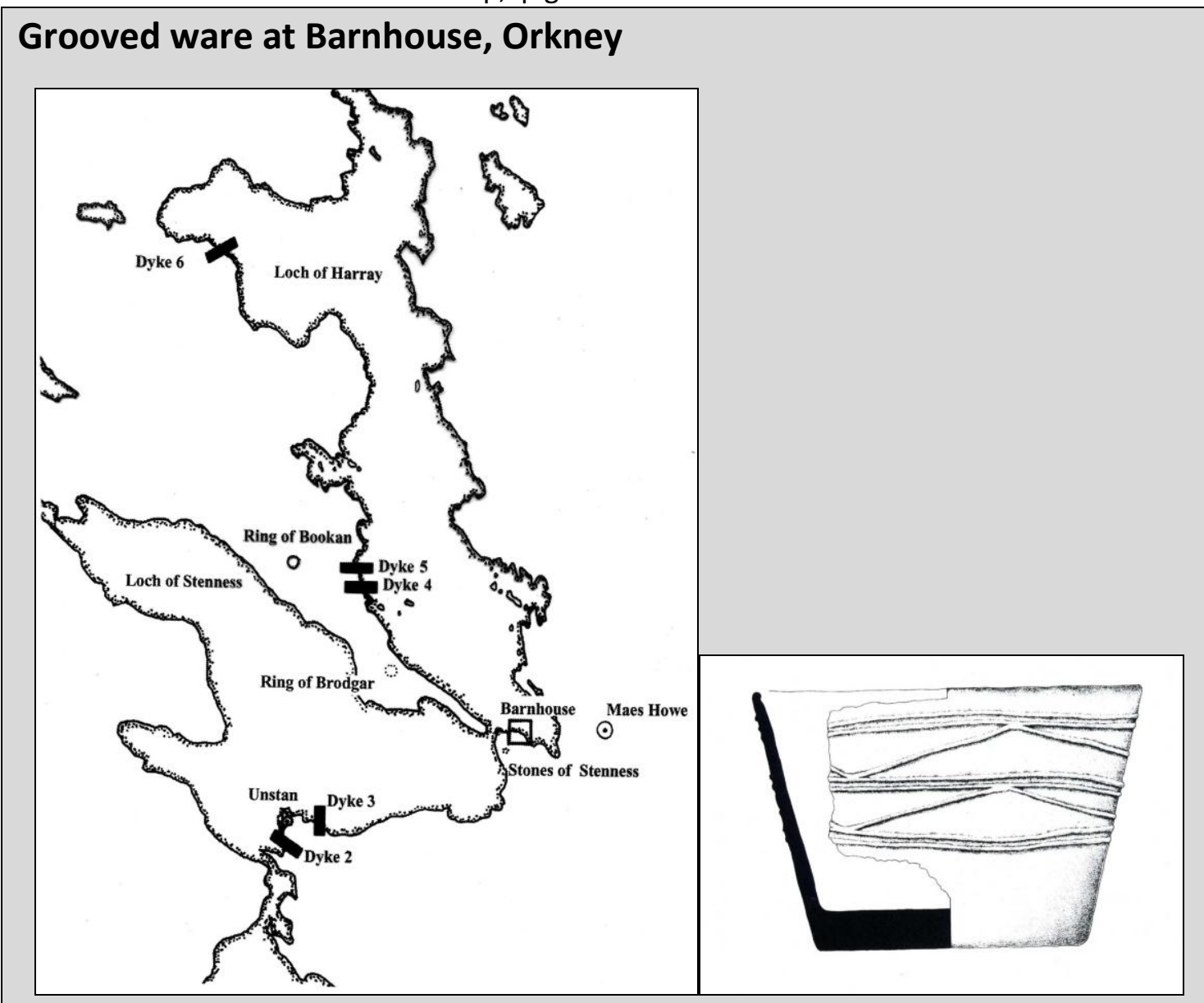

Figure 15: (left) Map of the vicinity of Barnhouse showing locations of igneous dykes (Jones 2002, Fig. 6.15) and (right) Grooved Ware vessel SF 3720 from Barnhouse 
Science in Scottish Archaeology

Excavations of the houses belonging to the Late Neolithic settlement at Barnhouse close to the Stones of Stenness, Maeshowe and Ness on Mainland Orkney revealed much Grooved Ware pottery (Error! Reference source not found.). Jones' study $(2002,2005)$ of this pottery looked at correlations between size of vessel, its decoration, fabric, content and findspot, enabling a detailed view of the production and consumption of this pottery to be built up. There were five main fabric types, one shell-tempered, two rock-tempered which contained fragments of igneous rocks from different dyke outcrops in the vicinity of the settlement and common sedimentary rocks (sandstone, siltstone) and two untempered. The catchment area that the potters visited for these raw materials was evidently quite wide (Figure 15). In any case the source of clay or the way the clay was treated seems to have been matter of deliberate personal choice on the part of each potter or potters in each house. Each potter or house may have had its own 'recipe(s)'. Furthermore, rock-tempered pots were found at the settlement's periphery, while shell-tempered vessels were more common closer to the central area where the communal firing presumably took place. ORA has established a range of foodstuffs in the pots - milk, beef, barley, fruit (apples?) and multiple contents - this range being wider than that encountered in Grooved Ware elsewhere in Orkney which appears to be more commonly restricted to porcine and ruminant fats (Mukherjee, Gibson and Evershed 2008).

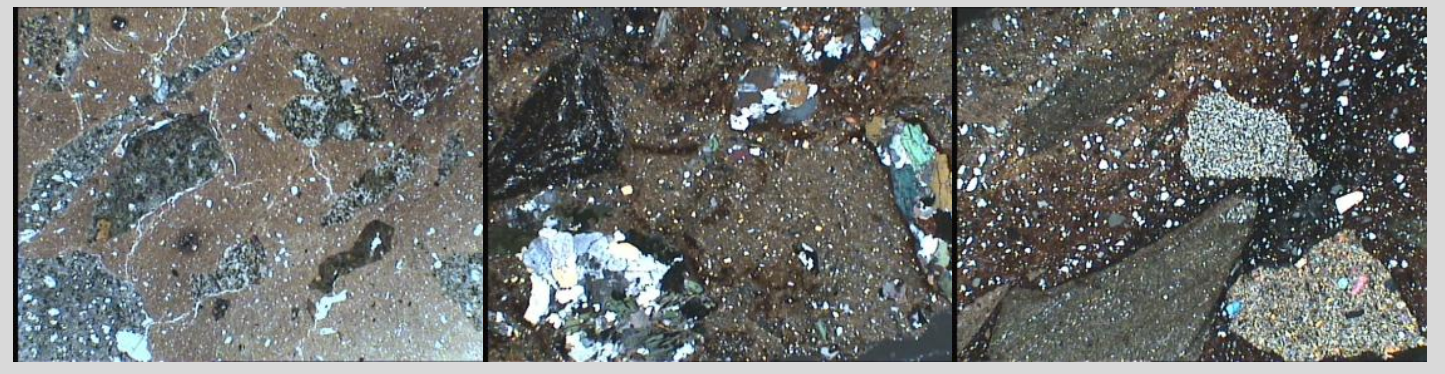

Figure 16: Photomicrographs of thin sections of Grooved Ware at Barnhouse: 552 siltstone and camptonite 3507 granite and X; 1316 sandstone and siltstone 
Table 2: Ceramics: a selection of recent fabric, technological and functional (organic residue) analyses

\begin{tabular}{|c|c|c|c|c|c|}
\hline & Petrographic & Chemical & Technological & Organic residue & Experimental \\
\hline Prehistoric & $\begin{array}{l}\text { Neolithic Orkney: } \\
\text { Barnhouse (Jones } \\
2002) \\
\text { Pool (MacSween } \\
2007) \quad\end{array}$ & $\begin{array}{l}\text { Pool: ICP (Bradford) } \\
\text { (MacSween 2007) }\end{array}$ & $\begin{array}{l}\text { Metallurgical } \\
\text { SEM-EDAX, PE } \\
\text { 2011) }\end{array}$ & $\begin{array}{l}\text { Grooved ware in } \\
\text { Scotland: Mukherjee et } \\
\text { al 2008); } \\
\text { Barnhouse: Jones et al. } \\
\text { 2002; } \\
\text { Bronze Age in W Isles: } \\
\text { Craig et al. } 2005\end{array}$ & $\begin{array}{l}\text { Making and firing } \\
\text { Neolithic pots on Orkney } \\
\text { (Jones and Brown 2000; } \\
\text { Appleby and Harrison: } \\
\text { http://www.applepot.co. } \\
\text { uk/neolithic_pottery/ind } \\
\text { ex.htm) }\end{array}$ \\
\hline $\begin{array}{l}\text { Iron } \\
\text { Age/Roman }\end{array}$ & $\begin{array}{lr}\text { Roman pottery at } \\
\text { Antonine } \\
\text { (Gillings } & \text { 1991); } \\
\text { mortaria } & - \\
\text { Williams) } & \text { D }\end{array}$ & $\begin{array}{l}\text { NAA (at SURRC) of IA } \\
\text { pottery from the W } \\
\text { Isles (Topping 1985); } \\
\text { NAA of pottery at } \\
\text { Antonine Wall forts } \\
\text { (Gillings 1991) }\end{array}$ & & & $\begin{array}{l}\text { Dimpled bases: Iron Age } \\
\text { decoration or the cook's } \\
\text { delight? Towers and } \\
\text { Mcllfatrick in } \\
\text { http://www.gla.ac.uk/de } \\
\text { partments/archaeology/ } \\
\text { newslinks/ceramicviews/ }\end{array}$ \\
\hline $\begin{array}{l}\text { Medieval } \\
\text { and post- } \\
\text { medieval }\end{array}$ & $\begin{array}{l}\text { White Gritty (Jones } \\
\text { et al. 2002-03) }\end{array}$ & $\begin{array}{l}\text { White Gritty: ICP-ES } \\
\text { (Jones et al 2002-03); } \\
\text { Red ware: ICP-MS } \\
\text { (Haggarty et al. } \\
\text { 2011). } \\
\text { Throsk pottery: NAA } \\
\text { analysis (in Caldwell } \\
\text { et al. 1992) }\end{array}$ & $\begin{array}{l}\text { White Gritty: SEM-EDAX of } \\
\text { lead glaze (Jones et al } \\
2002-03 \text { ) }\end{array}$ & & $\begin{array}{l}\text { Bell's Parian ware: Brown } \\
\text { in } \\
\text { http://www.gla.ac.uk/de } \\
\text { partments/archaeology/ } \\
\text { newslinks/ceramicviews/ }\end{array}$ \\
\hline
\end{tabular}




\subsection{Metals}

In Hunter, Cowie and Heald's review of research priorities for Archaeometallurgy in Scotland (2006) they pointed out the potential for more systematic research in Scotland, particularly making the case that there has been comparative little work on metal sources, or indeed on the comprehensive examination of the wealth of artefactual evidence in museum collections. The existence of ore sources across Scotland is widely known, and there is plenty of evidence of metal working, but few have been the subject scientific excavation. It is only comparatively recently that, for example, there has been an extensive synthesis of mould and crucible fragments (Heald 2005). Likewise only a small fraction of the extensive holdings of the NMS have and been investigated analytically or technologically, with a similar situation in other major collections.

At the same time the ability of new scientific methods to obtain good precision compositional data without sampling or with micro samples has increased dramatically. While the need to ensure that any analysis is truly representational remains a key issue (i.e. it is not skewed by surface corrosion, inhomogeneity, applied layers etc) the feasibility of gathering large analytical data sets is now more limited by research personnel than by technique, although equipment and facilities regularly available for archaeological and historical artefact analysis remains a limiting factor.

A selection of recent work is summarised in Table 3, a list that indicates the opportunities for further work are substantial. The authors adopt and extend the recommendations of Hunter et al:

- Identification and study of mines and metal sources (with a focus on proxyenvironmental records as a first step).

- Definition and interpretation of regional alloy patterns at all periods.
- Broad study of ironworking evidence in Scotland to produce models of its organisation, similar to the recent synthesis of non-ferrous metalworking.

- Metallographic study of artefacts to understand iron technology and its influences in Scotland, notably the question of any Roman influence and changes in the Early Historic/Norse period.

- Continuation of analytical study of precious metal artefacts from the archaeological through to historical periods to accumulate more data for investigating trade and exploitation.

- Technological and analytical examination of key artefacts particularly using newly available methods such as micro CT imaging.

- Developing links between lead ores and lead incorporated into base and precious metal alloy artefacts using lead isotopes. 
Table 3: Metals: a selection of recent investigations

\begin{tabular}{|c|c|c|c|c|}
\hline & Analysis & Technique & Publication & Comment \\
\hline Prehistoric gold & Micro-chemical & & $\begin{array}{l}\text { Chapman et al } \\
2000\end{array}$ & $\begin{array}{l}\text { Gold sources; Irish case } \\
\text { study (Chapman et al 2006) } \\
\text { could be usefully applied to } \\
\text { Scotland }\end{array}$ \\
\hline $\begin{array}{l}\text { Bronze Age Cu } \\
\text { alloys }\end{array}$ & Isotopic & TIMS & $\begin{array}{l}\text { Rohl and } \\
\text { Needham } 1998\end{array}$ & \\
\hline LBA Cu alloys & Chemical & & $\begin{array}{l}\text { Cowie et al. } \\
1998\end{array}$ & $\begin{array}{l}\text { Circulation zones; alloying } \\
\text { traditions }\end{array}$ \\
\hline IA/Roman iron & Metallography & & $\begin{array}{l}\text { McDonnell } \\
\text { 1998a, b }\end{array}$ & Iron working on broch sites \\
\hline Roman $\mathrm{Cu}$ alloys & Chemical & XRF & $\begin{array}{l}\text { Dungworth } \\
1997\end{array}$ & Alloying traditions \\
\hline $\begin{array}{l}\text { Viking and later } \\
\text { silver }\end{array}$ & Chemical & XRF & $\begin{array}{l}\text { Kruse and Tate } \\
1995 \\
\text { Eremin \& Tate } \\
\text { in Glenn, } \\
\text { Wilthew (1995) }\end{array}$ & $\begin{array}{l}\text { Silver sources and recycling } \\
\text { zones } \\
\text { Technology and typology }\end{array}$ \\
\hline Norse $\mathrm{Cu}$ alloys & Chemical & XRF & $\begin{array}{l}\text { Eremin et al. } \\
2002\end{array}$ & Alloying traditions \\
\hline $\begin{array}{l}\text { Medieval and } \\
\text { later iron and } \\
\text { iron slag }\end{array}$ & $\begin{array}{l}\text { Metallography } \\
\text { and SEM-EDAX }\end{array}$ & & $\begin{array}{l}\text { Photos-Jones \& } \\
\text { Atkinson 1998; } \\
\text { Photos-Jones et } \\
\text { al } 1998\end{array}$ & $\begin{array}{l}\text { Iron technology; operation of } \\
\text { iron bloomeries }\end{array}$ \\
\hline $\begin{array}{l}\text { Traditional } \\
\text { ferrous metals }\end{array}$ & $\begin{array}{l}\text { Chemical and } \\
\text { mechanical }\end{array}$ & $\begin{array}{l}\text { SEM-EDAX, } \\
\text { HHXRF, } \\
\text { mechanical } \\
\text { stress tests }\end{array}$ & $\begin{array}{l}\text { Wilson } \\
\text { (forthcoming) }\end{array}$ & $\begin{array}{l}\text { Conservation and } \\
\text { maintenance of traditional } \\
\text { ironwork (HS in partnership } \\
\text { with Napier University) }\end{array}$ \\
\hline Excavated iron & & $\begin{array}{l}X- \\
\text { radiograph } \\
y\end{array}$ & & $\begin{array}{l}\text { Excavated iron from multiple } \\
\text { periods and sites, routinely } \\
\text { X-rayed at NMS }\end{array}$ \\
\hline Pewter & Chemical & XRF & $\begin{array}{l}\text { Wilthew et al. } \\
1988\end{array}$ & $\begin{array}{l}\text { Survey of Scottish pewter } \\
\text { compositions }\end{array}$ \\
\hline
\end{tabular}

\subsection{Lithics}

Lithics have offered many opportunities for materials analysis. In the work on identifying and sourcing a range of lithics (Table 4), geological reconnaissance in the field is essential as the investigations of sandstone, pitchstone and steatite (soapstone) have shown. Miller and Ruckley (2005) and Miller et al (2006) identifed the stones, mainly sandstones, used in a large number of Pictish and West Highland sculpture; their approach was perforce non-destructive (Table 4), combined with magnetic susceptibility measurements which were able to refine the stones' basic petrographic classification. In the case of studies requiring a sample to be taken for elemental or other analysis, two points stand out: (a) inter-source discrimination usually demands that the analytical technique be capable of determining with high precision the relevant elements present at very low concentration; this was the case for steatite/soapstone from some of the main quarries on Shetland and in 
Science in Scottish Archaeology

Norway which could be differentiated on the basis of rare earth element compositions; (b) intra-source variation in composition also has to be considered.

Flint and chert deserve comment as the prominence they hold as artefacts in Scotland has not been shared by progress in investigating their sources by science-based methods. The compilation of sources throughout northern Britain, begun by Wickham-Jones and Collins' (1978), has been supplemented by more geographically focused prospection, for example on Islay, Colonsay and lona (Marshall 2001). The approach of chemical characterisation of flint axes and known prehistoric flint mines in the chalk environment of southern England (de Sieveking et al 1972) appears less applicable to the Scottish situation because many flint occurrences are with gravels and thus are not only secondary but could also be mixed; instead the palynological approach may offer scope to judge from Harding et al's (2004) identification of over sixty species of dinocyst and other types of microplankton in flint nodules from Islay. Owen et al's (1999) chemical characterisation of chert in the Southern Uplands is promising although the results are as yet insufficiently fine-grained to be used for archaeological purposes.

Apart from issues of identification and sourcing of stone in Scottish buildings and monuments, both ancient and more recent, there is the continuing need for research in heritage science. Historic Scotland's Conservation Department, which is at the forefront of this effort, supports a range of work, as well as having its own science-based facilities. Historic Scotland (2011) has compiled a list of its own publications on conservation: Technical Advice Notes (TANs), Inform Guides, Research/Study Reports, Technical Papers, Guide for Practitioners, Case Studies, Technical Reference and Guidance Manuals and Reference Reports. The TANs deserve special reference for their wideranging topics, from the quarries of Scotland (McMillan et al 2006), to specific stone types such as slate (Walsh 2000), building stones of Edinburgh (McMillan et al. 1999), earth structures and construction (Walker and McGregor 1996), maintenance and repair of cleaned stone buildings (Young et al. 2003; for Edinburgh see also Hyslop 2004) and Scottish stone used in Ireland (Curran 2010). Charlestown Consultants, part of the Scottish Lime Centre ${ }^{14}$, also have such facilities, specialising in the analysis and evaluation of mortars (Scottish Lime Centre 2003), plasters and renders. Critical to the understanding of decay processes and determining preservation strategies is knowledge about moisture transport and the formation/movement of salts within stone and mortar studies. There have been studies at Skara Brae (Hamilton 2006) and more recently work relating to mortar and concrete render (Griffin et al. 2010).

${ }^{14}$ http://www.scotlime.org/trad analysis.html 
Science in Scottish Archaeology

Table 4: Lithics: provenance determinations

\begin{tabular}{|c|c|c|c|c|}
\hline Material (date) & Type of analysis & $\begin{array}{l}\text { Techniques of } \\
\text { analysis }\end{array}$ & $\begin{array}{l}\text { Main } \\
\text { publication(s) }\end{array}$ & Comment \\
\hline \multirow[t]{3}{*}{$\begin{array}{l}\text { Pitchstone } \\
\text { (prehistoric) }\end{array}$} & \multirow[t]{2}{*}{ Chemical } & \multirow[t]{3}{*}{ NAA, XRF } & $\begin{array}{l}\text { Williams-Thorpe } \\
\text { \& Thorpe } 1984\end{array}$ & \multirow[t]{2}{*}{$\begin{array}{l}\text { Distribution of } \\
\text { Arran pitchstone }\end{array}$} \\
\hline & & & Ballin and & \\
\hline & $\begin{array}{l}\text { Geological } \\
\text { characterisation }\end{array}$ & & Faithfull 2009 & $\begin{array}{l}\text { Gazetteer of } \\
\text { Arran pitchstone } \\
\text { sources }\end{array}$ \\
\hline \multirow{2}{*}{$\begin{array}{l}\text { Steatite (mainly } \\
\text { Viking-Norse) }\end{array}$} & \multirow{2}{*}{$\begin{array}{l}\text { Chemical } \\
\text { (mineralogical) }\end{array}$} & \multirow[t]{2}{*}{ ICP-MS; XRD } & Jones et al 2007 & \\
\hline & & & $\begin{array}{l}\text { Clelland et al } \\
2009\end{array}$ & \\
\hline Jet and related & Chemical & XRF & $\begin{array}{l}\text { Sheridan et al } \\
2002\end{array}$ & \\
\hline $\begin{array}{l}\text { Stone battle- } \\
\text { axes and axe } \\
\text { hammers }\end{array}$ & Petrology & & $\begin{array}{l}\text { Fenton } 1988 \text { in } \\
\text { Stone Axes } 2 .\end{array}$ & $\begin{array}{l}\text { Stone Axes } 3 \text { is in } \\
\text { preparation }\end{array}$ \\
\hline Flint & \multicolumn{2}{|l|}{ Palynology } & & $\begin{array}{l}\text { Harding et al. } \\
(2004)\end{array}$ \\
\hline Chert & Chemical & ICP-MS & & $\begin{array}{lll}\begin{array}{l}\text { Owen } \\
(1999)\end{array} & \text { et } & \text { al. }\end{array}$ \\
\hline \multirow[t]{2}{*}{ Bloodstone } & \multirow[t]{2}{*}{ Chemical } & \multirow[t]{2}{*}{ ESR } & & \multirow{2}{*}{$\begin{array}{l}\text { Clarke and } \\
\text { Griffiths (1990) }\end{array}$} \\
\hline & & & & \\
\hline Sandstone & $\begin{array}{l}\text { Grain size, } \\
\text { mineralogy } \\
\text { distribution and } \\
\text { textural-structural } \\
\text { characteristics, } \\
\text { combined with } \\
\text { magnetic } \\
\text { susceptibility }\end{array}$ & & $\begin{array}{l}\text { Miller } \quad \text { and } \\
\text { Ruckley } \quad(2005) \\
\text { and Miller et al. } \\
(2006)\end{array}$ & \\
\hline
\end{tabular}

\subsection{Vitreous materials}

Surprisingly little work has been carried out on Scottish vitreous materials. This is largely because very little vitreous material was produced in Scotland until the post-medieval period. Glass-making in Scotland became significant only from the $17^{\text {th }}$ century onwards, prior to that it is thought that all the glass had been imported. The exceptions are Bronze Age faience, which was being made in several areas in Britain (Sheridan and Shortland 2004), Late Iron Age glass beads and bangles, the vitreous material cramp
(Photos-Jones et al. 2007) and vitrified forts where vitrification has been used for dating studies as well as geochemistry (Sanderson et al. 1985).

Recent advances in analytical techniques being applied to glasses, such as isotopic techniques and sensitive, less destructive, techniques such as LA-ICP MS have allowed far more detailed characterisation of glasses and other vitreous materials, particularly in terms of identifying raw materials and provenance studies. There is a great deal of potential for such techniques in looking at Scottish vitreous materials in terms of identifying imported glasses, locally produced glasses and potential links between 
glassmaking and other industries such as the manufacture of alkalis from seaweed. Limitations remain in that completely nondestructive analysis of glasses is difficult, although recent advances in $\mathrm{HH}-\mathrm{XRF}$ has

allowed work into in situ historic window glass in England to be carried out successfully (e.g. Dungworth 2011) and there is the potential for this to be extended into Scotland.

Table 5: Work on Scottish vitreous materials

\begin{tabular}{|c|c|c|c|c|}
\hline $\begin{array}{l}\text { Material } \\
\text { (date) }\end{array}$ & $\begin{array}{l}\text { Type of } \\
\text { analysis }\end{array}$ & Technique(s) & Publication & Comment \\
\hline BA faience & Chemical & SEM-EDS & $\begin{array}{l}\text { Sheridan and } \\
\text { Shortland } 2004\end{array}$ & $\begin{array}{l}\text { Composition } \\
\text { and technology } \\
\text { of Scottish } \\
\text { faience }\end{array}$ \\
\hline $\begin{array}{l}\text { Iron Age and } \\
\text { Early Historic } \\
\text { glass }\end{array}$ & Chemical & XRF & Henderson (1982) & \\
\hline Cramp & & $\begin{array}{l}\text { SEM-EDS, ICP- } \\
\text { ES, ORA }\end{array}$ & $\begin{array}{l}\text { Photos-Jones et al } \\
2007\end{array}$ & \\
\hline Iron Age beads & Chemical & LA-ICP MS & Bertini et al. 2011 & $\begin{array}{l}\text { Composition } \\
\text { and provenance } \\
\text { of several } \\
\text { classes of Iron } \\
\text { Age beads }\end{array}$ \\
\hline Glass corrosion & Chemical & Raman, SIMs & Robinet et al. 2004 & $\begin{array}{l}\text { In-situ study of } \\
\text { corrosion of } \\
\text { glass in } \\
\text { museums }\end{array}$ \\
\hline $\begin{array}{l}\text { Medieval } \\
\text { stained glass }\end{array}$ & Chemical & $\begin{array}{l}\text { Atomic } \\
\text { Absorption } \\
\text { Spectrometry }\end{array}$ & Tennant et al. 1984 & \\
\hline
\end{tabular}

\subsection{Other materials}

Significant work has also been carried out on other materials types including textiles, plastics, organic materials and residues and material such as amber. Many individual studies of collections in museums have been undertaken as unpublished technical reports in NMS. The analysis of dyes used in pre 1850 Scottish tartans (Quye et al. 2003) has shed new light on the use and trade of raw materials used for dyestuffs in this period, historical research which can be extended to many other textiles, particularly as the identification of post 1850 dyes is developed. The importance of analysis to identify modern materials is well recognised for artefacts made of plastic and early films but perhaps less so for long term preservation and reference or archival materials (such as casts of stone sculptures, site records and photographs). 
Table 6: selected work on other materials

\begin{tabular}{|c|c|c|c|}
\hline Material & Type of analysis & Publication & Comment \\
\hline Textile dyes & HPLC & $\begin{array}{l}\text { Quye et al 2003; } \\
\text { Surowiec et al } 2006\end{array}$ & $\begin{array}{l}\text { Analysis of historic } \\
\text { textiles including } \\
\text { tartans }\end{array}$ \\
\hline Modern materials & FTIR & Quye 1995 & $\begin{array}{l}\text { Composition and } \\
\text { degradation } \\
\text { plastics }\end{array}$ \\
\hline $\begin{array}{l}\text { Amber beads from } \\
\text { Mid-Nithsdale, } \\
\text { Balmashanner, } \\
\text { Knowes of Trotty } \\
\text { and Glentrool }\end{array}$ & IR & $\begin{array}{l}\text { Beck and Shennan } \\
1991,34-5\end{array}$ & $\begin{array}{ll}\text { Baltic } & \text { source } \\
\text { confirmed } & \end{array}$ \\
\hline Photographs & XRF, SEM-EDS & Eremin et al 2002 & $\begin{array}{l}\text { Analysis of } 19^{\text {th }} \\
\text { century Scottish } \\
\text { photographs }\end{array}$ \\
\hline
\end{tabular}

\subsection{Conservation science}

Conservation is itself a science-based discipline which is undertaken in laboratories, workshops and studios across the public and private sectors in Scotland. Conservation work often makes use of some of the analytical techniques listed above, some of which may exist in-house (eg X-radiography at $A O C$ archaeology). The very nature of conservation involves detailed study of individual objects, and this often has the potential to reveal new information about technology and history of use, see the box feature on the Carpow logboat below. ICON Scotland, the Scottish branch of the Institute of Conservation ${ }^{15}$ communication and coordinate across the sector, but there is considerable scope for closer working with professional archaeology where funding can be made available. 
Science in Scottish Archaeology

Table 7: Selected examples of conservation science

\begin{tabular}{|c|c|c|c|}
\hline Material & $\begin{array}{l}\text { Type of } \\
\text { analysis }\end{array}$ & Publication & Comment \\
\hline $\begin{array}{l}\text { Waterlogge } \\
\text { d wood }\end{array}$ & $\mathrm{LC}$ & Skinner 2001 & $\begin{array}{l}\text { Conservation and preservation of } \\
\text { waterlogged wood }\end{array}$ \\
\hline $\begin{array}{l}17^{\text {th }} \\
\text { century } \\
\text { pocket } \\
\text { watch }\end{array}$ & Micro CT & Troalen et al. 2010 & $\begin{array}{l}\text { Details of highly corroded watch } \\
\text { revealed }\end{array}$ \\
\hline Metals & $\begin{array}{l}\text { Electrochemist } \\
\text { ry }\end{array}$ & Spencer 2002 & $\begin{array}{l}\text { Application of potentiostatic } \\
\text { reduction to treatment of leaded } \\
\text { copper alloys. }\end{array}$ \\
\hline $\begin{array}{l}\text { Egyptian } \\
\text { mummies }\end{array}$ & $\mathrm{CT}$ & McLeod et al. 2000 & $\begin{array}{l}\text { Ongoing project, extensive research } \\
\text { into NMS mummy collection }\end{array}$ \\
\hline $\begin{array}{l}\text { Royal } \\
\text { Forteviot } \\
\text { dagger } \\
\text { burial }\end{array}$ & X-radiography & $\begin{array}{l}\text { http://www.aocarchaeology } \\
\text {.com/pdf/Forteviot_dagger. } \\
\text { pdf }\end{array}$ & \\
\hline
\end{tabular}




\section{The Carpow Logboat}

In 2006 a Bronze Age log boat was recovered from the banks of the Tay at Carpow. Perth \& Kinross Historic Trust formed a partnership with National Museums Scotland for the conservation of this remarkably preserved $9 \mathrm{~m}+$ long boat. Without appropriate treatment the waterlogged timber would shrink and deform. Treatment required understanding the material science of waterlogged wood, knowing the degree of degradation and water content of the oak, and having access to large scale specialist facilities and expertise. Dr Theo Skinner, who was responsible for the conservation, reviewed possible treatment methods before selecting impregnation by polyethylene glycol (PEG) followed by freeze drying. Scanning Electron Microscopy (SEM) was used to identify surface accretions. Sulphur was found as a potential problem, and samples were taken for further analysis by X-ray spectroscopy at the Swiss synchrotron facility. In collaboration with The Mary Rose Trust a potential new method to prevent the future build up of damaging sulphuric acid using calcium phytate was devised. The depth profile of water content in the timber was measured and used to specify the necessary PEG treatment and impregnation times, a programme which ran for approximately 18 months. Each section of the log boat was then treated in the NMS large object freeze drier (developed as a national facility for conservation of marine and wetland material), monitoring progress by measurement of water loss. Conservation work will run to the end of 2011, the integration of scientific analysis and measurement continuing hand-in-hand with practical treatment throughout.

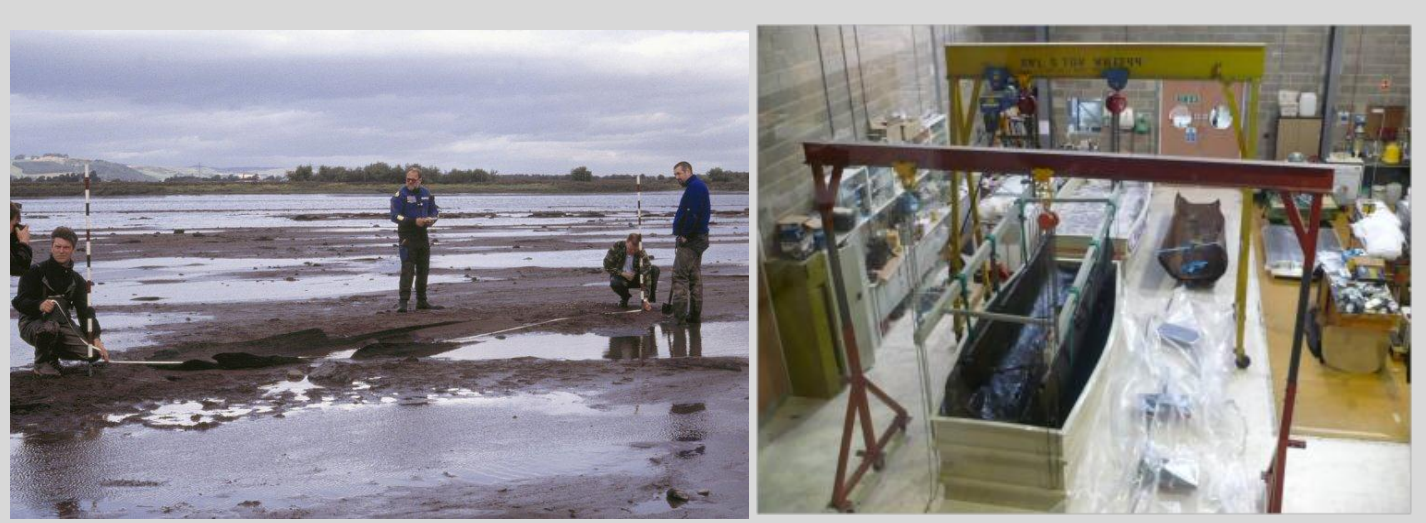

Figure 17: The Carpow longboat during excavation (left) and undergoing treatment in the large objects facility at the National Museums Scotland Collection Centre (right) @RCAHMS and @ Strachan, D Carpow in Context Society of Antiquaries of Scotland: Edinburgh 


\subsection{Understanding recommendations}

- Fuller and more consistent application of science to support post-excavation study.

- The greater use of in situ nondestructive analysis in museums and on site.

- More in-depth technological examination and analysis of key artefacts and collection groups in collections in Scotland.

- Enhance partnerships and strategies that will maximise equipment and facility availability and use for informed application of heritage science in Scotland.

- Secure or stabilise funding for central analytical facilities, including largescale systems such as $\mathrm{X}$-radiography.

- Ensure that heritage science in Scotland remains a core component of the UK wide scene through active participation in the Heritage Science Forum and by demonstrating public benefit and increasing opportunities for engagement.

- Research and development in ORA. Application of ORA to later pottery. Adopt more holistic approaches to organic residues that incorporates, for example, the botanical and faunal records. Develop further the proteinbased method.

- Encourage a more rounded characterisation of ceramics, glass, metals and lithics such that questions of origin and technology are looked at together. Where possible link this work to corresponding effort elsewhere in the UK and beyond.

- Encourage more experimental work linked with analysis/examination.
- Exploit further the applications of stable isotope analysis.

- Assess the need and opportunities for better facilities for the preservation and interpretation of wet organic materials from excavation or underwater sites.

- Highlight what techniques are not currently used but should be used on Scottish material.

\section{In addition, the following comprise potential opportunities}

- Further workon the sourcing of steatite, and flint, and the sourcing of rock types to help understand sources, distribution systems and chronology behind building and sculpted stones.

- Identify and study of mines and metal sources (with a focus on proxy environmental records as a first step).

- Define and interpret regional alloy patterns at all periods.

- Make an over-arching study of ironworking evidence in Scotland to produce models of its organisation, similar to the recent synthesis of nonferrous metalworking.

- Undertake the metallographic study of artefacts to understand iron technology and its influences in Scotland, notably the question of any Roman influence and changes in the Early Historic/Norse period.

- Investigate the production, chronology and function of Crogan pottery in Scotland.

- Investigate the material and technological aspects of Scottish industries, such as glass, paints/varnishes and other materials used in building and decorating, on a diachronic basis from their earliest 
Science in Scottish Archaeology manifestations to the early twentieth century. 


\section{People and the Environment}

\subsection{Introduction}

Long term, archaeological perspectives of the interactions between people and the environment have great relevance for the present and future as they can provide policy and decision makers with the background to understanding current processes, likely trajectories of change, probable thresholds, tipping points and the likely outcomes of present environmental changes and human reactions to them. While the case for the modern relevance of deep time environmental knowledge is widely accepted, the relevance of past human responses to change is not. Arguments that the past can provide effective 'analogues' for modern and future times will never be truly convincing because the present circumstance is so very different from that of the past. Archaeological studies with deep time perspective can, however, have relevance as they provide 'completed experiments' that can be used to understand processes of change, and these could be developed as a major theme of Science in Scottish Archaeology.

Recent work in the North Atlantic (McGovern et al. 2007; Dugmore et al. 2009) and the American Southwest (Hegmon et al. 2008) has shown how studies of past societies that track the consequences of their decision-making can have relevance for now and the future. In studying the past it is possible to assess unfolding stories of change at any particular point in time: The story of Rome for example, has very different implications depending at what point in time the study is brought to a close: - whether at the time of the final triumph over Carthage, or at the end of the reign of Augustus or with the sack of Rome in $410 \mathrm{AD}$. It is possible to assess the dislocation and suffering associated with past transformations of society; how the consequences of specialisation and decisionmaking that develop rigidity traps, can promote hierarchy and conformity or collaboration and mobility. The existence of appropriate infrastructure and societal 'connectivity' can largely determine the degree of suffering related to change. These transformations may be driven by changing patterns of economy, trade, environment, politics, culture or technology and it can be shown that the resilience of societies in the face of change is heavily influenced by previous choices. The path dependency resulting from choices is key and can only be assessed over the 'longue durée' (measured in centuries). Only such a time-perspective can track the consequences of different decisions and paths chosen and thus answer the question 'how did the world get to be as it is now?'). A key challenge is to understand the circumstances when environment may have an effect of society- and this is highly conditional on the social-political-economic context. Small changes may have significant effects on a sensitised system, whereas in other contexts dramatic changes may have comparatively limited effects if societal resilience is significant.

When examining the interactions of people and environment, scale is very important as systems cannot be fully understood by focusing on just one level. Ideally at least three are needed- the scale of the 'target' enquiry, and one at a scale larger and one smaller. For example, in the development of resilient communities, policy makers will be aware that the communal scale is best understood by analysis that considers communities, smaller scales (e.g. households) and larger scales (e.g. regions). The development of resilience at one scale may require transformations at another scale where resilience itself may be reduced.

This importance of scale of study to assist general public understanding, to encourage the application of palaeoenvoronmental data to any understanding of modern contingency, and to allow the study of societal development in the past is crucial to this section of the Science Panel Report.The following section is ordered in terms of increasing spatial scale.Geoarchaeology (4.2), archaeobotany (4.3), zooarchaeology (4.4) and palaeoentomology (4.5) all generally find 
site specific applications. Pollen analysis (4.6), on the other hand, can effectively address the environment on a wider scale that is inherent in geomorphological and sedimentological enquiries (4.7). The section on landscapescale geomorphology and sedimentology argues the need to move from site to landscape scale, engaging with geological and geomorphological approaches to explain the evolution of the cultural landscape. Palaeoclimatology (4.8) explicitly deals with even wider regional environmental changes that in turn have, of course, great importance for the individual site. Each section begins with a brief explanation of the technique in question, Scottish applications and a selection of relevant literature. The current capacity in Scotland is assessed and emerging opportunities discussed.

It has long been understood that archaeology effectively integrated with the study of past environments is the only way in which longterm interactions between people and the environment in the past can be understood. It offers an invaluable understanding of the resilience of earlier peoples, how that might have been developed or lost, how and why critical thresholds in the course of development or loss are crossed, how sustainability over the longue durée was achieved, and the long term consequences of different choices and social organisations. Rich, multi-disciplinary and comparable data sets are needed that can be developed in different ways and interrogated at different scales. These will provide the potential for the enhanced scientific underpinning of current and future policy decisions.

\subsection{Geoarchaeology}

Geoarchaeology, which uses earth-science techniques to study the archaeological record, can be applied to a wide range of scales, from the reconstruction of palaeoenvironments and how they have been affected by human activity (see section 4.7) to on-site analyses of human-made or altered soils and sediments in order to interpret human activities and site formation processes (Goldberg and Macphail 2006; Rapp and Hill 1998). The specific methods used are equally wide ranging, and are similar to the methods commonly used by physical geographers, geologists and soil scientists. Detailed field descriptions of soil or sediment profiles (Reed et al. 2000) are typically supported by follow-up laboratory analyses. These can include:

- particle-size analysis to confirm the energy and agent of deposition (e.g. by wind, water, ice, gravity),

- loss-on-ignition to estimate organic content,

- magnetic susceptibility to determine if the soil or sediment has been affected by heating,

- $\mathrm{pH}$ tests to determine the level of acidity/alkalinity, electrical conductivity tests to determine the soluble salt or nutrient content, mineralogical analyses to determine the origins of sediments,

- micromorphology to determine the microscopic components and structures of undisturbed soil or sediments in thin section, and

- elemental analyses such as soil carbon content, phosphate analysis or the increasingly more common multielement analyses (Courty et al. 1989; English Heritage 2007; Wilson et al. 2005, 2008b).

In recent years innovative applications of stable isotope analyses and organic residue (lipid biomarker) analysis to the study of agricultural soils has also enhanced the understanding of the biological origins of ancient manures (Bull et al. 1999; Simpson et al. 1998).

\section{Geoarchaeological Studies in Scotland}

The application of geoarchaeological techniques to the analysis of archaeological soils and sediments in Scotland has been diverse, encompassing all of the techniques discussed above, and much of the research in 
this field has been world-leading. Most research has focused on the elucidation of site formation processes, the identification and quantification of the chemical and organic residues of daily activities, the interpretation of the spatial organisation of indoor and outdoor activity areas and the living conditions in houses, and the understanding of anthropogenic soil development resulting from past land use. In addition to the direct application of geoarchaeological techniques to archaeological questions, a significant body of work based in Scotland has focused on the development and testing of emerging geoarchaeological techniques.

\section{Site formation processes.}

Geoarchaeological methods applied to soils and sediments on Scottish archaeological sites have contributed to the understanding of the soil environment immediately predating the site, the differentiation of natural and anthropogenic sediments, the origins and modes of formation of archaeological deposits, and the post-depositional alteration of archaeological deposits. Particular attention has been paid to:

- the depositional and postdepositional processes that have affected the complex stratigraphy on settlement sites (e.g. Banks et al. 2000; Davidson et al. 1992; Guttmann et al. 2003; Limbrey 1989; Schwenninger 1999),

- the process of vitrification of Iron Age hillforts (Brothwell et al. 1974; Friend et al. 2007; Youngblood et al. 1978),

- the mode and tempo of midden formation (Simpson and Barrett 1996, Simpson et al. 2005), the formation of farm mounds in the Northern Isles (Davidson et al. 1986),

- the intensive cultivation of midden heaps in Scottish prehistory (Guttmann 2005),
- the movement of waste materials from urban to rural sites in Scotland (Davidson et al. 2006),

- taphonomic processes such as bioturbation (Davidson 2002; Lancaster and Simpson 2003).

\section{Prospection and the analysis of activity} areas.

A very wide range of geoarchaeological techniques have been used to determine the composition of on-site archaeological soils and sediments in Scotland, and have thereby contributed to interpretations of the activities and conditions that created those soils and sediments. In particular, micromorphological analysis, magnetic analyses, and geochemical analyses, including both phosphate and multielement techniques, have been used to locate and interpret activity areas associated with human and animal activities on prehistoric and medieval farmsteads and within buildings (e.g. Edwards 1983; Giles et al. 1999; Jones et al. 2010; Milek 2005; Smith et al. 2001). It is worth noting that the application of plant opal phytolith analysis to the interpretation of activity areas, which saw pioneering research on Scottish archaeological sites in the late 1980s and early 1990s (Powers 1993; Powers and Gilbertson 1986, 1987; Powers et al. $1986)$ is currently rarely practiced, even though ethno-historic work by Smith (1996) demonstrated the value of integrating this technique with the more common geoarchaeological methods, and even though it continues to make valuable contributions to the interpretation of archaeological sediments elsewhere in the world (e.g. Piperno 2006; Shahack-Gross 2011).

\section{Anthropogenic soil development.}

The long history of soil science in Scotland has meant that even before the emergence of geoarchaeology as a discipline, soil scientists were engaged with issues related to the soil environments of prehistoric settlements and the effects of agriculture on Scottish soils (e.g. Romans and Robertson 1975, 1983). Over the last two decades there has been a growing trend in research on anthropogenic soil development, the historic management of 
cultivated soils (e.g. by manuring), and the development of artificially thickened (plaggen) soils in Scotland (e.g. Bond et al. 2004, 2005; Davidson and Carter 1998; Davidson and Simpson 1984; Davidson et al. 2007a, 2007b; Dercon et al. 2005; Dockrill et al. 2007; Guttmann et al. 2003, 2005a, 2006, 2008; Shiel and Askew 1988; Simpson 1985; Simpson and Guttmann 2002; Simpson et al. 1997, 1998, 1999, 2005, 2007; Thomas et al. 2007; Turner et al. 2004, 2010). The techniques employed in these studies of Scottish anthropogenic soils and the manures that have been used to fertilise them have been at the cutting-edge of research, and diverse, including elemental analyses, lipid biomarker analysis, soil carbon content, stable isotopes, particle size analysis, and soil micromorphology.

\section{Methodological Research.}

Geoarchaeologists working on Scottish archaeological sites have been world leaders in the development of new methodologies, often making use of reference samples derived from Scottish experimental and ethno-historic sources. One of the first to realise the potential of using recently abandoned crofts as a testing ground for geoarchaeological techniques, and to use them for demonstrating the potential of geoarchaeology to elucidate site formation processes, was Quine (1986; Davidson et al. 1992). Since then, a number of researchers have made use of soils and sediments from recently abandoned crofts to test and validate different geoarchaeological techniques, including the use of multi-element analysis, stable isotopes, organic content, magnetic susceptibility, $\mathrm{pH}$, and phytoliths analysis to identify activity areas on archaeological sites (Entwistle and Abrahams 1997; Entwistle et al. 1998, 2000; Smith 1996; Wilson et al. 2005, 2006a, 2006b, 2006c, 2007, 2008b, 2009). Other important methodological research that has focused on the anthropogenic soils associated with abandoned Scottish crofts includes the use the image analysis in micromorphology (Adderley et al. 2006; Bryant and Davidson 1996), and the applicability of agroecosystem models to historic and archaeological questions of land management and soil sustainability (Adderley et al. 2000). On the basis of burning experiments conducted on the Isle of Lewis, a technique was developed to identify different fuel ash sources based on different mineral magnetic signatures, and this technique has been applied to a range of sites in the Northern and Western Isles (Church et al. 2007; Peters et al. 2001, 2002, 2004). In addition to these Scotland-based studies, methodological research has been conducted at Scottish institutions on soil and sediment materials taken from outside the country (e.g. Adderley et al. 2001, 2004, 2007), and Scottish-based geoarchaeologists have been involved with the publication of important methodological reviews (e.g. Adderley et al. 2010; Bull et al. 1999; Guttmann et al. 2005a and b; Davidson and Simpson 2001, 2005; Davidson et al. 2007).

\section{Geoarchaeological Research Capacity in Scotland}

In Scotland, there is expertise and facilities for the full range of analytical geochemistry techniques and loss-on-ignition in the School of Humanities at the University of Glasgow, the Schools of Geosciences and Biological Sciences at the University of Aberdeen, the School of Biological and Environmental Sciences at the University of Stirling, and the James Hutton Institute (formerly the Macaulay Land Use Research Institute), while expertise in soil micromorphology is concentrated at the Universities of Stirling and Aberdeen. There are also in-house geoarchaeologists in some archaeological consultancy firms such as AOC Archaeology Group, Argyll Archaeology, Headland Archaeology and Wessex Archaeology but as yet there is not a coherent network that can bring the smaller commercial archaeology units in contact with geoarchaeological expertise. It is notable, however, that Scottish geoarchaeologists have taken a lead in innovative methods of transferring geoarchaeological knowledge and skills to field archaeologists (Cowie et al. 2009; Wilson et al. 2008a, 2010), including the launching of the open-access, web-based Soil Analysis 
Support System for Archaeologists

(www.sassa.org.uk).

Emerging

Opportunities

in

Geoarchaeology

There is tremendous potential for geoarchaeological methods to make important contributions to the interpretation of Scottish archaeological sites, but, as in other areas of science assisted archaeology, it is essential that geoarchaeological expertise be consulted and integrated at an early stage in the research design. A network of archaeological science experts and archaeological consultancy firms could improve the flow of information about the benefits and costs of particular sampling strategies and techniques. It is also worth noting that the potential for geoarchaeology to contribute to the interpretation of archaeological soils and sediments could be improved by the integration of additional methodologies not normally used in conjunction with the more common geoarchaeological techniques discussed above. Plant opal phytolith analysis, for example, could be employed more frequently to locate sites where peat, turf, plant and animal waste (including ash) is expected to have been introduced into the soil (e.g. Powers et al. 1989) and to assist with the identification of fuel ash residues, animal fodder, bedding materials, and animal excrements (e.g. Shahack-Gross 2011). Biomolecular analyses, including lipid biomarker analysis using GC/MS and DNA analysis, should be employed more frequently in situations where it would be beneficial to identify dung and/or decomposed plant materials to the species level. Pollen analysis of archaeological sediments could be employed on a more regular basis in order to improve the interpretation of land use in the immediate vicinity of sites as well as the interpretation of deposits composed primarily of decomposed plant materials, such as sediments identified as originating from dung or hay on the basis of thin section or phytoliths analyses (e.g. Tipping et al. 2009; Whittington and Edwards 1999). Palynological analysis of grave fills can also potentially contribute to the interpretation of plants and flowers incorporated into burial practices (e.g. Clarke 1999). Finally, diatom analysis could be employed more frequently to locate sites where peat, turf or their ashes are expected to have been introduced into the soil, and to assist with the identification of fuel ash residues (e.g. Bathurst et al. 2010)

It is important to stress that in regards to prospecting for potential sites that the palaeo-landscape should be treated as a continuous entity from the coastal corridor through the intertidal to offshore, rather than splitting it at the present day coastline. This zone is also particularly suited to analysis using geophysical techniques. Also, as pointed out elsewhere in this panel, the geomorphology of upland landscapes might not contain all the necessary archive of palaeo-climate and its direct relevance to human inhabitation and use, this is especially true for the majority of sites which again would have been dominated by locations closer to the (palaeo)shoreline.

Due to its northerly location and diverse and often marginal environments, including both coasts and uplands, there are a number of emerging opportunities for geoarchaeological research in Scotland to contribute to archaeological and scientific research of world-wide significance. In a northern European context, for example, Scotland's recently abandoned crofts are a particularly important resource for the development and validation of new geoarchaeological methods. There continues to be potential to extend the use of this rich source of information, particularly in the understanding of the organic and chemical residues of different activities. Scotland also has the potential to be at the forefront of research into the monitoring of site preservation conditions in the wake of human-induced and natural environmental changes, including coastal erosion related to changing sea levels and storminess, aeolian deflation and deposition in coastal regions, soil pollution related to urban settlements and mining activities, deforestation and forest plantation, flooding, 
Science in Scottish Archaeology and dewatering as a result of gravel or clay extraction.

\subsection{Archaeobotany}

Archaeobotany as part of the archaeological study of sites generally falls into the category of using plant macrofossils to reconstruct economic and dietary information from sites. Charcoal fragments and occasionally wood, may also be identified to look at which arboreal species were used for fuel and construction materials. Commonly archaeobotanical materials are also identified as a necessary preparation for use in ${ }^{14} \mathrm{C}$ dating.

\section{Plant macrofossils}

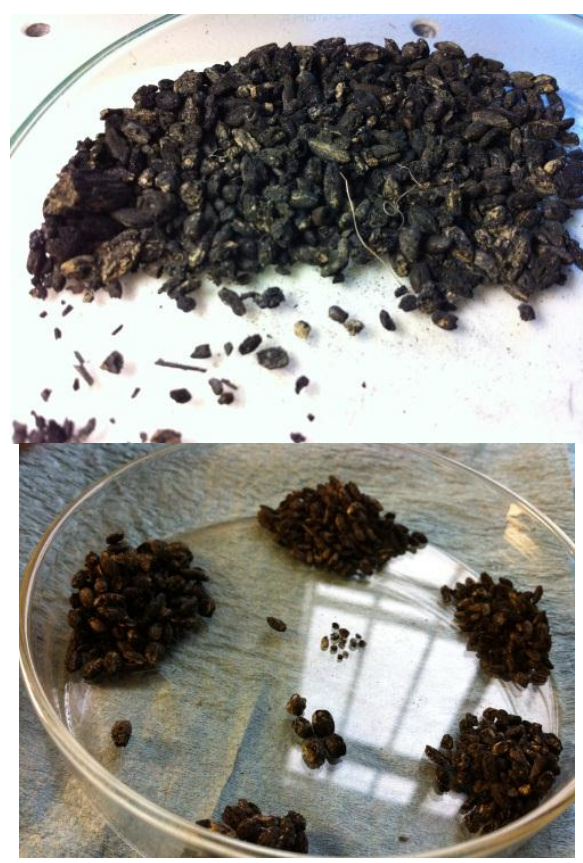

Figure 18: Charred grain before and after sorting of a flotation sample into species, including here oats, barley and wheats, together with wild taxa. CScott Timpany

The most common from of plant macrofossil study on archaeological sites is looking at charred plant remains, generally charred cereal grains and nutshell remains. Samples are usually collected through a bulk sampling strategy from negative features encountered on the site (e.g. pits, postholes, slot trenches). Strategies may include the specific targeting of some features such as corn-drying kilns, hearths and pits where charred grain can often be found in abundance. Other times strategies may be more ad hoc and up to the discretion of the on-site archaeologist. In ideal circumstances site strategies would be established in collaboration with an archaeobotanist prior to excavation commencing with regular site visits by the archaeobotanist during the excavation itself.

Bulk samples taken from site are generally processed using the flotation method (cf. Kenward et al. 1984) with the sample then refined into two (retent and flot) categories. Archaeobotanical material will then be sorted by the archaeobotanist (flot sample) together with (where applicable) a sampling processing team (retent sample). This process then requires that the team are trained to recognise (though not necessarily identify) charred plant material, which can then be further examined by the archaeobotanist. Depending on the project itself the charred plant material may be merely assessed for preservation, variety and abundance or the material may undergo full analysis. Often a mixture of the two is employed, though ideally an assessment phase should be done as standard and analysis wherever (funds allowing) possible.

In Scotland the main area of study involving plant macrofossils has been the study of charred cereal grain. The reason for this is two-fold: firstly charred plant remains are the most likely plant material to be preserved on archaeological sites and secondly the expansion in the number of archaeological units across Scotland coupled with, until recently, the boom in development has meant more studies have taken place. Charred cereal grains are often taken to assessment level on archaeological sites with full analysis rare. The focus of the cereal grain work is often to build a picture of the crops that were grown during the time period of the particular site and to relate this to subsistence life styles or cultivation for trade and as a landuse. Often little is said about the grain beyond the confines of the site itself and thus there is an opportunity to begin linking individual sites to emerging wider [national] pictures (e.g. Neolithic cultivation - see below). 
Science in Scottish Archaeology

The charred weed seed assemblages often get little attention, with reporting and discussions focusing more on grain. This can represent a loss of important information as weed seeds or non-cereal plant remains can represent a number of activities on site for example; turves used as fuels, construction materials in structures and kilns together with providing data on harvesting techniques and field conditions (poor drainage etc.). This lack of attention may come from only assessment work having been carried out on sites and these remains not, perhaps, being considered suitable for ${ }^{14} \mathrm{C}$ dating. Charred wild taxa such as apple pips and hazel nutshells are more commonly identified from sites with hazel nutshell in particular being prominent (e.g. McComb and Simpson 1999) allowing comment on the gathering and use of wild foodstuffs. In more urban locations and in particularly from medieval contexts, charred (and waterlogged) plant macrofossils may be studied to not only look at evidence for economy and diet but also in connection with the trade of exotic plants such as walnuts, figs and grapes.

Where waterlogged sediments are present on sites, such as peats and silts, plant macrofossil assessment/analysis may be undertaken on non-charred plant material. Archaeobotanical studies on such material are often to do with palaeovegetational reconstruction of former environments, which are often carried out to support other proxies such as pollen and/or insect analysis as part of a multi-proxy approach. To date such studies of waterlogged plant remains are fairly sparse in comparison to the wealth of pollen studies that have been carried out across Scotland. However, plant macrofossils offer an increased possibility of comparing the wider vegetational communities signalled in the pollen record to what was growing locally (e.g. field layer) and also comparing these with modern analogues (e.g. Rodwell 2000). Combining the pollen with the plant macrofossil record gives an increased chance of linking pollen-types to species. Another, and growing, use of waterlogged plant remains is to establish a further link in with proxy climate data. This usually involves the identification of mosses (e.g. Sphagnum) from raised bog sequences and may be used in conjunction with testate amoebae and/or tephra studies.

\section{Charcoal and Wood}

Charcoal studies from archaeological sites in Scotland, to date, have generally been focused on the identification of fragments to tree-type. This is largely done in respect of the essential identifying of material for ${ }^{14} \mathrm{C}$ dating on sites and thus there are plenty of examples of publications where the only mention of charcoal fragments is as an id for dating. Where charcoal fragments have been identified it is usually as a fraction of the sample (e.g. 20-100 fragments) to investigate which arboreal species where used for fuel or possible construction material and then to link this back to the woodland, which would have been present during the period of activity. Regular features on archaeological sites where charcoal fragments are identified include burnt mounds, domestic hearths, pits and kilns (grain and metal working). However, charcoal fragments offer much more information than can be gained just through identifications, with further anthracological data available such as through the morphology of fragments, ring curvature and the presence of fungal material.

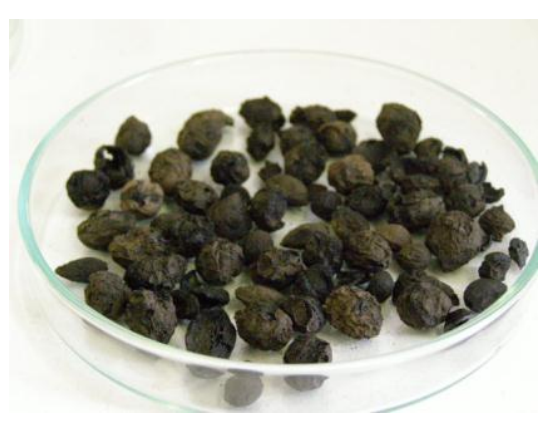

Figure 19: Charred fruit stones - This sample was taken from an isolated pit at Powmyre Quarry, Strathmore, Angus. All of the other pits at the site were prehistoric, however, this sample containing fruit stones of plums, blackthorn and wild cherry, together with apple pips and hazel nuts is likely to be medieval in age.@Scott Timpany

Waterlogged wood may also be present on archaeological sites where suitable deposits 
are present (e.g. peats). Studies on waterlogged wood range from looking at large timbers and tree remains (e.g. pine stumps) to small wood fragments identified with plant macrofossils during studies related to palaeovegetational reconstruction. Studies on timbers can come from construction materials such as from crannog sites (Crone 1993, 2000; Crone et al. 2001) together with archaeological objects e.g. stakes and barrelparts (e.g. Jones et al. 2007) where tool mark, wood identification and dendrochronological analysis may be undertaken. More natural wood remains such as the remnants of former woodlands have also been examined in Scotland (Tipping et al. 2008a) in order to reconstruct former woodland environments, build chronologies and investigate the character and openness of such wooded environments. However, despite the strong presence of buried tree remains such as pine stumps across Scotland such studies are still fairly sparse and again are more likely to take place during multi-proxy studies (e.g. Tipping et al. 2008b).

\section{Practitioners and archaeobotanical reference collections in Scotland}

These are few but mention can be made of the Dickson Laboratory at Northlight Heritage's Bioarchaeology Unit in Glasgow, and at Headland Archaeology.

\section{Looking towards the future}

\section{Plant macrofossils}

- Particular targeting of features such as Neolithic pits in order to look at why these features seemed to have been used so frequently to store/contain charred cereal grain

- Neolithic agriculture: charred cereal grain and its chronological distribution. Maps could be made in an attempt to identify where agriculture began in Scotland, how this spread, where it spread from and any trends in crop use. To date this has happened sporadically with archaeobotanist's on occasion collating data (e.g. Table 8: Dates for Neolithic cultivation from sites across Scotland; an example of collated data.) and with recent academic interest (such as Rosie Bishop's postgraduate work, Bishop et al. 2009). This process could also be undertaken for other periods in Scotland.

- Recent research has shown that charred grain have the potential to inform of climatic episodes such as periods of increased wetness and dryness. This information can be applied to agricultural sites and help us to understand some of the challenges people in the past faced together with helping to build more regional rather than national climate records. An area where this may be particularly useful is prehistoric farming in isolated/marginal locations and in corn-drying kiln studies. Such information could be linked to dendrochronological, tephra and testate amoebae studies.

- More research into the weed seeds collected from sites may increase our understanding of the different farming (cultivation, harvesting and processing) methods employed throughout history and prehistory. It would be interesting to compare the taxa found from marginal locations with those from more central locations. This information could then be contrasted and compared with the arable weed assemblages identified in the pollen records.

\section{Charcoal/Wood}

- More could still be achieved looking at the buried tree remains such as pine stumps across Scotland, both from an ecological point of view seeking what the root systems tell about soil conditions and how tree morphology can inform current research of woodland composition/openness. Can periods 
of poor growth be linked to phases of wet climate? Can tree-rings add to the dendrochronological sequences being developed to aid in the formation of a master chronology of pine in Scotland?

- Charcoal fragments can be examined for more than just identification to family/species identification. More can be done with charcoal morphology in particular looking at the rings for curvature information and possible periods of cyclic cutting. This can reveal potential woodland management and be related to pollen records etc. This would be of particular interest with features such as burnt mounds, smithing kilns and potential construction material.

Table 8: Dates for Neolithic cultivation from sites across Scotland; an example of collated data.

\begin{tabular}{|c|c|c|c|c|c|c|}
\hline Site & Start/End & $\begin{array}{l}\text { Dated } \\
\text { material }\end{array}$ & $\begin{array}{l}\text { Date } \\
\text { cal } \\
\text { BC }\end{array}$ & Date BP & $\begin{array}{l}\text { Lab } \\
\text { code }\end{array}$ & Author \\
\hline $\begin{array}{l}\text { Crathes, } \\
\text { Aberdeenshire }\end{array}$ & Start & $\begin{array}{l}\text { Club/bread } \\
\text { wheat } \\
\text { grain }\end{array}$ & $\begin{array}{l}3950- \\
3700\end{array}$ & $5015 \pm 35$ & $\begin{array}{l}\text { SUERC- } \\
10085\end{array}$ & Murray et al. 2009 \\
\hline $\begin{array}{l}\text { Crathes, } \\
\text { Aberdeenshire }\end{array}$ & End & $\begin{array}{l}\text { Naked } \\
\text { barley } \\
\text { grain }\end{array}$ & $\begin{array}{l}3820- \\
3650\end{array}$ & $4945 \pm 35$ & $\begin{array}{l}\text { SUERC- } \\
4034\end{array}$ & Murray et al. 2009 \\
\hline $\begin{array}{l}\text { Garthdee, } \\
\text { Aberdeenshire }\end{array}$ & Start & $\begin{array}{l}\text { Naked } \\
\text { barley } \\
\text { grain }\end{array}$ & $\begin{array}{l}3800- \\
3650\end{array}$ & $4950 \pm 35$ & $\begin{array}{l}\text { SUERC- } \\
8613\end{array}$ & $\begin{array}{l}\text { Murray et al. } \\
\text { forthcoming }\end{array}$ \\
\hline $\begin{array}{l}\text { Garthdee, } \\
\text { Aberdeenshire }\end{array}$ & End & $\begin{array}{l}\text { Naked } \\
\text { barley } \\
\text { grain }\end{array}$ & $\begin{array}{l}3780- \\
3640\end{array}$ & $4925 \pm 35$ & $\begin{array}{l}\text { SUERC- } \\
8607\end{array}$ & $\begin{array}{l}\text { Murray et al. } \\
\text { forthcoming }\end{array}$ \\
\hline $\begin{array}{l}\text { Powmyre } \\
\text { Quarry, Angus }\end{array}$ & Start/End & $\begin{array}{l}\text { Emmer } \\
\text { wheat } \\
\text { grain }\end{array}$ & $\begin{array}{l}3770- \\
3640\end{array}$ & $4920 \pm 35$ & $\begin{array}{l}\text { SUERC- } \\
30981\end{array}$ & Masser 2010 \\
\hline $\begin{array}{l}\text { Claish, } \\
\text { Stirlingshire }\end{array}$ & Start/End & $\begin{array}{l}\text { Emmer } \\
\text { wheat } \\
\text { grain }\end{array}$ & $\begin{array}{l}3790- \\
3620\end{array}$ & $4885 \pm 50$ & $\begin{array}{l}\text { AA- } \\
49461\end{array}$ & Barclay et al. 2002 \\
\hline $\begin{array}{l}\text { Balbridie, } \\
\text { Aberdeenshire }\end{array}$ & Start & Oat grain & $\begin{array}{l}3770- \\
3370 \\
\end{array}$ & $4820 \pm 80$ & $\begin{array}{l}\text { OxA- } \\
1767 \\
\end{array}$ & $\begin{array}{l}\text { Fairweather } \\
\text { Ralston } 1993 \\
\end{array}$ \\
\hline $\begin{array}{l}\text { Balbridie, } \\
\text { Aberdeenshire }\end{array}$ & End & $\begin{array}{l}\text { Emmer } \\
\text { wheat } \\
\text { grain }\end{array}$ & $\begin{array}{l}3700- \\
3360\end{array}$ & $4765 \pm 80$ & $\begin{array}{l}\text { GU- } \\
1421\end{array}$ & $\begin{array}{ll}\text { Fairweather } & \text { and } \\
\text { Ralston } 1993\end{array}$ \\
\hline $\begin{array}{l}\text { Eilean } \\
\text { Domhnuill, } \\
\text { Western Isles }\end{array}$ & Start & $\begin{array}{l}\text { Barley } \\
\text { grain }\end{array}$ & $\begin{array}{l}3710- \\
3520\end{array}$ & $4830 \pm 45$ & $\begin{array}{l}\text { OxA- } \\
9079\end{array}$ & Mills et al. 2004 \\
\hline $\begin{array}{l}\text { Eilean } \\
\text { Domhnuill, } \\
\text { Western Isles }\end{array}$ & End & $\begin{array}{l}\text { Barley } \\
\text { grain }\end{array}$ & $\begin{array}{l}2930- \\
2760\end{array}$ & $4265 \pm 30$ & $\begin{array}{l}\text { OxA- } \\
9159\end{array}$ & Mills et al. 2004 \\
\hline $\begin{array}{l}\text { Balfarg, } \\
\text { Fife }\end{array}$ & Start/End & $\begin{array}{l}\text { Barley } \\
\text { grain }\end{array}$ & $\begin{array}{l}3700- \\
3520\end{array}$ & $4830 \pm 40$ & $\begin{array}{l}\text { UtC- } \\
1302\end{array}$ & $\begin{array}{l}\text { Barclay and Russell- } \\
\text { White } 1993\end{array}$ \\
\hline
\end{tabular}


Science in Scottish Archaeology

\begin{tabular}{|c|c|c|c|c|c|c|}
\hline $\begin{array}{l}\text { Culduthel, } \\
\text { Inverness- } \\
\text { shire }\end{array}$ & Start & $\begin{array}{l}\text { Naked } \\
\text { barley } \\
\text { grain }\end{array}$ & $\begin{array}{l}3650- \\
3510\end{array}$ & $4780 \pm 30$ & $\begin{array}{l}\text { SUERC- } \\
20229\end{array}$ & Murray, forthcoming \\
\hline $\begin{array}{l}\text { Culduthel, } \\
\text { Inverness- } \\
\text { shire }\end{array}$ & End & $\begin{array}{l}\text { Naked } \\
\text { barley } \\
\text { grain }\end{array}$ & $\begin{array}{l}3640- \\
3370\end{array}$ & $4725 \pm 30$ & $\begin{array}{l}\text { SUERC- } \\
27863\end{array}$ & Murray, forthcoming \\
\hline $\begin{array}{l}\text { Biggar } \\
\text { Common East, } \\
\text { Lanarkshire }\end{array}$ & Start/End & $\begin{array}{l}\text { Barley } \\
\text { grain }\end{array}$ & $\begin{array}{l}3650- \\
3100\end{array}$ & $4645 \pm 65$ & $\begin{array}{l}\text { AA- } \\
18155\end{array}$ & $\begin{array}{l}\text { http://www.historic- } \\
\text { scotland.gov.uk }\end{array}$ \\
\hline $\begin{array}{ll}\text { Skara } & \text { Brae, } \\
\text { Orkney } & \\
\end{array}$ & Start & $\begin{array}{l}\text { Barley } \\
\text { grain }\end{array}$ & $\begin{array}{l}3640- \\
3370\end{array}$ & $4735 \pm 40$ & $\begin{array}{l}\text { SUERC- } \\
3127\end{array}$ & Ascough et al 2007 \\
\hline $\begin{array}{ll}\text { Skara } & \text { Brae, } \\
\text { Orkney } & \end{array}$ & End & $\begin{array}{l}\text { Barley } \\
\text { grain }\end{array}$ & $\begin{array}{l}3010- \\
2700\end{array}$ & $4270 \pm 40$ & $\begin{array}{l}\text { SUERC- } \\
3126\end{array}$ & Ascough et al 2007 \\
\hline $\begin{array}{l}\text { Westgate, } \\
\text { Aberdeenshire }\end{array}$ & Start & $\begin{array}{l}\text { Naked } \\
\text { barley } \\
\text { grain }\end{array}$ & $\begin{array}{l}3630- \\
3360\end{array}$ & $4675 \pm 30$ & $\begin{array}{l}\text { SUERC- } \\
31286\end{array}$ & $\begin{array}{l}\text { Murray et al. } \\
\text { forthcoming }\end{array}$ \\
\hline $\begin{array}{l}\text { Westgate, } \\
\text { Aberdeenshire }\end{array}$ & End & $\begin{array}{l}\text { Naked } \\
\text { barley } \\
\text { grain }\end{array}$ & $\begin{array}{l}3520- \\
3360\end{array}$ & $4660 \pm 30$ & $\begin{array}{l}\text { SUERC- } \\
31288\end{array}$ & $\begin{array}{l}\text { Murray et al. } \\
\text { forthcoming }\end{array}$ \\
\hline $\begin{array}{l}\text { Barnhouse, } \\
\text { Orkney }\end{array}$ & Start & $\begin{array}{l}\text { Charred } \\
\text { grain }\end{array}$ & $\begin{array}{l}3650- \\
3000\end{array}$ & $4590 \pm 75$ & $\begin{array}{l}\text { OxA- } \\
3499 \\
\end{array}$ & Ashmore 2005 \\
\hline $\begin{array}{l}\text { Barnhouse, } \\
\text { Orkney }\end{array}$ & End & $\begin{array}{l}\text { Naked } \\
\text { barley } \\
\text { grain }\end{array}$ & $\begin{array}{l}3330- \\
2880\end{array}$ & $4360 \pm 60$ & $\begin{array}{l}\text { OxA- } \\
2736\end{array}$ & Ashmore 2005 \\
\hline $\begin{array}{l}\text { Castlehill, } \\
\text { Inverness }\end{array}$ & Start/End & $\begin{array}{l}\text { Charred } \\
\text { grain }\end{array}$ & $\begin{array}{l}3520- \\
3100\end{array}$ & $4595 \pm 50$ & $\begin{array}{l}\text { AA- } \\
39809\end{array}$ & $\begin{array}{l}\text { http://www.historic- } \\
\text { scotland.gov.uk }\end{array}$ \\
\hline $\begin{array}{l}\text { Kinbeachie, } \\
\text { Black Isle }\end{array}$ & Start & $\begin{array}{l}\text { Barley } \\
\text { grain }\end{array}$ & $\begin{array}{l}3500- \\
3100\end{array}$ & $4575 \pm 45$ & $\begin{array}{l}\text { OxA- } \\
8204\end{array}$ & Barclay et al. 2001 \\
\hline $\begin{array}{l}\text { Kinbeachie, } \\
\text { Black Isle }\end{array}$ & End & $\begin{array}{l}\text { Barley } \\
\text { grain }\end{array}$ & $\begin{array}{l}3340- \\
2930 \\
\end{array}$ & $4455 \pm 40$ & $\begin{array}{l}\text { OxA- } \\
8206 \\
\end{array}$ & Barclay et al. 2001 \\
\hline $\begin{array}{l}\text { Meadowend } \\
\text { Farm, } \\
\text { Aberdeenshire }\end{array}$ & Start & $\begin{array}{l}\text { Naked } \\
\text { barley } \\
\text { grain }\end{array}$ & $\begin{array}{l}3490- \\
3120\end{array}$ & $4560 \pm 35$ & $\begin{array}{l}\text { SUERC- } \\
16835\end{array}$ & $\begin{array}{l}\text { Timpany et al. } \\
\text { forthcoming }\end{array}$ \\
\hline $\begin{array}{l}\text { Meadowend } \\
\text { Farm, } \\
\text { Aberdeenshire }\end{array}$ & End & $\begin{array}{l}\text { Naked } \\
\text { barley } \\
\text { grain }\end{array}$ & $\begin{array}{l}3340- \\
2930\end{array}$ & $4450 \pm 40$ & $\begin{array}{l}\text { SUERC- } \\
16894\end{array}$ & $\begin{array}{l}\text { Timpany et al. } \\
\text { forthcoming }\end{array}$ \\
\hline
\end{tabular}

\subsection{Vertebrate Archaeozoology}

The study of vertebrate remains recovered within ancient soils and sediments enables insight into past environmental and climatic conditions (Yalden 2001; Mainland 2008), diet, farming, hunting and herding practices (Charles and Halstead 2001), trade and exchange of animals and animal products (Jones O'Day et al. 2004), and the symbolic and cosmological role of animals in society
(Jones O'Day et al. 2004). It is the skeletal and dental remains of vertebrates that are most usually preserved within such deposits. Soft tissue and other non-skeletal material (hides, fur, horn, hooves etc.) will only be found in anaerobic conditions where the absence of oxygen has inhibited bacterial decay (Lyman 1994): examples include waterlogged deposits and very dry or cold environments. In aerated soils, preservation of teeth and bone is 
Science in Scottish Archaeology

dependent on a neutral-alkaline $\mathrm{pH}$ soil conditions $(\mathrm{pH} \geq 7)$. Acidic soil conditions $(\mathrm{pH}<7)$ promote skeletal decomposition, and in soils of lower pHs bone will be absent, poorly preserved ('spongy'), or recovered only where carbonization had occurred prior to burial, as the burning process removes the inorganic component of bone, effectively mineralising bone and making it more resistant to both biological decay and soil acidity (Lyman 1994).

Vertebrates will have become incorporated in ancient deposits through a variety of mechanisms both anthropogenic and natural (e.g., predators, natural deaths) and have been modified during and after deposition by further such processes (e.g. soil conditions, modification by carnivores, re-deposition). Non-anthropogenic bone accumulations include predator kills and den sites (e.g. hyenas, roosts of owls, eagles and other raptors and lacustrine, littoral and cave contexts which have acted as natural 'traps' capturing passing animals (Lowe and Walker 1997). In anthropogenically derived deposits, animal bones are typically found in a disarticulated state, reflecting processing of animal carcasses for food and craft working. Occasionally, articulated bodies are found and may represent natural and accidental deaths, deliberate disposal of fallen animals or activities of predator species (e.g. owl roosts in buildings). The deposition of whole or partial skeletons may also reflect noneconomic activities, as part of religious or other symbolic acts (e.g., Morris 2008).

Archaeozoology has two basic applications: palaeoenvironmental reconstruction and analysis of human interactions with animals. Many vertebrate species, particularly the birds and the smaller mammalian fauna (rodents, voles, shrews, mice, etc.) are habitat specific or have specific dietary requirements or environmental tolerances and can be used as indicators of particular ecosystems and/or climatic conditions in the past (Mainland 2008). This type of analysis is more commonly undertaken on naturally accumulated assemblages (see e.g. references in Lowe and Walker 1997; Mainland 2008).
Anthropogenically derived archaeofaunas accumulate through human activities - food preparation and consumption, funerary and initiation rites, hunting and herding practices, etc. - and enable insight into diverse humananimal interactions within past societies (see, e.g. references in Reitz and Wing 2008; Charles and Halstead 2004).

Most zooarchaeological research will start with a basic taxonomic and anatomical identification, requiring access to a good modern comparative zoological collection (Reitz and Wing 2008). Subsequent methodological approaches will depend on the assemblage and/or research questions involved, but at a minimum will typically include reconstruction of age-at-death from tooth eruption and wear, modelling of taphonomic modifications, including analyses of bone fragmentation and butchery patterning, biometrics and analyses of palaeopathology. These basic methods are now routinely supplemented by more detailed analyses, including inter alia isotopic studies (e.g., Mulville et al. 2009), aDNA (e.g. Haynes et al. 2005; Chessa et al. 2009) and other biomolecular techniques (e.g., Evershed 2008; Craig et al. 2005), morphometrics (e.g. Cucchi et al. 2009; O'Reagan and Kitchiner 2005), histomorphometrics (e.g. Mainland et al. 2007), skeletochronological analyses (e.g. Chirtz et al. 2009).

\section{The Scottish Resource}

\section{Archaeofaunal assemblages}

It has only really been since the 1970 s that faunal remains within archaeological contexts in Scotland, as in the rest of the UK, have been routinely and systematically sampled, recovered, analysed and archived. Nevertheless, an interest in archaeofaunal remains as a potential source of evidence for Scottish pre-/history is apparent from the Antiquarian excavations onwards; indeed the observations of some of the $19^{\text {th }}$ and early $20^{\text {th }}$ century researchers, such as Turner (1895) on the Oban 'bone caves', or Platt's (e.g. 1934; 1956) work in Orkney and Shetland remain significant sources of evidence today, 
Science in Scottish Archaeology particularly where the actual assemblages have subsequently been lost.

Conditions conducive to bone survival are not well distributed across Scotland, which is largely dominated by acidic and peaty soils (McCormick and Buckland 1997; Kitchiner 1998). Large, well, preserved assemblages are found mainly in the Western and Northern Isles (e.g. Armit 2006; Hunter 2007; Dockrill et al. 2009; Parker Pearson et al. 1999), particularly within coastal sands and machair (e.g. Parker Pearson et al. 2004; Moore and Wilson 2011; Bigelow et al. 2005). Good bone preservation is also evident in the limestone caves of the West Highlands (e.g. Creag Nan Uamh, Assynt, Callander et al. 1927; Smoo Cave, Pollard et al. 2005; High Pasture Cave, Drew 2005) and in river gravels, clays and sands (e.g. Bishopbriggs, Jacobi et al. 2009). Anaerobic conditions are very rare but are evident in the larger urban contexts, where proximity to rivers and changing water tables, and large accumulations of waste material have promoted exceptional preservation of vertebrate remains (including soft tissue) in cities such as Edinburgh (e.g. Holyrood Archaeology Project Team 2010; Barclay and Ritchie 2010; Jones 2001), Perth (Bowler 2004; Bogdan et al. in press) and Aberdeen (Cameron and Stones 2001; Hodgson and Jones 1982), as well as some of the smaller Scottish burghs (e.g. Kirkwall, Cox et al. 1998; Elgin, Hall et al. 1998). Crannogs and other structures within littoral and near-shore marine environments are a further source of well preserved bone in a Scottish context (e.g. Hale 2000; Dixon 2004; Crone 2000), though to date comparatively little faunal research has been undertaken on such sites.

Preservation conditions have thus created a resource which is biased geographically and to a lesser extent temporally. This has been exacerbated by a tendency for University research projects to gravitate towards the Highlands and Islands of Scotland, areas which had historically benefitted from extensive Antiquarian and early $20^{\text {th }}$ century interest (Downes et al. 2005). In the Western Isles, there is thus reasonably good evidence for human-animal interactions from the
Mesolithic onwards (McCormick and Buckland 1998; McCormick 2006; Mulville 2005; Mulville 1999; Parks and Barrett 2009) and in the Northern Isles from the Neolithic onwards (McCormick and Buckland 1998; Mainland and Simpson 1995; Bond 2007; Rackham 1989; Mainland 1993; Barrett 2005; Moore and Wilson 2011; Bond et al. 2010). The transition to farming of Neolithic, Bronze Age or Iron Age hunting and herding practices is, however, inadequately known over much of Mainland Scotland (McCormick and Buckland 1998). In contrast, understanding of the historic periods is biased towards the larger urban centres, Perth, Edinburgh and Aberdeen (Bogdan et al. in press; Cameron and Stones 2001; Hodgson and Jones 1982; Holyrood Archaeology Project Team 2010). Post-Medieval utilisation of faunal resources has received very little attention over most of Scotland, even in areas such as Orkney or the Hebrides, where bone is more likely to survive.

Research on Scottish archaeofaunas has largely been focused on biogeographical (especially the post-glacial recolonisation of Scotland and the Scottish islands by its mammalian fauna) (Kitchiner 1998; Kitchener et al. 2004) and economic questions (diet, subsistence, farming practice, etc.) (McCormick and Buckland 1998). Noneconomic uses of animals have been less well studied, though there is a growing interest in this area (Mulville 1999; Morris 2005). Scottish faunal material has also featured prominently in applications of innovative analytical developments within 'scientific archaeology', most notably in the fields of biomolecular and isotopic studies (e.g. Mulville et al. 2009; Haynes et al. 2005; Evershed 2008; Craig et al. 2005) though such research has largely been undertaken outwith Scotland (see below).

There are two good overviews of Scottish faunal change from early post-glacial periods onwards, which provide a synthesis of the faunal evidence for Scotland (Kitchiner 1998; McCormick and Buckland 1998), though these do require updating to incorporate more recent research, including some significant 
Science in Scottish Archaeology assemblages such as Scatness in Shetland, Pool in Orkney and Dun Vullan in the Western Isles, as well as assemblages from the early Medieval period onwards. Some period specific syntheses for the faunal data are also available (e.g., Mesolithic, Kitchiner et al. 2004) but most reviews tend to be both geographically and chronologically focused (e.g. Atlantic Iron Age - Bond 2002; Gilmour and Cook 1998). Mainland and Simpson (2005) provide a multi-period overview of potentials for faunal (and other environmental) research within, Orkney. Species specific reviews for Scotland exist for pigs (Smith 2000), horses, cats and dogs (Smith 1998) and for fur-bearing animals (Fairnell and Barrett 2007); Haynes et al. (2005) and Nicholson et al. (2004) include a summary of the Scottish evidence in their papers on the origins of the microfauna of the Northern Isles; Serjeantson (2001; 2009) provides similar overview for various avian species.

\section{Marine resources/fish}

The taxonomic identification of fish remains recovered from archaeological sites by sieving, allows reconstruction of the ecology, economy and diet of past human populations; furthermore, data provides information about fishing: development of fishing equipment and fishing techniques. This offers a unique insight into the fishing strategies utilised in the past and on the status of past fish resources in the regions of provenance. The use of biometrical techniques allows the size reconstruction of economically important fish groups. The analysis of otoliths (fish ear stones) provides valuable information on the age of the fish caught, as well as on their season of capture.

The study of archaeological fish remains provides important information of relevance to not only archaeologists but also to those involved in marine/coastal ecology, marine biology and conservation. The long time dimension which archaeology provides allows the exploration of relationships between coastal marine communities and habitats, and indicates where environmental changes may have taken place historically along the coastline.

The first records of fish bone presence in archaeological deposits derive from Antiquarian reports and consist of only notes outlining the 'presence of fish bone' (Anderson 1895, Bishop 1914, Calder 1937, Fairhust 1939, Mapleton 1875).

The introduction of careful sieving techniques of selected bulk samples during the 1970s and 1980s (Payne 1972, Guerreschi 1973, Williams 1973, Jones 1983, Mantle et al 1984) produced large quantities of tiny microscopic and very small organic elements; these remains derived from a range of very small specimens and a wide range of marine fishes. The result of sieving allowed the first crucial detailed study of fish remains from Mesolithic middens from Oronsay and Colonsay which provided quite considerable evidence on the reliance on saithe (Pollachius virens) by Mesolithic populations as a major source of nourishment (Mellars \& Willkinson 1980); furthermore, this study underlined the importance of otolith analysis and its contribution of seasonality reconstruction.

Mellars \& Wilkinson's study gave way to intense analysis of fish remains in Scotland where fishing has been historically a very important industry which provided work and nutrition to a high proportion of the population from the earliest human occupation until its demise as a major industry in the 1960s (Coull 1997).

The first synthesis of fish remains recovered from the Mesolithic to Viking Age sites was done by Barrett et al in 1999. This publication underlined the importance of such analysis based on material recovered by careful sieving (Barrett 1995, 1997, Ceron-Carrasco 1994, 1998a, b, c and d, 1999, Colley 1983a, 1983b, 1983c, 1984, 1987, 1989, Jones 1991, Nicholson 1997a and b, 1998) and gave rise to large scale work on the importance of fishing from prehistory to medieval periods throughout Scotland, but particularly in the Western and Northern Isles (Barrett 2003, 2005, Barrett et al 2008, Barrett et al 2001, 
Ceron-Carrasco 2005, Ingrem 2005). Furthermore, careful sampling and sieving has also provided material to study fishing on the East Coast particularly from medieval deposits (Ceron-Carrasco 1998, 2000a, 2000b, 2001, 2007), the material recovered provided archaeological evidence, backed up by historical and ethnographic evidence, of the rise of fishing industry in this area.

An attempt to produce an online database with information on marine fish, mollusca and all other marine organisms that survive in archaeological deposits was undertaken in 2004-06 by Ceron-Carrasco et al. (2007) at the University of Edinburgh. An archaeological database of Marine Resource Exploitation in Scotland (MARES) contains archaeological evidence for marine resource exploitation in Scotland from the earliest known settlement (c. $9000 \mathrm{cal} \mathrm{BC}$ ) to the end of the Medieval period (c. AD 1500). Currently, MARES provides data for northern and western Scotland relating to fishing, hunting of marine mammals and seabirds, shellfish gathering, seaweed usage, and drift wood procurement. As well as details of archaeological finds, it includes information on site location, discovery and excavation history, context and associations, chronology (including available radiocarbon dates), current location of finds, and bibliographic sources. The data was drawn from a wide range of sources, including published and 'grey' literature and collections held by museums, universities, and commercial field units. The online database can be accessed at http://webdb.ucs.ed.ac.uk/mares/.

Unfortunately MARES has not been updated since 2006 due to lack of financial support and the fact that many of the major projects have not yet been published, understandably raw data will not be released till publication. The database probably only includes the raw data of less than a quarter of the overall fish remains recovered from archaeological sites in Scotland, that have been analysed in the last 15 years or so. 


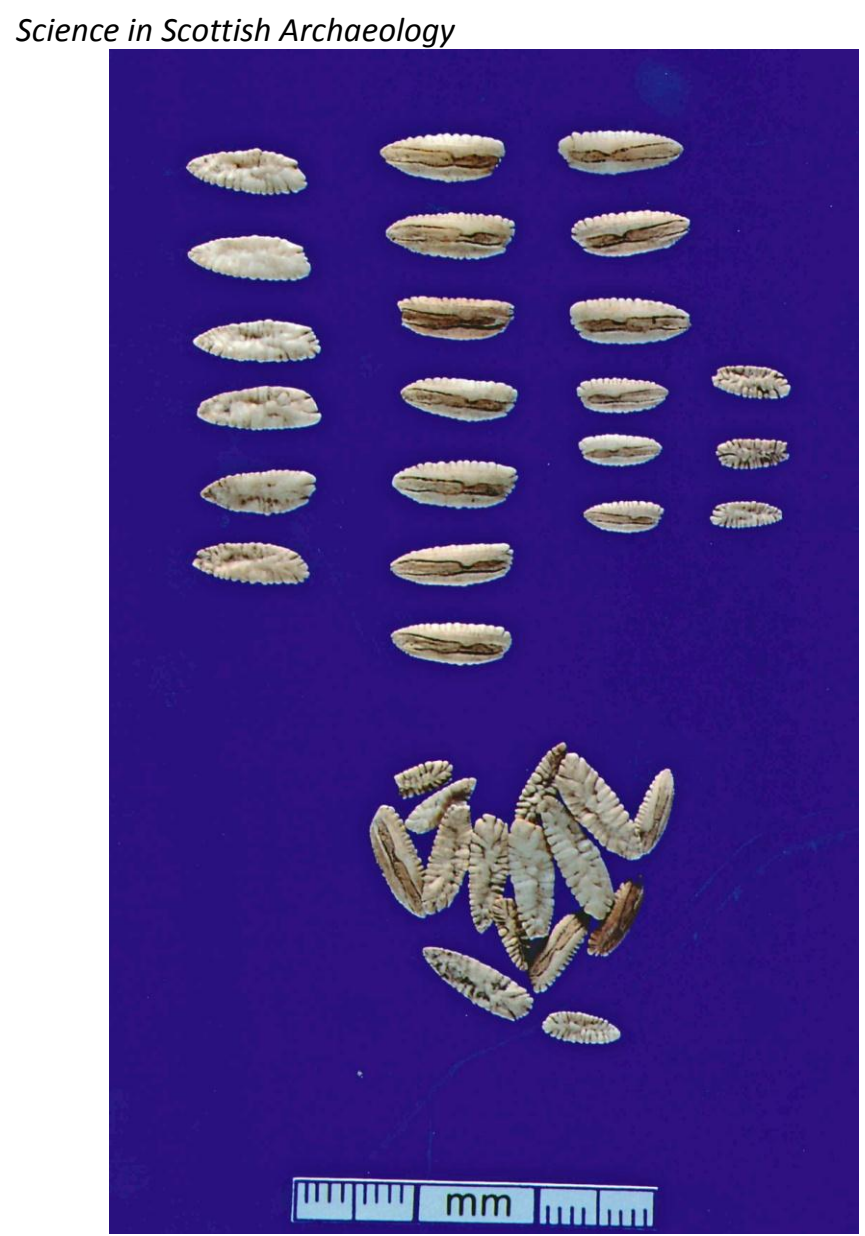

Figure 20: Otoliths of $2^{\text {nd }}-3^{\text {rd }}$ year saithe (Pollachius virens) recovered at the Iron Age settlement of Bostadh Beach, Lewis, Western Isles. (C) Cerón-Carrasco 2005

\section{Practitioners and research collections}

Until relatively recently, there have been very few archaeozoologists working in Scotland. The commercial units, AOC, Headland, etc. have tended to employ archaeozoologists on an occasional basis, the exceptions being Catherine Smith who has been based in Perth since the 1980s and has worked extensively on Scottish Medieval and Post-Medieval assemblages and Dr. Finbar McCormick who was based in Edinburgh with AOC Scotland, until leaving for Ireland at the end for the 1990s, and has published diverse assemblages from across Scotland. Of the Scottish Universities, Edinburgh has had an archaeozoologist, Dr. Lazlo Bartosiewicz, in post since the early 2000s, Aberdeen has recently invested in a major archaeozoological research centre led by Prof. Keith Dobney, and the University of the Highlands and Islands, Orkney campus has recruited Dr. Ingrid Mainland, who is also heading commercial activities in archaeozoology for the commercial unit ORCA. At the National Museums of Scotland, Dr. Andrew Kitchiner, Principal Curator of Vertebrate Zoology curates the national faunal collections for archaeology and is engaged in archaeozoological research. Historic Scotland does not, however, directly employ the services of an archaeozoologist (unlike English Heritage which has several archaeozoologists based in its Environmental Studies section at Fort Cumberland and a further two employed as Regional Scientific Advisors).

Over the past three decades perhaps more archaeozoological research on Scottish faunas has been undertaken by researchers working outwith Scotland. This reflects both the paucity of researchers based within Scotland and the strong research activities of English Universities in the Scottish islands: in the Western Isles, Jacqui Mulville (Cardiff and Sheffield); in the Northern Isles, Julie Bond, 
Science in Scottish Archaeology

Rebecca Nicholson, Ingrid Mainland (Bradford), James Barrett and Jen Harland (York/Cambridge). Scottish faunas have also been widely employed in the development and application of biomolecular, isotopic and other innovative analytical methodologies, again until recently outwith Scotland: e.g., lipids, Bradford, Bristol, York (Craig et al. 2005; Mukerjhee et al. 2008), isotopic analyses, Bradford, Cardiff, York, CNRS (Evans et al. 2009; Mulville et al. 2009; Balasse et al. 2009), aDNA, Durham [Aberdeen] (Haynes et al. 2005), dental microwear, Bradford][Orkney] (Mainland 2000), morphometrics, Durham [Aberdeen] (Cucchi et al. 2009)

A modern reference collection of vertebrate skeletons with a secure taxonomic identification is a fundamental prerequisite for archaeozoological research (Reitz and Wing 2008). In Scotland the foremost modern zoological reference collection for Scottish and European faunas is held at the National Museum, under the curation of Andrew Kitchiner and is open for consultation by researchers. Smaller reference collections for teaching and research are held by the Depts. of Archaeology at Glasgow and Edinburgh Universities, and are actively being developed at the Universities of Aberdeen and the Highlands and Islands. These collections tend to reflect the specific research activities of university staff at the institution and can generally be accessed by contacting the department concerned.

Existing archaeological collections provide a further resource for study, for identifications, comparative study and teaching but perhaps most importantly as an analytical resource. There is an increasing recognition of the value of archive faunal assemblages for application of new methodologies. This is demonstrated well by the changing focus of palaeodietary studies over the last decade, which has seen greater emphasis being placed on the reconstruction of animal diet as a research question rather than as a means through which human diet can be assessed (Thomas and Mainland 2005; e.g. Mulville et al. 2009;
Balasse et al. 2009); such projects rely heavily on archived faunal material.

A further important resource for Scottish archaeofaunal research is the living vertebrate population of Scotland. Many Scottish species or breeds are distinctive, either biologically or in terms of their habitat and as such may be used as analogies for past populations, habitat and environmental conditions as well as providing useful genetic data. The Soay sheep on St Kilda (Chessa et al. 2009), the red deer on Rum (Stevens et al. 2006), the Orkney vole (Haynes et al. 2005) and the North Ronaldsay seaweed-eating sheep (Mainland 2000; Balasse et al. 2009) are just some examples of modern Scottish species/breeds which have been used in archaeozoological research.

\section{Marine Resources}

Research capacity, in terms of materials for marine resources, is substantial in Scotland as most sites will yield substantial quantities of fish remains for analysis. Unfortunately none of the Scottish universities at present appear to be involved in teaching or stimulating studies of fish remains, the focus of more recent post graduate research in this area derived from the University of York where Dr James Barrett taught in this field until moving to the University of Cambridge where the identification of archaeological cod trade has been undertaken on a method formulated by Barrett et al. (2008). The method is based on isotopic measurements ( $\delta 13 \mathrm{C}$ and $\delta 15 \mathrm{~N}$ ) of cod bone collagen and was successfully applied to investigate cod trade from the Viking to Medieval periods in several European archaeological sites. Master degrees in isotope analysis of fish remains have also been undertaken at Durham University (Jimenez-Cano 2010).

At the University of Edinburgh the Department of Archaeology has a zooarchaeological teaching unit which offers postgraduate courses in this subject; however this appears to have concentrated mainly on the study of mammal remains.

Links should be closely established with the University of Aberdeen Marine Biology 
Laboratory which houses the most complete fish skeletal reference collection for marine fish species of the North Atlantic (which is mainly used for the study of marine mammal diet analysis). They also have facilities for thinsectioning of otoliths, which is crucial to establish seasonality. This is a great source of scientific analysis as well as the Freshwater Fisheries Laboratory in Pitlochry, for the study of salmon and trout. Other related resources include the archives at the School of Scottish Studies at the University of Edinburgh for ethnographic and historical and analogical studies.

\section{Research priorities}

The following research priorities for archaeofaunal studies in Scotland can be suggested; these are by necessity generic and it is anticipated that there will be some overlap with the ScARF period panels.

\section{The faunal history of Scotland}

It is apparent from the above that there are significant gaps in the early prehistoric faunal record for much of Mainland Scotland and for the later historic in all regions outwith the major urban centres. A research programme identifying and targeting sites of the relevant date in specific geographic areas which are more likely to preserve faunal remains could help redress this deficit. Of particular potential are lacustrine environments and near-shore marine deposits. The underutilised urban deposits in the smaller towns and cities of Scotland could also prove useful in extending understanding of later historic periods. It can be anticipated that there will be diverse additional pockets of good bone preservation across Scotland, reflecting underlying geologies and soils; establishing where some of these are on a region-byregion basis and targeting zooarchaeological research in these zones could also prove beneficial.

With regard to period-specific priorities, the following areas can be identified as being critical for better understanding of the history of Scottish archaeofaunas:
The Mesolithic/Neolithic transition. The introduction of domesticated animals to and/or the process of domestication in Scotland represents a significant change in human interactions with animals; yet very little is currently known about the origins of domestication in Scotland, whether any indigenous domestication occurred, or if domesticates were introduced (and in the case of sheep this is a given), the routes by which the these species arrived (see also below).

Bronze Age herding practices. Almost nothing is known about pastoral farming in the second millennium BC in Scotland. There is an urgent need to target sites of this period which are likely to preserve faunal material.

Post-Medieval faunas in Scotland. The period from the $17^{\text {th }}$ century onwards witnessed one of the most fundamental changes to agriculture in Scotland, with farming practices and breeds introduced across the country. The faunal evidence could provide primary data for this process and its impact on farming and farming society; yet there exist very few faunal collections dating to this period outwith the cities.

Several priorities for thematic research, which cross-cut chronological boundaries can also be identified:

Non-economic uses of animals. There has been a tendency to use Scottish archaeofaunas to address research questions relating to the human diet and subsistence and economic uses of animals with little consideration given to their symbolic or ritual role in past societies. Developing methodologies for identifying and ascribing meaning to variability in depositional practice at different scales (from excavation layer to landscapes) is thus a key area for future research.

The practice of ancient herding systems. Traditionally, archaeozoology has focused on the products of past farming systems, meat, milk, wool, etc. Developments in scientific archaeology, in particular in stable isotopic 
Science in Scottish Archaeology

studies, but also other approaches such as morphometrics and dental microwear analysis are enabling a more holistic understanding of past farming practices; foddering and grazing strategies and their impacts both on the landscape and herd productivity; seasonality of diet; the articulation of such practices within the landscape (intensive vs. extensive grazing, transhumance, sheilings, etc.). While most research on Scottish materials has to date been undertaken outwith Scotland, the facilities and archaeozoologists now in place in Scotland, make this a key area both for future research but also as one in which Scottish institutions will feature prominently internationally.

Biogeography of Scottish faunas. The origins of Scottish fauna, both wild and domesticated - colonisations, introductions, extinctions - is a further key area for research and which again has become more viable through recent methodological developments in scientific archaeology, here aDNA studies and morphometrics. Due to recent investment, Aberdeen has significant strengths in this area, both in terms of staff and facilities and again Scotland and Scottish research questions are well placed to lead the way for future research developments and applications in this area.

Marine Resources. The opportunities are always available; Scotland is surrounded by sea and has immense freshwater resources. Most excavations carried out in Scotland produce fish remains, new techniques in isotopic and related analysis should be encouraged along with the standard analysis. One of the main aims for future research should be to provide data that can be of use in the present and future management of fishery resources and which can be incorporated in the history of marine resource exploitation and uses in Scotland. An online database should be further developed in order to safeguard the raw data which may remain unpublished so that it becomes available to future generations of researchers in Scotland.
Archived faunal resources - collections and publications

Conserving the resource. As outlined above, existing archaeofaunal collections are a valuable resource for future research, especially for novel analytical approaches, as biomolecular and isotopic studies have demonstrated. Many of the newer techniques are destructive, and there is some indication that faunal material is considered more expendable than other archaeological materials. There is thus a need to ensure that museums and other archives do not unintentionally allow an overexploitation of the archaeofaunal resource, particularly for periods or species that may be significant in terms of their quantity or biogeography, while at the same time allowing adequate access to this material. Developing national guidelines for destructive sampling should be one response to this issue.

Disseminating the resource. Accessing the grey literature is a perennial problem for archaeology, and is particularly difficult for specialist areas such as archaeozoology. Facilitating access to published faunal reports and grey literature through development of a publication repository for Scotland, similar to that provided by the ADS, is thus a priority for future development in this area. Large-scale regional comparisons of faunal data (and other environmental) data are a powerful tool for exploration of diverse research questions (e.g. Connelly et al. 2011). Such analyses are, however, beset by problems of data comparability and compatibility. Incorporation of Scottish archaeofaunas in initiatives such as the tDAR/TAG (http://archaeologydataservice.ac.uk/TAG/int ro.jsf ) collaboration between the Archaeology Data Service and the University of Arizona which seek to overcome these issues through data management is a further priority.

\section{Practitioners}

Archaeozoology in Scotland has had a recent upsurge in staff and facilities, mainly within the University sector which undoubtedly will 
help promote the various research priorities identified by the ScARF panels and further the profile of the subject, both nationally and internationally. A lack in current provision, however, is within government bodies, most notably Historic Scotland. This makes it difficult to develop national recommendations for, among other issues, sampling, recovery or archiving or for public dissemination and outreach of archaeozoology and other aspects of environmental archaeology (as is undertaken in England by the English Heritage Scientific Advisors and/or the EH zooarchaeological team at Fort Cumberland).

\subsection{Archaeoentomology in Scotland: Background and Potential}

Archaeoentomology is the area of Quaternary Entomology which deals with insects from archaeological contexts. These range from reconstructions of natural and anthropogenic contexts to reconstructions of climate. Application of the technique depends on anaerobic preservation which is optimal in permafrost, very wet and very dry environments (Buckland et al. 2004a). Occasionally, insect remains can also be preserved by mineralisation and charring. Insects are the most abundant animals and their study involves different categories. Beetles (Coleoptera), flies (Diptera) including Chironomidae, and other groups as for example Hemiptera (bugs), Orthoptera (grasshoppers), Siphonaptera (fleas) and Anoplura (lice) are all frequently found in archaeological deposits. As the number of species is immense, study is dependant on the state of taxonomy for each group. For some groups larval and pupal stages have yet to be described and work has therefore concentrated upon the adult stage, particularly of beetles.

Insects from archaeological sites are recovered from soil samples retrieved from suitable contexts during the excavation. In Northern Europe, samples of particular interest are from areas in the excavation with organic preservation, in particular floors, middens, storerooms, drains and there is little point in a random sampling technique. The ideal sample size is 5 litres, however smaller or larger samples can be examined depending on context and availability. Columns of samples, taken in $100 \mathrm{~mm}$ slices with due regard to stratigraphic boundaries, from peaty or other organic deposits nearby the site can provide an understanding of surrounding environments. For samples taken from waterlogged deposits the technique used for concentrating insect remains is paraffin flotation (Coope 1986). The float is then examined under a stereomicroscope, sorted for entomological material and then examined using a comparative collection. In the case of Chironomidae, their high frequency in lacustrine sediments dictates much smaller and closer interval sampling and significant faunas may be recovered from $1 \mathrm{cc}$ of sediment (cf. Brooks 2006).

The Coleoptera, beetles, may be very sensitive indicators of change and many species have particular habitat and temperature requirements. They are used, for example, to provide data on climate change, changes in woodland frequency or its character, changes in the nature of a settlement, human activity and trade, health, hygiene, death and decay (Buckland et al. 2004b). Diptera, true flies, in particular their pupae and puparia are usually closely related to the contexts in which they have bred, and provide immediate information on these environments, often with an emphasis on the forensic aspect of the research where appropriate (Panagiotakopulu 2004). Chironomidae, non biting midges and Simuliidae, the blackflies, are indicative of water quality, and their sensitivity to change makes them excellent indicators of both degree of eutrophication and climate change (Brooks 2006). the caddis flies, Trichoptera, are also found in lake and river sediments (Greenwood et al. 2006) and Acarina, mites, may be useful indicators of a variety of man-made habitats, particularly dung (Schelvis 1997). The ectoparasites (e.g. Anoplura (lice), Cimicidae (bed bugs), Siphonaptera (fleas) and keds (Diptera, Hippoboscidae), may be host specific and 
Science in Scottish Archaeology

frequently spend their entire life cycle on their hosts, so they can be used to indicate presence of humans and animals, hygiene conditions, disease and trade (Panagiotakopulu 2001, Panagiotakopulu 2004b). The BUGScep database includes an extensive entomological bibliography, the fossil archive, including all published Scottish records, and information on habitat and distribution of Coleoptera (Buckland \& Buckland 2006).

Fossil insect studies from Scotland are largely restricted to beetles and a few studies of Diptera. There are a few studies from both the Western and Northern Isles (e.g. Roper 1999; Buckland 1999; Skidmore 1996) but, apart from extensive studies in urban Aberdeen (Kenward \& Hall 2001) and of the crannog at Buiston (Kenward et al. 2000; Skidmore 2000), work from the mainland is scarce. In the broader context, Buckland and Sadler (1997) summarise palaeoentomological studies from Scotland including a discussion of extinctions and introductions of species from the Late glacial onwards, although this is in need of updating. Late glacial faunas from several sites in Dumfrieshire (Bishop \& Coope 1977), Corstophine \& Saughton on the edge of Edinburgh (Coope 1968) and Burnhead in Lanarkshire (Coope 1962) have demonstrated the potential of Coleoptera as climatic indicators, marking the changing climate during the Late glacial. A more detailed picture of Holocene change is presented by chironomid assemblages from sites in the Cairngorms (e.g. Battarbee et al. 2001) and a succession from Whitrig Bog, near Kelso in the Borders (Brooks \& Birks 2000), where the succession has also been collated with the Icelandic tephra sequence (Pyne-O'Donnell et al. 2008).

Studies from Red Moss in northeast Scotland (Clark 2003), where beetle and pollen evidence were brought to bear on the Elm Decline (Clark \& Edwards 2004), and the Outer Hebrides (Dinnin 1996, Buckland \& Dinnin 1993) show the decline of forest faunas as a result of clearance during the Late Holocene. The transition to an agropastoral economy seems apparent in the insect faunal assemblages from Skara Brae (Sadler 1993, Buckland \& Sadler 1997), although this is less clear in the case of Knap of Howar (Kenward 1983), also on Orkney. Warsop (2000) and Skidmore have also examined small faunas from the Neolithic site at Eilean Domhnuill a Spionnaidh on North Uist.

From the foreshore next to the broch at Dun Vulan on South Uist, Roper (1999) recovered extensive dung and fodder fauna as well as a littoral one. The dispersal of storage pests to the outermost reaches of the Empire during the Roman period are indicated by the fauna from faecal material in the ditch at Bearsden on the Antonine Wall (Dickson et al. 1979). The Buiston Crannog deposits of Late to postRoman date (Kenward et al. 2000; Skidmore 2000) represent the most extensive study so far undertaken and point the way towards the potential of insect fossils for site interpretation. Assemblages from several Norse sites on the Northern Isles have been related to studies of Viking colonisation in reference to more extensive studies from the North Atlantic islands (cf. Sadler 1993; Sadler \& Buckland 1998). Later medieval sites include a pit adjacent to a monastery at Pluscarden Priory, near Elgin (Buckland 1995; Skidmore 1995), urban deposits in Aberdeen and Inverness (Smith 2002), burials in Glasgow Cathedral (Buckland 2002), and a garderobe at Carrick Castyle in Argyll (Warsop \& Skidmore 1998) and these serve to demonstrate the range of information from health, hygiene and economy to forensic science. The use of analogues for archaeological record has also been highlighted with entomological work from abandoned Hebridean blackhouses (Smith 1996), and there is a clear need for more taphonomic studies.

The potential for palaeoentomological data from Scotland to detail the rapid climatic transition from the Late glacial to the Holocene (cf. Brooks \& Birks 2000) and the more subtle climate changes during the Holocene is great, and could be used, for example, to examine the putative effects of 
Science in Scottish Archaeology climate change on human settlement during the Bronze Age, when there are extensive shifts in cultivation limits and upland settlement, the reasons for which are disputed (cf. Buckland et al. 1996). Changes in the forest, extent of pastoralism compared with arable, introductions of faunas as a result of trade with Roman and Norse expansion, urbanisation and history of disease are all areas for exploration using insect remains and a combination of the various branches of archaeoentomology. Obtaining a good understanding of development of insect assemblages in relation to expanding patterns of human occupation will not only provide answers to archaeological questions, but will also give a new outlook for future considerations concerning environmental change and conservation.

Quaternary entomology is taught in Scottish (Edinburgh), English (York, Birmingham, Oxford, Royal Holloway) and Irish (Belfast) Universities, and several researchers work based in Museums (e.g. BMNH) and in association with archaeological consultancy Units. Insect collections are housed in Edinburgh GeoSciences, Birmingham Archaeology and Oxford Archaeology. A list of publications in Quaternary Entomology, Qbib is available at

(http://www.bugscep.com/qbib.html) and a database archiving all existing work in archaeoentology is also web based: www.BugsCep.com.

\subsection{Pollen Analysis}

\subsubsection{Introduction to the technique}

Pollen analysis (palynology) is perhaps the most widely adopted, and arguably the most successful, of the biological techniques used in reconstructing past environments (Lowe \& Walker 1997). Put simply, it is a method for investigating former vegetation by means of the pollen grains (and spores) that plants produce (Fægri \& Iversen 1989; Moore et al. 1991). These sub-microfossils are typically found preserved in abundance in a wide variety of wet and acidic sedimentary deposits, such as lake muds and peats. Pollen may also collect within soils and be present in archaeological contexts (e.g. ditches, ponds, structural turves, plaggen soils, etc.). Pollen records within these materials can often be extremely difficult for palynologists to interpret, affected as they may be by problems such as poor pollen preservation or mixing (Dimbleby 1985).

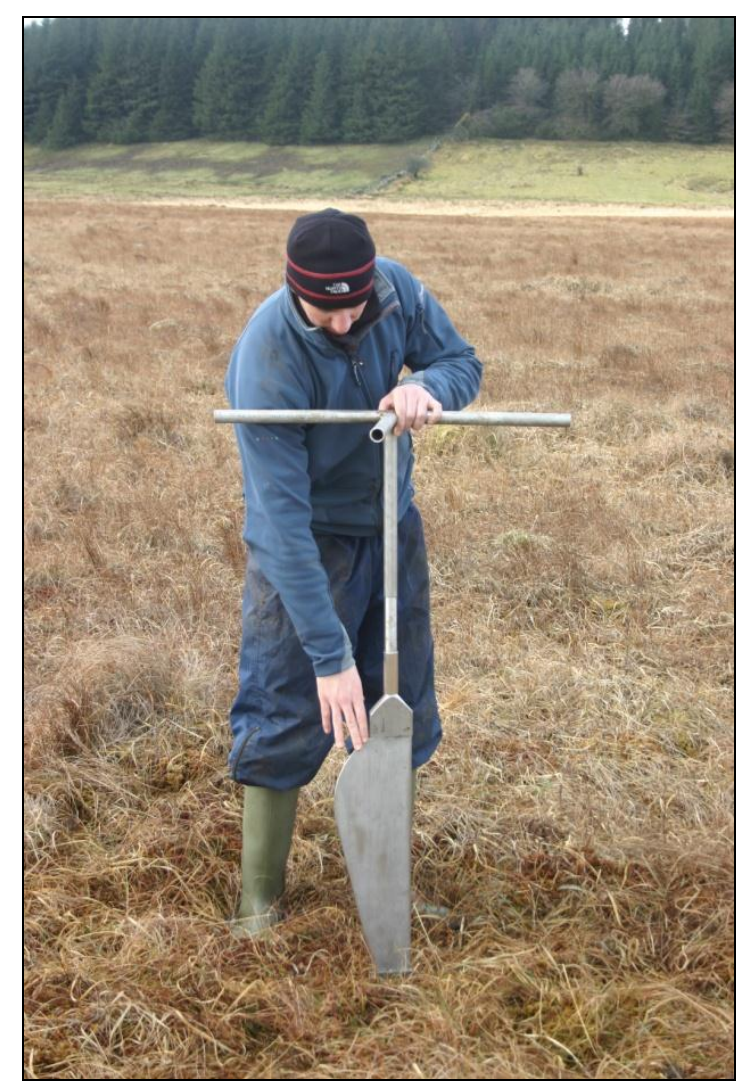

Figure 21: Core samples for pollen analysis taken from natural peatland contexts (e.g. fens and bogs) are typically collected using a handoperated 'Russian' corer such as the one pictured here, (C) J Schofield.

Where polleniferous material is stratified and can be securely dated, it can be used to build up a picture of how individual taxa and plant communities have changed over time. This allows secondary deductions about, for example, climate change and human disturbance to the environment. The technique is flexible, enabling vegetation to be considered at a variety of geographical scales, from regional through to local (Janssen 1973; Jacobson \& Bradshaw 1981). In cases where several pollen profiles have been studied across a landscape (e.g. Glen Affric, 
Science in Scottish Archaeology northern Scotland [Davies \& Tipping 2004], and the Bowmont valley, southern Scotland [Tipping 2010]), this can allow spatial reconstructions of the vegetation mosaic, and provide greater confidence in linking cause and effect; anthropogenic impacts on vegetation are often seen as highly variable both spatially and temporally, whereas changes driven by natural factors (e.g. climate) may appear synchronous between sites.

The literature on pollen analysis is vast and extended discussion of this is impossible here. For Scotland alone, Tipping (1994) listed 239 sites providing palynological data for just the mid- to late Holocene, and this corpus of information continues to grow, providing excellent coverage for most areas (the Moray Firth being identified as one exception; Edwards 1999). A number of reviews are available which consider advancements within the technique and the role it has played in studies of vegetation change within Scotland (e.g. Walker 1984; Tipping 1994; Edwards \& Whittington 2003). Consequently, the supporting references included here are necessary somewhat selective and the focus concentrated narrowly upon some of the more recent developments within the field, particularly where these relate to the interplay between people and the environment.

Oldfield (1993, 16) comments that; 'interpreting palaeoecological data is rarely a matter of unambiguous, objective certainty'. Fossil pollen assemblages cannot, as yet, be directly translated into plant abundances, or used to produce maps of vegetation cover except at the broadest (landscape) scales, although research into modelling procedures is advancing in this direction. One central question that still needs to be addressed is defining exactly where the pollen that accumulates in any sediment has come from. Studies of modern analogues can help address this, and research into modern pollenvegetation relationships in the Outer Hebrides (Brayshay et al. 2000) and northwest Scotland (Bunting 2003) have proved useful in furnishing information on treeless landscapes (e.g. grasslands, moorlands, heathlands and machair). Software for simulating landscape scenarios from pollen data is being developed and refined (e.g. Middleton \& Bunting 2004; Bunting \& Middleton 2005), and this approach could provide answers to questions often posed about the past vegetation mosaic and land use in the areas immediately surrounding prehistoric monuments and settlements. For example, Tipping et al. (2009) have already applied a modelling exercise to reconstruct the possible spatial arrangement of plant communities around a Neolithic 'timber hall' in northeast Scotland.

A number of supplementary techniques are commonly applied together with pollen analysis, yet there is little opportunity to go further than pass comment on these here. These commonly include analyses of site stratigraphies and sediments, microscopic charcoal (e.g. Edwards \& Whittington 2000; Edwards et al. 2000; Tipping and Milburn 2000), and increasingly, consideration of nonpollen palynomorphs (NPPs; e.g. Clark 1999). The latter have always appeared in residues prepared for pollen analysis but, for many years, they received little attention from palynologists. The analysis of one group of NPPs in particular, the coprophilous fungal spores (van Geel et al. 2003; Figure 22) seems to be growing in importance given their proven value as indicators of past grazing intensity (Blackford \& Innes 2006; Raper \& Bush 2009). 


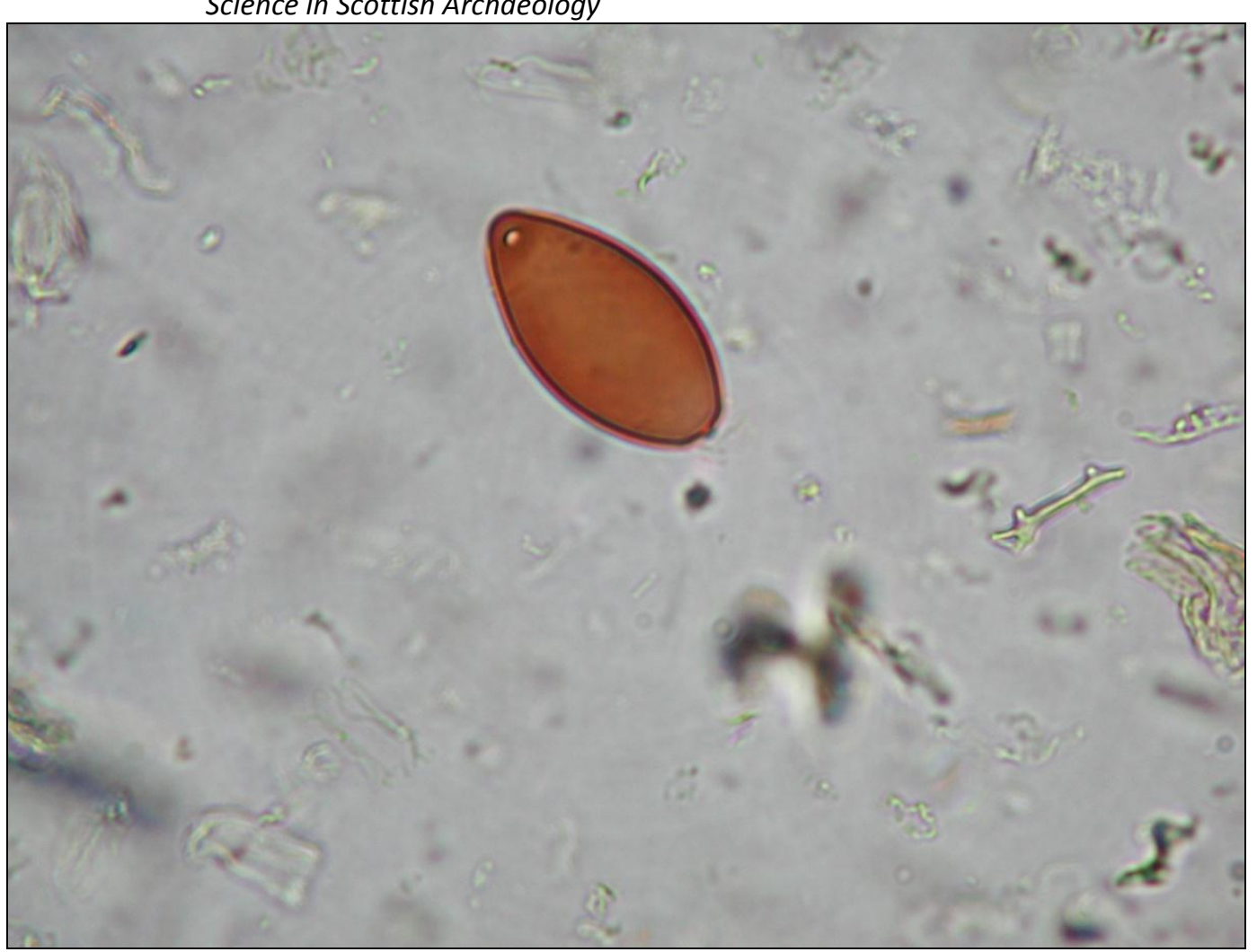

Figure 22: Pollen-based studies which consider the impact of people - and their domestic livestock - on past landscapes may now also include the analysis of coprophilous fungal spores, such as Podospora-type (HdV368, pictured here), (c) J Schofield.

\subsubsection{Pollen analytical facilities and expertise within Scotland}

Many of the universities within Scotland possess the facilities and expertise to undertake pollen-based research. Amongst those institutions which are currently active, palynologists at the Universities of Aberdeen and Stirling have long-standing research interests within Scotland, whilst the focus at the University of Edinburgh is upon vegetation reconstruction in Neotropical environments. A number of archaeological units (including Headland Archaeology and GUARD Archaeology) also offer to undertake pollen analysis on a commercial basis though preparation of samples is outsourced to other laboratories.

\subsubsection{Recommendations for the future}

In the foreseeable future, the main applications of pollen analysis will (and should) be to continue to provide the environmental context from which discussion of the archaeological record may begin. Key themes which may continue to attract the attention of palynologists in Scotland, and which will also be of interest to archaeologists, include:

- the visibility of Mesolithic huntergatherers in areas where archaeological data are limited or absent (cf. the Mesolithic in the Outer Hebrides [e.g. Bohnke 1988; Edwards 1996] and Shetland [e.g. Bennett et al. 1992; Edwards et al. 2009])

- the continuity of upland settlement and restructuring of agriculture in response to climate change during the Late Bronze Age and Early Iron Age (e.g. Davies et al. 2004; Tipping et al. 2008b)

- the precise timing and nature of the adoption of cereals, which may be advanced through optimizing techniques for cereal pollen detection (e.g. Edwards et al. 2005) 
Science in Scottish Archaeology

- disentangling the causes that lie behind the prehistoric decline of pine woodlands in northern Scotland (e.g. Tipping et al. 2008a).

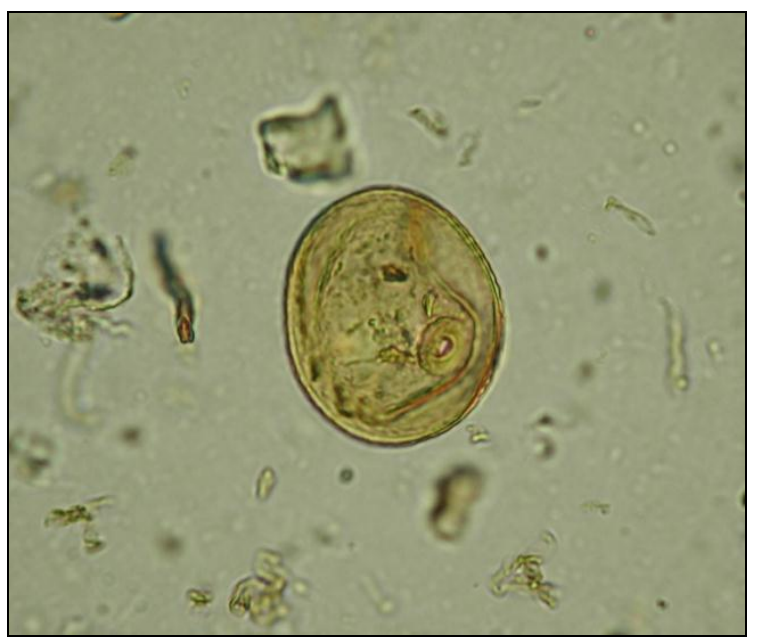

Figure 23: Cereals such as rye, oats, wheat and barley characteristically produce larger pollen grains (typically $>\mathbf{3 7} \mu \mathrm{m}$ ) than other grasses. This makes them suitable for assessment using optimising techniques that involve the rapid scanning of pollen residues at low magnification (x100), ㄷ J Schofield.

A series of other general challenges might also be usefully addressed. These include:

- Continual improvements to pollen taxonomy, with consistent application of nomenclature between workers (cf. Bennett et al. 1994).

- Advancing the understanding of the relationships between pollen assemblages and plant communities through modern analogue studies; this may enable, for example, tighter definition of the scale of woodland clearance events and land use activities in prehistory.

- Improved mapping of plant communities in time and space from pollen data.

- Clearly determining how to distinguish woodland management techniques (e.g. coppicing, pollarding, etc.; cf. Göransson 1987), and how to define key land use activities (e.g. summer transhumance, woodland pastoralism, etc.), using pollen analytical data.

- Defining reliable measures of plant diversity from pollen data.

\subsection{Landscape-scale Geomorphology and Sedimentology}

\section{Introduction to the techniques}

People change in many direct and indirect ways the landscapes they live in (e.g. Goudie 2006). Landscapes also constrain what people can do. Archaeologists need to know about and record evidence for the contemporary landscape context of a site and geomorphological and sedimentological evidence for landscape-shaping processes contemporary with and after occupation.

Many approaches are not the preserve only of the specialist. Data on landscape-scale geomorphology should be insisted upon by those overseeing the design of projects and collected as a matter of course by archaeologists during excavation or survey. All that changes is the recognition that an archaeological site has a larger landscape context. The most appropriate spatial scale for data collection depends on the archaeological work. Developer-funded excavation often constrains what can be done in a small area but desk-top survey can be undertaken and 'natural' contexts recorded in detail. The spatial scale of landscape archaeology most comfortably fits that of the geomorphology and truly synthetic work can emerge. Often the river catchment emerges as the natural scale for people in the landscape. There is value in looking afresh at the techniques developed by Jarman, Bailey and Jarman (1982).

Desktop survey should include reference to British Geological Survey mapping, particularly of 'drift' rather than solid geology ['drift' is an antique description for superficial sediments, of most interest to the archaeologist (www.bgs.ac.uk/geoindex)]. This web-site also 
contains borehole data, sometimes out-dated but often very detailed. Developer-funded work has the great advantage of often providing high-resolution contour surveys from which landforms can be mapped, and civil engineering borehole logs. Landscape context is defined through field mapping, aerial photo interpretation and, increasingly, from remote-sensed data. There are conventions for geomorphological mapping (e.g., Goudie 1981: Rose and Smith 2008). Mapping is made easier through remotesensed satellite imagery (see section 5 . Detecting and Imaging Heritage Assets) draped over high-resolution digital terrain models within a Geographic Information System (GIS) platform (Smith and Pain 2011). Such images define with stunning clarity even small-scale landforms and archaeological features as visually insignificant as broad rig (Smith, Rose \& Booth 2006). The technique is expert-driven but is being explored for archaeological work, notably at the Royal Commission on Ancient and Historic Monuments of Scotland. Interpretation of geomorphological features can also be expert-driven but most can be identified and mapped with only a passing knowledge of physical geography. There should always be a route by which field archaeologists can contact geomorphologists, particularly in the academic community. Landform surfaces need to be surveyed not only in a relative sense (i.e. from a temporary bench mark) but to Ordnance Datum. A simple change in working methods would provide much valuable detail.

Landscape as palimpsest is a good analogy. To define the landscape contemporary with an archaeological site requires the peeling-away of later features, as well as the reconstruction of processes that may have distorted the archaeological record (Schiffer 1987). The approach is sediment-stratigraphic, supported by chronological tools (see section 1 .

Chronology). Sediment stratigraphies are recorded on-site with great care by archaeologists, but frequently not using the terms used by geomorphologists. Jones, Tucker and Hart (1999) is a useful attempt to standardise description. What is also needed is a change in the approach to interpretation. Alluvial and colluvial sediment fills on archaeological sites are all too frequently recorded only as archaeologically 'sterile' and thus uninteresting. They are not. Such features may represent major landscapechanging events. They may have been anthropogenic in origin, and so of equal significance as the material culture is to the archaeologist. They may have shaped the perceptions of people and altered the way in which the landscape was regarded. Such features need to be recorded, dated, evaluated and interpreted with the same care given to demonstrably anthropogenic sediments. Off-site sediment stratigraphies are usually seen as the preserve of the specialist but again they need not be. It is important that they are considered as inseparable from the archaeology. There is little additional training in recording and sampling these. The only general rule is to preserve the sediment stratigraphy: tins or gutters are much better than bags. Most sedimentological analyses, be they particle size through laser diffraction, non-destructive core scanning geochemical techniques are expert-driven and not readily available to the archaeological community, but SUERC may have a role to play here in providing greater access to these tools for the archaeological community.

\section{The Published Literature}

Recent thorough surveys of the literature of landscape change and driving forces pertinent to Scotland are by Ballantyne (2008) and Macklin et al (2010). Geomorphologists have their own research concerns, introduced briefly here, but anthropogenic activity is one of these. Ballantyne (2008) reviews the evidence for postglacial geomorphic processes and rates of landscape change in the Scottish highlands. Many geomorphologists are drawn to upland areas because processes and their effects are more spectacular, and in the uplands, driving forces of change are perhaps easier to define in the absence of large farming populations, although a direct and proportional 
relationship between human population size, activities and geomorphic effects should not be assumed. Positive feedbacks abound in which small-scale change can be greatly magnified. This bias to upland areas markedly skews our understanding of regions more densely and continuously populated: a comparable survey to Ballantyne's for lowland regions in Scotland has yet to be written, largely because there are too few data.

Holocene geomorphic processes in both upland and lowland regions are seen as episodic rather than constant, with low frequencies but high magnitudes, and to have been rapid rather than gradual. Again, too few landscape features in Scotland have been dated sufficiently to explore this: a major effort to define the chronology of debris flows (Ballantyne 2004) resulted in only equivocal evidence for episodicity. Episodic change is seen to have been prompted by rapid climate change (e.g. Mayewski et al 2004) or by infrequent intensities of anthropogenic activities. Macklin et al (2010) have argued strongly for a climatic driver (increased precipitation) to explain accelerated fluvial activity in the Holocene, based on perceived synchroneity across Britain of events such as floodplain construction or incision/erosion. However, in too few river catchments has the timing and scale of anthropogenic activities been reconstructed. These two drivers are not mutually exclusive, of course. Attention has also focused in recent years on the connectivity in sediment supply between landscape features. They are less clearly connected than might be assumed. This probably means that describing change in one landscape element, such as in the example above of rivers, says far less about change in other elements in the catchment, like slopes above the river. Sediment is stored in parts of the landscape for substantial periods in a rather jerky 'conveyor belt'. These current research concerns form an important context to analyses relevant to archaeologists.

Archaeological site locations and land uses are very often related to the underlying geology or to highly dynamic geomorphic processes. The association of early Neolithic timber halls with well-drained glaciofluvial terraces is clear (Murray, Murray and Fraser 2009). The association in the highlands between settlement and alluvial fans is also clear (e.g. Barclay 1995) though interpretation is not: do fans provide the best soil or do they provide locations which will not be eroded? Habitation in caves requires knowledge of past sea level change (Bonsall \& Sutherland 1992). Sea level change is also fundamental in understanding sediment supply to areas of machair (Ritchie 1966, 1979; Gilbertson et al 1999) or to explaining the setting of marine crannogs (Sands \& Hale 2001). It should be noted that recent exciting approaches to landscape need to have a deep grounding in the physical as well as the experiental attributes of landscape (Tilley 1994; Barton et al 1995; Richards 1996; Cummings \& Whittle 2003). This need has led in recent years for closer links between archaeologist and geomorphologist in distinguishing natural from human-made features (Bradley 2000; Tilley et al 2000).

Geomorphic processes also distort the archaeological record. Erosion is one obvious effect and impending erosion is a strong justification for rescue excavation. Over ten years Tom Dawson of the SCAPE Trust has developed a methodology and database for coastal archaeology in Scotland that is among the best in the world (http://www.scapetrust.org). Slope erosion will impact on site preservation (Wilkinson et al 2006). Within coastal dune systems the archaeological record becomes exceptionally difficult to understand because wind erosion selectively erodes sand separating archaeological contexts, deflating sediments and conflating the archaeological sequence (Cowie 1996; Ritchie and Whittington 1994).

Archaeological site prospection often requires knowledge of landforms and geomorphological processes (e.g. Brown 1997; Howard \& Macklin 1999; Timberlake 2001; Macklin, Howard and Passmore 2003). Threats from fluvial erosion are clear but work in Scotland has as yet to explore this problem in detail, or use data in resource management despite the lead on the English side of the 
Science in Scottish Archaeology

border (Howard et al. 2008; Passmore and Macklin 1997; Passmore and Waddington 2009, 2011). Tipping et al. (2008) tried to predict the likelihood of subsurface engineering work impacting on such concealed sites along the River Kelvin from understanding the age of floodplain sediment: here the threat was only to Mesolithic or even Upper Palaeolithic deposits, if they existed, because the present floodplain had been constructed before the Neolithic period.

Sediment in river terraces can be a product of human activity through soil erosion from forest clearance and cultivation as soils become wetter, driven by weaker evapotranspiration. In extreme cases the entire river terrace can be seen as anthropogenic in origin (Tipping 1992), which creates a dilemma for archaeological resource managers. An understanding of the chronology of river terrace formation can thus greatly enhance archaeological interpretation. Environmental stress to communities is often mediated through accelerated geomorphic processes (e.g. Dawson et al. 1990; Carter 1998; Foulds \& Macklin 2006).

Lakes act as stores of sediment from the catchment up-valley. They are sources for innumerable palaeoecological techniques, discussed elsewhere in this section. They can preserve records of eroding soil that are more complete than in floodplains and river terraces because they are less likely to be eroded. Geochemical techniques (Engstrom and Wright 1984; Entwistle et al 1995; Croudace et al 2006; Vogel et al 2008) can define sediment sources if catchment geology is varied. Geomagnetic signals in lake sediment can define whether topsoil was eroded, affecting large areas of farmed land, or subsoil and parent materials from deeply incised gullies (Oldfield et al 2003). Other evidence for soil erosion comes from the distortion of ${ }^{14} \mathrm{C}$ assays as old organic matter is washed in (Edwards and Whittington 2001), sometimes to curtail research programmes as at Buiston in Ayrshire (Tipping et al in Crone 2000, 46). Sometimes apparent anthropogenic impacts on lakes have other causes (Wells, Hodgkinson and Huckerby 2000; Coles 2001).

\section{Existing Research Capacity}

All Scottish universities currently support activities related to geomorphology, though archaeologists should be aware of a broad differentiation in the discipline between contemporary, process-driven approaches and those concerned with environmental change. The SAGES initiative (Scottish Alliance for Geosciences and Society) has pooled the expertise in geoscience and environmental science from across Scotland's research base, creating a multi-disciplinary alliance between the Universities of Aberdeen, Abertay, Dundee, Edinburgh, Glasgow, St Andrews, Stirling, SAMS UHI, SUERC, and the West of Scotland.

http://www.sages.ac.uk/themes/landscape/ is the best way in to the current academic resource and interests (see also http://www.sages.ac.uk/sagesfacilities/).

Archaeology and past societies have not, however, driven the output of this collaboration.

Geomorphologists are absent in commercial excavation units in Scotland. Often the pedologist, if one is employed, assumes responsibility, but the two disciplines require very different skills and knowledge.

\section{Emerging Opportunities}

The SAGES initiative demonstrates that Scotland contains an internationally significant research community into geomorphic processes and change. Future climate change has provided the impetus for the SAGES initiative but the focus needs to move to understanding the complex interactions over time between people and environment. Scotland is better placed in this regard than anywhere else in north west Europe because of its location at the eastern edge of the Atlantic Ocean where climatic changes were probably greatest. It is imperative, as indicated at the outset of this Panel Report, that modern day researchers understand the vulnerability and resilience of past communities, and how coping strategies 
emerged and shifted. Many of the stresses faced by these communities will have been mediated through the physical landscape. Their solutions to crises are critical for a modern undetrstanding. This must be the most significant opportunity to establish new and deeper collaborations.

Archaeological resource managers have yet to work with geomorphologists in understanding the preservation of the historic environment, although the value of this has been demonstrated by recent work in England. This new work was funded almost in its entirety by the Aggregates Levy Sustainability Fund Grant Scheme 2008-2011. This financial source was not used for this work in Scotland and this opportunity was missed. It is to be hoped that others emerge in the near-future.

It cannot be expected in the current economic climate that commercial excavation units will employ geomorphologists, but accessing specialist workers in Scottish universities can be made much easier by a register of workers and their interests: that for the SAGES initiative is far from complete. Almost all specialists will offer advice and guidance by email, telephone or a site visit. Very often what the archaeologist uncovers is of direct value to the specialist. Training in non-expert techniques should be facilitated. Short courses for field archaeologists should be developed, with recognition of new skills acknowledged by organisations such as the IFA. Masters courses need to be developed.

Landscape archaeology has to be collaborative. There is no value in an archaeological site distribution when landscape change has not been factored in. A change in legislation to allow geomorphological work to be developerfunded on archaeological sites would lead immediately to new data. There is almost no data for lowland regions of Scotland, where developer-led archaeology is centred. Geomorphologists have focused on particular parts of the landscape, such as hills and mountains, and river systems because their sediments and landforms are at least relatively easy to analyse and date, but work on slopes and aspects like soil erosion and colluviation which are probably more central to archaeological interpretations have been neglected (e.g. Brown 2009). Work on this is much more advanced on the continent (Lang 2003; Hoffmann, Lang and Dikau 2008; Dreibrodt et al 2009). Because landscapes are less well connected than previously thought there is a need to establish independent chronologies of change for different landscape features.

\subsection{Palaeoclimatology}

\section{North Atlantic climate - key processes}

The atmospheric processes responsible for the existence of the North Atlantic climate place northern Europe within the North Atlantic storm track. During winter, this results in the passage of numerous frontal cyclones, the occurrence of high winds and associated periods of higher than average rainfall, usually associated with a positive North Atlantic Oscillation (NAO) Index. Regional patterns of air temperature change are also responsive to short-term changes in the NAO, itself based on monthly time series of air pressure differences between Iceland and the Azores. Over longer time periods, changes in the NAO are affected by fluctuations in the extent of sea ice across the Greenland Sea and northern North Atlantic. Similarly, climate changes during the Holocene appear to have been profoundly influenced by changes in oceanic thermohaline circulation that have alternately brought warmer salty water to higher latitudes and colder freshwater to lower latitudes. Greenland ice core research has shown that during the Holocene, there have been significant changes in both atmospheric and oceanic circulation across the North Atlantic region. These have been characterised by marked changes in regional storminess, rainfall, atmospheric and ocean temperature as well as in ocean circulation. Although past variation in air temperature has attracted most attention across the archaeological community, other changes in weather and climate may have had considerable significance to archaeology. In 
Science in Scottish Archaeology particular, ice core chemistry time series (e.g. sea-salt sodium (storminess) non sea-salt potassium (dust transport) as well as stable isotope data (e.g. deuterium excess (sea surface temperature)) have scarcely been used as contextual backgrounds in archaeological research.

The ice core data also demonstrates that past patterns of climate change have not been synchronous across the North Atlantic region. For example, the existence of a climate 'seesaw' between western Greenland and northern Europe has been known for over 200 years. The existence of this 'seesaw' is of fundamental importance to archaeology for two key reasons. First, it demonstrates that reconstructed changes in climate for Scotland for different time intervals during the Holocene need not be matched by similar changes elsewhere across northern Europe. Second, the oxygen isotope record of inferred palaeotemperatures derived from Greenland ice cores cannot be regarded as a template for past changes in temperature across northern Europe.

The patterns of climate change described above are particularly significant for the transition between Palaeolithic and Mesolithic. Thus the close of the last ice age across northern Europe was characterised by high-magnitude perturbations in climate the most significant of which was the Younger Dryas. This period of ca. 1,100 yr of extreme cold climate was accompanied by significant southward displacement across the North
Atlantic of both the polar atmospheric and oceanic fronts, as well as the local development of ice caps and valley glaciers and the development of permafrost.

\subsubsection{Dendroclimatology in Scotland}

Dendrochronology is the scientific method of dating tree-rings by matching patterns of wide and thin rings between trees of the same species from the same region (Figure 24). There is a long history of using tree-ring dating in archaeology (Baillie 1982). The fact that trees of the same species show the same general pattern of wide and thin rings through a region and that this common variability can be used for dating implies a regional scale forcing upon growth. This regional forcing can only be climate related as all other influences on growth - whether ecological or management related - are often site specific. Therefore, by understanding how climate controls growth, it is possible to reconstruct past climate from measurements of various parameters (e.g. ring-width, density and stable isotopes) from tree-ring samples (Fritts 1976). Through the dating of preserved material from historical structures (e.g. beams) and sub-fossil material (e.g. preserved in lake sediments), living chronologies, and therefore climate reconstructions, can be extended back in time (Figure 24). 


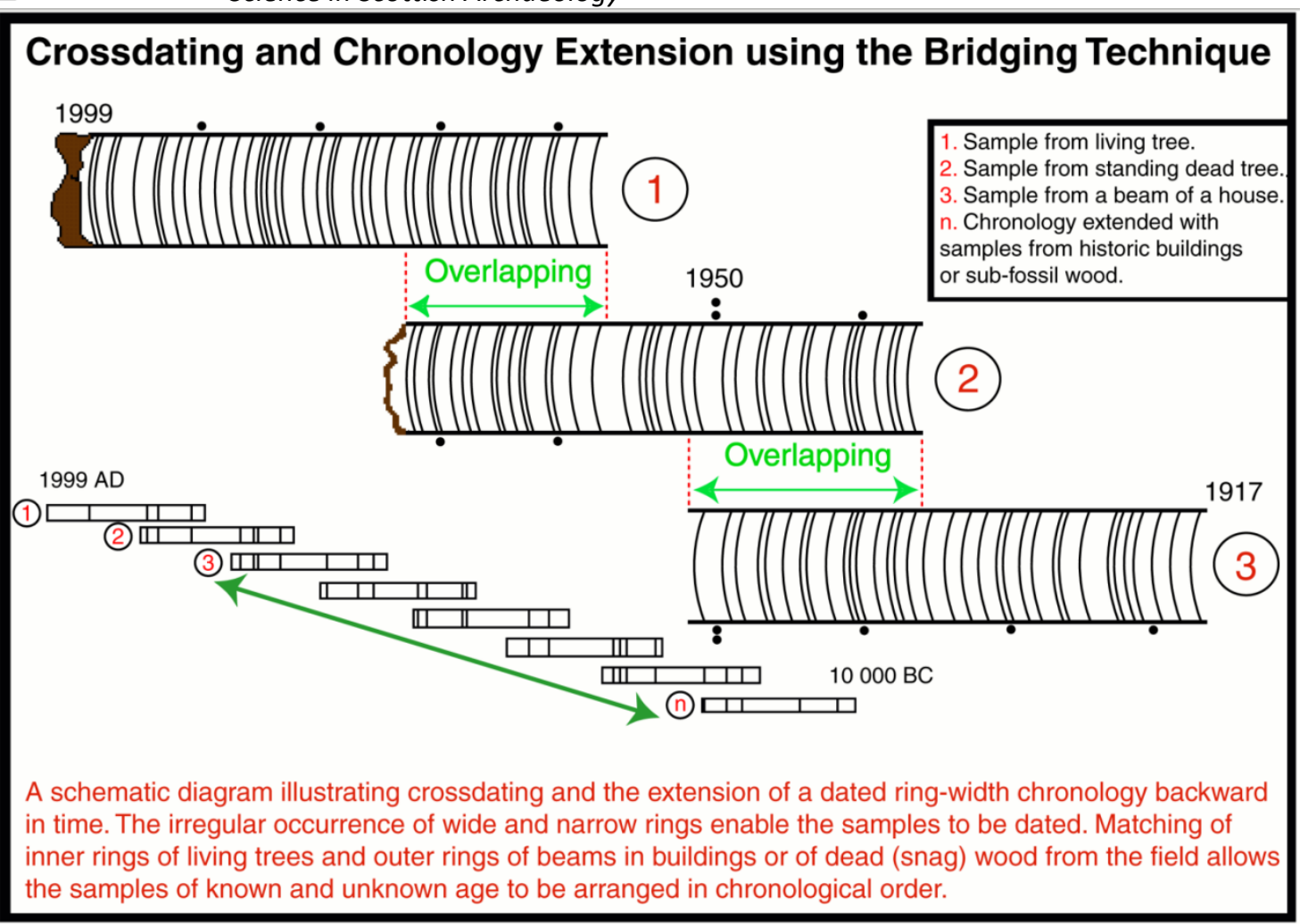

Figure 24: Schematic representation of crossdating in dendrochronology. @R Wilson

In Scotland, Hughes et al. (1984) showed that a highly robust reconstruction of Edinburgh mean summer temperatures could be derived using ring-width and maximum latewood density data obtained from several pine sites throughout the Scottish Highlands. However, the Hughes et al. (1984) reconstruction only went back to AD 1721 and they concluded that:

\section{"Further sampling of ancient living trees should allow the extension of the Edinburgh record back into the seventeenth century, the most severe phase of the Little Ice Age, and result in a valuable reconstruction. A proxy record for more distant times may be obtained using the large quantities of sub-fossil pine found in the British uplands."}

Despite this early study, further sampling for dendroclimatological purposes, has however not been made until recently. One of the current research foci of the Tree-Ring
Laboratory at the University of St Andrews is to develop tree-ring chronologies for all seminatural pine woodlands in the Scottish Highlands. The Scottish Pine Project ${ }^{16}$ not only aims to update and improve the Hughes et al (1984) reconstruction, but to substantially push these quantified estimates of temperature much further back in time. Figure 25 presents preliminary analyses showing the potential for gleaning summer temperature information for the last 250 years using tree-ring data from the Cairngorm region. As with the Hughes et al. (1984) study, the good fit with the instrumental data is clear. However, the challenge for the future is to extend such reconstructions back prior to the period covered by the living trees. 


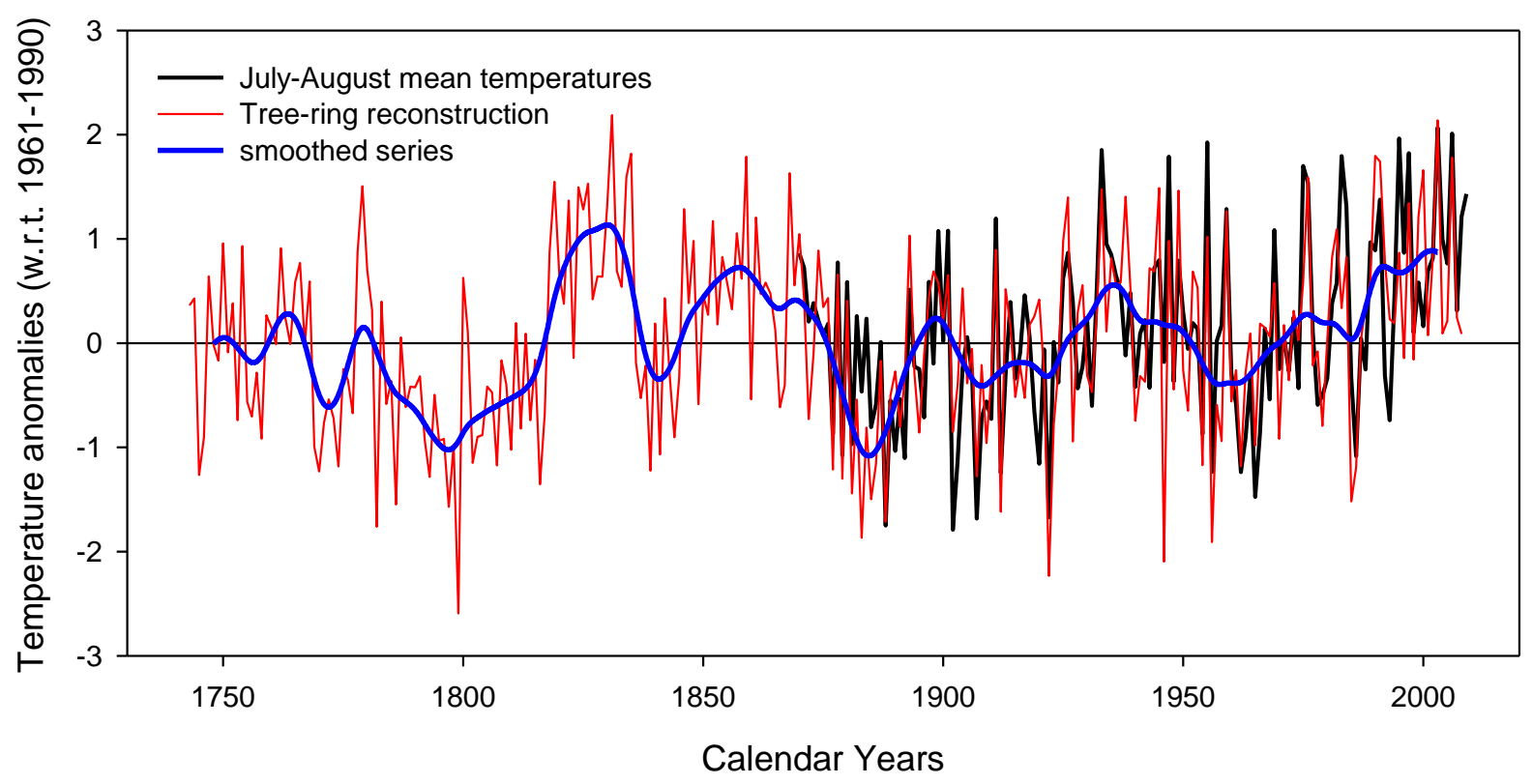

Figure 25: A preliminary mean July-August temperature reconstruction for the Cairngorms CR Wilson.

Finding appropriate preserved pine material in historical buildings is a challenge (Crone and Mills 2002) as most of the construction material used over the last $\sim 500$ years has been imported from the continent. The key to extending Scottish living pine chronologies back in time, therefore, lies in finding sources of complete stems with long tree-ring sequences. Woody macro-fossil material preserved in lake sediments provides such a source. The mountain lochs in regions which have been continuously forested for the last \% 8000 years, such as the north-west Cairngorms and Glen Affric, are ideal target regions. ${ }^{14} \mathrm{C}$ dates of pine macro-fossil material from lochs in the Rothiemurchus Estate have identified preserved pine material from the last $\sim 8000$ years with an abundant amount of material from the last 1000 years. These early results indicate that a millennial length pine chronology from the north-west Cairngorm region is a feasible and realistic objective in the near future (Wilson et al. submitted).
St Andrew's University has a tree-ring laboratory ${ }^{17}$ including two microscope based measuring systems as well as a scanner system and more advanced lab facilities for measuring stable isotopes and trace elements. There is also an X-ray densitometer system at Glasgow Chemistry Department. Active researchers in the field include $\mathrm{Dr}$ Rob Wilson (St Andrews University), Dr. Mike Jarvis (Glasgow University), Dr Coralie Mills ${ }^{18}$ (St Andrew's University; specialising in cultural wooded landscapes), Dr Anne Crone ${ }^{19}$ (AOC Archaeology Group; specialising in earlier periods and wetland archaeology), Colin Edwards $^{20}$ (Forestry Commission; interest in the effects of climate change on woodlands),

\footnotetext{
${ }^{17}$ http://www.st-andrews.ac.uk/ rjsw/TRL/

18 http://dendrochronicle.co.uk/

19 http://www.aocarchaeology.com/home.htm

20 http://www.forestresearch.gov.uk/fr/INFD64FHV2
} 
Science in Scottish Archaeology and $\operatorname{Dr}$ Neil Loader ${ }^{21}$ (University of Swansea; Isotope dendro-chemist with a recent $\mathrm{PhD}$ student completing a doctoral thesis on an isotope based tree-ring reconstruction using material from Glen Loyne).

This is an exciting time for Scottish dendroclimatology as it will be soon possible to extend current temperature reconstructions back at least 1000 years with a long term aim for going back 8000 years. Such climate proxy records will prove invaluable for identifying periods of warm/cool climate and due to their exact dating should prove useful for comparison to the archaeological record. It should also be emphasised that such long chronologies will also facilitate the dating of cultural artefacts and historical structures that are constructed from pine.

\subsubsection{Speleothems}

Speleothems are mineral deposits that form inside caves from dripping, flowing or standing water. Such caves are normaly hosted within carbonate rocks such as limestone or dolomite, that are karstified, i.e. partly dissolved with a range of scales of cavity. The familiar pendant stalactites and upstanding stalagmites form from water that drips from the cave ceiling, derived from pores or fractures in the overlying bedrock, which is normally composed of carbonates such as limestone or dolomite. Flowstones form from intermittent, larger flows of water on the floors of cave and are particularly likely to be intermittently associated with archaeological remains which they may underlie or encrust. The archaeological material can be introduced dry through overlying steep fissures or shafts, or be transported to the site by water flows, or

21

http://www.swan.ac.uk/staff/academic/Environm entSociety/Geography/loadern/ humans or animals may have introduced the material directly themselves.

Speleothems provide two particular points of interest for archaeologists (Fairchild et al. 2006). Firstly they can often be precisely and accurately dated, normally using uraniumseries isotopes and within the range of a few tens to a few hundred thousand years. Hence the age of archaeological remains can be constrained. Secondly measurements of growth rate, or one of several parameters of their chemical composition, can be proxies for past environments or climates at the time of deposition.

\section{Applications and recent publications}

There is a rapidly growing literature on linking speleothem and archaeological studies, ranging from pre-Quaternary deposits in South Africa right up to the present day (records of continued growth and recent or current human pollution can be obtained from speleothems). Representative examples of applications where speleothems are integral to the archaeological work are BarMatthews et al. (2010), Lundberg \& McFarlane (2007), Marean et al. (2007) and Vacca \& Delfino (2004), and an overview of relevant aspects of cave environments is to be found in Lewin \& Woodward (2009).

The most useful Scottish caves for speleothem study have been in the Assynt district of Sutherland, although the most useful samples climatologically (Proctor et al. 2000, 2002; Trouet et al. 2009) are in different caves from those of most archaeological interest, although there are examples where they coincide (Hebdon et al. 1997).

\section{The existing research capacity in Scotland and in the UK}

There are no established speleothem groups in Scottish Universities, but there is plenty of appropriate infrastructure in Scottish Universities should an appropriate person be appointed there in due course. In the UK as a whole there are groups at the Universities of Birmingham, Bristol, Durham, London (Birkbeck College and Royal Holloway), 
Science in Scottish Archaeology

Oxford, and UEA with some interest and expertise at several others.

\section{A forward look}

Speleothems have advanced rapidly in the last 10 years to become one of the pre-eminent avenues of investigation of past environments and climates and a new research-level text (Fairchild \& Baker, 2012) marks this coming of age. The techniques of study have also advanced considerably in terms of sensitivity and limited destructivity. Whenever speleothem material occurs at archaeological sites, it is likely to provide useful information. Recent excavations on Skye have involved speleothem researchers; however the initial contact was by accident, suggesting that a wider awareness of the possibilities of speleothems would be useful in the archaeological community. In this respect, the Upland Caves Network (http://www.uplandcavesnetwork.org/ ) has provided a useful forum for interchange of ideas in the last three years. The work of the British Cave Research Association (http://bcra.org.uk/ ) and its linked caving clubs such as the Grampian Speleological Group

(http://www.sat.dundee.ac.uk/ arb/gsg/) are vital for the ongoing research.

\subsubsection{Testate amoebae and chironomids}

\section{Techniques}

Sedimentary deposits are excellent archives of environmental change, and can frequently be used to reconstruct past climate. Arguably, the best techniques from raised (ombrotrophic) peat bogs and lake sediments are testate amoebae and chironomid analyses respectively. Testate amoebae (Protozoa: Rhizopoda) are unicellular animals with a discrete shell enclosing the cytoplasm. These shells, or tests, are resistant to decay within peat and hence can be used as indicators of past hydrological change in raised bogs, specifically through the estimation of past water-table depth. Testate amoebae are abundant in wetlands, and have been used to reconstruct quantitatively the past bog water table depth through the transfer function approach (e.g. Woodland et al. 1998; Charman et al. 2007). Chironomids (Insecta: Diptera) are non-biting midges, and typically the dominant invertebrate within lake sediments after oligochaetes. The larvae possess a chitinous head capsule, which is replaced 4 times during the larval cycle through ecdysis. The head capsules of the $3^{\text {rd }}$ and $4^{\text {th }}$ larval instars are typically robust, and survive the processes of fossilization. They can be picked from sediment core samples and identified to genus level or sometimes higher taxonomic resolution (species group or species). Chironomids respond to a number of environmental drivers, but most datasets collected over large environmental gradients show summer temperature to be the key driver affecting distribution. This has allowed a number of regional transfer functions to be developed for reconstructing past air temperatures quantitatively (e.g. Brooks and Birks, 2001; Larocque et al. 2001; Langdon et al. 2008).

\section{Previous use in Scotland}

There are many raised peat bogs in Scotland and a reasonable amount of research has been undertaken on them for reconstructing past climate change using a range of proxies, including testate amoebae. Langdon and Barber (2005) studied the palaeoclimate records from seven peat bogs across northsouth and east-west geographical and climatological gradients in Scotland. Testate amoebae were analysed from five of the sites as they are typically abundant in all peats except the most decomposed and/or driest. It is usually difficult therefore to find enough fossil testate amoebae to count in blanket peats (e.g. Langdon and Barber, 2001). The sites that Langdon and Barber (2005) studied were also synthesised in a regional comparison of testate amoebae records from Northern Britain (Charman et al. 2006), which also included other Scottish sites such as Tore Hill Moss, Speyside (Blundell and Barber, 2005) and sites from the Scottish Borders (Mauquoy and Barber, 1999; 2002). The palaeoclimate records developed from these sequences have shown a clear Holocene event 
Science in Scottish Archaeology

stratigraphy in terms of changes in bog surface wetness, with broad scale wetter/cooler climates occurring around $4500,4200,3800,3300,2700,2200-2500$, $1800,1400,800-1000,500$ and 150-250 cal. Years BP, but with some regional differences (Langdon and Barber, 2005). Furthermore, over the last 7500 years, a millennial scale cycle in wet/cool climates has been observed from Temple Hill Moss, SE Scotland (Langdon et al. 2003).

There has been relatively less work undertaken on chironomid analysis in Scotland. A Lateglacial sequence was analysed by Brooks and Birks (2000) from Whitrig Bog, Scottish Borders, that showed remarkable coherence between the chironomid inferred temperatures and Greenland ice core records, particularly noting the clear correlations of cool phases during the interstadial. In terms of Holocene records, the only sequence with quantitative summer temperature estimates is from Lochnagar, Grampians (Dalton et al. 2005). Although the authors argue that the major trends affecting the lake during the mid to late Holocene are due to $\mathrm{pH}$ changes, the temperature reconstruction does show similar general trends to a mid to late Holocene (last 6000 years) sequence from Talkin Tarn, in Cumbria (Langdon et al. 2004) suggesting that broad scale temperature patterns across northern Britain may be coherent for the mid to late-Holocene. There is one other notable chironomid record from Scotland; that from Lochan Uaine, Cairngorms (Brooks and Birks 2001) that has also been studied for a range of other palaeoclimate proxies (Battarbee et al. 2001). A climate deterioration around 2700 cal. BP was noted, although a chironomid inferred summer temperature quantitative reconstruction of this sequence has not been published.

\section{Research capacity in Scotland}

There is currently no one conducting research on chironomids in Scottish universities, and the only expert in testate amoebae analysis is Dmitri Mauquoy at the University of Aberdeen. However, the equipment needed for these analyses is not specialised or expensive, and will be present at all universities engaged in palaeoecological research. Testate amoebae analysis requires high power microscopes (the same as pollen) and minimal preparation (mainly washing in water and sieving) as strong chemicals can destroy the tests. Preparations for chironomid analysis are relatively easy as well, involving mild chemicals $(\mathrm{KOH})$ and sometimes a sonic bath to disaggregate the lake sediments, and the analysis itself requires only low and high power microscopes. The research facilities are therefore present in Scotland, and it is only the expertise that is lacking.

\section{Future research potential}

There are some fundamental questions to be answered in the process of generating high quality, quantitative (e.g. summer temperatures), well resolved palaeoclimate records for Scotland. Currently very few exist, as highlighted by the recent review of British Isles palaeoclimatology in the mid to lateHolocene by Charman (2010). Filling this palaeoclimate 'gap' will be essential for understanding the natural and regional palaeoclimate variability on centennial to millennial timescales. More specifically, there are no current regional calibration sets, for chironomids or testate amoebae, in Scotland, and generating these datasets would further aid reconstructions through the understanding of regional variability within the modern and fossil data (cf Holmes et al. 2011).

See also the section on diatoms in the SCARF Palaeolithic and Mesolithic panel report ${ }^{22}$.

$22 \quad$ Also available at
http://www.scottishheritagehub.com/content/525
-environmental-reconstruction




\subsection{People and the environment recommendations}

- The establishment of a national online database and publication/report repository on mammal, fish, and bird bone collections from Scottish archaeological sites, which would highlight areas in Scotland with good preservation conditions for bone, safeguard raw data that may remain unpublished and make it available to future generations of researchers, including scientists responsible for present and future management of fish, bird and animal populations.

- Active promotion of new collaborative research between biologists with expertise in living Scottish species, facilities housing important reference collections, organisations curating important ethnographic and historical archives, and archaeologists and bioarchaeologists working on Scottish remains, through a series of workshops aimed at the development of new project proposals addressing large and important themes such as the biogeography of Scottish faunas (colonisations, introductions, extinctions, etc).

- Provision of environmental archaeology expertise and advice within Historic Scotland, which could develop national recommendations for sampling, recovery, data archiving and management, and public dissemination of the results of environmental archaeology studies.

- The establishment of a network of environmental archaeologists/palaeoecologists and archaeological consultancy firms in Scotland, in order to improve the flow of information about benefits and costs of particular sampling strategies and techniques, and assemblages that are available for study. This could begin with a series of workshops and short courses to facilitate introductions and discussions between archaeological scientists and commercial archaeologists, and should lead to the establishment of a directory of specialists who are willing to be contacted by field practitioners with queries.

- Active promotion, funding, and integration of cutting-edge methods such as the analysis of testate amoebae, chironomids, lipid biomarkers, phytoliths, soil micromorphology, isotopes, tooth abrasion and hypoplasia, and coprophilous fungal spores and other non-pollen palynomorphs in Scottish archaeology in order to enhance the understanding of past environments, stresses and coping strategies, and the vulnerability and resilience of past communities in Scotland. 


\section{Detecting and Imaging Heritage Assets}

\subsection{Introduction}

Prospecting for archaeological sites is a central concern of archaeology, and the development of new techniques for detection, along with the continued application of well-established approaches, has put an understanding of landscape at the heart of archaeological research. Analysis of the results of the various detecting and imaging techniques described in this section have also enabled the visualisation of the past over a variety of scales - from recreating a carved stone slab, to digitally modelling Rosslyn chapel, to helping reconstruct entire landscapes of past human activity.

Detecting and imaging techniques can effectively complement other archaeological or environmental science approaches, including excavation, coring, field-walking and topographic survey, in order to help understand the formation of complex and multi-period landscapes. Recent developments have, for example, enabled the exploration of submerged landscapes, potentially revolutionising current understanding of prehistory. Developments in the speed and resolution of a variety of techniques have improved detection, providing a more reliable knowledge-base that can support detailed analysis and interpretation, and modelling and visualisation of the past. Advances in, for example, the application of laser technology has enabled rapid and accurate survey of artefacts, buildings and landscapes. These techniques are most effective if they (and the results of previous survey and analysis) are built into archaeological research from the beginning. The choice of suitable technique will depend on local conditions, the required resolution of data (dependant on the questions being asked), and cost. Several techniques can be used for both prospection and for interpretation, and the value of their data increases exponentially when part of an integrated archaeological or environmental strategy (including e.g. field-walking, excavation, coring and soil sampling).

Both relatively established techniques and emerging approaches are discussed below, beginning with those that operate at a landscape scale and produce extensive information cost effectively, and progressing to intensive and detailed techniques that necessarily operate at a site or artefact level. Underpinning this structure is the need to apply multi-scaled approaches that recognise cost/benefit and the applicability of techniques to context.

Aerial reconnaissance is the original form of extensive archaeological remote sensing. Beginning with O.G.S. Crawford in the 1920s, reconnaissance in light aircraft has revolutionised the understanding of archaeology, particularly in lowland arable areas where the majority of heritage assets may have been discovered from the air and recorded on obliquely taken photographs. Ongoing reconnaissance continues to record otherwise unknown sites, and there is a growing recognition of the importance of archival imagery collected for other purposes such as map making and infrastructure projects, in fortuitously recording archaeological sites and the broader landscape. The photographic record reveals a range of archaeological and landscape information, though the nature of that information varies according to scale and date of photography, terrain type, land-use, type of site, and climatic and seasonal conditions.

Geophysical survey has traditionally operated at a site level, though with the development of larger data-collecting arrays that can be towed by vehicles this technique is progressively achieving landscape-scale coverage. Geophysical survey encompasses a variety of techniques that can be used in combination through multi-sensor arrays. Gradiometry, measuring differences in the magnetic field (the magnetic gradient), is the most utilised technique for prospection, particularly for negative features (e.g. pits, 
middens, ditches). Magnetic susceptibility is used to measure the magnetic properties of soil - a proxy for human activity - and can therefore be used for locating sites and interpreting their use. Resistance survey is another prospection technique for features such as ditches and walls, measuring differences in the electrical resistivity of the soil (rather than magnetic properties). Ground Penetrating Radar (GPR) provides information on depth and stratigraphy - the data can then be used to enable 3D modelling of a buried site. Other techniques include Electromagnetic (EM) survey, detecting both resistivity and magnetic data and Electrical Resistance Tomography (ERT), providing similar information as GPR though working best in different conditions.

Underwater surface mapping - or bathymetry - can be carried out using a number of techniques, utilising either acoustic or magnetic signals and is particularly effective when combined with coring or grab sampling. Single Beam Echosounders measure acoustic pulses bounced off underwater surfaces to create a bathymetric map. Multibeam echosounders use the same principle though to a much higher resolution. Sidescan sonar enables the reconstruction of the seafloor as a whole by firing acoustic pulses from either side of the sonar. Magnetic Signature Analysis can be used to trace submerged metal, although it has had limited archaeological use as yet. Underwater sub-surface mapping can also be undertaken by technology that utilises acoustic pulses, with techniques for rendering 3D imagery of the results currently being developed. The interface between land and sea can also be explored through tidal geophysics.

Laser scanning has the potential to revolutionise landscape scale archaeological survey, but in Scotland, to date, its availability remains limited and resolution is not always that required to realise its full potential. It works with a laser beam reflected off surfaces and measurement of the time taken for the return signal, supplemented by GPS positioning and inertial navigation in the case of airborne scanners. Highly accurate 3D records can be made of heritage assets, from artefacts through to landscapes. These records can be subsequently modelled and used for a variety of purposes, e.g. the replication of artefacts or virtual access to inaccessible locations. Airborne Laser Scanning (ALS) otherwise known as lidar (light detection and ranging is increasingly being used in archaeology to create highly accurate digital terrain models (DTMs) that can be manipulated to explore the topographical nuances of the land surface and reveal archaeology hidden to visual survey. The data it produces, which can be rendered to remove vegetation cover, can help reveal archaeological information underneath.

Hyper- or Multi-Spectral remote sensing captures information from across the electromagnetic spectrum by recording variations in wavelengths of light invisible to the naked eye. This data can then be processed and analysed to detect and model archaeological information, through for example, identifying changes in crop growth that are difficult to detect visually. At present the sensors do not have adequate radiometric resolution to routinely pick up archaeological sites (i.e. they are too coarse grained) but improvements in sensor resolution has the potential to open up detection of heritage assets across a much broader range of the electro-magnetic spectrum than the narrow visual bandwidth.

Harnessing the opportunities afforded by these techniques requires suitable training and skills together with an understanding of local and regional conditions. The data produced requires skilled training in order to convert it to archaeological purposes, and can be combined with other information to good effect, such as integrating the results of laser scanning with the photographic record. Powerful 3D models can be created to aid understanding of, for example, the architectural phases of a building, or to create a virtual research environment to bring together physically separate resources. These techniques can be used to visualise the currently invisible aspects of the past, 
Science in Scottish Archaeology reconstructing past environments through both invasive and non-invasive techniques.

The variety of techniques and approaches available for detecting and imaging heritage assets are considerable and powerful. Integration with other techniques, often working at different resolutions, and with other forms of archaeological analysis, provides a well-rounded picture of how people lived in the landscape. The archival resource of these techniques, often representing decades of work, represents a considerable research resource and data set. The results of such survey work build up a picture of landscape use and development, which can be developed into landscape characterisation. Survey also provides the parameters for future archaeological work and ground-observation in an iterative process. The results from certain techniques can be combined to provide a comprehensive understanding of the resource, while the results of, for example, laser scanning can provide detailed models of heritage assets that can be subsequently analysed and researched.

Collaboration is essential to ensure that the research resource is as effectively gathered, integrated, interrogated and disseminated as possible. Fruitful collaborations with the field of environmental science, or through processes of resource management, offer considerable potential for value added to research. Detecting and imaging techniques feed into the interpretation, presentation and visualisation of archaeology, and contribute considerably to research as well as management and public appreciation. The application of these techniques also provides a locus for interaction with other disciplines, such as architecture and engineering - the repurposing of marine data from other industries for reconstructing past environments is a good example of crossdisciplinary and collaborative working. Exploring the developing role that the techniques outlined in this section, along with emerging technologies and approaches, will have in archaeology is important to ensure that these considerations are built in to the day-to-day considerations of archaeological research.

\subsection{Aerial reconnaissance and photographs}

Aerial reconnaissance and photography has been established for over 100 years, and its application for archaeology across Europe has demonstrated that it is one of the most effective methods of archaeological reconnaissance and recording. This is especially true in lowland areas where millennia of ploughing have levelled most archaeological sites, rendering them invisible except to the airborne surveyor as differential crop growth. In Scotland this survey record, comprising about 8000 sites concentrated into lowland arable areas, built up since the 1940s, has completely and utterly revolutionised the knowledge-base for these areas. There is currently no other effective method of recording these sites, and many periods and site-types would be almost unknown without this data. Thus most Neolithic cursus monuments and Roman Temporary Camps, for example, are known only because of aerial survey. 


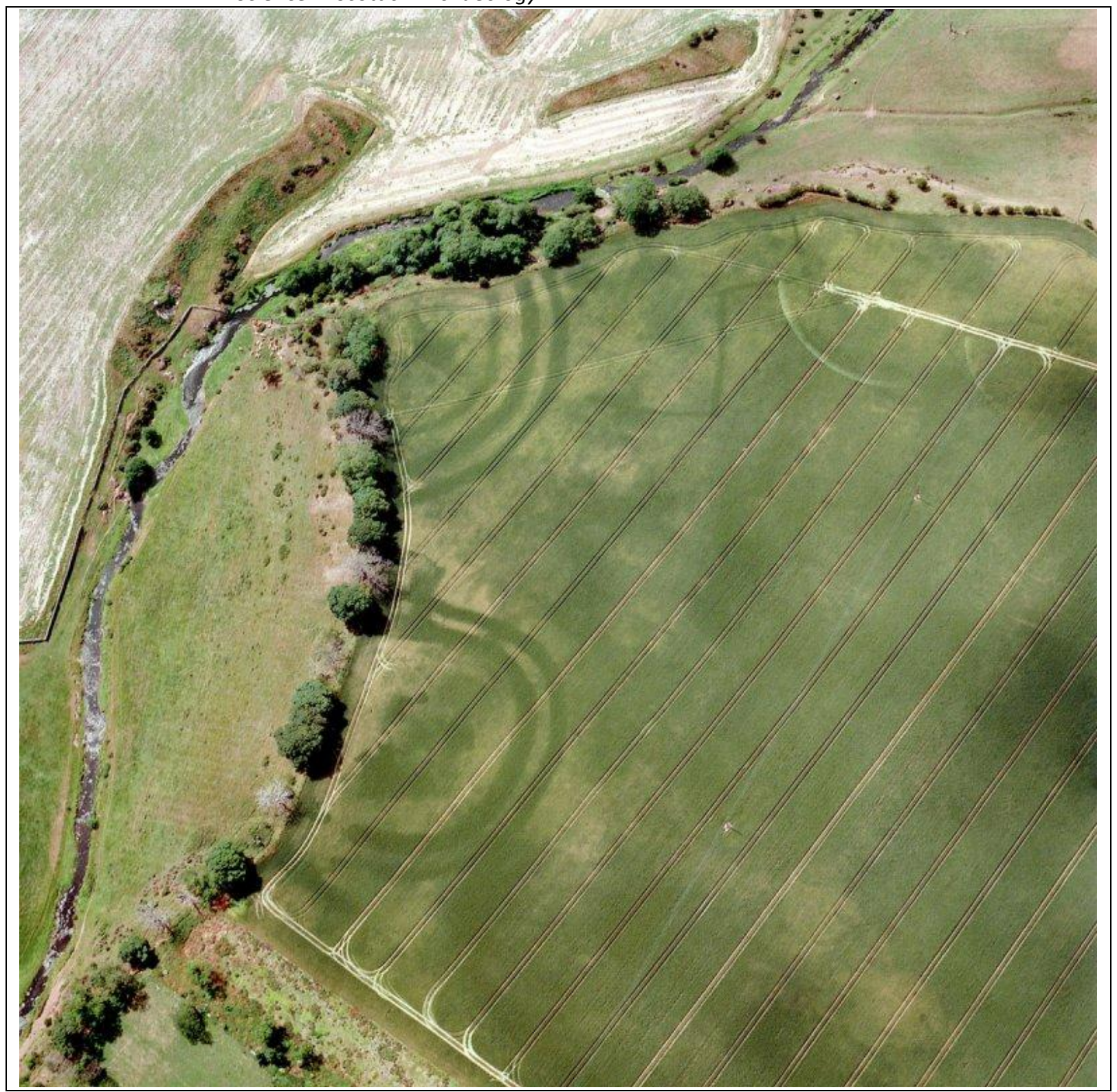

Figure 26: Differential crop growth has revealed a complex of plough-levelled sites at Aytonlaw in Berwickshire. Cropmarking, recorded from the air during aerial reconnaissance has completely revolutionised understandings of lowland areas, identifying sites that there is no other effective means of discovering and recording. Most of the known Iron Age monuments in lowland south-east Scotland, for example, are only known from this type of record. CRCAHMS

The aerial perspective has also shown to be very effective in recording upstanding, earthwork monuments, especially where the combination of low winter sunlight and low vegetation combine to throw even slight surface variations in topography into relief through a combination of highlights and shadow (Figure 27). This can be enhanced through a slight dusting of snow, but often snow-cover disguises as much as it reveals. Appropriately lit and targeted aerial photographs can be incredibly powerful tools for archaeological interpretation. 


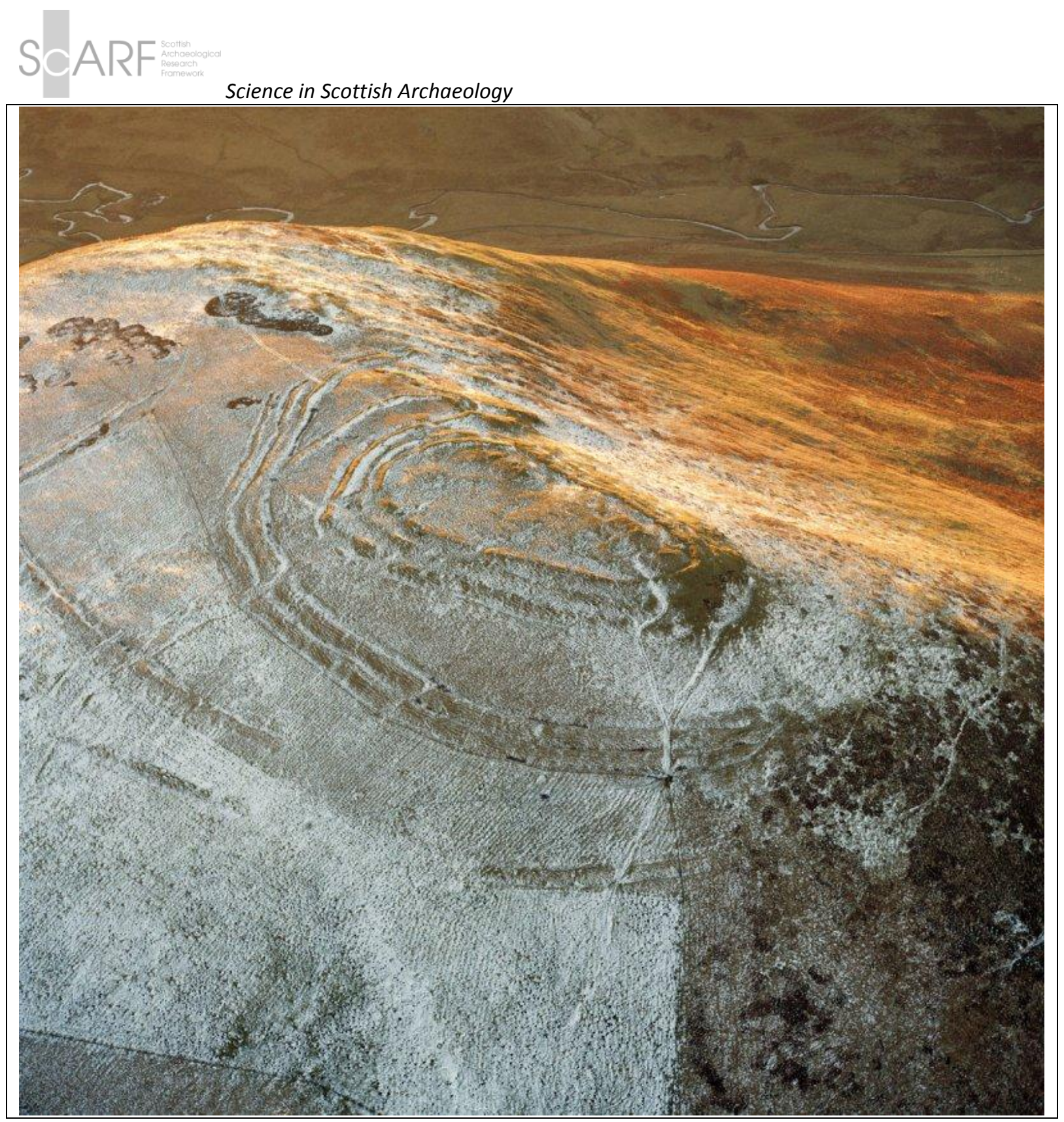

Figure 27: This oblique aerial view centred on the remains of Woden Law Fort in the Cheviots records the fine detail of the earthworks and adjacent cord rig in remarkable detail and provides a powerful interpretative tool. The low winter sun and slight dusting of snow reveal details that would be very timeconsuming to understand on the ground. CRCAHMS

\section{Why aerial survey and photographs?}

The aerial perspective has proved a highly effective tool for detecting and recording heritage assets, providing the only means of recording some sites (e.g. plough-levelled sites revealed as cropmarking), adding value to the records of upstanding sites as sources that permit rapid understanding and in providing the most textured records available to see the broader landscape and traditional sites in context. Aerial reconnaissance is the most effective method of finding sites and creating basic records, both using light aircraft for active prospection, but also in undertaking 'survey' in existing aerial photograph collections. These are very good sources of heritage information, often recorded fortuitously on photographs taken for other purposes, such as military intelligence and to provide map making data. In cases where landuse change has dramatically altered landscapes (e.g. afforestation, urban sprawl, upland pasture improvement) historic aerial photographs may be the only available record. Aerial photographs are a very 
Science in Scottish Archaeology

powerful way of conveying complex information about the layout and contexts of our sites, that have no immediate parallel and give real meaning to a picture being worth a 1000 words. Aerial survey can be a rapid and effective method of monitoring condition and material change in monuments, though, while this approach is routine in England and Wales, and increasingly widely adopted in continental Europe, it is not applied in Scotland.

There are three main types of aerial photographs: over 100,000 oblique, generally site orientated images captured during observer-directed survey largely held by RCAHMS, the majority taken since the mid1970s; about 1.5 million vertical photographs, collected for a variety of non-archaeological purposes (mainly map making) largely since the mid-1940s (also held by RCAHMS); and web-based vertical photographs (often wrongly referred to as satellite images) such as Google Earth, which add a valuable contemporary view, with limited 'historic' elements. All are valuable reservoirs of information on sites and monuments and at a landscape scale, and the collections of historic vertical photographs are a virtually un-tapped resource that archaeologists should use more. All require a basic level of understanding of purpose/application to ensure appropriate usage, including the basic difference between types of photographs and the survey methodology that lies behind them. Observerdirected survey and photography, whereby reconnaissance is undertaken in a small aircraft, with an observer looking for particular targets and only photographing what they are interested in, dominates archaeological recording. It produces vital results, but suffers from the fact that only sites that are noticed by the observer/photographer are recorded and so the resulting dataset suffers from the biases imposed by their own knowledge. So-called 'vertical' photographs are usually collected as a block-coverage exercise across a large area using cameras mounted on the aircraft automatically taking photographs at selected intervals to produce overlapping pictures that can be used for stereo-viewing (e.g. 60\% overlap). These photographs are only truly vertical at the centre of the picture, with increasing distortion towards the edges of the frame. Generally, these photographs are not taken for archaeological purposes because of the greater expense involved with more expensive, purpose converted, aircraft and cameras, but they do not suffer from the observer bias that may be a problem with other types of imagery. They offer potentially greater scope to explore the unfamiliar that may not be in the mind of the airborne surveyor and therefore do not get recorded.

\section{Understanding aerial photographs}

To make best use of this resource it is necessary to have a good understanding of the type of photographs and what they may tell. For example, what is the scale of the photograph: At 1:5,000 a feature $5 \mathrm{~m}$ across will measure $1 \mathrm{~mm}$ across, or about the size of a blunt pencil point. At 1:10,000 the same feature will measure $0.5 \mathrm{~mm}$ across, and at smatter scales (e.g. 1:25,000, 1:100,000) the feature will be vanishingly small. Small pits will not be visible on 1:25,000 scale photographs and if this is the type of archaeology expected then time should not be wasted on such photos. Equally, there is little point in targeting photographs taken during the winter if there is a desire to see cropmarking. This is a process of implementing your survey strategy and increasing the chances of getting good results.

Aerial photographs are raw material for archaeologist: they contain information and this requires interpretation and mapping. These processes are vital to creating reliable archaeological information that can facilitate the understanding and management of heritage assets. Exploration of prehistoric lowland settlement patterns, in East Lothian for example, requires accurate mapping to create robust settlement morphologies that can be analysed systematically. Here, over 40 years of sustained aerial survey, the results of which have now been systematically mapped, underpin the understanding of regional 
Science in Scottish Archaeology settlement patterns and contribute to the creation of settlement frameworks.

Aerial survey, especially observer directed reconnaissance, is a subjective process very much dependent on the perspectives, assumptions and prejudices of the observer (Palmer 2005). Effective use of aerial photographic data requires an understanding of these processes - which are not unique to aerial data. Indeed, all archaeological distribution maps are maps of recovery, more likely to reflect the present than any reality in the past, since known distributions are usually produced by transformations of what existed in the past, rather than directly conveying past patterns. So differential patterns of past and present land use may conspire to either hide or reveal sites, while the knowledge and interests of antiquarians and modern archaeologists may directly impact on the known distributions of sites. Furthermore, interpretation is not a self-evident process; it must be taught and practised so that experience must be developed based on knowledge of external factors such as postdepositional processes and the types of site that are likely to be encountered.

\section{Aerial survey for Scottish archaeology}

Aerial reconnaissance for archaeology in Scotland was initiated by OGS Crawford, who undertook pioneering flights here in the 1930s (Crawford 1930, 1939), principally exploring conjectured lines of Roman campaigns. However, it was not until 1945 that more regular survey was undertaken by $\mathrm{JK}$ St Joseph, under the Cambridge University Committee for Aerial Photography (CUCAP), initially facilitated by the RAF who supplied the aircraft and pilot. St Joseph continued an almost annual survey across most of the British Isles, chasing the harvest northwards, with a personally inspired, but by no-means exclusive emphasis on Roman archaeology. The CUCAP flying in Scotland tailed off under David Wilson in the 1980s after St Joseph retired, but also saw a shift to more vertical coverage taken for commercial contracts (e.g. Forestry Commission). The main research outputs from this period were in Roman archaeology, starting with the publication of Crawford's Rhind lectures (1949) and continuing through a series of St Joseph papers (e.g. 1976).

The real expansion in aerial reconnaissance occurred in 1976 and 1977, two very dry summers that can now been seen as better than average years for cropmark formation. In 1976 RCAHMS commenced its aerial survey programme, following exploratory flights in 1975, and in 1977 lan Shepherd and lan Ralston initiated the Aberdeen Aerial Surveys (AAS). The initial focus of both survey programmes, supported from Central Government (Scottish Development Department), lay in exploring arable areas for plough-levelled monuments visible as differential cropmarking, but they soon expanded to take in upland areas (Cowley 2005). Both surveys have continued on an annual basis, though at the time of writing (2011) the future of AAS is unclear with the retirement of Moira Grieg. The remit of RCAHMS is national though until the early 2000s an emphasis on the south and east is evident, while AAS focused on the north-east, extending along the Moray Plain and overlapping considerably with RCAHMS in Angus. These sustained survey programmes were supplemented by regional fliers, often partly sponsored by SDD and later RCAHMS grants, who flew particular areas of interest. The main period of activity of the 'sponsored fliers' was from the mid 1980s to the mid 1990s, after which progressive difficulties in resourcing (time and funds) and tightening up of regulations for aerial survey by the Civil Aviation Authority saw this contribution to flying wither to virtually nothing. The contraction of regional fliers has been offset to some degree by RCAHMS expanding its remit to become truly national, ensuring that coverage extended to all areas practicable in a single engine aircraft, and occasionally employing helicopters.

These processes have placed many thousands of sites on record, especially in lowland areas, and these are now embedded in management policies (i.e. scheduling) and in academic 
discourse. However, throughout there has been a sustained emphasis on data collection, and relatively little analysis or publication of the results took place until the last 10-15 years (below). Indeed, in the early years many sites were added to the RCAHMS database with generic classifications, such as 'enclosure' or 'cropmark', on the rationale that with more information would come more reliable classifications. Predictably, the sheer mass of cropmark information that rapidly accrued, ensured that any review of the generic classifications would be a daunting task. However, with the appointment of an Aerial Survey Mapping Manger to RCAHMS in 2005 (Kevin Macleod) the systematic mapping and classification of cropmarked sites is now underway. For example, detailed mapping of the Antonine Wall, undertaken as part of its nomination as a World Heritage Site, included the reinterpretation and mapping of the aerial photographic record. Reliable interpretation and accurate mapping was critical to the success of the nomination and the information gathered is actively used in management (Jones and McKeague 2011).

The analysis of the results has still some way to go, although the last 15 years has seen considerable developments. The publication of Roman material, principally by St Joseph, David Wilson and Gordon Maxwell, led the way for many years, supplemented by a few general papers (e.g Maxwell 1978, 1983, 1987), the RCAHMS publication on south-east Perth (RCAHMS 1994) and Lesley Macinnes' PhD (1983). More recently a series of thematic PhD's have been completed drawing principally on aerial information, namely Brophy (cursus monuments - 1999; 2012), Jones (Roman Temporary Camps - 2006) and Millican (Neolithic Pit-defined monuments 2009). In tandem, a series of publications have addressed regional patterns (Cowley and Brophy 2001, Cowley 2008, 2009a), other specific themes (e.g. long cists - Cowley 2009b; maritime landscapes - Cowley and Martin 2011) and reflected on best practice (Cowley 2002, Cowley and Dickson 2007, Jones 2005, Cowley and Gilmour 2005a, 2005b), addressing criticism of survey bias identified elsewhere (Hanson and Macinnes 1991).

\section{Research capacity}

Scotland has an international holding of aerial photographs, numbering many millions and covering large parts of the globe. The Scottish material is also substantial adding up to over 1.5 million images, spanning the period since 1946, and this represents a barely-tapped research resource. The PhD research projects already undertaken (above) demonstrate the potential of these resources. With the imminent release of aerial mapping data through web-mapping services this will be accessible, though access to other parts of the collection and digital browsing facilities are not all they might be.

Experience in interpretation of aerial photographs is vested in a small group of professionals, and the Department of Archaeology, University of Glasgow, offers taught postgraduate courses that include aerial photograph interpretation. Undergraduate and Masters students undertake dissertations on aspects of the aerial record intermittently, but there is certainly extra capacity in this area. The Scotland's Rural Past initiative ${ }^{23}$ has included basic familiarisation with aerial photographs in its training modules. The West Lothian Archaeology Group ${ }^{24}$ is active experimenting with various survey techniques, including aerial photography, in a robust scientific framework.

\section{Emerging opportunities, future research areas, and future needs}

The systematic mapping of the cropmark record and its delivery as a web-mapping service is a great step forward and may

\footnotetext{
${ }_{24}^{23}$ http://www.scotlandsruralpast.org.uk/

http://www.armadale.org.uk/archaeologyintro.ht
}

$\underline{\mathrm{m}}$ 
Science in Scottish Archaeology encourage more routine engagement with this material. There are myriad cropmark record themes for which aerial photographs are the principal source, but amongst the key areas are the later prehistoric landscapes of the Tweed, the Moray Plain (where the uncatalogued Barri Jones archive of aerial photographs is a potentially invaluable resource).

The effective management of plough-levelled archaeology has attracted some research interest (Dunwell and Ralston 2008a), but this too remains a rich seam, especially in the light of the adoption of the European Landscape Convention.

\section{Airborne Multi-Spectral Prospection}

Airborne Multi-spectral prospection can detect buried archaeological remains that are not visible, or readily apparent, in conventional aerial photography. It is a passive technique and records how the sun's energy is either absorbed, transmitted or reflected by the earth's surface depending on the physical and chemical properties of that surface.

Multispectral sensors record the reflected energy from a variety of wavelengths from visible light through to infrared. The infrared portion of the spectrum is extremely sensitive to subtle variations in surface vegetation, topsoil and topography caused by buried archaeological remains which are always detectable using to visible light.

Thermal images taken at pre-dawn and midday can be used to determine thermal inertia (the variation in these two temperatures) which can be influenced by archaeological remains with some retaining heat and others losing it more rapidly. Figure 28, Figure 29 and Figure 30 are from a survey over an enclosure on the Isle of Coll. (see also Winterbottom and Dawson 2005).

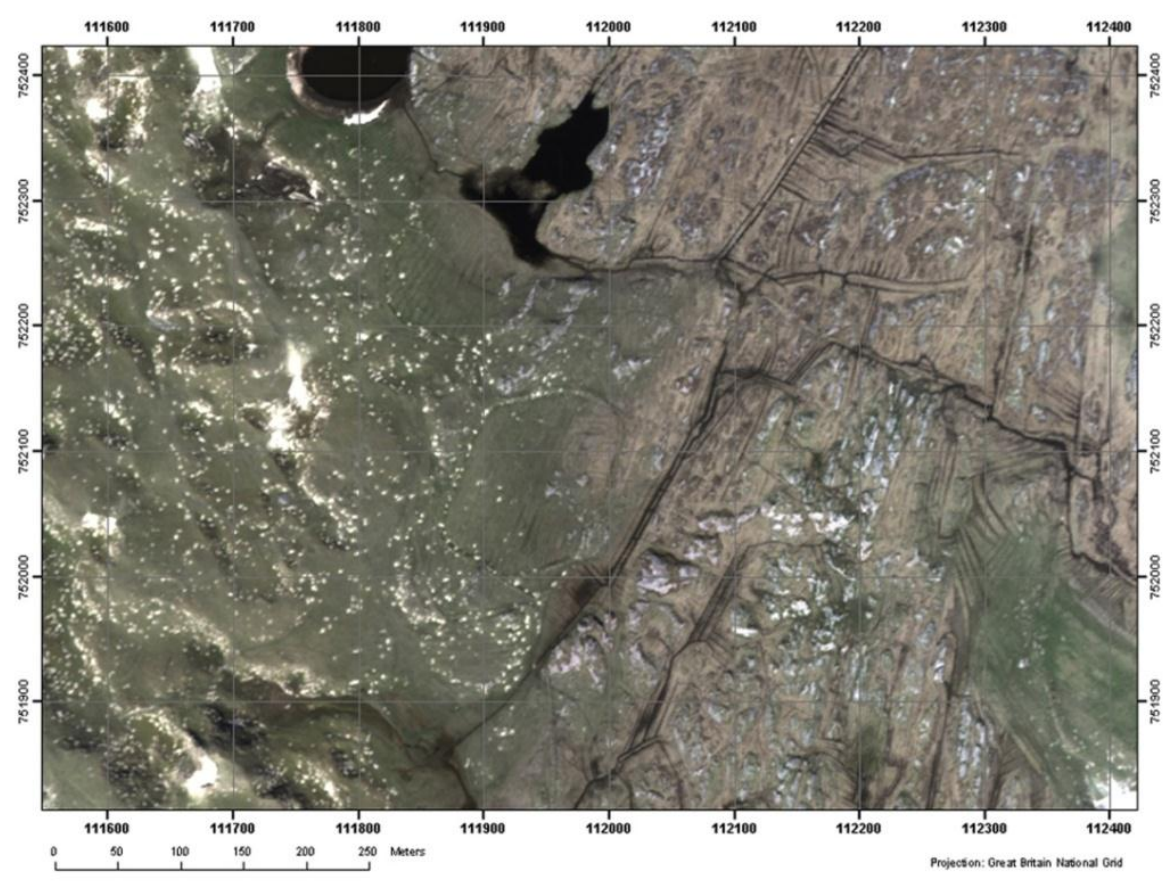

Figure 28: Multi-spectral survey of an area on the Isle of Coll showing an enclosure in the centre of the image. This is a true colour composite using the 4, 3, 2 bands in the red, green and blue display respectively i.e. the visible light range. (c) Dawson/Winterbottom/NERC. 


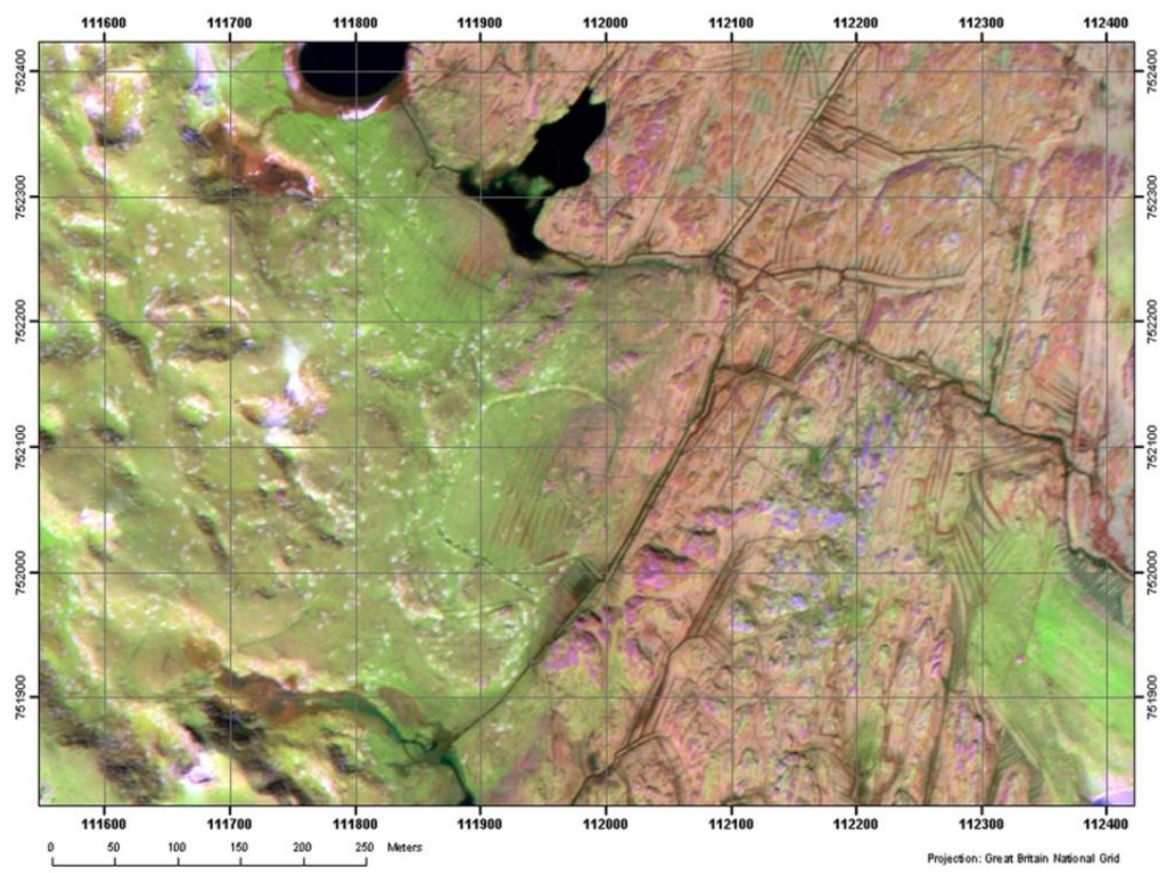

Figure 29: This is a false colour composite using the 9, 7, 3 bands in the red, green and blue display respectively i.e. the inferred light range. This combination maximises variations in vegetation and the structure, moisture content and nutrient content in the soil resulting in a shaper definition of the enclosure.ㄷ Dawson/Winterbottom/NERC

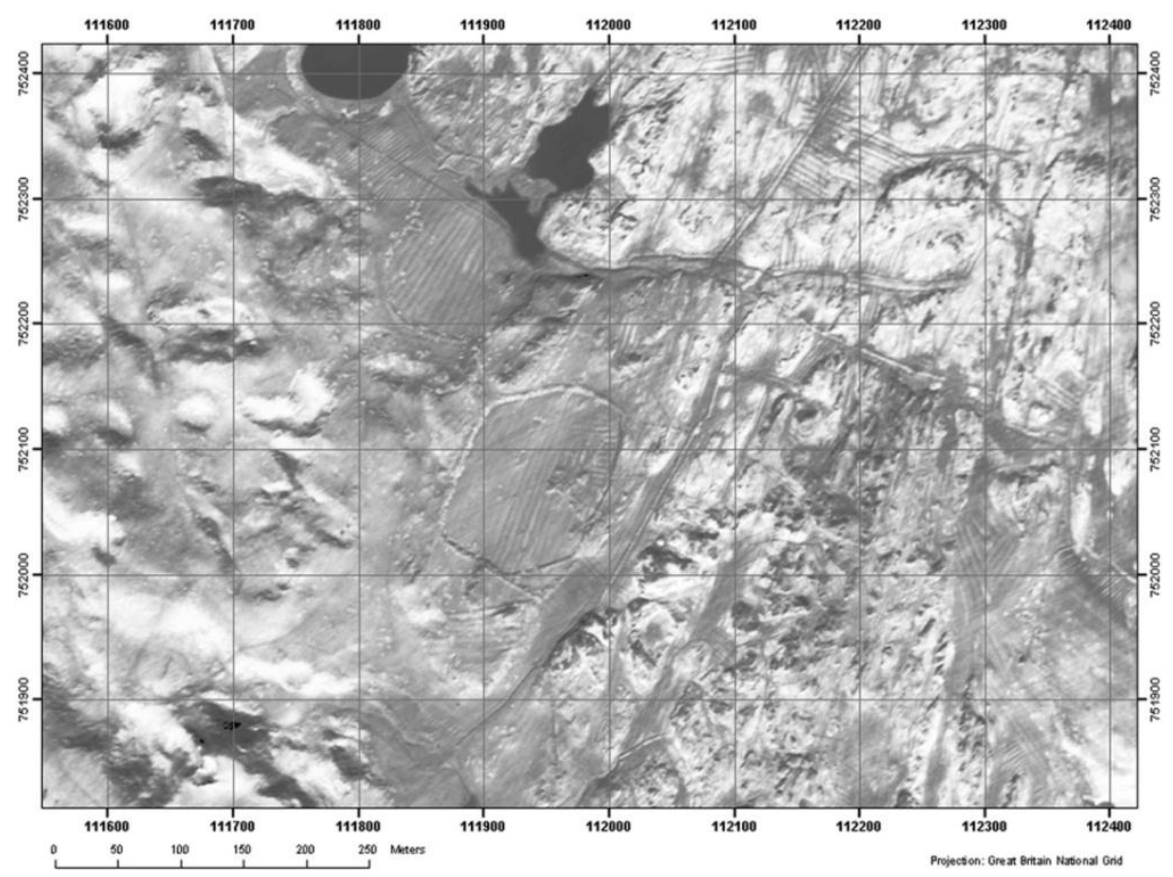

Figure 30: This is a daytime thermal image using band 11 of the spectrum i.e. infrared. This image enhances topographic variations and result in the turf banks and ridge and furrow being particularly visible. (C) Dawson/Winterbottom/NERC 


\subsection{Geophysical Survey}

Geophysics crosses disciplines, periods and geographic areas and as such is a vital technique within the wider archaeological, and associated environmental, research frameworks. Geophysical survey applied to archaeological sites has a long history, with its first documented use in Britain in 1946 (Gaffney \& Gater 2003), with the discipline being discussed and written about, as a research tool, by the late 1950s in the journal Archaeometry. The early 1990s saw a step change in the application of geophysics with surveys becoming more common in rescue archaeology, with the move to developer-paid archaeology and the incentive to gain enhanced information to allow accurate estimation of excavation costs. In 2004 a conference "Going Over Old Ground" (Jones \& Sharpe 2006) looked at the state of the application of geophysics in Scottish archaeology which has lagged behind the rest of Britain. Given the relatively low application of geophysical surveys to archaeological sites in Scotland, the Institute for Archaeologists Geophysics Special Interest Group (GeoSIG) has worked with Scotland's Association of Local Government Archaeological Officers (ALGAO) to try and raise the profile of geophysics in developer funded archaeology through a series of seminars.

Although no standards or guidelines specific to Scotland exist the industry follows those set by the IfA and English Heritage and these have recently been formally adopted by Scotland's ALGAO: The Institute for Archaeologists IfA Standards \& Guidance: Geophysical Survey ${ }^{25}$ and Guidelines

http://www.archaeologists.net/sites/default/files/ node-files/geophysicsSG.pdf established by English Heritage, Geophysical Survey in Archaeological Field Evaluation ${ }^{26}$.

Due to the variety of complex features that may be found below the ground surface, a wide variety of techniques and equipment are available to the surveyor. The table below highlights the main techniques applied to archaeology. http://www.englishheritage.org.uk/content/publications/docs/geophy $\underline{\text { sics-guidelines.pdf }}$ 
Science in Scottish Archaeology

Table 9: Summary of Geophysical Techniques and their application

\begin{tabular}{|c|c|c|}
\hline Technique & Features Detected & Appropriate Application \\
\hline Gradiometry & $\begin{array}{l}\text { Ditches and pits } \\
\text { Made surfaces, metalled roads \& } \\
\text { trackways } \\
\text { Drains and gulleys } \\
\text { Pottery and tile kilns } \\
\text { Hearths and ovens } \\
\text { Ferrous debris including some slag }\end{array}$ & $\begin{array}{l}\text { Usually the technique of first choice. } \\
\text { Suitable for greenfield sites with } \\
\text { archaeology up to a meter or so } \\
\text { beneath the surface and able to } \\
\text { cover large areas in a time and cost } \\
\text { effective manner. Igneous geology } \\
\text { can reduce its efficacy. }\end{array}$ \\
\hline Magnetic Susceptibility & $\begin{array}{l}\text { Depending on sample interval: } \\
\text { Areas of anthropogenic activity } \\
\text { Ditches and pits } \\
\text { Pottery and tile kilns }\end{array}$ & $\begin{array}{l}\text { A quick, inexpensive technique suited } \\
\text { to locating general areas of activity } \\
\text { on a landscape level. }\end{array}$ \\
\hline Area Resistance & $\begin{array}{l}\text { Walls, foundations and rubble } \\
\text { spreads } \\
\text { Made surfaces } \\
\text { Metalled roads \& trackways } \\
\text { Stone coffins, cists and graves } \\
\text { Drains and gulleys } \\
\text { Ditches and pits }\end{array}$ & $\begin{array}{l}\text { A very commonly applied technique } \\
\text { ideal for locating foundations, but } \\
\text { also able to detect ditches and pits. } \\
\text { This technique benefits from not } \\
\text { being affected by underlying geology } \\
\text { and so is often deployed on sites with } \\
\text { underlying igneous or metamorphic } \\
\text { geology. }\end{array}$ \\
\hline
\end{tabular}




\section{Gradiometry}

Of all the geophysical techniques available, gradiometry is the most time and cost effective. As such it is the industry standard and usually the technique of first choice.

It is excellent for locating ditches, pits, middens, hearths, kilns and, depending on the soils and materials used, will often show walls and foundations. Although gradiometry is used routinely in Cornwall, Norway and Iceland, there has been much discussion about the efficacy of gradiometry in Scotland, owing to the large amount of igneous geology. In reality there are few areas where this technique cannot be applied. Unfortunately many people dismiss the use of all geophysical techniques based on the potential issues of this one technique.

Although normally used to survey sites in detail, the instrument can be used in scanning mode to identify hot-spots that can be later surveyed in detail. This is especially effective on very large sites (>100ha) when it is not cost effective to survey the whole development area in detail. However, no data is recorded in the scanning phase. It is vital to have a skilled operator to undertake this phase of activity as per the English Heritage and IFA guidelines.

A gradiometer comprises two magnetometer sensors mounted $1 \mathrm{~m}$ or $0.5 \mathrm{~m}$ apart on a vertical axis. Each sensor measures the earth's magnetic field, in nanoTesla (nT), and the instrument records the difference between the observed readings for each sensor. By doing so the instrument is recording subtle changes or anomalies in the earth's magnetic field caused by material in the top metre or so of the earth's surface. By measuring the magnetic field in this manner, variations due to large-scale geological variations and diurnal fluctuations are filtered out. Data is normally collected at $0.25 \mathrm{~m}$ intervals along traverses $1 \mathrm{~m}$ apart within the series of $20 \mathrm{~m}$ or $30 \mathrm{~m}$ grids, which are later merged together.
Many different types of magnetometers and gradiometer are available but the two most commonly used instruments in archaeology in the United Kingdom are the Geoscan Research FM256 and the Bartington 601. These have fluxgate sensors and are often configured as a dual system which is simply two instruments carried together allowing for quicker survey times, with associated cost savings. Continental workers sometime use large multi-array wheeled systems. These are normally still configured as a gradiometer, but often use alkali vapour or proton precession sensors which tend to be more sensitive. Although use of such systems is increasing in the UK, on most sites uneven ground limits the efficacy of these systems.

\section{Magnetic Susceptibility}

Also relying on magnetic properties of the soil, magnetic susceptibility can be used either as a reconnaissance tool to locate possible sites, or as a research tool to aid interpretation of specific features revealed by excavation or the nature of occupation of a site.

Whilst use of magnetic susceptibility has declined in recent times, it still remains a quick effective way of covering large landscapes to locate areas of interest/activity. Measurements can be taken at $20 \mathrm{~m}$, or so intervals, to identify hotspots that can be later surveyed in more detail by gradiometry. Unlike gradiometer scanning, it benefits from recording data that can be displayed to show potential areas of enhanced susceptibility and interest.

Laboratory measurement of magnetic susceptibility of soil samples gives data on individual contexts and also relative intensity of occupation.

The Bartington Magnetic Susceptibility system is the one most commonly used in the United Kingdom 


\section{Area Resistance Survey}

Area resistance survey can provide detailed plans of building foundations and other stone structures, garden features and burials along with ditches and pits. Whilst slower than gradiometry, resistance is a very effective area prospection technique. At its best it can provide 'building plans', but can also be an effective application on those types of monument where magnetic enhancement is limited or unlikely to have occurred (e.g. burials and barrows). In addition it is largely unaffected by geology and for its ability to discern such ephemeral features as flower beds, paths and graves.

This technique passes a small electrical current through the ground and measures the resulting resistance. Data are normally collected $1 \mathrm{~m}$, or $05 \mathrm{~m}$, intervals within $20 \mathrm{~m}$ or $30 \mathrm{~m}$ grids which are later merged together.

Although a variety of resistance systems are available, the Geoscan Research RM 15 (soon to be replaced by the RM85) is the industry standard in archaeology. This system enables a variety of electrode arrays to be deployed. It also allows the probe separation to be adjusted enabling different detection depths. In archaeological prospection it is standard to use a Twin Probe array with a $0.5 \mathrm{~m}$ probe separation giving a maximum detection depth of $0.75 \mathrm{~m}-1 \mathrm{~m}$. Increasing the probe separation will enable deeper features to be detected, but at the cost of lateral resolution.

\section{Ground Penetrating Radar Survey}

While gradiometer and resistance surveys provide detailed plans of buried archaeological remains, ground penetrating radar (GPR) survey is the best technique for providing accurate information on the depth and stratigraphy of features. GPR is currently the technique of choice when depth information is required, or when resolution of a complicated area survey is needed.
The technique can be applied in transect or as an area prospection tool enabling threedimensional modelling of a buried site. In the latter it is normal to collect data at least $0.05 \mathrm{~m}$ intervals along traverses $0.5 \mathrm{~m}$ apart to enable detailed time slice maps to be produced. It is also sometimes appropriate to collect data on an orthogonal grid to improve resolution. Selection of the correct antenna, which affects the depth of penetration of the signal and its lateral resolution is important. Although most companies in the UK use systems with a single antenna new systems with multi-frequency antennas arrays are becoming more common.

In Ground Penetrating Radar surveys pulses of electromagnetic energy are directed downwards into the earth. The transmitted wave is affected by variations in the electrical properties of the subsurface, specifically the dielectric constant and the conductivity of the subsurface which, in turn, are influenced by material type, moisture content and pore fluids. Contrasts, or changes, in these properties cause reflection of the energy wave creating an anomaly. The subsurface is mapped by recording the amplitude of this reflected energy and its travel time. The data are recorded as two-way times i.e. how long it takes for the electromagnetic wave to travel to an interface and be reflected back to the receiver. As a result GPR records detailed vertical sections through the ground, which can provide a wealth of stratigraphic information and can define any discontinuities: it is one of the few geophysical techniques that can provide a good estimation of the depth of potential features. The travel times can be converted to depth using an assumed, measured or calculated velocity. The dielectric constant of a material is a direct measure of its water content, which is directly related to the velocity of the electromagnetic energy. However, the velocity is also governed by the electrical conductivity of the subsurface. 
Science in Scottish Archaeology

It should be noted that GPR is extremely sensitive to the conductivity of the soil and this is dominated by the proportion of clay minerals present. In Scotland, the amount of clay is often very high, the conductivity is therefore high and GPR often does not have any penetration of significance (less than a few centimetres). The technique is highly site dependant.

A wide variety of radar systems are available, the ones more commonly deployed in archaeology include GSSI's SIR 3000, Software and Sensors' Pulse Ekko and Mala systems. As GPR systems are classified as radio systems there are restrictions on the frequency of antennas that can be used, however this does not negatively impact on the use of GPR in archaeology in the UK. Anyone operating a GPR system within the UK needs to hold an OfCom licence and keep a log.

\section{Electromagnetic Survey}

Electromagnetic (EM) survey is useful for many near surface applications including mapping soil properties, utilities, and contamination of ground and water tables, identification of buried metallic objects, and depth to bed rock. The technique allows for simultaneous collection of both magnetic susceptibility and conductivity data, and as such is a fast versatile survey instrument.This technique has the same resolution as other resistance surveys but the way in which it is used reduces the 'apparent resolution'. It is particularly useful on sites were ground conditions preclude the use of gradiometry and resistance survey.

A wide variety of EM system are available, although the ones most commonly used within the UK are Geonics EM31, EM38 and EM61, each looking at different depths.

\section{Electrical Imaging}

Electrical imaging systems, enabling Electrical Resistance Tomography (ERT) surveys, are comparable to GPR systems in that they record vertical sections through the ground enabling a three dimensional image to be recorded. Imaging is suitable on sites having soils with a high moisture or clay content where GPR is not suitable, and can also retrieve data from a greater depth. However, it can suffer from limited resolution on some site types.

As with Area Resistance Survey this technique passes a small electrical current through the ground and measures the resulting resistance. However, rather than maintaining a constant probe separation readings are taken at different probe separations result in a pseudo-section; an image of a vertical slice through the ground showing the variation in resistance values. The technique can be applied in transect or as an area prospection tool enabling three-dimensional modelling of a buried site.

Although geophysical survey is routinely used in field based archaeology throughout the world, particularly in the rest of Britain, its use in Scotland is relatively limited. The current lack of application and trust in the use of geophysical survey in Scotland is being considered by ALGAO and the IFA's GeoSIG. However the application of geophysical survey in Scotland, both in research and rescue archaeology, perhaps suffers from having no equivalent of English Heritage's Ancient Monuments Laboratory within Historic Scotland or RCAHMS. All contractors use guidelines from English Heritage (English Heritage 2008) and the Institute for Archaeology (Gaffney et al 2002). Not only are surveys less commonly applied/commissioned in Scotland, but the total area per survey is generally less (with obvious exceptions). To what degree this is a function of the size of Scottish development is difficult to answer. Innovative techniques, for example Electrical Resistance Tomography and Electromagnetic survey, are also less readily applied. 
Science in Scottish Archaeology

Table 10: A summary of the suitable application of various techniques

\begin{tabular}{ll}
\hline Technique & Suitable for \\
\hline $\begin{array}{l}\text { Electrical Resistance } \\
\text { Tomography }\end{array}$ & $\begin{array}{l}\text { Voids, Geology (e.g } \\
\text { bedrock, peat) }\end{array}$ \\
$\begin{array}{l}\text { Ground Penetrating } \\
\text { Radar }\end{array}$ & $\begin{array}{l}\text { Voids, Geology (e.g } \\
\text { bedrock, peat), } \\
\text { Services, Tarmac / } \\
\text { concrete }\end{array}$ \\
Gradiometry & $\begin{array}{l}\text { Ditches, pits and kilns } \\
\text { (if predominantly } \\
\text { sedimentary geology), } \\
\text { services }\end{array}$ \\
& $\begin{array}{l}\text { Ditches, pits and kilns } \\
\text { (if predominantly } \\
\text { Resistance }\end{array}$ \\
& $\begin{array}{l}\text { metamorphic or } \\
\text { igneous geology), } \\
\text { Masonry / stonework, } \\
\text { Lawns }\end{array}$
\end{tabular}

Unfortunately geophysical survey is viewed primarily as a pre-excavation tool in both research and developer led projects. Geophysical surveys are often viewed as selfcontained finite elements within a project and as a result much potential additional information is discarded. More often than not, once the geophysical survey has served its purpose, usually to just locate the trial trenches, it is put aside and not considered again. This is unfortunate as much information could be gained by reexamination of results following excavation and indeed re-examination of survey results in light of excavation may provide further information to the project. In addition, the data often contains a wealth of geomorphological information which could prove useful but is often disregarded.

There are obviously exceptions to this, for example the large scale gradiometer survey of the Heart of Neolithic Orkney World Heritage Site (Card et al 2007) and various surveys on the Antonine Wall (Stephens et al 2008).
These two examples show two very different approaches. On Orkney an area of some 250ha has been surveyed with the aim of placing the visible monuments in their wider archaeological context. The surveys on the Antonine Wall have taken the form of several individual surveys / survey areas with the aim of answering very specific questions regarding interpretation and construction of different elements of the site.

Unlike many scientific techniques applied to archaeology, geophysical equipment is relatively cheap, portable and readily available. Many universities have dedicated archaeological geophysical survey equipment, such as fluxgate gradiometers and twin probe resistance systems, including Glasgow, Aberdeen and the University of the Highlands and Islands. In addition, other Universities, such as Edinburgh, Stirling and St Andrews, house more traditional geophysical equipment, including GPR, ERT, EM and Seismics, in their Earth Sciences departments which can be used on archaeological sites. In addition, NERC ${ }^{27}$ has the Geophysical Equipment Facility, partly housed at Edinburgh's Earth's Sciences Department. While the facility is primarily aimed at NERC funded research projects and studentships, any British groups may apply for loan of the equipment within the pool. The GPR systems, suitable for use on archaeological sites, are especially underutilised and NERC would welcome increased use of the system. NERC also offer training in the use of their equipment and excellent technical support.

Geophysics in archaeology also benefits from the involvement of the commercial sector. There are many commercial archaeological geophysical companies throughout Britain who undertake not only developer led

\footnotetext{
${ }^{27}$ http://gef.nerc.ac.uk/
} 
Science in Scottish Archaeology evaluation surveys, but also contribute to research, either in their own right or as part of wider multi-institutional research projects. Within Scotland there are at least four dedicated archaeological geophysics consultancies; CFA Archaeology Ltd, GUARD Archaeology Ltd, O'Grady Geophysical Surveys, ORCA Geophysics and Rose Geophysical Consultants.

Visualisation and dissemination of geophysical survey data are often disappointing and survey data are not readily available, although this may be improved with the current ALGAO and GeoSIG proposals. Glasgow University (Jones and Sharpe 2006) started a database of geophysical surveys in Scotland but unfortunately this has not been maintained by other groups working within Scotland. Therefore, initially rather than identify areas and directions of research within Scottish archaeology, more basic work is required to provide 'structure' and benchmarks for geophysics in Scotland. Encouragement of innovative techniques when routine geophysical techniques are not consistently or routinely appliedmay not fall on fertile ground. The recommendations are:

- The creation (adoption) of national guidelines - EH and GeoSIG guidelines

- The establishment of a searchable database of geophysical surveys (McKeague and Jones forthcoming)

With a strong recommendation of encouragement for the following:

- Early involvement of geophysicists in project design

- Ongoing discussions with the geophysicists

The outlook in Scottish geophysics is, however, far from gloomy. Geophysical survey is being used more in general landscape studies and this is a clear area of growth. Ground Penetrating Radar is being used more frequently in the study of buried landscapes. In particular, in mapping peat as part of the Scottish Wetland Archaeology Programme (SWAP) projects (Clarke et al. 1999) where survey data can be integrated with invasive techniques such as augering or coring and considered with geochemical studies. This enables true multidisciplinary studies which enhance an understanding not only of the palaeo-landscapes but also add to the knowledge and understanding of the various techniques and their interaction. This is an active area of research at Glasgow University.

The current growth in the use of air-borne and ground based LiDAR provides an ideal opportunity to consider the integration of geophysical and LiDAR data. Aerial LiDAR data has been collected for the entire inner buffer zone of the World Heritage Site in Orkney, and also been collected for Scotland's other World Heritage Sites: Antonine Wall, Edinburgh Old and New Towns, St Kilda and New Lanark. This was funded by, and is the copyright of, the Centre for Digital Documentation and Visualisation (CDDV). An obvious next step is to integrate existing geophysical and LiDAR data were available. Aside from the interpretive benefits it should allow for a more digestible form of the geophysical data.

Given that commercial archaeological evaluations appear to be strongly led by the presence, or absence, of aerial photographic evidence, there is a clear role for geophysical survey in the evaluation of crop-mark sites in terms of accuracy of transcription, completeness of the information provided by the APs, but perhaps more importantly the state of preservation of such sites in the light of aggressive modern farming techniques. Such studies have been undertaken in the past, but there is scope for more, given the importance local authority curators place on such information. 
Science in Scottish Archaeology

The growth of marine/water-based archaeology and geophysical survey in the growing renewable sector present a clear area of research - geophysical investigation of intertidal zones enabling 'seamless' land based - water/marine based geophysical surveys and analysis.

In conclusion, it is important to view geophysical survey as a means of detecting and imaging heritage assets, not just part of the developer funded excavators' toolbox. Geophysics crosses disciplines, periods and geographic areas and as such has much to offer the wider field of archaeology. However, there is a need to build and expand upon the bedrock of geophysical applications and involvement in archaeological research within Scotland.

\subsection{Underwater Surface Mapping}

An increasing array of techniques is available for the investigation and mapping of palaeolandscape surfaces that are both at the present seafloor and are currently buried beneath this. The techniques are applied as part of routine surveys for industry (oil and gas site surveys, pipe line studies, geotechnical investigations, wind farm developments) and occasionally as bespoke surveys for archaeology. See also the ScARF Marine and Maritime panel report ${ }^{28}$.

\section{Single Beam Echosounder}

Bathymetry is typically measured using an echo sounder with either single or dual frequency transducers. These transducers measure the travel time for an acoustic pulse and with some equipment the strength of

28 Follow the links at www.scottishheritagehub.com to the Marine and Maritime panel report amplitude return. A bathymetric map and amplitude map is produced by extrapolating data between survey lines.

\section{Multibeam Echosounders}

Two types of technology exist for making very high resolution maps of bathymetry, namely multibeam sonar and swath-bathymetry sonar. In both cases, acoustic signals are used to obtain multiple return energy from a swath of points beneath and to the side of the survey vessel. Recent advances in multibeam technology, the deployment of the technology and the processing of the data have led to spectacular, very high resolution models of the seafloor and wreck sites. These models provide an indispensible tool not only for archaeological site survey but also for the management of archaeological sites.

\section{Sidescan Sonar Systems}

The sidescan sonar has become one of the most often used of survey tools in the marine environment as it affords the surveyor a 'picture' of the seafloor in terms of amplitude of acoustic return. The sidescan sonar is a side-looking sonar with acoustic energy propagated to either side of the sonar head along a swath over the seafloor. This energy is recorded as a time-series with the amplitude of returns measuring the strength of energy reflected from the bottom and objects on the bottom. Sidescan sonars operate in the range of frequencies between $100 \mathrm{KHz}$ and $900 \mathrm{KHz}$, the latter giving very high $(\mathrm{cm})$ resolution of the seafloor. The individual swaths are captured digitally so that a mosaic can be produced for a complete image of the seafloor over the survey area.

\section{Magnetic Signature Analysis}

Marine magnetic surveying has become a standard technique for mapping the location of ferromagnetic metallic objects, such as recent wrecks, on the seafloor. The magnetometer is typically towed near to the bottom along lines that are closely spaced 
Science in Scottish Archaeology apart. Recent advances in technology include improvement in signal to noise ration, use of multiple instruments and use with other instrument platforms. Surveying of metallic but non-ferromagnetic remains can be achieved by the use of electromagnetic-based survey equipment. This type of survey has had limited testing in the archaeological community.

\section{Scottish Research Capacity}

Marine equipment pools are held at St Andrews University, the University of the Highlands and Islands and the Scottish Association for Marine Science (SAMS). Several commercial companies also have marine survey capacity.

\section{Underwater Sub-Surface Mapping}

Sub-surface or sub-bottom mapping is necessary when a structure such as a wreck site or a feature such as a palaeo-landscape is buried. The majority of techniques used in maritime archaeology for imaging the subsurface rely on the propagation of an acoustic pulse. For sub-bottom surveying the depth of penetration below the seafloor and the resolution with which the data can be resolved is a function of the acoustic frequency spectrum. In general, in order to look further into the seafloor the lower the frequency the lower the resolution. A number of acoustic sources are available from high frequency pinger systems with $10-20 \mathrm{~cm}$ resolution through to low frequency boomer systems with $20-40 \mathrm{~cm}$ resolution. Typical deployment of these techniques is along survey lines and thus 2D cross sections to the sub-surface are acquired. Techniques for full 3D imaging are being currently developed.

Table 11: Nearshore marine survey methods

\begin{tabular}{|c|c|c|c|c|c|}
\hline Technique & $\begin{array}{l}\text { Equipment } \\
\text { Manufacturer }\end{array}$ & $\begin{array}{l}\text { Type } \\
\text { Frequency } \\
\text { (acoustic) }\end{array}$ & $\begin{array}{l}\text { Line } \\
\text { Spacing }\end{array}$ & $\begin{array}{l}\text { Coverage/ } \\
\text { resolution }\end{array}$ & Uses \\
\hline Echo-sounder & $\begin{array}{l}\text { Odem, } \\
\text { Lowrence, }\end{array}$ & $\begin{array}{l}\text { Single/Dual } \\
\text { Sonar 28- } \\
200 \mathrm{kHz}\end{array}$ & $\begin{array}{l}20- \\
100 m\end{array}$ & $10 / 10 m$ & 2D Bathymetry \\
\hline $\begin{array}{l}\text { Echo- } \\
\text { classification }\end{array}$ & $\begin{array}{l}\text { Roxanne, QTC } \\
\text { View, EchoPlus }\end{array}$ & $\begin{array}{l}\text { Single/Dual } \\
\text { Sonar 28- } \\
200 \mathrm{kHz}\end{array}$ & $\begin{array}{l}20- \\
100 m\end{array}$ & $10 / 10 m$ & $\begin{array}{l}\text { Textural analysis, } \\
\text { seafloor classification }\end{array}$ \\
\hline Sidescan Sonar & $\begin{array}{l}\text { Klein, } \\
\text { Edgetech, } \\
\text { Imagenex }\end{array}$ & $\begin{array}{l}\text { Multi-sonar } \\
100-600 \mathrm{kHz}\end{array}$ & $\begin{array}{l}50- \\
200 m\end{array}$ & Full/1m & $\begin{array}{l}\text { Textural analysis, } \\
\text { object identification, } \\
\text { seafloor classification }\end{array}$ \\
\hline $\begin{array}{l}\text { Swath- } \\
\text { sounding }\end{array}$ & $\begin{array}{l}\text { SEA Itd., } \\
\text { Geoacoustics }\end{array}$ & $\begin{array}{l}\text { Multi-sonar } \\
100-500 \mathrm{kHz}\end{array}$ & $\begin{array}{l}50- \\
200 \mathrm{~m}\end{array}$ & $\begin{array}{l}\text { Full } / 5 \mathrm{~cm}- \\
5 \mathrm{~m}\end{array}$ & $\begin{array}{l}\text { 3D } \\
\text { bathymetry/imaging, } \\
\text { seafloor } \\
\text { classification, } \\
\text { site management }\end{array}$ \\
\hline
\end{tabular}


Science in Scottish Archaeology

\begin{tabular}{|c|c|c|c|c|c|}
\hline Multi-beam & Reson, Simrad, & $\begin{array}{l}\text { Multi-sonar } \\
100-500 \mathrm{kHz}\end{array}$ & $\begin{array}{l}50- \\
200 \mathrm{~m}\end{array}$ & $\begin{array}{l}\text { Full } / 5 \mathrm{~cm}- \\
5 \mathrm{~m}\end{array}$ & $\begin{array}{l}\text { 3D } \\
\text { bathymetry/imaging, } \\
\text { seafloor classification, } \\
\text { site management }\end{array}$ \\
\hline $\begin{array}{l}\text { Sub-bottom } \\
\text { Profiling }\end{array}$ & $\begin{array}{l}\text { Applied } \\
\text { Acoustics, } \\
\text { Geoacoustics, }\end{array}$ & $\begin{array}{l}\text { Single Sonar } \\
10-0.5 \mathrm{Khz}\end{array}$ & $5-50 m$ & $\begin{array}{l}10 / 10- \\
50 \mathrm{~cm}\end{array}$ & $\begin{array}{l}\text { Buried objects, } \\
\text { palaeo-landscape }\end{array}$ \\
\hline $\begin{array}{l}\text { Electro- } \\
\text { magnetic }\end{array}$ & Fisher & & $10-30 m$ & & $\begin{array}{l}\text { Metallic (non-ferrous) } \\
\text { object detection }\end{array}$ \\
\hline Magnetometer & $\begin{array}{l}\text { GEM, } \\
\text { Geometrics }\end{array}$ & & $10-30 m$ & $10 / 3 m$ & $\begin{array}{l}\text { Metallic (ferrous) } \\
\text { object detection }\end{array}$ \\
\hline
\end{tabular}

\subsection{Laser Scanning}

Laser scanning is a rapid, non-contact, accurate and objective method for digitally recording the surface of any object in 3D. The technology has been used for many years in the engineering and oil industries. More recently, as technologies have advanced and costs have reduced, the heritage industry has begun to adopt and adapt this methodology for a range of heritage assets. Laser scanning can digitally document the current condition of everything from archaeological artefacts to entire archaeological sites, heritage structures, buildings and landscapes.

\section{Technology}

A laser beam scans the surface of the object of interest. The laser reflects off the surface and returns to the scanner, where the time taken for the return signal to be detected is used to calculate the distance to the object. The scanner does this up to 50,000 times a second, depending on the model, and so very quickly collects a large amount of accurate data. Each return signal is registered as a 'point' and the collective 3D data is known as a 'point cloud'. Point clouds are acquired from many positions around the target object and joined together in specialised software to generate the overall 3D dataset.

\section{Range of scanners}

There are a wide variety of laser scanners available to suit particular tasks. Simple desktop laser scanners are available for scanning small objects such as artefacts, while high-resolution hand held scanners can very accurately record objects at close-range. Tripod-based terrestrial laser scanners are suitable for scanning interiors and exteriors of buildings, archaeological sites and landscapes, at ranges of up to $300 \mathrm{~m}$ from the scanner. Accuracy varies according to the model but can be sub-mm for scanners suited to recording small objects, to a few $\mathrm{mm}$ for those suited to recording buildings and landscapes. Aerial laser scanning is also achievable via a system fixed to the underside of a helicopter or small airplane. While aerial laser scanning is being carried out, hyperspectral imaging data can also be collected. Hyperspectral imaging covers the entire electromagnetic spectrum, and has significant potential for archaeological imaging and site prospection.

\section{Scottish capability}

Within Scotland, Historic Scotland has the greatest resource in terms of laser scanning. HS currently owns six 3D scanners, capable of recording very small objects to large buildings. Historic Scotland has formed a partnership with the Digital Design Studio at Glasgow 
Science in Scottish Archaeology

School of Art to develop laser scanning and digital documentation as a whole within the heritage industry. The partnership is known as The Centre for Digital Documentation and Visualisation (CDDV). CDDV will deliver commercial projects as well as focusing on research and development for laser scanning and other emerging digital recording technologies.

The Royal Commission for Ancient and Historic Monuments Scotland and AOC Archaeology Group own and operate laser scanners, and Orkney College have recently purchased a scanner for archaeological projects. There are several commercial companies based in Scotland who carry out laser scanning, but these are almost entirely within the engineering and chartered land surveying industries. Some of these companies do carry out projects on heritage structures.

It is worth noting that the majority of laser scanning carried out in Scotland is on a commercial basis. This is a reflection of the relatively high costs of equipment and processing software. However, Historic Scotland, CDDV and AOC do carry out research and development to further the practical applications of 3D scanning for the cultural heritage sector.

\section{Scottish projects}

Currently, CDDV is working on a five-year project to deliver 'The Scottish Ten' (www.scottishten.org). This will digitally document Scotland's five UNESCO inscribed world heritage sites and five international heritage sites (Wilson et al. 2011a). The project marries scientific technologies with heritage conservation management. The primary aims of the Scottish Ten are to:

- Accurately record important historical sites for the benefit of future generations in Scotland and overseas.

- Maintain and develop Scotland as a centre of excellence in this field.
- Share and disseminate Scottish technical expertise and foster international collaboration.

- Provide digital media to site managers to enable them to improve care for the heritage resource.

- Recognise international Scottish cultural connections.

CDDV have also laser scanned large sites such as Stirling Castle and Rosslyn Chapel in recent years and has investigated the potential for 3D recording of historic iron structures (Wilson et al. 2010, Pritchard et al. 2009). Historic Scotland is beginning a rolling programme of digital documentation of all 345 properties in its care and works in partnership with academic institutions such as Glasgow University and Orkney College to laser scan archaeological sites. Historic Scotland has laser scanned several archaeological sites, including Ness of Brodgar and Links of Noltland in Orkney and Forteviot in Perthshire. HS also carries out close-range high-resolution scanning, such as on the skull on a knight excavated at Stirling Castle. This was the recent focus for 'History Cold Case' a BBC production which looked at virtual reconstruction of people, based on laser scan data and forensic archaeology techniques. Historic Scotland is also working in partnership with RCAHMS on the 3D documentation of Birkhill Fireclay Mine.

RCAHMS have commissioned the laser scanning of several Pictish carved stones and other monuments over a number of years. They have recently acquired a long-range terrestrial laser scanner to carry out survey projects.

$A O C$ have been involved in the laser scanning of historic buildings, archaeological landscapes and artefacts since 2005, during which time several hundred sites of a wide range of types have been recorded in all parts of the UK, including the Western Isles and Orkney. In 2006, AOC initiated a Knowledge 
Science in Scottish Archaeology

Transfer Partnership with the University of Nottingham to research and develop methodologies for laser scanning and other 3D survey techniques. This took the form of a two-year post-doctoral project based in Historic Scotland's Edinburgh offices. The company has since continued to build on this expertise and has undertaken a wide range of recording projects for private individuals, commercial developers, architects and statutory bodies. Key AOC projects include: laser scanning of Rosslyn Chapel, Myrehead windmill, Caisteal Grugaig broch, terrain modelling at Keiss in Caithness (Cavers et al. 2010), object and close-range scanning, for instance, the Ormaig cup and ring-marked stones in Argyll (Cavers et al. 2008). Headland Archaeology was commissioned to laser scan The City of Adelaide historic ship in 2009 on a commercial basis (Atkinson et al. 2009). This was carried out in advance of the deconstruction of the listed vessel.

\section{Future for laser scanning in Scotland}

In Scotland, the future is optimistic for laser scanning technologies. As costs continue to fall, the technologies are available to more people working in heritage science. More work needs to be done on promoting the range of benefits and uses of laser scanning and other digital recording technologies. CDDV hosts an annual conference on Digital Documentation, which seeks to spread the message on laser scanning and ensure Scotland remains at the leading-edge of this and other digital technologies.

\subsection{Visualisation}

Point clouds themselves can be the end product of laser scanning, allowing viewing and manipulation of the dataset in 3D and accurate measurements to be taken directly. They can also be integrated with traditional survey and GPS data. However, much more can be derived. Processing allows architectural drawings to be produced (plans and cross-sections etc.). By mapping highresolution photographs onto the processed point cloud photo-realistic virtual reality images and visualisations can be generated. Physical models can now be printed directly from 3D data derived from laser scanning, allowing accurate replication of artefacts without the deleterious effect of any matrix contact process.

For the heritage sector, there are a number of immediate uses for this 3D data:

- Accurate survey record (historic buildings and archaeological sites)

- Cultural heritage management

- Conservation and maintenance

- Condition monitoring of sites at risk

- Coastal erosion monitoring and terrain modelling

- Virtual tourism

- Virtual access to inaccessible places

- Education, interpretation and understanding

- Recording and replication of small objects

\section{D Modelling}

3D scanning data can be used as a basis for the production of accurate and realistic 3D models and visualisations. This is a particularly important growth area in Scotland. Representations of historic landscapes, buildings or archaeological sites can be modelled according to 3D scan data, historical records, photos etc., allowing virtual reconstructions to be generated. There is significant potential for using this data as an interactive education tool. 


\subsection{Detecting and imaging heritage assets recommendations}

- Encourage coordinated effort to fund and carry out combined aerial photography, LiDAR, multi/hyper-spectral data and geophysical survey.

- Enhance the systematic mapping of the aerial photographic cropmark record and its delivery as a web-mapping service.

- Adopt national guidelines for geophysical survey such as those of English Heritage and GeoSIG.

- Progress the creation of an on-line Scottish geophysical survey database along the lines of what the RCAHMS has for long offered, through Canmore, on aerial survey.

- Encourage more geophysical survey at the landscape level and in underwater work.

- Enhance the opportunities for geophysical survey in community-based archaeological projects.

- Ensure continuity in Scotland's strong role in employing emerging technologies for digital recording and imaging in the heritage sphere. 


\section{Statistical modelling in archaeological applications $^{29}$}

Throughout the contents of sections 1-5 above there is an implicit use of mathematical or statistical procedures to process, treat and visualise data in many different forms. It is therefore desirable to make a few statements about these procedures that be conveniently under the general term of statistical modelling. This can be regarded as a conceptual description of the processes that generate the data we observe. The mathematical formulation of this conceptual description implies setting the corresponding equations, and defining the parameters (unknown quantities) that appear in these equations. Computationally, we need to fit the model (estimate parameters) using data that we have observed or measured.

The first and simplest example of a statistical model comes in ${ }^{14} \mathrm{C}$ calibration where the process starts with calibrating a single measurement. The process of calibration converts $a{ }^{14} \mathrm{C}$ age (in year $\mathrm{BP}$ ) and its associated uncertainty to a calendar age with a derived uncertainty. The ${ }^{14} \mathrm{C}$ age is derived from a measure of the ${ }^{14} \mathrm{C}$ activity in the sample, assumed for most materials (the exception being aquatic or marine samples) to have been in equilibrium with the atmosphere at time of 'life'.

29 For an expanded treatment of statistical modelling see the ScARF Wiki: http://www.scottishheritagehub.com/content/6statistical-modelling-archaeological-applications And Section 9 on statistical and computational methods in Brothwell \& Pollard (2001).
The statistical model begins here by describing a probability distribution for the ${ }^{14} \mathrm{C}$ date and its uncertainty conditioned on its unknown 'true' calendar age (the model parameter). This distribution is most commonly the Normal or Gaussian distribution. The ${ }^{14} \mathrm{C}$ distribution is then 'compared' to the calibration curve to identify the calendar time window most compatible with the observed ${ }^{14} \mathrm{C}$ activity. The result is a range of possible (or plausible) calendar ages for the sample identified by the distribution curve on the calibrated date axis (see below for a graph downloaded from the OxCal web site).

The sophistication of calibration modelling has been aided by major developments in the calibration software. Nowadays, there are a number of calibration programs available for terrestrial samples and for marine samples, the most widely used being Calib, BCal and OxCal and which are easily downloadable from the web or run on-line. In addition there are a number of special purpose programmes such as as BPeat, BChron, and CaliBomb. 


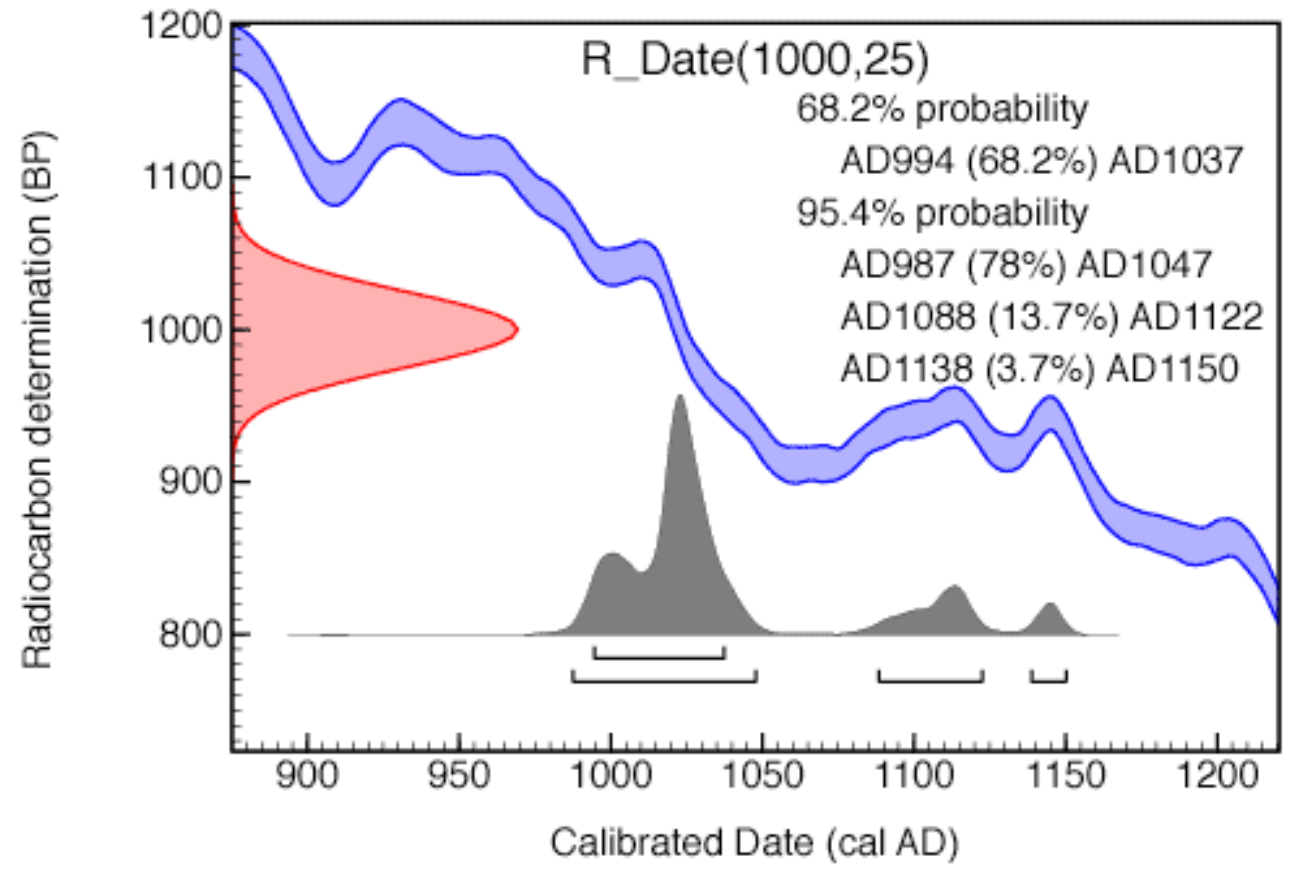

Figure 31: Radiocarbon calibration, downloaded from http://c14.arch.ox.ac.uk/embed.php?File=explanation.php ORAU May 2011

\section{Chronology building}

Dealing with one sample at a time is no longer a common occurrence, as frequently archaeologists will have a set of ${ }^{14} \mathrm{C}$ results related in some known way. In the simplest chronology construction setting, there would be a series of archaeological samples which are related through stratigraphy (which means that the relative ages of the samples from oldest to youngest can be defined). It may then be possible that some (or all) of the samples can be radiocarbon dated, and then in building the chronology, the dates would need to be calibrated, whilst respecting the stratigraphic relationships. This step requires a more complex model but one which still has at its heart the model for calibrating a single ${ }^{14} \mathrm{C}$ date. In recent years within Archaeology there has been a major growth in the adoption of Bayesian models (Bayliss and Bronk Ramsay, 2004), characterized by the formal inclusion of the concept of 'prior' knowledge or beliefs into the modeling process.

Bayesian modeling and analysis has three key components, formally they are described as the prior, the likelihood and the posterior. Bayes theorem is used to define the posterior in terms of the likelihood (involving the data) and the prior (expressed in terms of the model parameters). The model parameters could for instance be the start and end date of an occupation layer or period, and these quantities will be described mathematically within the model. 
First the prior captures expert archaeological knowledge about the parameters, so an archaeologist may be prepared to say that the start date can be no earlier than a particular event or time-period, and that similarly the end date can be no later than another. An alternative approach would be to define the parameter of interest as the duration of occupation, so that the prior would provide a statement of the form "duration was greater than 20 years but less than 150 years". Such statements would be written probabilistically (mathematically), so that in the latter case, one possibility would be to say that duration was equally likely to take any value between 20 and 150 years (or in other words to assume a Uniform distribution for duration). Considerable care is required in constructing the prior (Steir et al. 2000).

The likelihood is the next component and again is presented in probabilistic terms- here the observations are linked to the radiocarbon dates and the unknown parameters. The probability for each radiocarbon date is described given the unknown model parameters, and then these probabilities are generally multipled together to give the likelihood. The likelihood thus depends on the unknown parameters.

Finally, the posterior is then another probabilistic statement about the unknown parameters, but this time (unlike for the prior) the dates have also been used to define this statement, and in this way the archaeological knowledge is combined with the ${ }^{14} \mathrm{C}$ measurements. The Bayesian approach is probably best attempted in the context of calibration of radiocarbon ages using the readily available $\mathrm{OxCal}$ and $\mathrm{BCal}$.

\section{General statistical modelling in Archaeology}

More traditional statistical modelling is relevant to most archaeological science data. Some key terms are introduced here ${ }^{30}$. Fundamentally, lying behind much of Statistics is the assumption of a population, from which a representative sample of individuals has been drawn. Statistical inference is the process whereby one generalises from the sample of observations to a wider population. The first step in defining a statistical model is to define a probability model that describes the variation in the attribute of interest within the population. A parameter of the probability model describes a population, while a statistic describes a sample. There are arguments concerning statistical models and the validity of the concept of population as applied in an archaeological context. Nonetheless, the idea of population is important, and linked to this is the idea of a probability model, which describes the variation of the variable of interest in the population. Commonly used probability models include the Normal and Poisson.

\section{Hypothesis testing and confidence intervals}

Hypothesis or significance testing is a formal method of statistical inference. The hypotheses are framed in terms of population parameters (such as the population mean or average).

\section{Correlation and regression}

When there are several variables (measured on the same artifact), then a common investigation concerns the relationships

${ }^{30}$ A fuller treatment is available from the ScARF wiki:

http://www.scottishheritagehub.com/content/6statistical-modelling-archaeological-applications 
Science in Scottish Archaeology

between the two. Such a question of interest would be answered using a) either Spearman or Pearson correlation coefficients (depending on distributional assumptions) and b) if it is considered that the value of one variable (response) is in fact determined by the other (explanatory), then one might consider building a regression model. This latter type of modeling structure can also be extended to the situation where there are potentially many explanatory variables.

\section{Multivariate data}

There are a variety of techniques including clustering, principal components analysis and discriminant analysis, commonly described as multivariate techniques, since they are applied to data sets where there are many artefacts, and on each artefact, there are a number of variables measured. Each specimen whether it be a pottery shard, glass fragment, or coin will have a number of measurements made on it (eg metallurgical analysis, or shape (length, breadth etc) or decoration). Since the measurements are made on a single specimen, they are likely to be related, so in this sense, we have an extension from the bivariate (two variablecorrelation) case to the multivariate (many variable case).

Section 3 outlines the use of principal components and discriminate analysis which have been applied to elemental composition data of pottery. 


\section{The Vision for Science in Scottish Archaeology}

Archaeological science has revolutionised the understanding of Scotland's past. If this success is to be maintained and expanded, a strategic view that looks to the next ten years and beyond, considering how existing good work and expertise can be developed through partnership and collaboration is essential. Successful archaeological science therefore:

Engages in high quality, high impact research: allowing cutting-edge archaeological science to contribute to work exploring important contemporary topics such as the impacts of environmental and climate change and the potential pathways towards resilience and adaptability. As datasets become richer and more detailed researchers can engage with ever bigger questions, in collaboration internally and abroad, thereby unleashing the potential contribution that archaeology can provide to wider debates. In order to do this, mechanisms need to be developed to ensure data is permanently archived, accessible and useful, with the CANMORE database offering a suitable platform for nationwide databases and publication/report repositories.

Promotes knowledge exchange and transfer: enabling the archaeological science community to better communicate and work together, establishing routes of communication between field practitioners and scientists and improving infrastructure. A network of archaeological science advisers should be developed, potentially with leadership from Historic Scotland, so that researchers and commercial archaeology units have access to the best specialist advice, are aware of what others are doing, and can better work in collaboration. An online 'clearing house' or match-making service could use social media to match people (e.g. specialists or students) to material available for study (e.g. environmental samples, artefactual collections, or skeletal assemblages). This should include archived material from old sites, to which new scientific methods can and should be applied, and it is therefore essential that facilities and mechanisms are in place to enable the longterm storage of environmental and artefactual materials from Scottish archaeological sites.

Develops collaborative partnerships: promoting a long-term set of interdisciplinary working groups that meet regularly to discuss and debate archaeological science issues, and also help deal with the understanding and expectation of what science can reveal. An annual meeting should be held in the fashion of a 'horse trade' at which archaeologists and archaeological scientists could highlight the work they have been doing - the materials they have that require analysis, the specialisms/students they have available, or the upcoming research projects they are involved in. Such meetings could be rolled into a suitable public outreach event.

Facilitates training and career development in archaeological science: promoting and participating in national and European-wide networks for training in archaeological science knowledge and skills, and increasing research capacity and specialist knowledge in Scotland, 
especially in those areas where expertise is not currently available or is overly dependent on one or two researchers (e.g. ancient DNA, isotopes, plant phytoliths, chironomids). Targeted investment in and development of archaeological science research capacity and expertise, especially durable research clusters where critical mass would ensure that the departure of a single researcher would not leave the lab facility vulnerable to closure, will help to protect the long-term sustainability of Scotland's archaeological science facilities.

Has an effective dissemination strategy: improving communication between a variety of groups - including the research community, the press and the general public. Mechanisms that already exist to engage the wider community should be built upon, including Scottish Archaeology Month and National Science week. Getting wider communities involved in meaningful data generation is essential in both raising the profile of archaeological science, as well as improving available data sets.

Scotland can become a world leader in the application and development of archaeological science: one need only look at how over the last ten years the application and development of scientific techniques are revolutionising contemporary understandings of the past. In order to build a legacy for the next generation of researchers on this solid foundation, a stable funding regime, access to resources and viable career paths for future researchers are of fundamental importance. 


\section{Bibliography}

Akçar, N., Ivy-Ochs, S and Schlüchter, C 2008 'Application of in-situ produced terrestrial cosmogenic nuclides to archaeology: A schematic review.' Eiszeitalter und Gegenwart Quaternary Science Journal 57(1-2), 226-238

Adderley, W P., Simpson, I A., Lockheart, M J., Evershed, R P and Davidson, D A 2000 'Modelling traditional manuring practice: soil organic matter sustainability of an early Shetland community?', Human Ecology 28, 415-431.

Adderley, W P., Simpson, I A and MacLeod, G W 2001 'Testing high resolution X-ray computed tomography for the micromorphological analyses of archaeological soils and sediments', Archaeological Prospection 8, 107-112.

Adderley, W P., Alberts, I L., Simpson, I A and Wess, T J 2004 'Calcium-iron-phosphate features in archaeological sediments: characterisation through microfocus synchrotron $\mathrm{X}$-ray scattering analyses', Journal of Archaeological Science 31, 1215-1224.

Adderly, W P., Simpson, I A., and Davidson, D A 2006 'Historic landscape management: a validation of quantitative soil thin-section analyses', Journal of Archaeological Science 33, 320-334.

Adderley, W P., Simpson, I A., Barrett, R and Wess, W J 2007 'Archaeological soils and sediments: Application of microfocus synchrotron X-ray scattering, diffraction and fluorescence analyses in thin section', American Chemical Society 968, 194-209.

Adderley, W P., Wilson, C A., Simpson, I A and Davidson, D A 2010 'Anthropogenic features', in Stoops, G., Marcelino, V and Mees, F (eds) Interpretation of Micromorphological Features of Soils and Regoliths. Elsevier: Amsterdam, 569-588.

Aitchison J 1990 'Relative variation diagrams for describing patterns of compositional variability', Journal of Mathematical Geology 22, 487-511.

Aitchison J and Egozcue J J 2005 'Compositional Data Analysis: where are we and where should we be heading?', Math Geol 37(7), 829-850.

Aitken, M J and Hawley, H N 1967 'Archaeomagnetic measurements in Britain IV' Archaeometry 10, 129-35.

Alexander, D 2005 'Redcastle, Lunan Bay, Angus : the excavation of an Iron Age timber-lined souterrain and a Pictish barrow cemetery', Proc Soc Antiq Scot 135, 41-118 .

Alexander, S 2007 Fading of Luminescence of Feldspars, Unpublished PhD Thesis, University of Glasgow

Alexander Bentley, R 2006 'Strontium isotopes from the earth to the archaeological skeleton: a review', Journal of Archaeological Method and Theory 13(3), 135-187.

Ambrose, S H 1993 'Isotopic analysis of palaeodiets: methodological and interpretative considerations', in Sandford M K (ed) Investigations of Ancient Human Tissue: Chemical Analyses in Anthropology, Gordon and Breach: Langhorne, Pennsylvannia, 59-130. 
Anderson, E C., Libby, W F., Weinhouse, S., Reid, A F, Kirshenbaum, A D and Grosse, A V 1947 'Natural radiocarbon from cosmic radiation', The Physical Review 72, 931-936.

Anderson, E C and Libby, W F 1951 'World-wide distribution of natural radiocarbon', The Physical Review 81, 64-69.

Anderson J 1895 'Notice of a cave recently discovered at Oban, containing human remains, and a refuse-heap of shells and bones of animals, and stone and bone implements'. Proc Soc Antiq Scot 29 (1894-5), 211-30.

Anthony I M C 2004 'Luminescence Dating of Scottish Burnt Stone Mounds : New results from sites Orkney and Shetland', Unpublished PhD Thesis University of Glasgow

Anthony I M C., Sanderson D C W., Cook, G T., Abernethy D and Housley R A 2001 'Dating a burnt mound from Kilmartin, Argyll, Scotland', Quaternary Science Reviews 20, 921-925.

Armit, I 2006 Anatomy of an Iron Age Wheelhouse: The Cnip Excavations, Lewis. Society of Antiquaries of Scotland: Edinburgh.

Ascough, P L., Cook, G T., Dugmore, A J., Barber, J., Higney, E and Scott, E M 2004 'Holocene variations in the Scottish marine radiocarbon reservoir effect', Radiocarbon 46, 611-620.

Ascough, P L., Cook, G T and Dugmore, A J 2005a 'Methodological approaches to determining the marine radiocarbon reservoir effect', Progress in Physical Geography 29, 532-547.

Ascough, P L., Cook, G T., Dugmore, A J., Scott, E M and Freeman, S P H T 2005b 'Influence of mollusc species on marine $\Delta R$ determinations'. Radiocarbon 47, 433-440.

Ascough, P L, Cook, G T, Church, M J., Dugmore, A J., Arge, S V and McGovern, T H 2006 'Variability in North Atlantic marine radiocarbon reservoir effects at c.1000 AD', The Holocene 16, 131-136.

Ascough, P L., Cook, G T., Dugmore, A J. and Scott, E M 2007 'The North Atlantic Marine Reservoir Effect in the Early Holocene: Implications for Defining and Understanding MRE Values'. Nuclear Instruments and Methods in Physics Research B 259, 438-447.

Ascough, P L., Cook, G T and Dugmore, A J 2009 'North Atlantic marine ${ }^{14} \mathrm{C}$ reservoir effects: implications for late-Holocene chronological studies'. Quaternary Geochronology, 4(3), 171-180.

Ashmore, P 2005 'Dating Barnhouse' in Richards, C (ed) Dwelling among the monuments: the Neolithic village of Barnhouse, Maeshowe passage grave and surrounding monuments at Stenness, Orkney MacDonald Institute for Archaeological Research: Cambridge, 385-389

Atkinson, D., Dalland, M. and van Wessel, J 2009 City of Adelaide, Laser scan survey. Headland Archaeology. Unpublished report COA07.

Bacvarov, K., McSweeney, K and Ignatova-Terziyska, S 2011 Interdisziplinäre Forschungen Früher Gefässbestattungen (Interdisciplinary research of earlier vessel burials, in German). in Nikolov, V., 
Bacvarov, $\mathrm{K}$ and Popov, $\mathrm{H}$ (eds) Interdisziplinäre Forschungen zum Kulturerbe auf der Balkanhalbinsel. Humboldt Union in Bulgarien: Sofia, 151-162.

Bacvarov, K and McSweeney, K 2011 Potted babies: a bioarchaeological approach to the study of jar burial symbolism. Festschrift for Marion Lichardus-Itten. Studia Praehistorica 14. Bulgarian Academy of Sciences, National Institute of Archaeology and Museum: Sofia, 399-408.

Baillie, M G L 1977 'An oak chronology for south central Scotland', Tree-Ring Bulletin, 37, 33-44.

Baillie M G L 1982 Tree-Ring Dating and Archaeology The University of Chicago Press: Chicago.

Balasse, M., Tresset, A., Dobney, $\mathrm{K}$ and Ambrose, S H 2005 'The use of isotope ratios to test for seaweed eating in sheep', Journal of Zoology 266, 283-291.

Balasse, M., Tresset, A and Ambrose, S H 2006 'Stable isotope evidence $\left({ }^{13} \mathrm{C},{ }^{18} \mathrm{O}\right)$ for winter feeding on seaweed by Neolithic sheep of Scotland', Journal of Zoology 270, 170-176.

Balasse, M., Mainland, I and Richards, M 2009 'Stable isotope evidence for seasonal consumption of marine seaweed by modern and archaeological sheep in the Orkney archipelago (Scotland)', Environmental Archaeology 14, 1-14.

Ballantyne, C K 2002 'A general model of paraglacial landscape response', The Holocene 12, 371-376.

Ballantyne C K 2004 'Geomorphological changes and trends in Scotland: debris-flows'. Scottish Natural Heritage Commissioned Report No. 052 (ROAME No. F00AC107A).

Ballantyne, C K 2008 'After the Ice: Holocene geomorphic activity in the Scottish Highlands', Scottish Geographical Journal 124 (1), 8-52.

Ballin T B and Faithfull, J 2009 'Gazetteer of Arran Pitchstone Sources: Presentation of exposed pitchstone dykes and sills across the Isle of Arran, and discussion of the archaeological relevance of these outcrops', Scottish Archaeological Internet Reports [online] 38. Society of Antiquaries of Scotland: Edinburgh. Available at <http://www.sair.org.uk/sair38/index.html $>$ [Accessed 08 December 2011].

Banks, I., Alldritt, D., Duncan, J.S., Photos-Jones, E., Simpson, I A., Taylor, K and Simpson, B 2000 'Excavation of an Iron Age and Romano-British enclosure at Woodend Farm, Johnstonebridge, Annandale, 1994 and 1997', Proc Soc Antiq Scot 130, 223-281.

Barclay, G., Brophy, K and MacGregor, G 2002 'Claish, Stirling: an early Neolithic structure and its context', Proc Soc Antiq Scot 132, 65-137.

Bar-Matthews, M., Marean, C W., Jacobs, Z. et al. 2010 'A high resolution and continuous isotopic speleothem record of palaeoclimate and paleoenvironment from 90 to 53 ka from Pinnacle Point on the south coast of South Africa', Quaternary Science Reviews 29, 2131-2145.

Barclay, G 1985 ‘Excavations at Upper Suisgill, Sutherland', Proc Soc Antiq Scot 115, 159-198. 
Barclay, G J and Russell-White, C J 1993 'Excavations in the ceremonial complex of the fourth to second millennium BC at Balfarg/Balbirnie, Glenrothes, Fife', Proc Soc Antiq Scot 123, 43-210.

Barclay, G J., Carter, S P., Dalland, M M., Hastie, M., Holden, T H.,MacSween, A and Wickham-Jones, C R 2001 'A possible Neolithic settlement at Kinbeachie, Black Isle, Highland.' Proc Soc Antiq Scot $131,57-85$.

Barclay, G J., Brophy, K and MacGregor, G 2002 'Claish, Stirling: An Early Neolithic Structure in its Context', Proc Soc Antiq Scot 132, 65-137.

Barclay, G J and Ritchie, A (eds 2010 'Artefactual, Environmental and Archaeological evidence from the Holyrood Parliament Site Excavations', Scottish Archaeological Internet Reports [online] 40. Society of Antiquaries of Scotland: Edinburgh. Available at <http://www.sair.org.uk/sair40/index.html> [Accessed 19 January 2012].

Barrett J H 1995 "Few know an earl in fishing-clothes'. Fish middens and the economy of the Viking Age and Late Norse earldoms of Orkney and Caithness, northern Scotland', Unpublished Ph.D Thesis. The University of Glasgow.

Barrett J H 1997 'Fish trade in Norse Orkney and Caithness: A zooarchaeological approach', Antiquity 71, 616-638.

Barrett J H 2003 'Excavations at Quoygrew (Orkney, Scotland) and the growth of the mediaeval fish trade', in Pieters, M., Verhaeghe, F., Gevaert, G., Mees, J and Seys, J (eds) Colloquium: Fishery, trade and piracy - fishermen and fishermen's settlements in and around the North Sea area in the Middle Ages and later, Instituut voor het Archeologisch Patrimonium Rapport 13: Oostende, 8-12.

Barrett J H 2005 'Economic intensification in Viking Age and medieval Orkney, Scotland: Excavations at Quoygrew', in Mortensen, A and Arge, S V (eds) Viking and Norse in the North Atlantic: Select papers from the proceedings of the fourteenth Viking Congress, Tórshavn, 19-30 July 2001, Føroya Fródhskaparfelag, Annales Societatis Scientiarum Færoensis Supplementum XLIV: Tórshavn, 264283.

Barrett J H., Nicholson R A and Cerón-Carrasco R 1999 'Archaeo-ichthyological evidence for longterm socioeconomic trends in northern Scotland: 3500 BC to AD 1500', Journal of Archaeological Science 26, 353-388.

Barrett J H., Beukens R P and Nicholson R A 2001 'Diet and ethnicity during the Viking colonisation of northern Scotland: Evidence from fish bones and stable carbon isotopes', Antiquity 75, 145-154.

Barrett J H., Johnstone C., Harland J., Van Neer W., Ervynck A., Makowiecki D., Heinrich D., Hufthammer A K., Enghoff I B., Amundsen C., Christiansen J S., Jones A K G., Locker A., HamiltonDyer S., Jonsson L., Lõugas L., Roberts C and Richards M 2008 'Detecting the medieval cod trade: A new method and first results', Journal of Archaeological Science 35(4), 850-861.

Barton, N B., Berridge, P J., Walker, M J C and Bevins, R E 1995 'Persistent places in the Mesolithic landscape: an example from the Black Mountain Uplands of South Wales', Proceedings of the Prehistoric Society 61, 81-116. 
Bass, W M 2005 (Fifth Edition) Human Osteology: A Laboratory and Field Manual. Special Publication No.2 of the Missouri Archaeological Society: Columbia, Missouri.

Bathurst, R., Zori, D and Byock, J 2010 'Diatoms as bioindicators of site use: locating turf structures from the Viking Age', Journal of Archaeological Science 37, 2920-2928.

Battarbee, R W., Cameron, N G., Golding, P., Brooks, S J., Swirsur, R., Harkness, D., Appleby, P., Oldfield, F., Thompson, R., Monteith, D T., and McGovern, A 2001 'Evidence for Holocene climate variability from the sediments of a Scottish remote mountain lake', Journal of Quaternary Science $16,339-346$.

Baxter, M J, 1994 Exploratory multivariate analysis in archaeology, Edinburgh University Press: Edinburgh.

Baxter, M J 2011 'Statistical modelling of artefact compositional data', Archaeometry 23, 131-148.

Bayliss, A and Bronk Ramsay, C 2004 'Pragmatic Bayesians: a decade of integrating radiocarbon dates into chronological models', in Buck, C E and Millard, A (eds) Tools for Constructing Chronologies- crossing disciplinary boundaries Springer Verlag: London, 25-41.

Beck, C W and Shennan, S 1991 Amber in Prehistoric Britain, Oxbow: Oxford.

Bendall C., Wigg-wolf D., Lahaye Y., Von Kaenel H-M and Brey G P 2009 'Detecting changes of Celtic gold sources through the application of trace element and $\mathrm{Pb}$ isotope laser ablation analysis of Celtic gold coins', Archaeometry 51(4), 598-625.

Bennett, K D., Boreham, S., Sharp, M J. and Switsur, V R 1992 'Holocene history of environment, vegetation and human settlement on Catta Ness, Lunnasting, Shetland', Journal of Ecology 80, 241273.

Bennett, K D., Whittington, G and Edwards, K J 1994 'Recent plant nomenclatural changes and pollen morphology in the British Isles', Quaternary Newsletter 73, 1-6.

Berstan R., Dudd S N., Copley M S., Morgan, E D., Quye, A and Evershed, R P 2004 'Characterisation of 'bog butter' using a combination of molecular and isotopic techniques', Analyst 129, 270 - 275.

Bertini N, Shortland A, Milek K and Krupp E M 2011 'Investigation of Iron Age north-eastern Scottish glass beads using element analysis with LA-ICP-MS', Journal of Archaeological Science 38(10), 27502766.

Bigelow, G., Ferrante, S M., Hall, S T., Kimball, L M., Proctor, R E and Remington, S L 2005 'Researching catastrophic environmental changes on northern coastlines: A geoarchaeological case study from the Shetland Islands', Arctic Anthropology 42, 88-102.

Birks, H J B 2000 'Chironomid-inferred Late-glacial air temperatures at Whitrig Bog, southeast Scotland', Journal of Quaternary Science 15, 759-764.

Bishop A H 1914 'An Oronsay shell-mound: A Scottish pre-Neolithic site', Proc Soc Antiq Scot 48, 52108. 
Bishop, P., Sanderson, D C W and Stark M T 2004 'OSL and radiocarbon dating of a pre-Angkorian canal in the Mekong delta, southern Cambodia', Journal of Archaeological Science 31, 319-336.

Bishop, P., Sanderson D., Hansom J and Chaimanee, N 2006 'Age-dating of tsunami deposits: lessons from the $26^{\text {th }}$ December 2004 tsunami in Thailand', Geographical Journal (171), 379-384.

Bishop, R R., Church, M J and Rowley-Conwy, P A 2009 'Cereals, fruits and nuts in the Scottish Neolithic'. Proceedings of the Society of Antiquaries of Scotland 139, 47-103.

Bishop, W W and Coope, G R 1977 'Stratigraphical and faunal evidence for Lateglacial and early Flandrian environments in South-West Scotland', in Gray, J M and Lowe, J J (eds) Studies in the Scottish Lateglacial Environment, Pergamon: Oxford, 61-88.

Blackford, J J and Innes, J B 2006 'Linking current environments and processes to fungal spore assemblages: surface NPM data from woodland environments', Review of Palaeobotany and Palynology 141, 179-187.

Blakely, R 1977 (ed) Biocultural Adaptation in Prehistoric America, Southern Anthropological Society Proceedings No.11. University of Georgia Press: Athens.

Blundell A C and Barber K E 2005 'A 2800-year palaeoclimatic record from Tore Hill Moss, Strathspey, Scotland: the need for a multi-proxy approach to peat-based climate reconstructions', Quaternary Science Reviews 24, 1261-1277.

Blytheway, J A and Ross, A H 2010 'A Geometric Morphometric Approach to Sex Determination of the Human Adult Os Coxa', Journal of Forensic Sciences 55.4, 859-864.

Bocherens, $\mathrm{H}$ and Drucker, D 2003 'Trophic level isotopic enrichment of carbon and nitrogen in bone collagen: case studies from recent and ancient terrestrial ecosystems', International Journal of Osteoarchaeology 13(1-2), 46-53.

Bogdan, N Q., Hodgson, G W I., Smith, C., Jones, A., Fraser, M., Heppel, D., Clarke, A S., Jones, A K G., Smart, I H M., Longmore, R B., Ceron-Carrasco, R and MacKay, D (in press) The Perth High Street Archaeological Excavation. Fascicule IX. The environmental evidence. Historic Scotland Report: Edinburgh.

Bohncke, S J P 1988 'Vegetation and habitation history of the Callanish area', in Birks, H J B., Birks, P E., Kaland, P E and Moe, D (eds) The cultural landscape: past, present and future. Cambridge University Press: Cambridge, 445-461.

Bond, J 2002 'Pictish pigs and Celtic cowboys: food and farming in the Atlantic Iron Age'. in Ballin Smith, B and Banks, I (ed) In the Shadow of the Brochs; the Iron Age in Scotland. Tempus: Stroud, 177-190.

Bond, J 2007 'The bioarchaeological evidence', in Hunter, J (ed) Investigations in Sanday, Orkney. Vol 1: Excavations at Pool, Sanday. The Orcadian Itd: Kirkwall, 169-286. 
Bond, J M., Guttmann, E and Simpson, I A 2004 'Bringing in the sheaves: farming intensification in the post-broch Iron Age', in Housley, R and Coles, G (eds) The North Atlantic: Culture and Environment. Oxbow Monographs: Oxford, 138-145.

Bond, J M., Nicholson, R A and Simpson, I A 2005 'Living off the land: farming and fishing at Old Scatness', in Turner V E., Nicholson R A., Dockrill S J and Bond J M (eds) Tall Stories? Two millennia of Brochs. Shetland Amenity Trust: Lerwick, 209-218.

Bond, J M., Nicholson, R A and Cussans, J E 2010 'Biological evidence', in Dockrill, S J., Bond, J M., Turners, V., Brown, L D., Bashford, D., Cussans, J E and Nicholson, R A. (eds) Excavations at Old Scatness Broch 1: The Pictish Village and Viking Settlement. Shetland Heritage: Lerwick, 131-206

Bonsall, C., Cook, G., Manson, J and Sanderson, D 2002 'Direct dating of Neolithic pottery: progress and prospects', $\left(8^{\text {th }}\right.$ Neolithic Studies) Documenta Praehistorica 29, 47-59.

Bonsall, J C and Sutherland, D G 1992 'The Oban Caves', in Walker, M J C., Gray, J M and Lowe, J J (eds) The South-West Scottish Highlands: Field Guide. Quaternary Research Association: Cambridge, 115-121.

Bowler, D P 2004 Perth: the Archaeology and Development of a Scottish Burgh Tayside and Fife Archaeological Committee \Historic Scotland: Perth.

Boyd, W E 1982 'Archaeological implications of a new palaeoenvironmental model for part of the Ayrshire coast', Glasgow Archaeological Journal 9, 15-17.

Bradley, R 2000 An Archaeology of Natural Places. Routledge: London.

Brayshay, B A., Gilbertson, D D., Kent, M., Edwards, K J., Wathern, P. and Weaver, R E 2000 'Surface pollen-vegetation relationships on the Atlantic seaboard: South Uist, Scotland', Journal of Biogeography 27, 359-378.

Brickley, M and McKinley, J 2004 Guidelines to the Standards for Recording Human Remains. BABAO and IFA. Available at < http://www.babao.org.uk/HumanremainsFINAL.pdf>. Accessed 09 December 2011.

Bridge M C, Haggart B A and Lowe J J 1990 'The history and palaeoclimatic significance of subfossil remains of Pinus sylvestris in blanket peats from Scotland', Journal of Ecology 78, 77-99.

Britton, K., Muldner, G and Bell, M 2008 'Stable isotope evidence for salt-marsh grazing in the Bronze Age Severn Estuary, UK: implications for palaeodietary analysis at coastal sites', Journal of Archaeological Science 35, 2111-2118.

Britton, K., Grimes, V., Dau, J and Richards, M P 2009 'Reconstructing faunal migrations using intratooth sampling and strontium and oxygen isotope analyses: a case study of modern caribou (Rangifer tarandus granti)', Journal of Archaeological Science 36, 1163-1172.

Bronk Ramsey, C., Manning, S W., Reimer, P J., and van der Plicht, H 2006 'Developments in radiocarbon calibration for archaeology', Antiquity 80, 783-798. 
Brooks, S J 1996 'Three thousand years of Environmental History in a Cairngorms Lochan Revealed by Analysis of Non-biting Midges (Insecta: Diptera: Chironomidae)', Botanical Journal of Scotland 48, 89-98.

Brooks, S J and Birks, H J B 2000 'Chironomid-inferred Late-glacial air temperatures at Whitrig Bog, southeast Scotland', Journal of Quaternary Science 15, 759-764.

Brooks, S J 2006 'Fossil midges (Insecta: Diptera: Chironomidae) as palaeoclimatic indicators for the Eurasian region', Quaternary Science Reviews 25, 1894-1910.

Brooks, S J and Birks, H J B 2000 'Chironomid-inferred late-glacial air temperatures at Whitrig Bog, south-east Scotland', Journal of Quaternary Science 15, 759-764.

Brooks, S J and Birks, H J B 2001 'Chironomid-inferred air temperatures from late-glacial and Holocene sites in north-west Europe: progress and problems', Quaternary Science Reviews 20, 17231741.

Brophy, K 1999a The cursus monuments of Scotland. PhD thesis, University of Glasgow

Brophy, K 1999 'The cursus monuments of Scotland', in Barclay, A and Harding, J (eds) Pathways and ceremonies: the cursus monument of Britain and Ireland. Neolithic Studies Group Seminar Papers 4: Oxford, 119-29.

Brophy, K 2000 The cursus monuments of Scotland, Unpublished PhD thesis, University of Glasgow

Brophy, K 2012 Reading between the lines: the Neolithic cursus monuments of Scotland. Stroud: Amberley.

Brophy, K and Cowley, D C (eds) 2005 From the Air: understanding aerial archaeology, Tempus: Stroud.

Brothwell, D and Pwers, R 1966 'A massive cist with multiple burials of Iron Age date. Part III The Iron Age people of Dunbar', Proc Soc Antiq Scot 98, 184-198.

Brothwell, D R., Bishop, A C and Woolley, A R 1974 'Vitrified forts in Scotland: a problem in interpretation and primitive technology', Journal of Archaeological Science 1, 101-107.

Brown, A G 1997 Alluvial Geoarchaeology, Cambridge University Press: Cambridge.

Brown, A G 2009 'Colluvial and alluvial response to land use change in Midland

England: an integrated geoarchaeological approach', Geomorphology 108, 92-106.

Bruce, M., Cross, J F and Kerr, N W 1997 'Human remains', in Rains, M J and Hall, D W (eds) Excavations in St Andrews 1980-1989. A Decade of work in a historic Scottish burgh, Tayside and Fife Archaeological Committee (Monograph 1): Glenrothes, 118-31.

Bryant, R G and Davidson, D A 1996 'The use of image analysis in the micromorphological study of old cultivated soils: an evaluation based on soils from the Island of Papa Stour, Shetland', Journal of Archaeological Science 23, 811-822. 
Buckland, P C 1995 'A Beetle fauna from the organic deposit F23 in the stone-lined pit (F22)', in McCormick, F 'Excavation at Pluscarden Priory, Moray', Proc Soc Antiq Scot 124, 417-418.

Buckland, P C 1999 'An insect fauna from the Biggins', in Crawford, B E and Ballin Smith, B The Biggins, Papa Stour, Shetland. The history and archaeology of a royal Norwegian farm, Society of Antiquaries of Scotland (Monograph Series 15): Edinburgh, 120-122.

Buckland, P C 2002 'Insect fauna from within the cranium of skeleton 570', in Driscoll, S T Excavations at Glasgow Cathedral 1988-1997, Society for Medieval Archaeology (Monograph 18) Maney Publishing, 157.

Buckland, P C and Sadler, J P 1989 'A biogeography of the human flea, Pulex irritans L. (Siphonaptera : Pulicidae)', Journal of Biogeography 16, 115-120.

Buckland, P C and Dinnin, M J 1993 'Holocene Woodlands: the Fossil Insect Evidence', in Kirby, K and Drake, C M (eds) Dead wood matters: the ecology and conservation of saproxylic invertebrates in Britain, English Nature (Science 7): Peterborough, 6-20.

Buckland, P C., Sadler, J P and Smith, D 1993 'An Insect's Eye-view of the Norse Farm', in Batey, C E., Jesch, J and Morris, C D (eds) The Viking Age in Caithness, Orkney and the North Atlantic, Edinburgh University Press: Edinburgh, 518-528.

Buckland, P C., Sadler, J P and Smith, R F 1996 'Contrasting Patterns of Polar Biogeography. North and South in Atlantic Insect Populations', in Biscoito, M J (ed) Proceedings of the 1st Symposium, Fauna and Flora of the Atlantic Islands. Boletim do Museu Municipal do Funchal (História Natural), Suppl. 4, 145-174.

Buckland, P C and Sadler, J P 1997 'Insects', in Edwards, K J and Ralston, I B M (eds) Scotland. Environment and Archaeology 8,000 BC to AD 1000, J. Wiley and Sons: Chichester, 105-108.

Buckland, P C., Panagiotakopulu, E and Buckland, P. I. 2004a 'Fossil insects and the Neolithic: methods and potencial', Antaeus, 27, 235-252.

Buckland, P C., Panagiotakopulu, E and Buckland, P I 2004b 'What's eating Halvdan the Black? Fossil insects and the study of a burial mound in its landscape context', in Larsen, J H and Rolsen, P Halvdanshaugen - arkeologi, historie og naturvitenskap. Universitetets Kulturhistoriske Museer Skrifter 3(35): Oslo, 3-376.

Buckland P I and Buckland P C 2006 Bugs Coleopteran Ecology Package (Versions: BugsCEP v7.63; Bugsdata v7.11; BugsMCR v2.02; BugStats v1.22).

Buckley, P et al. 2009 'Species identification by analysis of bone collagen using matrix-assisted laser desorption/ionisation time-of-flight mass spectrometry', Rapid Commu Mass Spec 23, 3843-3854.

Buikstra, J E and Ubelaker, D H 1994 Standards for Data Collection from Human Skeletal Remains: Proceedings of a Seminar in the Field Museum of Natural History Organized by Jonathan Haas. Arkansas Archaeological Survey Research series No. 44: Fayetteville, Arkansas. 
Buikstra, J E and Beck, L A (eds) 2006 Bioarchaeology: The contextual analysis of human remains, Elsevier: London.

Bull, I D., Simpson, I A., van Bergen, P F. and Evershed, R P 1999 'Muck ' $n$ ' molecules: organic geochemical methods for detecting ancient manuring', Antiquity 73, 86-96.

Bunting, M J 2003 'Pollen-vegetation relationships in non-arboreal moorland taxa', Review of Palaeobotany and Palynology 125, 285-298.

Bunting, M J and Middleton, D 2005 'Modelling pollen dispersal and deposition using HUMPOL software, including simulating windroses and irregular lakes', Review of Palaeobotany and Palynology 134, 185-196.

Burbidge C I., Allsworth Jones P., Housley R A., Sanderson D C W., Pyle D., Bazely O., McCave N and van Andel T 2005 Middle Palaeolithic sites in Russia and Ukraine: site summaries and fieldwork 2004 University of Glasgow: Glasgow.

Burbidge C I., Sanderson D C W., Housley R A., and Allsworth Jones P 2007 'Survey of Palaeolithic sites by luminescence profiling, a case study from Eastern Europe', Quaternary Geochronology 2(14), 296-302

Bytheway, J A and Ross, A H 2010 'A Geometric Morphometric Approach to Sex Determination of the Human Adult Os Coxa', Journal of Forensic Sciences 55(4), 859-864.

Calder S T 1937 'A Neolithic Double-Chambered Cairn of the Stalled Type and Later Structures on the Calf of Eday, Orkney', Proc Soc Antiq Scot 71 (1936-37), 156-60.

Caldwell, D H and Dean, V E 1992 'The Pottery London, Cockspow and Stirling Industry at Throsk, Stirlingshire, in the 17th and early 18th century', Post-Medieval Archaeology 26, 1-46.

Callander, J G., Cree, J E., Ritchie, J 1927 'Preliminary reports on caves containing Paleolithic relics near Inchnadamph, Sutherland', Proc Soc Antiq Scot 61, 169-172.

Cameron, A S and Stones, J A (eds) 2001 Aberdeen: An in-depth view of the city's past; excavations at seven major sites within the medieval Burgh. Society of Antiquaries of Scotland: Edinburgh.

Card, N., Cluett, J., Downes, J., Gater, J and Ovenden, S 2007 'Bringing a landscape to life? researching and managing the 'The Heart of Neolithic Orkney' World Heritage Site', World Archaeology 39(3), 417-435.

Cardy, A 1997 'The environmental material. The human bones', in Hill, P. Whithorn and St Ninian: the excavations of a monastic town 1984-1991. Sutton Publishing: Stroud, 51-62.

Carter, S 1998 'Palaeopedology', in McCullagh, R P J and Tipping, R (eds) The Lairg Project 19881996. The Evolution of an Archaeological Landscape in Northern Scotland. Scottish Trust for Archaeological Research Monograph 3: Edinburgh, 150-161. 
Cavers, M G., Hepher, J and Hale, A 2008 'A comparison of laser scanning and photogrammetric techniques used to record rock art at Ormaig, Argyll, Scotland', $6^{\text {th }}$ World Archaeology Congress (WAC6), Dublin.

Cavers, M G., Henderson, J C., Barber, J and Heald, A 2010 'Towards a total archaeological record: integrated 3D survey and archaeological recording at Kiess, Caithness, Scotland' in Jerem, E., Redö, $F$ and Szeverényi, V (eds) CAA2008. On the Road to Reconstructing the Past. Proceedings of the 36th Annual Conference on Computer Applications and Quantitative Methods in Archaeology. Budapest, 2-6 April 2008. Budapest, 2010, Budapest: Archaeolingua.

Cavers, G., Crone, A., Engl, R., Fouracre, L., Hunter, F., Robertson, J and Thoms, J 2011 'Excavations at Dorman's Island, Whitefield Loch: an Iron Age Crannog in SW Scotland', J Wetland Archaeol 10, 71108.

Ceron-Carrasco R 1994 'Investigation of the fish remains from an Orkney farm mound', in Van Neer, W (ed) 'Fish Exploitation in the Past'. Annales del Musée Royal de l'Afrique Centrale, Sciences Zoologiques 274: Tervuren, 122-155.

Ceron-Carrasco 1998a 'Fishing: Evidence for Seasonality and Processing of Fish for Preservation in the Northern Isles of Scotland During the Iron Age and Norse Times', Environmental Archaeology 3, 73-80.

Ceron-Carrasco R 1998b 'The fish remains', in Ewart G and Baker F 'Carrick Castle: symbol and source of Campbell power in south Argyll from the 11th to 17th century', Proc Soc Antiq Scot 128, 992-4.

Ceron-Carrasco R 1998c 'The fish bone assemblage from St. Boniface, Papa Westray, Orkney', in Lowe, C St. Boniface Church, Orkney: Coastal Erosion and Archaeological Assessment. Sutton Publications: Edinburgh and Historic Scotland, 149-155.

Ceron-Carrasco R 1998d 'The fish remains from Scalloway, Shetland', in Sharples, N Scalloway on Shetland: A Broch and its Environments. Oxbow Monograph 82: Oxford.

Ceron-Carrasco R 1999 'The fish remains from Dun Vulan, South Uist', in Parker-Pearson, M and Sharples, N Between Land and Sea. Excavations at Dun Vulan, South Uist. Sheffield Univesity Academic Press: Sheffield, 274-282.

Ceron-Carrasco R 2000a 'The Fish Remains from Murraygate, Dundee', in Brown, G and Roy, M 'Excavations at 27-35 Panmure Street/72-8 Murraygate, Dundee', Tayside and Fife Archaeological Journal 6, 32-69.

Ceron-Carrasco R 2000b 'The fish remains', in Cachart, R 'Excavations at South Street, St. Andrews', Tayside and Fife Archaeological Journal 6, 128-130.

Ceron-Carrasco R 2001 'The fish remains'. in Moloney, C and Baker, L M 'Evidence for the form and nature of a medieval burgage plot in St. Andrews: an archaeological excavation of the site of the Byre Theatre, Abbey Street, St. Andrews', Tayside and Fife Archaeological Journal 7, 48-86. 
Ceron-Carrasco R 2005 'Of Fish and Men' (De iasg agus dhaoine): Aspects of the utilisation of marine resources as recovered from selected Hebridean archaeological sites. British Archaeological Reports British Series 400: Oxford.

Ceron-Carrasco R 2007 'Fish Remains' in Toolis, R and Sproat, D 'The transformation of an early postmedieval town into a major modern city: excavation and survey of the Waverly Vaults, New Street, Edinburgh, Scotland', Post-medieval Archaeology 41(1), 155-179.

Ceron-Carrasco, R., Stone, D and Bonsall, C 2007 'Marine Resource Exploitation in Scotland: Introducing the MaRES DATABASE', in Huster Plogmann, H (ed) The Role of Fish in Ancient Times. Proceedings of the $13^{\text {th }}$ Meeting of the ICAZ Fish Remains Working Group. Basel 2005. Verlag Marie Leidorf GmbH: Rahden/Estf.

Chamberlain, A 2006 Demography in Archaeology. Cambridge University Press: Cambridge.

Chapman, R J., Leake, R C., Warner, R A., Cahill, M C., Moles, N R., Shell, C A and Taylor, J J 2006 'Microchemical characterisation of natural gold and artefact gold as a tool for provenancing prehistoric gold artefacts: a case study in Ireland', Applied Geochemistry 21(6), 904-18.

Charisi, D., Eliopolis, C., Vanna, V. Koilias, C G. and Maniolis, S K 2011 'Sexual Dimorphism of the Arm Bones in a Modern Greek Population' Journal of Archaeological Science 56, 10-18.

Charles, M and Halstead, P 2001 'Biological resource exploitation', in Brothwell, D R and Pollard, A M (eds) Handbook of Archaeological Sciences. Wiley: Chichester, 359-440.

Charman, D J 2010 'Centennial climate variability in the British Isles during the mid-late Holocene', Quaternary Science Reviews 29, 1539-1554.

Charman D J., Blundell A., Chiverrell R C., Hendon, D and Langdon P G., 2006 'Compilation of nonannually resolved Holocene proxy climate records: Stacked records of Holocene peatland palaeowater table reconstructions from northern Britain', Quaternary Science Reviews 25, 336-350.

Charman, D J., Blundell, A and ACCROTELM Members 2007 'A new European testate amoebae transfer function for palaeohydrological reconstruction on ombrotrophic peatlands', Journal of Quaternary Science 22, 209-221.

Chenery, C., Muldner, G., Evans, J., Eckardt, H., Lewis, M., 2010 'Strontium and stable isotope evidence for diet and mobility in Roman Gloucester, UK'. Journal of Archaeological Science 37, 150163.

Chessa, B., Pereira, F., Arnaud, F., Amorim, A., Goyache, F., Mainland, I. et al. 2009 'Revealing the history of sheep domestication using retrovirus integrations', Science 324, 532-536.

Chesterman, J T 1979 'Investigations of the human bone from Quanterness', in Renfrew, C Investigations in Orkney, Society of Antiquaries of London: London, 98-111.

Chesterman, J T 1983 'The human skeletal remains', in Hedges, J W Isbister, a chambered tomb. British Archaeological Reports British Series 115: Oxford, 73-132. 
Chirtz, K L., Dykeb, G J., Zazzoc, A., Listerd, A M., Monaghane, N T and Sigwartb, J D 2009 'Palaeobiology of an extinct Ice Age mammal: Stable isotope and cementum analysis of giant deer teeth', Palaeogeography, Palaeoclimatology, Palaeoecology 282, 133-144.

Church, M J and Peters, C 2004 'Application of mineral magnetism in Atlantic Scotland archaeology 2: magnetic susceptibility and archaeobotanical taphonomy in West Lewis, Scotland', in Housley, R A and Coles, G M (eds) Atlantic Connections and Adaptations: Economies, Environments and Subsistence in Lands Bordering the North Atlantic. Oxbow Books: Oxford, 99-115.

Church, M J., Peters, C., Batt, C M. 2007 'Sourcing fire ash on archaeological sites in the Western and Northern Isles of Scotland, using mineral magnetism', Geoarchaeology 22(7), 747-774.

Clark, A J., Tarling, D H and Noel, M 1988 'Developments in archaeomagnetic dating in Britain'. Journal of Archaeological Science 15(6), 645-667.

Clarke, C., Utsi, E and Utsi, V 1999 'Ground penetrating radar investigations at North Ballachulish Moss, Highland, Scotland', Archaeological Prospection 6, 107-121.

Clark, P A 1994 Isochron Methods for Luminescence Dating in Archaeology, Unpublished PhD thesis, University of Glasgow

Clark, R J 1992 Photostimulated Luminescence as an Archaeological Dating Tool, Unpublished PhD thesis, University of Glasgow

Clark, R J H 2007 'The scientific investigation of artwork and archaeological artefacts: Raman microscopy as a structural, analytical and forensic tool', Appl. Phys. A 89, 833-840.

Clark, R J and Sanderson, D C W 1994 'Photostimulated Luminescence Excitiation Spectrometry Of Feldspars And Micas', Radiation Measurements 23(2/3), 641-646.

Clark, S H E 2003 'Insect faunas associated with the fossil remains of Pinus sylvestris L. in blanket peat from Northeast Scotland', Scottish Geographical Journal 119, 39-52.

Clark, S H E and Edwards, K J 2004 'Elm bark beetle in Holocene peat deposits and the northwest European elm decline', Journal of Quaternary Science 19, 525-528.

Clarke, C 1999 'Palynological investigations of a Bronze Age cist burial from Whitsome, Scottish Borders, Scotland', Journal of Archaeological Science 26, 553-560.

Clelland, S J., Batt, C M., Stern, B and Jones,R E 2009 'Scientific analysis of steatite: recent results, Chapter 11', in Forster, A K and Turner, V E (eds) Kleber: Shetland's oldest industry: Shetland soapstone since prehistory, Shetland Amenity Trust: Shetland, 106-17.

Coles, B 2001 'The impact of Western European beaver on stream channels: some implications for past stream conditions and human activity', Journal of Wetland Archaeology 1, 55-82.

Colley S 1983a The role of fish bone studies in economic archaeology: with special reference to the Orkney Isles. Unpublished Ph.D Thesis. University of Southampton. 
Colley S 1983b 'Interpreting prehistoric fishing strategies: an Orkney case study', in Grygson, C and Clutton-Brock, J (eds) Shell Middens Fishes and Birds. British Archaeological Reports International Series 183: Oxford, 157-171.

Colley S 1983c 'Marine resource exploitation', in Hedges, J W (ed) 'Trial excavations on Pictish and Viking Settlements at Saevar Howe, Birsay, Orkney', Glasgow Archaeological Journal 10(111-113), MF 87-92, MF 94-102.

Colley S 1984 'Some methodological problems in the interpretation of fish remains from archaeological sites in Orkney', in Desse-Berset, $\mathrm{N}$ (ed) $2^{\text {nd }}$ Fish Osteoarchaeology Meeting. Paris, Centre National de la Reserche Scietifique (Notes et Monografiques Techniques 16), 117-131.

Colley S 1987 'The marine faunal remains', in Hedges J W (ed) Bu, Gurness and the Brochs of Orkney - Part 1: Bu. British Archaeological Reports British Series 163: Oxford, 126-134.

Colley S 1989 'The fish bones', in Morris C D (ed) The Birsay Bay Project. Vol. 1. University of Durham, Department of Archaeology (Monograph Series Number 1): Durham, 248-259.

Conolly, J., Colledge, S., Dobney, K., Vigne, J D., Peters, J., Stopp, B., Manning, K and Shennan, S 2011 'Meta-analysis of zooarchaeological data from SW Asia and SE Europe provides insight into the origins and spread of animal husbandry', Journal of Archaeological Science 38(3), 538-545.

Cook, G T., Bonsall, C., Hedges, R E M., McSweeney, K., Boroneant, V and Pettitt, P B 2001 'A freshwater diet-derived reservoir effect at the stone age sites in the Iron Gates gorge', Radiocarbon $43,453-460$.

Cook, G T., Bonsall, C., Hedges, R E M., McSweeney, K., Boroneant, V., Bartosiewicz, L and Pettitt, P B 2002 'Problems of dating human bones from the Iron Gates', Antiquity 76, 77-85.

Cook, G T., Dixon, N., Russell, N., Naysmith, P., Xu, S and Andrian, B 2010 'High precision radiocarbon dating of the primary construction phase of Oakbank crannog, Loch Tay, Perthshire', Radiocarbon $52,346-355$.

Coope, G R 1962 'Coleoptera from a peat interbedded between two boulder clays at Burnhead near Airdrie'. Transactions of the Geological Society of Glasgow 24, 279-286.

Coope, G R 1968 'Fossil beetles collected by James Bennie from Late Glacial silts at Corstorphine, Edinburgh', Scottish Journal of Geology 4, 339-348.

Coope, G R 1986 'Coleoptera analysis', in Berglund, B E (ed) Handbook of Holocene Palaeoecology and Palaeohydrology, J. Wiley and Sons: Chichester, 703-713.

Coull, J R 1997 The Sea Fisheries of Scotland: A Historical Geography John Donald Publishers Ltd: Edinburgh

Courty, M A., Goldberg, P and Macphail, R I., 1989 Soils and Micromorphology in Archaeology. Cambridge Manuals in Archaeology. Cambridge University Press: Cambridge. 
Cowie, J., Cairns, D., Blunn, M., Wilson, C A., Pollard, E., Davidson, D A 2009 'Supporting geoarchaeologists in the field: a case study in decision support and knowledge management', International Journal of Information Management 29, 397-406.

Cowie, T G 1996 'Torrs Warren, Luce Sands, Galloway: a report on archaeological and palaeoecological investigations undertaken in 1977 and 1979' Trans Dumfriesshire Galloway Natur Hist Antiq Soc 71, 11-105.

Cowie, T., Northover, P and O'Connor, B 1998 'The St Andrews, Fife hoard: context and chronology in the Scottish Late Bronze Age', in Mordant, C., Pernot, C and Rychner, V (eds) L'atelier du bronzier en Europe du XXe au VIIle siècle avant notre ère, Paris, 141-54 (= Actes du colloque international 'Bronze '96' Neuchatel et Dijon 1996, Tome III).

Cowley, D C 2005 'Aerial Reconnaissance and Vertical Photography in Upland Scotland: Integrating the Resources', in Bourgeois, J and Meganck, M (eds) Aerial Photography and Archaeology, Archaeological Reports Ghent University, ARGU, Academia Press: Ghent, 267-280.

Cowley, D C 2008 'Cropmarked - aerial survey and the plough-levelled archaeology of East Lothian', Transactions of the East Lothian Antiquarian and Field Naturalists' Society XXVII, 1-19.

Cowley, D C 2009a 'The Traprain environs in a regional perspective', in Haselgrove, C (ed) The Traprain Law Environs Project - Fieldwork and Excavations 2000-2004, Society of Antiquaries of Scotland: Edinburgh, 205-23.

Cowley, D C 2009b 'Early Christian Cemeteries in south-west Scotland', in Murray, J (ed) St Ninian and the Earliest Christianity in Scotland: Papers from the conference held by The Friends of the Whithorn Trust in Whithorn on September 15th 2007, British Archaeological Reports British Series 483: Oxford, 43-56.

Cowley, D C 2011 'Remote sensing for archaeology and heritage management - site discovery, interpretation and registration', in Cowley D C (ed) Remote Sensing for Archaeological Heritage Management, Proceedings of the $11^{\text {th }}$ EAC Heritage Management Symposium, Reykjavík, Iceland, 2527 March 2010, Archaeolingua, 45-57.

Cowley, D C and Brophy, K 2001 'The impact of aerial photography across the lowlands of southwest Scotland', Trans Dumfries Galloway Natural Hist. Antiquarian Soc.75, 47-72.

Cowley, DC and Gilmour, S 2005 'Some observations on the nature of aerial survey' in Brophy, K and Cowley, DC (eds.) From the air: understanding aerial archaeology, Stroud: Tempus, 50-63

Cowley, D C and Gilmour, S 2003 'Discovery from the air: a pit-defined cursus monument in Fife' Scottish Archaeological Journal 25.2 (2003), Edinburgh University Press, 171-8

Cowley, D C and Dickson, A L 2007 'Clays and 'difficult soils' in eastern and southern Scotland: dealing with the gaps', in Mills, J and Palmer, R (eds) Populating Clay Landscapes: Recent advances in archaeology on difficult soils, Tempus: Stroud, 43-54.

Cowley, D C and Martin C 2011 'Coastal Command - surveying Scotland's maritime superhighway', Current Archaeology 258 (September 2011), 20-25. 
Cox, E., Owen, O and Pringle, D 1998 'The discovery of Medieval deposits beneath the Earl's Palace, Kirkwall, Orkney', Proc Soc Antiq Scot 128, 567-580.

Cox, M 2000 'Ageing adults from the skeleton', in Cox, M and Mays, S (eds) Human Osteology in Archaeology and Forensic Science Greenwich Medical Media Ltd: London, 61-82.

Craig, O E., Taylor, G., Mulville, J., Parker Pearson, M and Collins, M J 2005 'The identification of prehistoric dairying activities in the Western Isles of Scotland: an integrated biomolecular approach', Journal of Archaeological Science 32, 91-103.

Crawford, O G S 1930 'Editorial Notes', Antiquity IV, 273-8.

Crawford, O G S 1939 ‘Air Reconnaissance of Roman scotland', Antiquity XIII, 280-92

Crawford, O G S 1949 Topography of Roman Scotland: North of the Antonine Wall, Cambridge University Press: Cambridge.

Crone, A 1993 'Crannogs and chronologies' Proc Soc Antiq Scot 123, 245-54

Crone, B A 1997 'The dendrochronological evidence: a tree-ring chronology from Whithorn, Dumfries and Galloway', in Hill, P Whithorn and St Ninian. The Excavation of a Monastic Town 198491, 595-6. Sutton Publishing: Stroud

Crone, B A 1998a 'Dendrochronological analysis of three wooden posts', in Lelong, O and Pollard, T 'The excavation and survey of prehistoric enclosures at Blackshouse Burn, Lanarkshire', Proc Soc Antiq Scot 128, 42-3

Crone, B A 2000a 'Native tree-ring chronologies from some Scottish medieval burghs', Med Archaeol $44,201-216$.

Crone, A 2000b The History of a Scottish Lowland Crannog: Excavations at Buiston, Ayrshire 1989-90. Scottish Trust for Archaeological Research Monograph 4: Edinburgh

Crone, A 2002 'The wood assemblage; species composition, woodworking and dendrochronology', in Ellis, C., Crone, A., Reilly, E and Hughes, P 2002 'Excavation of a Neolithic wooden platform, Stirlingshire'. Proc Prehist Soc 68, 247-56.

Crone, B A 2006 'A $10^{\text {th }}$ century tree-ring event in Scotland - proxy evidence for social and economic change?', in Woolf, A (ed) Landscape and Environment in Dark Age Scotland St John's House Papers No. 11: St Andrews , 49-56.

Crone, B A 2008 'Dendrochronological analysis of the oak and pine timbers'. Stirling Castle Palace. Archaeological and historical research 2004-2008. Available online at http://sparc.scran.ac.uk Last accessed $29^{\text {th }}$ May 2012.

Crone, B A., Henderson, J C and Sands, R J S 2001 'Scottish crannogs: construction, conflation and collapse- problems of interpretation' in Raftery, B and Hickey, J (eds) Recent Developments in Wetland Research, University Monographs: Dublin, 55-67. 
Crone, A and Mills, C M 2002 'Seeing the wood and the trees: dendrochronological studies in Scotland', Antiquity 76, 788-794.

Crone, B A and Gallagher, D 2008 'The medieval roof over the Great Hall in Edinburgh Castle', Med Archaeol 52, 231-260.

Crone, A and Sproat, D 2011 'Revealing the history behind the façade: a timber-framed building at 302 Lawnmarket, Edinburgh' Architectural Heritage 22, 19-36.

Croudace, I W., Rindby, A. and Rothwell, R G 2006 'ITRAX: description and evaluation of a mew X-ray core scanner', in Rothwell, R G (ed) New ways of looking sediment cores and and core data. Geological Society Special Publication 267, 51-63.

Cross, J F and Bruce, F 1989 'The Skeletal Remains', in Stones, J A (ed) Three Scottish Carmelite Friaries. Excavations at Aberdeen, Linlithgow and Perth 1980-1986. Society of Antiquaries of Scotland (Monographs Series 6): Edinburgh, 119-42.

Cucchi, T., Barnett, R., Seale, J and Dobney, K 2009 'Analyses of the vole remains from excavations at the Holm of Papa Westray', in Ritchie, A (ed) On the fringe of Neolithic Europe: excavation of a chambered cairn on the Holm of Papa Westray, Orkney. Society of Antiquaries of Scotland: Edinburgh, 87-90.

Cucchi, T., Fujita, M and Dobney, K 2009 'New insights into pig taxonomy, domestication and human dispersal in Islands South East Asia: Molar shape analysis of Sus remains from Niah caves (Sarawak)', International Journal of Osteoarchaeology 19, 508-530.

Curran, J., Warke, P A., Stelfox, D., Smith, B J and Savage, J 2010 Stone by Stone: A Guide to Building Stone in the Northern Ireland Environment. Appletree Press: Belfast.

Cummings, V and Whittle, A W R 2003 'Tombs with a view: landscape, monuments and trees', Antiquity 77, 255-266.

Dalton, C., Birks, H J B., Brooks, S J., Cameron, N G., Evershed, R P., Peglar, S M., Scott, J A and Thompson, R 2005 'A multi-proxy study of lake-development in response to catchment changes during the Holocene at Lochnagar, northeast Scotland', Palaeogeography, Palaeoclimatology, Palaeoecology 221, 175-201

Damon, P E., Cheng, S and Linick, T W 1989 'Fine and hyperfine structure in the spectrum of secular variations of atmospheric ${ }^{14} \mathrm{C}^{\prime}$, Radiocarbon $31,704-718$.

D'Angela, D and Longinelli, A 1990 'Oxygen isotopes in living mammal's bone phosphate: further results.', Chemical Geology 86(1), 75-82.

Dansgaard, W 1964 'Stable isotopes in precipitation', Tellus 16, 436-468.

Davidson, D A 2002 'Bioturbation in old arable soils: quantitative evidence from soil micromorphology', Journal of Archaeological Science 29, 1247-1253. 
Davidson, D A and Simpson, I A 1984 'The formation of deep topsoils in Orkney', Earth Surface Processes and Landforms 9, 75-81.

Davidson, D A., Harkness, D D and Simpson, I A 1986 'The formation of farm mounds on the Island of Sandy, Orkney', Geoarchaeology 1(1), 45-59.

Davidson, D A., Carter, S A and Quine, T A 1992 'An evaluation of micromorphology as an aid to archaeological interpretation', Geoarchaeology 7(10), 55-65

Davidson, D A and Carter, S P 1998 'Micromorphological evidence of past agricultural practices in cultivated soils: the impact of a traditional agricultural system on soils in Papa Stour, Shetland', Journal of Archaeological Science 56, 417-428.

Davidson, D A and Simpson, I A 2001 'Archaeology and soil micromorphology', in Brothwell, D R and Pollard, A M (eds) Handbook of Archaeological Sciences. Wiley: Chichester, 167-177.

Davidson, D A and Carter, S P 2003 'Soils and their evolution', in Edwards, K J and Ralston, I B M (eds) Scotland: Environment and Archaeology 8000 BC-AD 1000. Wiley: Chichester, 45-62.

Davidson, D A and Simpson, I A 2005 'The time dimension in landscape ecology: cultural soils and spatial pattern in early landscapes', in Weins, J and Moss, M (eds) Issues in Landscape Ecology. Cambridge University Press: Cambridge, 152-158.

Davidson, D A., Dercon, G., Stewart, M and Watson, F 2006 'The legacy of past urban waste disposal on local soils', Journal of Archaeological Science 33, 778-783.

Davidson, D A., Dercon, G., Simpson, I A., Dalsgaard, K., Spek, T and Plant, D A 2007a 'The identification and significance of inputs to anthrosols in north-west Europe', Atti della Società Toscana di Scienze Naturali. Memorie serie A. 112, 79-83.

Davidson, D A., Wilson, C A., Meharg, A., Stutter, C and Edwards, K J 2007b 'The legacy of past manuring practices on soil contamination in remote rural areas', Environment International 33, 7883.

Davies, A D and Sanderson, D C W 2009 'Single grain OSL analysis: a discussion of how to clean discs', Ancient TL 27(2), 47-50

Davies, A L and Tipping, R 2004 'Sensing small-scale human activity in the palaeoecological record: fine spatial resolution pollen analyses from Glen Affric, northern Scotland', The Holocene 14, 233245.

Davies, A L., Tisdall, E. and Tipping, R 2004 'Holocene climatic variability and human settlement in the Scottish Highlands: fragility and robustness', in Housley, R A and Coles, G (eds) Atlantic connections and adaptations: economies, environments and subsitence in lands bordering the North Atlantic. Symposia for the Association of Environmental Archaeology No.21. Oxbow: Oxford, 2-11.

Dawson, A G., Smith, D E and Long, D 1990 'Evidence for a tsunami from a mesolithic site in Inverness, Scotland', Journal of Archaeological Science 17, 509-512. 
Deckers K., Sanderson, D C W and Spencer J Q 2005 'Thermoluminescence screening of nondiagnostic sherds from stream sediments to obtain a preliminary alluvial chronology: An example from Cyprus', Geoarchaeology 20(1), 67-77.

Demarchi, B., Williams, M G., Milner, N., Russell, N., Bailey, G and Penkman, K 2011 'Amino acid racemization dating of marine shells: a mound of possibilities', Quaternary International 239, 114124.

DeNiro, M J and Epstein, S 1978 'Influence of diet on the distribution of carbon isotopes in animals', Geochimica et Cosmochimica Acta 42(5), 495-506.

Dercon, G., Davidson, D A., Dalsgaard, K., Simpson, I A., Spek, T and Thomas, J 2005 'Formation of anthropogenic soils in NW Europe: identification of inputs based on particle size distribution', Catena 59, 341-356.

Dickson, J H., Dickson, C A and Breeze, D J 1979 'Flour or bread in a Roman military ditch at Bearsden, Scotland', Antiquity 53, 47-51.

Dimbleby, G W 1985 The palynology of archaeological sites. Academic Press: London.

Dinnin, M 1996 'The development of the Outer Hebridean entomofauna: a fossil perspective', in Gilbertson, D., Kent, M and Grattan, J (eds) The Outer Hebrides. The Last 14,000 Years, Sheffield Environmental and Archaeological Research Campaign in the Hebrides 2, Sheffield Academic Press: Sheffield. 163-184.

Dixon, N 2004 The Crannogs of Scotland: an Underwater Archaeology. Tempus: Gloucestershire.

Dockrill, S J., Gater, J A and Simpson, I A 2007 'Beyond Mound 11: Investigations within the Tofts Ness Landscape', in Dockrill, S J (ed) Investigations in Sanday, Orkney Volume 2: Tofts Ness, Sanday. An island landscape through 3,000 years of prehistory. Historic Scotland: Edinburgh, 113-141

Dockrill, S J., Bond, J M., Turner, V E., Brown, L D., Bashford, D., Cussans, J E and Nicholson, R A. 2009 Excavations at Old Scatness, Shetland Volume 1: The Pictish Village and Viking Settlement. Shetland Heritage Publications: Lerwick.

Downes, J., Foster, S M., Wickham-Jones, C R (eds) 2005 The Heart of Neolithic Orkney World Heritage Site Research Agenda. Historic Scotland: Edinburgh.

Dreibrodt, S., Nelle, O., Lütjens, I., Mitusov, A., Clausen, I and Bork, H R 2009 'Investigations on buried soils and colluvial layers around Bronze Age burial mounds at Börnhöved (northern Germany): an approach to test the hypothesis of 'landscape openness' by the incidence of colluviation', The Holocene 19 (3), 487-498.

Drew, C 2005 Refuse or ritual? The mammal bones High Pasture, Skye. Unpublished Masters Dissertation. University of Durham.

Driscoll, S T 1997 'A Pictish settlement in north-east Fife: the Scottish Field School of Archaeology excavations at Easter Kinnear', Tayside and Fife Archaeological Journal 3, 74-118 
Dugmore, A J 1989 'Icelandic volcanic ash in Scotland', Scottish Geographical Magazine 105(3), 168172.

Dugmore, A J 1991 'Tephrochronology and U.K. Archaeology.' in Budd, P., Chapman, B., Jackson, C., Janaway, R and Ottaway, B (eds) Archaeological Sciences, Oxbow Books: Oxford, 242-250.

Dugmore, A J., Larsen, G, and Newton, A J. 1995a Seven tephra isochrones in Scotland. The Holocene 5(3), 257-266.

Dugmore, A J., Shore, J.S., Cook, G T., Newton, A J., Edwards, K J and Larsen, G 1995b 'The radiocarbon dating of Icelandic tephra layers in Britain and Ireland', Radiocarbon 37(2), 286-295.

Dugmore, A J and Newton A J 2009 'Tephrochronology', in Gornitz, V (ed) Encyclopedia of Palaeoclimatolgy and Ancient Environments Springer: Dordrecht, 937-8.

Dunai, T J 2010 Cosmogenic Nuclides: Principles, Concepts and Applications in the Earth Surface Sciences. Cambridge University Press: Cambridge.

Dungworth, D 1997 'Roman copper alloys: analysis of artefacts from northern Britain', Journal of Archaeological Science 24, 901-10.

Dungworth, D 2011 Walmer Castle, Deal, Kent. Analysis of Window Glass. English Heritage Research Department Reports 02/2011.

Dunwell, A J and Ralston, I B M 2008a The Management of Cropmark Archaeology in Lowland Scotland: a case study from the Lunan Valley, Angus. Historic Scotland: Edinburgh.

Dunwell, A J and Ralston, I B M 2008b Archaeology and Early History of Angus. Tempus/The History Press: Stroud.

Easton, D R 2010 'World War II aerial photographs for military archaeology in Scotland', in Cowley D C., Standring R A and Abicht M Jm (eds), Landscapes through the lens: aerial photographs and historic environment, Oxbow: Oxford, 253- 62.

Eckardt, H., Chenery, C., Booth, P., Evans, J A., Lamb, A and Muldner, G 2009 'Oxygen and strontium isotope evidence for mobility in Roman Winchester', Journal of Archaeological Science 36, 28162825.

Edwards, K J 1983 'Phosphate analysis of soils associated with the Old Kinord field and settlement system, Muir of Dinnet, Aberdeenshire', Proc Soc Antiq Scot 113, 620-627.

Edwards, K J 1996 'A Mesolithic of the Western and Northern Isles of Scotland? Evidence from pollen and charcoal', in Pollard, T and Morrison, A (eds) The early prehistory of Scotland. Edinburgh University Press: Edinburgh, 23-38.

Edwards, K J 1999 'Palynology and people: observations on the British record', in Edwards, K J and Sadler, J P (eds) Holocene environments of prehistoric Britain. Quaternary Proceedings No.7. John Wiley and Sons: Chichester, 531-544. 
Edwards, K J and Whittington, G 2000 'Multiple charcoal profiles in a Scottish lake: taphonomy, fire ecology, human impact and inference', Palaeogeography, Palaeoclimatology, Palaeoecology 164, 6786.

Edwards, K J., Whittington, G and Tipping, R 2000 'The incidence of microscopic charcoal in late glacial deposits', Palaeogeography, Palaeoclimatology, Palaeoecology 164, 247-262.

Edwards, K J and Whittington, G 2001 'Lake sediments, erosion and landscape change during the Holocene in Britain and Ireland', Catena 42, 143-173.

Edwards, K J and Whittington, G 2003 'Vegetation change', in Edwards, K J and Ralston, I B M (eds) Scotland after the Ice Age: environment, archaeology and history, $8000 B C-A D$ 1000. Edinburgh University Press: Edinburgh, 63-82.

Edwards, K J., Schofield, J E., Whittington, G and Melton, N D 2009 'Palynology 'on the edge' and the archaeological vindication of a Mesolithic presence? The case of Shetland', in Finlay, N., McCartan, S., Milner, N and Wickham-Jones, C (eds)2009 From Bann Flakes to Bushmills: Papers in Honour of Professor Peter Woodman, Oxbow Books and The Prehistoric Society: Oxford, 113-123.

Elsasser, W., Ney, E P and Winckler, J R 1956 'Cosmic-ray intensity and geomagnetism', Nature 178, 1226-1227.

English Heritage 2007 Geoarchaeology: Using Earth Sciences to Understand the Archaeological Record. Available online at $<$ http://www.englishheritage.org.uk/content/publications/publicationsNew/geoarchaeology-earth-sciences-tounderstand-archaeological-record/geoarchaeology-2007.pdf >. Accessed 09 December 2011.

English Heritage 2008 Geophysical Survey in Archaeological Field Evaluation English Heritage: London.

Engstrom D R and Wright, H E Jr. 1984 'Chemical stratigraphy of lake sediments as a record of environmental change', in Haworth, E Y and Lund, J W G (eds) Lake Sediments and Environmental History. Leicester University Press: Leicester, 11-68.

Entwistle, J A., Lamb, H F., Abrahams, P W and Dodgshon, R A 1995 'A lake-sediment record of changing land-use intensity on the Isle of Lewis, Scotland', in Butlin, R A and Roberts, N (eds) Ecological Relations in Historical Times. Human Impact and Adaptation, Blackwell: Oxford, 45-67.

Entwistle, J A and Abrahams, P W 1997 'Multi-element analysis of soils and sediments from Scottish historical sites. The potential of inductively coupled plasma-mass spectrometry for rapid site investigation', Journal of Archaeological Science 24, 407-416.

Entwistle, J A., Abrahams, P W and Dodgshon, R A 1998 'Multi-element analysis of soils from Scottish historical sites. Interpreting land-use history through the physical and geochemical analysis of soil'. Journal of Archaeological Science 25, 53-68.

Entwistle, J A., Abrahams, P W and Dodgshon, R A 2000 'The geoarchaeological significance and spatial variability of a range of physical and geochemical soil properties from a former habitation site, Isle of Skye', Journal of Archaeological Science 27, 287-303. 
Eremin, K., Graham-Campbell, J and Wilthew, P 2002 'Analysis of copper-alloy artefacts from pagan Norse graves in Scotland', in Jerem, E and Biró, K T (eds) Archaeometry 98: proceedings of the 31st Symposium, Budapest, April 26 - May 3 1998, British Archaeological Reports International Series 1043: Oxford, 343-9.

Eremin, K., Tate, J and Berry, J 2003 'Non-destructive investigation of $19^{\text {th }}$-century Scottish photographs', in Townsend, J., Eremin, K and Adriaens, A (eds) Conservation science 2002: papers from the conference held in Edinburgh, Scotland 22-24 May 2002. Archetype: London, 201-207

Evans, R and Jones, R J A 1977 'Cropmarks at two archaeological sites in Britain', Journal of Archaeological Science 4, 63-76.

Evans, J., Stoodley, N and Chenery, C 2006a 'A strontium and oxygen isotope assessment of a possible fourth century immigrant population in a Hampshire cemetery, southern England', Journal of Archaeological Science 33, 265-272.

Evans, J., Chenery, C A and Fitzpatrick, A P 2006b 'Bronze age childhood migration of individuals near Stonehenge, revealed by strontium and oxygen isotope tooth enamel analysis', Archaeometry 48, 309-321.

Evans, J A., Tatham, S., Chenery, S R and Chenery, C A., 2007 'Anglo-Saxon animal husbandry techniques revealed though isotope and chemical variations in cattle teeth', Applied Geochemistry 22, 1994-2005.

Evans, J A., Montgomery, J and Wildman, G 2009 'Isotope domain mapping of Sr-87/Sr-86 biosphere variation on the Isle of Skye, Scotland', Journal of the Geological Society 166, 617-631.

Evans, J A., Montgomery, J., Wildman, G and Boulton, N 2010 'Spatial variations in biosphere 87Sr/86Sr in Britain', Journal of the Geological Society 167, 1-4.

Evershed, R 2008 'Experimental approaches to the interpretation of absorbed organic residues in archaeological ceramics', World Archaeology 40, $26-47$.

Fabel, D., Smart, D., Miguens-Rodriguez, M and Freeman, S P H T 2010 'Cosmogenic nuclide exposure ages from the 'Parallel Roads' of Glen Roy, Scotland', Journal of Quaternary Science 25, 597-603.

Fabel, D., Hansom, J,. Bishop, P., Dawson, A., Evans, D J A. and Schnabel, C (in prep) 'Cosmogenic ${ }^{10} \mathrm{Be}$ exposure dating of the emerged cobble / boulder beaches and ice-marginal features of Islay and Jura, W Scotland.'

Fægri, K and Iversen, J 1989 (4 ${ }^{\text {th }}$ edition) Textbook of pollen analysis, John Wiley and Sons: Chichester.

Fairchild, I J and Baker, A 2012 Speleothem Science: From process to past environments. WileyBlackwell: London 
Fairchild, I J., Smith, C L., Baker, A et al. 2006 'Modification and preservation of environmental signals in speleothems', Earth-Science Reviews 75, 105-153.

Fairhurst H 1939 'The galleried dun at Kildonan Bay, Kintyre'. Proc Sos Ant Scot 73, 185-228.

Fairnell E H and Barrett J H 2007 'Fur-bearing species and Scottish islands', Journal of Archaeological Science 34, 463-484.

Fairweather A and Ralston, I B M 1993 'The Neolithic timber hall at Balbridie, Grampain Region, Scotland: the building, the date, the plant macrofossils', Antiquity 67, 313-23.

Fenton, M B 1988 'The petrological identification of stone battle-axes and axe-hammers from Scotland', in McClough, T H and Cummins, W A (eds) Stone Axes vol 2 The Petrology of Prehistoric Stone Implements from the British Isles, Council for British Archaeology (Research Report 67), 92132.

Foulds, S A and Macklin, M G 2006 'Holocene land-use change and its impact on river basin dynamics in Great Britain and Ireland', Progress in Physical Geography 30, 589-604.

Franklin, D., O'Higgins, P and Oxnard, C E 2008 'Sexual dimorphism in the mandible of indigenous South Africans: a geometric approach', South African Journal of Science 104, 101-106.

Frere, S S and St Joseph, J K S 1983 Roman Britain from the Air, Cambridge University Press: Cambridge.

Friend, C R L., Dye, J and Fowlder, M B 2007 'New field and geochemical evidence from vitrified forts in South Morar and Moidart, NW Scotland: further insight into melting and the process of vitrification', Journal of Archaeological Science 34, 1685-1701.

Fritts H C 1976 Tree Rings and Climate. Academic Press Inc: London.

Fuller, B T., Richards, M P and Mays, S A 2003 'Stable carbon and nitrogen isotope variations in tooth dentine serial sections from Wharram Percy', Journal of Archaeological Science 30, 1673-1684.

Fuller, B T., Molleson, T I., Harris, D A., Gilmour, L T and Hedges, R E M 2005 'Isotopic Evidence for Breastfeeding and Possible Adult Dietary Differences from Late/Sub-Roman Britain', American Journal of Physical Anthropology 129, 45-54.

Fülöp, R H., Bishop, P., Fabel, D., Cook, G T., Schnabel, C., Naysmith, P and Xu, S 2009, 'Determining amounts and timing of soil erosion using in situ cosmogenic C-14 and Be-10', Geochimica et Cosmochimica Acta 73 (13-S1), A348-A405.

Fülöp, R H., Naysmith, P., Cook, G T., Fabel, D., Xu, S and Bishop, P 2010a 'Update on the performance of the SUERC in situ cosmogenic ${ }^{14} \mathrm{C}$ extraction line', Radiocarbon 52, 1288-1294.

Fülöp, R H., Bishop, P., Fabel, D., Cook, G T., Schnabel, C., Naysmith, P., Xu, S and Everest, J 2010b 'Quantifying site specific Holocene soil erosional events using depth-profiles of cosmogenic in-situ C14 and Be-10', Abstract EP33a-0759 presented at the 2010 AGU Fall Meeting, AGU, San Francisco, California, 13-17 December 2010. 
Gaffney, C F., Gater, J and Ovenden, S 2002 The Use of Geophysical Techniques in Archaeological Evaluations, IFA: Reading.

Gaffney, C F and Gater, J 2003 Revealing the Buried Past. Geophysics for Archaeologists, Tempus: Oxford.

Gage, J P., Francis, M J O and Triffit, J T 1989 Collagen and dental matrices, Butterworth-Heinemann.

Gear, A J and Huntley, B 1991 'Rapid changes in the range limits of Scots pine 4000 years ago', Science 251, 544-547.

Gearey, B R., Marshall, P and Hamilton, D 2009 'Correlating archaeological and palaeoenvironmental records using a Bayesian approach: a case study from Sutton Common, South Yorkshire, England', Journal of Archaeological Science 36, 1477-1487.

Gentles, D S 1989 Archaeomagnetic Directional Studies of Large Fired Structures in Britain. PhD thesis. Plymouth Polytechnic: Plymouth

Gilbertson, D D., Shwenninger, J L., Kemp, R A and Rhodes, E J 1999 'Sand-drift and soil formation along an exposed North Atlantic coastline: 14,000 years of diverse geomorphological and human impacts', Journal of Archaeological Science 26, 439-469.

Giles, M., Moore, J and Parker Pearson, M 1999 'The chemical and magnetic analysis of soils', in Parker Pearson, M., Sharples, N., Mulville, J and Smith, H (eds) Between Land and Sea: Excavations at Dun Vulan, South Uist. Academic Press: Sheffield, 342-344.

Gillings, M 1991 Ceramic production in a Roman frontier zone, Unpublished PhD thesis, Bradford University.

Gilmour, S and Cook, M 1998 'Excavations at Dun Valan: a reinterpretation of the reappraised Iron Age', Antiquity 72, 327-337.

Goldberg, P and Macphail, R 2006 Practical and Theoretical Geoarchaeology. Blackwell: Oxford.

Göransson, H 1987 'Neolithic man and the forest environment around Alvastra pile dwelling', Theses and Papers in North European Archaeology 20. Lund University Press: Stockholm.

Goudie, A 1981 Geomorphological Techniques. George Allen and Unwin: London.

Goudie, A 2006 The Human Impact on the Natural Environment. Blackwell: Oxford.

Graley, J A., Bierman, P R., Reusser, L J and Pavich, M J 2010 'Meteoric 10Be in soil profiles - A global meta-analysis', Geochimica et Cosmochimica Acta 74, 6814-6829.

Greenwood, M T., Wood, P J. and Monk, M A 2006 'The use of fossil caddisfly fauna assemblages in the reconstruction of flow environments from floodplain paleochannels of the River Trent, England', Journal of Paleolimnology 35, 747-761. 
Griffin, I., Hamilton, A., Tate, J 2010 'Deterioration of cement-rendered brick masonry buildings: case study of a World War II airfield in East Lothian, Scotland.' in Válek, J., Groot, C and Hughes, J J (eds) 2nd Conference on Historic Mortars - HMC 2010 and RILEM TC 203-RHM final workshop, 501 - 509

Guerreschi, A 1973 'A mechanical sieve for archaeological excavations'. Antiquity 47, 234-235

Guttmann, E B 2005 'Midden cultivation in prehistoric Britain: arable crops in gardens', World Archaeology 37(2), 224-239.

Guttmann, E B A., Simpson, I A and Dockrill, S J 2003 'Joined-up archaeology at Old Scatness, Shetland: thin section analysis of the site and hinterland', Environmental Archaeology 8, 17-31.

Guttmann, E B., Simpson, I A. and Davidson, D A 2005a 'Manuring practices in antiquity: a review of the evidence', in Smith, D N., Brickley, M B and Smith, W (eds) Fertile Ground. Symposia of the Association for Environmental Archaeology No. 22. Oxbow Books: Oxford, 68-76.

Guttmann, E B., Dockrill, S J and Simpson, I A 2005b 'Arable agriculture in prehistory: new evidence from soils in the Northern Isles', Proc Soc Antiq Scot 134, 53-64.

Guttmann, E B., Simpson, I A., Davidson, D A and Dockrill, S J 2006 'The management of arable land from prehistory to the present: case studies from the Northern Isles of Scotland', Geoarchaeology 21, 61-92.

Guttmann, E B., Simpson, I A., Nielsen, N and Dockrill, S J 2008 'Anthrosols in Iron Age Shetland: implications for arable and economic activity', Geoarchaeology 23 (6), 799-823.

Haggarty, G, Hall, D and Chenery, S 2011 Sourcing Scottish Redwares, Medieval pottery research group occasional paper 5

Hale, A 2000 'Marine crannogs: previous work and recent surveys', Proc Soc Antiq Scot 130, 537-558.

Hall, D W., Cook, G T and Hamilton, W D 2010 'New dating evidence for North Sea trade between England, Scotland and Norway in the 11th century AD', Radiocarbon 52, 331-336.

Hall, D W., MacDonald, A D S., Perry, D R and Terry, J 1998 'The archaeology of Elgin: excavations on Ladyhill and on the High Street, with an overview of the archaeology of the burgh', Proc Soc Antiq Scot 128, 753-829.

Hamilton, A 2006 Sodium sulphate crystallisation, water transport and stone decay. PhD thesis, University of Edinburgh.

Hamilton, J., Clarke, C., Dunwell, A and Tipping, R 2002 'A prehistoric ford near Rough Castle, Falkirk', Scottish Archaeological Journal 23, 91-103.

Hamilton, W D., Bayliss, A., Menuge, A., Bronk Ramsey, C and Cook, G T 2007 'Rev Thomas Bayes: Get ready to wiggle' - Bayesian modelling, radiocarbon wiggle matching, and the north wing Of Baguley Hall', Vernacular Architecture 38, 87-97. 
Hamilton, D. and Haselgrove, C 2000 'Absolute dating' in Haselgrove, C The Traprain Law Environs Project: Fieldwork and excavations 2000-2004, Society of Antiquaries of Scotland: Edinburgh, 187204.

Hansom, J D., Evans, D J A., Sanderson, D C W., Bingham, R G and Bentley, M J 2008 'Constraining the age and formation of stone runs in the Falkland Islands using Optically Stimulated Luminescence', Geomorphology 94, 117-130.

Hanson, W S 2005 'Sun, sand and see: creating bias in the archaeological record', in Brophy, K and Cowley, D C (eds) From the Air: understanding aerial archaeology, Tempus: Stroud, 73-85.

Hanson, W S and Macinnes, L 1991 'The archaeology of the Scottish lowlands: problems and potential', in Hanson W S and Slater, E A (eds), Scottish Archaeology: new perceptions, Aberdeen University Press: Aberdeen, 153-66.

Haran, M 1987 'The human skeleton', in Welander, R D E., Batey, C and Cowie, T G 'A Viking burial in Kneep, Uig, Isle of Lewis'. Proc Soc Antiq Scot 117, 149-174.

Haynes, S., Jaarola, M., Searle, J and Dobney, K 2005 'The origin of the Orkney vole: a proxy for reconstructing human movements', in Housley, R and Coles, G (eds) Atlantic connections and adaptations: Economies, environments and subsistence in the north Atlantic realm. Oxbow: Oxford, 114-119..

Heald, A 2005 Non-ferrous metalworking in Iron Age Scotland, 700 BC - AD 800, unpublished PhD thesis, University of Edinburgh.

Hebdon, $N$ J., Atkinson, T C., Lawson, T J and Young, I R 1997 'Rate of glacial valley deepening during the late Quaternary in Assynt, Scotland', Earth Surface Processes and Landforms 22, 307-315.

Hedges, R E M., Clement, J G., Thomas, C D L and O'Connell, T C 2007 'Collagen turnover in the adult femoral mid-shaft: modeled from anthropogenic radiocarbon tracer measurements', American Journal of Physical Anthropology 133, 808-816.

Hedges, R E M and Reynard, L M 2007 'Nitrogen isotopes and the trophic level of humans in archaeology.' Journal of Archaeological Science 34, 1240-1251.

Hegmon, M, Peeples, M, Kinzig, A, Kulow, S, Meegan, C M and Nelson, M C 2008 'Social transformation and its human costs in the prehispanic U.S. Southwest', American Anthropologist $110,313-324$.

Henderson, J C 2007 'Recognising complexity and realizing the potential of Scottish crannogs', in Barber, J., Clarke, C., Crone, A., Hale, A., Henderson, J., Housley, R., Sands, R and Sheridan, A (eds) Archaeology from the wetlands: proceedings of the 11th WARP conference 2005, Society of Antiquaries of Scotland (Monograph Series): Edinburgh, 231-241.

Henderson, J 1982 X-ray fluorescence analysis of Iron Age glass, Unpublished PhD thesis, Bradford University. 
Historic Scotland 2011 Focus: Informing the conservation of the built environment, Historic Scotland: Edinburgh.

Hodgson, D A., Roberts, S J., Bentley, M J., Smith, J A., Johnson, J., Verleyen, E., Vyverman, W., Hodson, A J, Leng, M J., Cziferszky, A., Fox, A J and Sanderson, D C W 2009a 'Exploring former subglacial Hodgson Lake, Antarctica Paper I: site description, geomorphology and limnology', Quaternary Science Reviews, 28(23-24), 2295-2309.

Hodgson, D A., Roberts, S J., Bentley, M J., Smith, J A., Johnson, J., Verleyen, E., Vyverman, W., Hodson, A J, Leng, M J., Cziferszky, A., Fox, A J and Sanderson, D C W 2009b 'Exploring former subglacial Hodgson Lake, Antarctica. Paper II: palaeolimnology', Quaternary Science Reviews 28(2324), 2310-2325.

Hodgson, G W I and Jones, A 1982 'The Animal Bone', in Murray, J C (ed) Excavations in the Medieval Burgh of Aberdeen 1973-81. Society of Antiquaries of Scotland: Edinburgh, 229-238

Hoffmann, T, Lang, A and Dikau, R 2008' Holocene river activity: analysing 14C-dated fluvial and colluvial sediments from Germany', Quaternary Science Reviews 27, 2031-2040.

Holmes, N., Langdon, P G., Caseldine, C J., Brooks, S J and Birks, H J B 2011 'Merging chironomid training sets: implications for palaeoclimate reconstructions', Quaternary Science Reviews 30, 27932804.

Holyrood Project Team 2010 'Artefactual, Environmental and Archaeological evidence from the Holyrood Parliament Site Excavations', Scottish Archaeological Internet Reports [online] 40. Society of Antiquaries of Scotland: Edinburgh. Available at <http://www.sair.org.uk/sair40/index.html> [Accessed 09 December 2011].

Hope-Taylor, B 1980 'Balbridie ... and Doon Hill', Current Archaeology 72, 18-19.

Hoppe, K A., Koch, PL. and Furutani, T T 2003 'Assessing the preservation of biogenic strontium in fossil bones and tooth enamel', International Journal of Osteoarchaeology, 13(1-2), 20-28.

Housley, R A., Blockley, S P E., Matthews, I P., MacLeod, A., Lowe, J J., Ramsay, S., Miller, J J and Campbell, E N 2010 'Argyll, Scotland: chronology of events', Journal of Archaeological Science 37, 577-593.

Housley, R A., van Andel, T H and Sanderson, D C W 2006 'A new research project to investigate the chronology connected with Neanderthal climate preferences and tolerances in the North-East Black Sea region', in Anikovich, M V and Platonova, N I (eds) 'The Early Upper Paleolithic of Eurasia: General Trends, Local Developments The problems of the early Upper Palaeolithic of the KostenkiBoschevo region and adjacent territories', St Petersburg: Russian Academy of Sciences NestorHistory 4, 26-38. (Ранняя пора верхнего палеолита Евразии: общее и локальное (материалы Международной конференции к 125-летию открытия палеолита в Костёнках, 23-26 августа 2006 г.). - Труды Костёнковско-Борщёвской археологической экспедиции ИИМК РАН. Вып. 4. С.-Пб.: Нестор-История, 2006).

Houston, I J 2001 'Imaging luminescence using focussed stimulation : a potential solution to problems of heterogeneity in dating sedimentary systems'. Unpublished MSc Thesis, University of Glasgow 
Howard, A J and Macklin, M G 1999 'A generic geomorphological approach to archaeological interpretation and prospection in British river valleys: a guide for archaeologists investigating Holocene landscapes', Antiquity 73, 527-541.

Howard, A J., Brown, A G., Carey, C J., Challis, L., Cooper, L P., Kincey, M and Tom, P 2008 'Archaeological resource modelling in temperate river valleys: a case study from the Trent Valley, UK', Antiquity 82, 1040-1054.

Hughes, M K., Schweingruber, F H., Cartwright, D and Kelly, P M 1984 'July-August temperature at Edinburgh between 1721 and 1975 from tree-ring density and width data', Nature 308, 341-343.

Hunter, F, Cowie, T and Heald, A 2006 'Research Priorities for Archaeometallurgy in Scotland', Scottish Archaeological Journal 28, 49-62.

Hunter, J (ed) 2007 Investigations in Sanday, Orkney. Vol 1: Excavations at Pool, Sanday. The Orcadian Itd: Kirkwall.

Hunter, J R 1996 'Recovering Buried Remains', in Hunter, J R, Roberts, C and Martin, A L (eds) Studies in Crime: An Introduction to Forensic Archaeology, Batsford: London, 7-23.

Hunter, J R, Roberts, C and Martin, A L (eds) 1996 Studies in Crime: An Introduction to Forensic Archaeology, Batsford: London

Hyslop, E K 2004 The performance of replacement sandstone in the New Town of Edinburgh, Historic Scotland Research Report, Historic Scotland: Edinburgh.

Ingrem, C 2005 'Fish bones', in Sharples, N (ed) A Norse Farmstead in the Outer Hebrides, Excavations at Mound 3, Bornais, South Uist. Oxbow Books: Oxford.

Jacobi, J., Rose, J., MacCleod, A and Higham, T F G 2009 'Revised radiocarbon ages on wooly rhinoceros (Coelodonta antiquitatis) from western central Scotland: significance for timing the extinction of woolly rhinoceros in Britain and the onset of the LGM in central Scotland', Quaternary Science Reviews 28, 2551-2556.

Jacobson, G L and Bradshaw, R H W 1981 'The selection of sites for paleovegetational studies', Quaternary Research 16, 80-96.

Janssen, C R 1973 'Local and regional pollen deposition', in Birks, H J B and West, R G (eds) Quaternary plant ecology. Blackwell: Oxford, 31-42.

Jarman, M R., Bailey, G N and Jarman, H N 1982. Early European Agriculture. Its foundations and development. Cambridge University Press: Cambridge.

Jay, M., Fuller, B T., Richards, M P., Knusel, C J and King, S S 2008 'Iron age breastfeeding practices in Britain: Isotopic evidence from Wetwang Slack, East Yorkshire', American Journal of Physical Anthropology 136, 327-337. 
Jimenez-Cano, Y 2010 Atlantic Cod trade and Fishing Strategies from the Late Iron Age to Norse Age in North-Western Scotland: A perspective from Isotopic Analyses. Unpublished M.Sc. dissertation in Human Palaeoecology, University of Durham.

Johnston, D A 1994 'Carronbridge, Dumfries and Galloway: the excavation of Bronze Age cremations, Iron Age settlements and a Roman camp', Proc Soc Antiq Scot 124, 233-91

Jones, A 1983 'A comparison of two on-site methods of wet sieving large archaeological soil samples', Science and Archaeology 25, 9-12.

Jones, A 1991 The fish remains from excavations at Freswick Links, Caithness. Unpublished Ph.D. Thesis. University of York.

Jones, A 2002 Archaeological Theory and Scientific Practice, Cambridge University Press: Cambridge, 103-44.

Jones, A 2005 'The Grooved ware from Barnhouse', in Richards, C (ed) Dwelling amongst the monuments: excavations at Barnhouse and Maes Howe, Orkney. McDonald Institute Monograph: Cambridge, 261-82.

Jones, A., Cole, W J and Jones, R E 2005 'The results of residue analysis using GC-MS on the Barnhouse Grooved ware assemblage', in Richards, C (ed) Dwelling amongst the monuments: excavations at Barnhouse and Maes Howe, Orkney. McDonald Institute Monograph: Cambridge, 283-92.

Jones, A P., Tucker, M E and Hart, J K 1999 The Description and Analysis of Quaternary Stratigraphic Field Sections. Technical Guide No. 7. Quaternary Research Association: London.

Jones, E 2001 'Through the Cowgate: life in 15th-century Edinburgh as revealed by excavations at St Patrick's Church', Scottish Archaeological Internet Reports [online] 42. Society of Antiquaries of Scotland: Edinburgh. Available at <http://www.sair.org.uk/sair42/index.html> [Accessed 09 December 2011].

Jones, E P., Jóhannesdóttir, F., Gündüz, I., Richards, M B and Searle, J B (in press) 'The expansion of the house mouse into north-western Europe. Journal of Zoology

Jones, R E., Will, R., Haggarty, G and Hall, D 2002-03, 'Sourcing Scottish White Gritty Ware', Medieval Ceramics 26-7, 45-84.

Jones, R E and Sharpe, L (eds) 2006 Going over old ground. Perspectives on archaeological geophysical and geochemical survey in Scotland, Proceedings of a conference held at the Department of Archaeology, University of Glasgow, Scotland, August 2003. British Archaeological Report 416: Oxford.

Jones, R E., Olive, V., Kilikoglou, V., Ellam, R., Bassiakos, Y., Bray, I and Sanderson D 2007 'A new protocol for the chemical characterisation of steatite: two case studies in Europe: the Shetland Isles and Crete', Journal of Archaeological Science 34, 626-641. 
Jones, R E., Challands, A., French, C., Card, N., Downes, J and Richards, C 2010 'Exploring the location and function of a late Neolithic house at Crossiecrown, Orkney by geophysical, geochemical and soil micromorphological methods', Archaeological Prospection 17, 29-47.

Jones R H 2005 'The advantages of bias in Roman Studies', in Brophy, K and Cowley, D C (eds) From the Air: understanding aerial archaeology, Tempus: Stroud, 86 - 93.

Jones, R H 2011 Roman Camps in Scotland. Society of Antiquaries of Scotland: Edinburgh.

Jones, R H and McKeague, P 2011 'Mapping the Antonine Wall', Scottish Geographical Journal $127(2), 146-62$

Jones O'Day, S., Van Neer, W and Ervynck, A (eds) 2004 Behaviour behind bones. The Zooarchaeology of Ritual, Religion, Status and Identity. (Proceedings of the 9th ICAZ conference) Oxbow Books: Oxford

Kenward, H K 1983 'Appendix 7: Beetles from Knap of Howar, Orkney', in Ritchie, A 'Excavation of a Neolithic farmstead at Knap of Howar, Papa Westray, Orkney', Proc Soc Antiq Scot 113, 121.

Kenward, H K., Hill, M., Jaques, D., Kroupa, A and Large, F 2000 'Evidence from beetles and other insects; evidence for living conditions on the crannog; Coleoptera analysis', in Crone, A The history of a Scottish lowland crannog: excavations at Buiston, Ayrshire 1989-90, Scottish Trust for Archaeological Research (Monograph 4): Edinburgh, 76-78; 99-101; 230-247; 300-320.

Kenward, H K and Hall, A R 2001 'Plants, intestinal parasites and insects', in Cameron, A S and Stones, J A (eds) Aberdeen; an in-depth view of the city's past, Society of Antiquaries of Scotland (Monograph Series 19): Edinburgh, 280-297.

Kinnaird, T., Sanderson D C W., Burbidge, C I and Peltenburg, E 2007 'OSL dating of Neolithic Kissonerga-Mylouthkia, Cyprus', Neolithics 2(7), 51-57.

Kitchener, A C 1998 'Extinctions and Introductions of Scottish Mammals and Birds', in Lambert, R A (ed) Introductions and Extinctions since the Ice Age. Scottish Cultural Press: Edinburgh, 63-92.

Kitchener, A C., Bonsall, C and Bartosiewicz, L 2004 'Missing mammals from Mesolithic middens: fossil and archeological records from Scotland', in Saville, A (ed) Mesolithic Scotland and its Neighbours: The Early Holocene Prehistory of Scotland, its British and Irish Context, and some Northern European Perspectives. Society of Antiquaries of Scotland: Edinburgh, 73-82.

Kitchener, A C and Rees, E E 2009 'Modelling the dynamic biogeography of the wildcat: implications for taxonomy and conservation', J. of Zoology 279, 144-155.

Kruse, S E and Tate, J 1995 'XRF analysis of Viking-age silver from Scotland', in Graham-Campbell, J The Viking-Age gold and silver of Scotland (AD 850-1100), National Museum of Scotland: Edinburgh, 73-9.

Lal, D 1988 'In-situ produced cosmogenic isotopes in terrestrial rocks', Annual Reviews of Earth and Planetary Science 16, 355-388. 
Lancaster, S J and Simpson, I A 2003 'Assessing and modelling faunal turbation', in Robson- Brown, K A (ed) Proceedings of the Archaeological Sciences Conference, 1999. British Archaeological Reports International Series 1111: Oxford, 64-85.

Lang, A 2003 'Phases of soil erosion-derived colluviation in the loess hills of South Germany', Catena $51,209-221$.

Langdon, P G and Barber, K E 2001 'New Holocene tephras and a proxy climate record from a blanket mire in northern Skye, Scotland', Journal of Quaternary Science 16, 753-759.

Langdon, P G., Barber, K E., Hughes, P D M 2003 'A 7500-year peat-based palaeoclimatic reconstruction and evidence for an 1100-year cyclicity in bog surface wetness from Temple Hill Moss, Pentland Hills, southeast Scotland', Quaternary Science Reviews 22, 259-274.

Langdon, P G and Barber, K E 2004 'Snapshots in time: precise correlations of peat-based proxy climate records in Scotland using mid-Holocene tephras', The Holocene 14, 21-33.

Langdon, P G and Barber, K E 2005 'The climate of Scotland over the last 5000 years inferred from multi-proxy peatland records: inter-site correlations and regional variability', Journal of Quaternary Science 20, 546-566.

Langdon, P G., Barber, K E and Lomas-Clarke, S H 2004 'Reconstructing climate and environmental change in Northern England through chironomid and pollen analyses: evidence from Talkin Tarn, Cumbria', Journal of Paleolimnology 32, 197-213.

Langdon, P G., Holmes, N and Caseldine, C J 2008 'Environmental controls on modern chironomid faunas from NW Iceland and implications for reconstructing climate change', Journal of Paleolimnology 40, 273-293.

Larocque, I., Hall, R I and Grahn, E 2001 'Chironomids as indicators of climate change: a 100-lake training set from a subarctic region of northern Sweden (Lapland)', Journal of Paleolimnology 26, 307-322.

Larsen, C S 1997 Bioarchaeology: interpreting behavior from the human skeleton, Cambridge University Press: Cambridge

Larson, G., Dobney, K., Albarella, U., Fang, M., Matisoo-Smith, E., Robins, J., Lowden, S., Finlayson, H., Brand, T., Willerslev, E., Rowley-Conwy, P., Andersson, L and Cooper, A 2005 'Worldwide Phylogeography of Wild Boar Reveals Multiple Centers of Pig Domestication', Science 307, 16181621.

Lawing, A M and Polly, P D 2010 'Geometric morphometrics: recent applications to the study of evolution and development', Journal of Zoology 280, 1-7.

Lewin, J and Woodward, J C 2009 'Karst geomorphology and environmental change', in Woodward, J C (ed) The Physical Geography of the Mediterranean. Oxford University Press: Oxford, 287-317.

Libby, W F 1946 'Atmospheric helium three and radiocarbon from cosmic radiation', The Physical Review 69, 671-672. 
Libby, W F., Anderson, E C and Arnold, J R 1949 'Age determination by radiocarbon content: Worldwide assay of natural radiocarbon', Science 109, 227-228.

Limbrey, S 1989 'Soil monoliths', in Morris, C D (ed) The Birsay Bay Project, Volume 1: Coastal Sites beside the Brough Road, Birsay, Orkney, Excavations 1976-1982, University of Durham, Department of Archaeology (Monograph Series 1): Durham, fiche 2, E7-8.

Linford, P 2006 Archaeomagnetic Dating. Guidelines on producing and interpreting archaeomagnetic dates. English Heritage Swindon.

Lorimer, D 1992 'The human remains', in Dalland, M 'Long cist burials at Four Winds, Longniddry, East Lothian', Proc Soc Antiq Scot 122, 197-206.

Lowe, D J 2010 'Tephrochronology and its application: A review', Quaternary Geochronology 6 (2), 107-53.

Lowe, J J and Walker, M J C $19972^{\text {nd }}$ edition Reconstructing Quaternary environments, Longman: London.

Lowe, J J., Pyne-O'Donnell, S D F., Blockley, S P E and Turney, C S M 2008 'Distal volcanic ash layers in the Lateglacial Interstadial (GI-1): problems of stratigraphic discrimination', Quaternary Science Reviews 27(1-2), 72-84.

Lundberg, J and McFarlane, D A 2007 'Pleistocene depositional history in a periglacial terrane: A 500 k.y. record from Kents Cavern, Devon, United Kingdom. ', Geosphere 3, 199-219.

Lunt, D 1974 'The prevalence of dental caries in the permanent dentition of Scottish prehistoric and mediaeval populations', Archives of Oral Biology 19, 431-7.

Lunt, D 1996 'The dentitions', in Proudfoot, E 'Excavations at the Long Cist on the Hallow Hill, St Andrews, Fife, 1975-7', Proc Soc Antiq Scot 126, 387-354.

Lunt, D A and Barnetson, L 1982 'Human Remains', in Watkins, T 'The excavation of an early Bronze Age cemetery at Barns Farm, Dalgetty, Fife', Proc Soc Antiq Scot 112, 48-141.

Lyman, R L 1994 Vertebrate Taphonomy, Cambridge University Press: Cambridge.

Macinnes, L 1983 Later Prehistoric and Romano-British settlement north and south of the Forth - a comparative study. PhD thesis, University of Newcastle upon Tyne

Macklin, M G., Howard, A D and Passmore, D G 2003 'The condition of alluvial archaeology in the UK: progress, constraints and opportunities', in Howard, A D, Macklin, M G, Passmore, D G (eds) Alluvial Archaeology in Europe, Balkema: Lisse, 3-14.

Macklin, M G., Jones, A F and Lewin, J 2010 'River response to rapid Holocene environmental change: evidence and explanation in British catchments', Quaternary Science Reviews 29, 15551576. 
Macleod, R I., Wright, A R., McDonald, J and Eremin, K 2000 'Mummy 1911-210-1', Journal of the Royal College of Surgeons of Edinburgh 45(2), 85-92.

MacSween, A 2007 'Pottery analysis', in Hunter, J (ed) Investigations in Sanday, Orkney. Vol. 1, Excavations at Pool, Sanday : a multi-period settlement from Neolithic to late Norse times, Orcadian in association with Historic Scotland: Kirkwall,

Maclnnes, L 1982 'Pattern and purpose: the settlement evidence', in Harding, D W (ed) Later Prehistoric Settlement in South-East Scotland, Edinburgh University Department of Archaeology: Edinburgh, 57-73.

MacInnes, L 1984 'Settlement and economy: east Lothian and the Tyne-Forth province', in Burgess, C and Miket, R (eds) Between and beyond the Walls: essays on the prehistory and history of north Britain in honour of George Jobey, John Donald: Edinburgh, 176-198

Mainland, I 1993 The animal bone from the 1988 excavations at the Earl's Bu, Orphir, Orkney. (Unpublished report). Sheffield Environmental Facility Report 9203.

Mainland, I L 2000 'A dental microwear study of seaweed-eating and grazing sheep from Orkney', International Journal of Osteoarchaeology 10, 93-107.

Mainland, I 2008 'The uses of archaeological faunal remains in landscape archaeology', in David, B and Thomas, J (eds) Handbook of Landscape Archaeology. Left Coast Press: California, 544-550.

Mainland, I and Simpson, I A 2005 'The formation and utilisation of the landscape', in Downes, J., Foster, S M., Wickham-Jones, C R (eds) The Heart of Neolithic Orkney World Heritage Site Research Agenda, Historic Scotland: Edinburgh, 87-95.

Mantle, S., Ramsay, R., Maynard, D and Williams, G 1984 'Wet sieving at Llawhaden, Dyfed', Circaea $2(3), 141-3$.

Mapleton R J 1875 'Note on a bone cave at Duntroon', Proc Soc Antiq Scot 10, 306-8.

Marean, C W., Bar-Matthews, M., Bernatchez, J et al. 2007 'Early human use of marine resources and pigment in South Africa during the Middle Pleistocene', Nature 449, 905-908.

Marquez-Grant, N and Fibiger, L 2011 The Routlege Handbook of Archaeological Human Remains and Legislation: An international guide to laws and practice in the excavation and treatment of archaeological human remains. Routledge: London.

Masser, P 2010 'Data structure report of an archaeological watching brief at Powmyre sand and gravel Quarry, Glamis, Angus. Phase 3 works.' Unpublished Client Report, Headland Archaeology Ltd

Maat, G J R., Maes, A., Aarents, .J and Nagelkerke, N J D 2006 'Histological Age Prediction from the Femur in a Contemporary Dutch Sample' Journal of Forensic Sciences 51, 230-237

Mauquoy, D and Barber, K E 1999 'A replicated 3000 year proxy-record from Coom Rigg Moss and Felecia Moss, The Border Mires, northern England', Journal of Quaternary Science 14, 263-275. 
Mauquoy, D, Barber, K E 2002 'Testing the sensitivity of the palaeoclimatic signal from ombrotrophic peat bogs in northern England and the Scottish Borders', Review of Palaeobotany and Palynology $119,219-240$.

Maxwell, G S 1978 'Air photography and the works of the Royal Commission on the Ancient and Historical Monuments of Scotland', Aerial Archaeology 2, 37-44

Maxwell, G S 1983 'Recent aerial survey in Scotland', in Maxwell, G S (ed) The impact of aerial reconnaissance on archaeology, CBA Research Report No. 49: York, 27-40.

Maxwell, G S 1987 'Settlement in Southern Pictland - a New Overview', in Small, A (ed) The Picts: a New Look at Old Problems, University of Dundee Department of Geography: Dundee, 31-44.

Maxwell, G S and Wilson, D R 1987 'Air reconnaissance in Roman Britain 1977-84', Britannia 18, 148.

Mayewski, P A et al. 2004 'Holocene climate variability', Quaternary Research 62, 243-255.

Mays, S 2010 The Archaeology of Human Bones, London: Routledge

McCormick, F 2001 'The mammal bone', in Cameron, A S and Stones, J A (eds) Aberdeen: An in-depth view of the city's past, Society of Antiquaries of Scotland (Monograph No. 19): Edinburgh, 271-275.

McCormick, F 2006 'The animal bone', in Armit, A Anatomy of an Iron Age Roundhouse, Society of Antiquaries of Scotland: Edinburgh, 161-174.

McCormick, F and Buckland, P C 1997 'Faunal change', in Edwards, K J and Ralston, I B M (eds) Scotland. Environment and Archaeology, 800 BC- AD 1000. Wiley: Chicester, 83-103.

McComb, A M G and Simpson D D A 1999 'The Wild Bunch: exploitation of the hazel in prehistoric Ireland'. Ulster Journal of Archaeology $3^{\text {rd }}$ series (58). 1-16.

McDonnell, G 1998a 'Preliminary metallurgical analysis of some iron objects', in Main, L 'Excavation of a timber round-house and broch at the Fairy Knowe, Buchlyvie, Stirlingshire, 1975-8', Proc Soc Antiq Scot 128, 293-417 (367-9).

McDonnell, G 1998b 'Irons in the fire - evidence of ironworking on broch sites', in Nicholson, R A and Dockrill, S J (eds) Old Scatness Broch, Shetland: retrospect and prospect, University of Bradford: Bradford, 150-62.

McGovern, T H, Vésteinsson, O, Friđriksson, A, Church, M J, Lawson, I T, Simpson, I A, Einarsson, A, Dugmore, A J, Cook, G T, Perdikaris, S, Edwards, K J, Thomson, A M, Adderley, W P, Newton, A J, Lucas, G, Edvardsson, R, Aldred, O and Dunbar, E 2007 'Landscapes of settlement in northern Iceland: historical ecology of human impact and climate fluctuation on the millennial scale', American anthropologist 109 (1), 27-51.

McKerrell H 1977 'Non-dispersive XRF applied to ancient metalworking in copper and tin bronze', PACT 1, 138-173. 
McKerrell, H 1974 The Application of Non-dispersive X-ray Fluorescence to Archaeological Material. Nuclear Enterprises: Edinburgh.

McKerrell, H and Stevenson R B K 1972 'Some analyses of Anglo-Saxon and associated oriental silver coinage', in Hall, E T and Metcalf, D M (eds) Methods of Chemical and Metallurgical Investigation of Ancient Coinage (Roy Numis Soc, Special Publication No. 8), 195-209.

McMillan, A A, Gillanders, R J and Fairhurst, J A 1999 Building Stones of Edinburgh, Edinburgh Geological Society: Edinburgh.

McMillan, M., Hyslop, E., Maxwell, I and Mckinney, A 2006 'Indigenous stone resources for Scotland's Built Heritage', International Association of Engineering Geology Paper Number 825. London.

McSweeney, K 1997 in Mercer, R and Midgley, M (with contributions by Burgess, C., Dickson, C., Finlayson, B. MacDonald, J. McSweeney, $\mathrm{K}$ and Tipping, R) 'The Early Bronze Age cairn at Sketewan, Balnaguard, Perth and Kinross', Proc Soc Antiq Scot 127, 281-338.

McSweeney, K 2008 in Rees, T., Gordon, D and Matthews A (with contributions by K McSweeney, N. Crowley and Photos-Jones, E) 'Excavations within the graveyard of the Holy Trinity, St Andrews, Fife', Tayside and Fife Archaeological Journal 14, 58-68.

Mellars, P and Wilkinson, M 1980 'Fish otoliths as indicators of seasonality in Prehistoric shell middens', Proceedings of the Prehistoric Society 46, 19-44.

Mercer, R and Midgley, M (with contributions by Burgess, C., Dickson, C., Finlayson, B. MacDonald, J. McSweeney, K and Tipping, R) 1997 'The Early Bronze Age cairn at Sketewan, Balnaguard, Perth and Kinross', Proc Soc Antiq Scot 127, 281-338.

Middleton, R and Bunting, M J 2004 'Mosaic v1.1: landscape scenario creation software for simulation of pollen dispersal and deposition', Review of Palaeobotany and Palynology 132, 61-66.

Mieklejohn, C., Merrett, D C., Nolan, R., Richards, M P and Mellars, P A 2005 'Spatial relationships, dating and taphonomy of the human bone from the Mesolithic site of Cnoc Coig, Oronsay, Argyll, Scotland', Proceedings of the Prehistoric Society 71, 85-105.

Milek, K. 2005 Soil micromorphology. in N. Sharples (ed.), A Norse Farmstead in the Outer Hebrides: Excavations at Mound 3, Bornais, South Uist. Oxford: Oxbow Books. 98-104.

Miles, A E W 1989 An early Christian chapel and burial ground on the Isle of Ensay, Outer Hebrides, Scotland, with a study of the skeletal remains, British Archaeological Reports, British Series 212: Oxford.

Miles, A E W and Bulman, J S 1994 'Growth Curves of Immature Bones from a Scottish Island Population of Sixteenth to mid-Nineteenth Century: Limb-bone Diaphyses and Some Bones of the Hand and Foot', International Journal of Osteoarchaeology, 4, 121-136. 
Miles, A E W and Bulman, J S 1995' Growth Curves of Immature Bones from a Scottish Island Population of Sixteenth to mid-Nineteenth Century: Shoulder Girdle, Ilium, Pubis and Ischium' International Journal of Osteoarchaeology, 5, 15-27.

Miller, S and Ruckley, N A 2005 'The role of geological analysis of monuments: a case study from St Vigeans and related sites', in Foster, S M and Cross, M (eds) Able minds and practised hands: Scotland's early medieval sculpture in the 21st century. Society for Medieval Archaeology (Monograph 23), 277-92.

Miller, S., McGibbon, F M., Caldwell, D H and Ruckley, N A 2006 'Geological tools to interpret Scottish medieval carved sculpture: combined petrological and magnetic susceptibility analysis', in Maggetti, M and Messiga, B (eds) Geomaterials in Cultural heritage, Geol. Soc. Spec. Publ. 257, 283305.

Millican, K M 2007 'Turning in circles: a new assessment of the Neolithic Timber Circles of Scotland', Proc Soc Antiq Scot 137, 2-33

Millican, K M 2009 Contextualising the cropmark record: the timber monuments of the Neolithic of Scotland. PhD thesis, University of Glasgow

Mills, C., Armit, I., Grinter, P and Mulder, Y 2004 'Neolithic land-use and environmental degradation: a study from the Western Isles of Scotland', Antiquity 78(302), 886-895.

Mills, C M and Crone, A 2012 'Dendrochronological evidence for Scotland's native timber resources over the last 1000 years', Scottish Forestry 66(1), $18-33$.

Montgomery, J 2002 Lead and strontium isotope compositions of human dental tissues as an indicator of ancient exposure and population dynamics: The application of isotope source-tracing methods to identify migrants among British archaeological burials and a consideration of antemortem uptake, tissue stability and post-mortem diagenesis, Department of Archaeological Sciences. The University of Bradford

Montgomery, J., Evans, J A and Neighbour, T 2003 'Sr isotope evidence for population movement within the Hebridean Norse community of NW Scotland', Journal of the Geological Society 160, 649653.

Montgomery, J and Evans, J A 2006 'Immigrants on the Isle of Lewis - combining traditional funerary and modern isotope evidence to investigate social differentiation, migration and dietary change in the Outer Hebrides of Scotland', in Gowland, R and Knusel, C (eds) The Social Archaeology of Funerary Remains Oxbow Books: Oxford, 122-142.

Moore, P D., Webb, J A and Collinson, M E 1991 ( $2^{\text {nd }}$ edition) Pollen analysis, Blackwell: Oxford.

Moore, H and Wilson, G 2011 (eds) Shifting Sands. Links of Noltland, Westray: Interim Report on Neolithic and Bronze Age Excavations, 2007-09. Historic Scotland. Archaeological Report No. 4

Morris, C D 1989 The Birsay Bay Project Volume 1. Coastal Sites beside the Brough Road, Birsay, Orkney Excavations 1976-82, University of Durham, Dept of Archaeology (Mon.Ser.No 1): Durham. 
Morris, E and Woodward, A 2003 'Ceramic Petrology and prehistoric pottery in the UK', Proceedings of the Prehistoric Society 69, 279-305.

Morris, J 2005 'Red deer's role in social expression on the isles of Scotland', in Pluskowski, A (ed) Just Skin and Bones. New Perspectives on Human-Animal Relations in the Historic Past. British Archaeological Reports International Series 1410: Oxford, 9-18.

Morris, J 2008 'Associated bone groups; one archaeologist's rubbish is another's ritual deposition', in Davis, O., Waddington, $\mathrm{K}$ and Sharples, $\mathrm{N}$ (eds) Changing Perspectives on the First Millennium BC, Oxbow: Oxford, 83-98.

Mukherjee, A J., Gibson, A M., Evershed, R P 2008 'Trends in pig product processing at British Neolithic Grooved Ware sites traced through organic residues in potsherds', Journal of Archaeological Science 35, 2059-73.

Muldner, G and Richards, M P 2005 'Fast or feast: reconstructing diet in later medieval England by stable isotope analysis', Journal of Archaeological Science 32, 39-48.

Muldner, G and Richards, M P 2007a 'Stable isotope evidence for 1500 years of human diet at the city of York, UK', American Journal of Physical Anthropology 133, 682-697.

Muldner, G and Richards, M P 2007b 'Diet and diversity at later medieval fishergate: The isotopic evidence', American Journal of Physical Anthropology 134, 162-174.

Muldner, G., Montgomery, J., Cook, G., Ellam, R., Gledhill, A and Lowe, C 2009 'Isotopes and individuals: diet and mobility among the medieval Bishops of Whithorn', Antiquity 83, 1119-1133.

Mulville, J 1999 'The mammal bone.' in Parker Pearson, M and Sharples, N with Mulville, J and Smith, H Between Land and Sea: Excavations at Dun Vulan, South Uist. Sheffield Academic Press: Sheffield, 234-274.

Mulville, J 2005 'Mammalian Bone; Resource Exploitation, Site Activities and Discussion' in Sharples, N (ed) A Norse Farmstead in the Outer Hebrides. Excavations at Mound 3, Bornais, South Uist. Cardiff Studies in Archaeology. Oxbow: Oxford, 165-168.

Mulville, J., Madgwick, R., Stevens, R., O'Connell, T C., Craig, C., Powell, A., Sharples, N and Pearson, M P 2009 'Isotope Analysis of Faunal Material from South Uist, Western Isles, Scotland', Journal of the North Atlantic 2, 51-59.

Munoz-Salinas, E., Bishop, P., Sanderson, D and Zamorano J 2010 'Interpreting luminescence data from a portable OSL reader : three case studies in fluvial settings', Earth Surface Processes and Landforms 36(5), 651-660.

Murray, D and Ralston, I 1997 'The excavation of a square-ditched barrow and other cropmarks at Boysack Mills, Inverkeilor, Angus', Proc Soc Antiq Scot 127, 359-86. 
Murray, H K and Murray, J C 2010 Westgate residential development, Blackhall Road, Inverurie Phase 3A: Archaeological Evaluation for proposed development. Murray Archaeological Services Ltd, Unpublished Client Report.

Murray, H K and Murray, J C (forthcoming) 'An early Neolithic building and Mesolithic occupation at Garthdee Road Aberdeen'. Proc Soc Antiq Scot

Murray, H K., Murray, J C and Fraser, S 2009 A tale of the unknown unknowns: a Mesolithic pit alignment and a Neolithic timber hall at Warren Field, Crathes, Aberdeenshire. Oxbow: Oxford.

Murray, R (forthcoming) Archaeological Excavations at Culduthel, Phases 7 and 8.

Neighbour, T 2005 (with contributions by Carter, S., Church, M., Johnson, M., McSweeney, K., Milburn, $\mathrm{P}$ and Warren, G) 'Excavation of a Bronze Age Kerbed Cairn at Olcote, Breasclete, Nr. Calanais, Isle of Lewis', Scottish Archaeological Internet Reports [online] 13. Society of Antiquaries of Scotland: Edinburgh. Available at <http://www.sair.org.uk/sair13/index.html> [Accessed 14 December 2011].

Nicholson, R A 1997a 'Fishing in the Northern Isles: a case study based on fish bone assemblages from two multi-period sites on Sanday, Orkney', Environmental Archaeology 2, 15-39.

Nicholson, R A 1997b 'Fish bones', in Buteux S (ed) Settlements at Skaill, Deerness, Orkney. British Archaeological Report 260: Oxford.

Nicholson, R A 1998 'Fishing in the Northern Isles: A case study based on fish bone assemblages from two multi-period sites on Sanday, Orkney'. Environmental Archaeology: The Journal of Human Palaeoecology 2, 15-28.

Oldfield, F 1993 'Forward to the past: changing approaches to Quaternary palaeoecology', in Chambers, F M (ed) Climate change and human impact on the landscape. Chapman and Hall: London, 13-21.

Oldfield, F., Wake, R., Boyle, J., Jones, R., Nolan, S., Gibbs, Z., Appleby, P., Fisher, E and Wolff, G 2003 'The late-Holocene history of Gormire Lake (NE England) and its catchment: a multiproxy reconstruction of past human impact', The Holocene 13, 677-690.

$\mathrm{O}$ ' Reagan, $\mathrm{H}$ and Kitchiner, A 2005 'The effects of captivity on the morphology of captive, domesticated and feral mammals', Mammal Review 35, 215-230.

Ortner, D J 2003 ( $2^{\text {nd }}$ Edition) Identification of Pathological Conditions in Human Skeletal Remains. Academic Press: San Diego.

O'Sullivan, J 1994 (with contributions by Carter, S., Dixon, D., Lorimer, D and Turnbull, G) 'Excavation of an early church and a women's cemetery at St Ronan's medieval parish church, lona', Proc Soc Antiq Scot 124, 327-365, fiche 3:A5-D11.

Outram, Z and Batt, C M 2010 'Dating at Old Scatness' in Dockrill, S J., Bond, J M., Turner, V E., Brown, L D., Bashford, D J., Cussans, J E and Nicholson, R A (eds) The Pictish and Viking Settlement. Excavations at Old Scatness, Shetland, Volume 1. Shetland Heritage Publications: Lerwick, 99-130. 
Owen AW, Armstrong, H A and JD Floyd, 1999 'Rare earth element geochemistry of upper Ordovician cherts from the Southern Uplands of Scotland' Journal of the Geological Society 156,191204.

Owen, O A and Dalland, M 1999 Scar - A Viking boat burial on Sanday, Orkney. Tuckwell Press: East Linton

Palmer, R 2005 'If they used their own photographs they wouldn't take them like that', in Brophy, K and Cowley, D C (eds) From the Air: understanding aerial archaeology, Tempus: Stroud, 94-116.

Panagiotakopulu, E 2001 'Fossil records of ectoparasites', Antenna 25, 41-42.

Panagiotakopulu, E 2004 'Dipterous remains and archaeological interpretation', Journal of Archaeological Science 31, 1675-1684.

Panagiotakopulu, E 2004b 'Pharaonic Egypt and the origins of plague', Journal of Biogeography 31, 269-275.

Parks, R and Barrett, J 2009 'Section 3.11 The zooarchaeology of sand', in Hardy, K and WickhamJones, C (eds) 'Mesolithic and later sites around the Inner Sound, Scotland: the work of the Scotland's First Settlers project 1998-2004', Scottish Archaeological Internet Reports [online] 31. Society of Antiquaries of Scotland: Edinburgh. Available at <http://www.sair.org.uk/sair31/> [Accessed 09 December 2011].

Parker Pearson, M., Sharples, N., Mulville, J and Smith, H 1999 Between Land and Sea: Excavations at Dun Vulan, South Uist Sheffield Academic Press: Sheffield.

Parker Pearson, M., Sharples, N., Symonds, J., Mulville, J., Raven, J., Smith, H and Woolf, A 2004 South Uist: Archaeology and History of a Hebridean Island. Tempus: Stroud.

Passmore, D G and Macklin, M G 1997 'Geoarchaeology of the Tyne Basin: Holocene river valley environments and the archaeological record', in Tolan-Smith, C (ed) Landscape Archaeology in Tynedale, University of Newcastle upon Tyne: Newcastle, 11-27.

Passmore, D G and Waddington, C 2009 Geoarchaeology and Landscape Management in the Tilltweed Catchment, North-East England: Volume 1. Oxbow: Oxford.

Passmore, D G and Waddington, C 2011 Geoarchaeology and Landscape Management in the Tilltweed Catchment, North-East England: Volume 2. Oxbow: Oxford.

Payne, S 1972 'Partial recovery and sample bias. The results of some sieving experiments', in Higgs, E (ed) Papers in Economic Prehistory. Cambridge University Press: Cambridge, 49-63. 
Peters, C., Church, M J and Mitchell, C 2001 'Investigation of fire ash residues using mineral magnetism', Archaeological Prospection 8, 227-237.

Peters, C., Thompson, R., Harrison, A., Church, M J 2002 'Low temperature magnetic characterisation of fire ash residues', Physics and Chemistry of the Earth 27, 1355-1361.

Peters, C., Church, M J and Batt, C 2004 'Application of mineral magnetism in Atlantic Scotland archaeology 1: techniques, magnetic enhancement and the identification of fuel sources' in Housley, R A and Coles, G M (eds) Atlantic Connections and Adaptations: Economies, Environments and Subsistence in Lands Bordering the North Atlantic. Oxbow Books: Oxford, 86-95.

Photos-Jones, E and Atkinson, J 1998 'Iron-working in medieval Perth: a case of town and country?', Proc Soc Antiq Scot 128, 887-904.

Photos-Jones, E., Atkinson, J A., Hall, A J and Banks, I 1998 'The bloomery mounds of the Scottish Highlands. Part 1: the archaeological background', Historical Metallurgy 32 (1), 15-32.

Photos-Jones, E., Hall A J., Ballin-Smith, B and Jones, R E 2007 'The Cramp of the Dead': Vitreous Fuel Ash Waste from Prehistoric Funerary Contexts as a Repository of Cremated Bone', Oxford Journal of Archaeology 26, 1-23.

Piperno, D R 2006 Phytoliths: A Comprehensive Guide for Archaeologists and Paleoecologists. Alta Mira Press: Oxford.

Platt, M I 1934 'Report on the animal remains', in Callander, J G (ed) 'A long stalled cairn or mausoleum near Midhowe, Rousay, Orkney', Proc Soc Antiq Scot 68, 348-350.

Platt, M I 1956 'The animal bone', in Hamilton, J R C (ed) Excavations at Jarlshof, Shetland. HMSO: Edinburgh, 213-215.

Pollard, A M., Batt, C and Stern, B 2007 Analytical Chemistry in Archaeology, Cambridge University Press: Cambridge.

Pollard, T (ed) 2005 'The excavation of four caves in the Geodha Smoo near Durness, Sutherland', , Scottish Archaeological Internet Reports [online] 18. Society of Antiquaries of Scotland: Edinburgh. Available at <http://www.sair.org.uk/sair18/> [Accessed 09 December 2011].

Poller, T 2005 Interpreting Iron Age settlement landscapes of Wigtownshire. PhD thesis, University of Glasgow.

Pollock, D 1985 'The Lunan Valley Project: medieval rural settlement in Angus', Proc Soc Antiq Scot 127, 339-58.

Powers, A 1993 Opal Phytolith Analysis: A Tool for the Investigation of Prehistoric Patterns of Plant and Land Resource Utilizations in a Marginal Island Environment. Unpublished PhD Thesis, University of Sheffield. 
Powers, A H and Gilbertson, D D 1986 'Phytolith Analysis of the Archaeological Sites at Baleshare (North Uist) and Hornish Point (South Uist), Outer Hebrides', Heritage Landscape Programme (Research Report Number 2) University of Sheffield: Sheffield.

Powers, A H., Gilbertson, D D and Jones, G 1986 The prospects for environmental discriminations in coastal sand dunes on the basis of phytolith type and abundance. Unpublished report for SDD.

Powers, A H and Gilbertson, D D 1987 'A simple preparation technique for the study of opal phytoliths from archaeological and Quaternary sediments', Journal of Archaeological Science 14, 529-535.

Powers, A H., Padmore, J and Gilbertson, D D 1989 'Studies of late prehistoric and modern opal phytoliths from coastal sand dunes and machair in northwest Britain', Journal of Archaeological Science 16, 27-45.

Price, T D and Gestsdóttir, H 2006 'The first settlers of Iceland: an isotopic approach to colonisation', Antiquity 80, 130-144.

Pritchard, D K., Mitchell, D S and Kacyra, B 2009 'The applied use of advanced documentation technologies in heritage conservation', ICOMOS Scientific Symposium Conference Proceedings, Valetta, Malta, 7 October 2009. Available at <http://www.international.icomos.org/adcom/malta2009/symposium.htm> Accessed 06/15/2010.

Proctor, C J., Baker, A., Barnes, W L and Gilmour, M A 2000 'A thousand year speleothem proxy record of North Atlantic climate from Scotland', Climate Dynamics 16, 815-820.

Proctor, C.J., Baker, A and Barnes, W L 2002 'A three thousand year record of north Atlantic climate', Climate Dynamics 19, 449-454.

Pyne-O'Donnell, S., Blockley, S P E., Turney, C S M and Lowe, J J 2008 'Distal volcanic ash layers in the Lateglacial Interstadial (GI-1); problems of stratigraphic discrimination', Quaternary Science Reviews 27, 72-84.

Quine, T A 1986 An Evaluation of Soil Analysis for Determining Formation Processes on Archaeological Sites. Unpublished PhD Thesis, University of Strathclyde, Glasgow.

Quye, A 1995 'Historical Plastics come of age', Chemistry in Britain 31(8), 617-620.

Quye, A., Cheape, $\mathrm{H}$ and Burnett, J 2003 'An historical and analytical study of red, pink, green and yellow colours in quality 18th-and early 19th-Century Scottish Tartans', Dyes in History and Archaeology 19, 1-12.

Rackham, D J 1989 'Domestic and wild mammals', in Morris, C D The Birsay Bay Project Volume 1. Coastal Sites beside the Brough Road, Birsay, Orkney Excavations 1976-82, University of Durham, Dept of Archaeology (Mon.Ser.No 1): Durham, 232-247

Raper, D and Bush, M 2009 'A test of Sporormiella representation as a predictor of megaherbivore presence and abundance', Quaternary Research 71, 490-496. 
Rapp, G and Hill, C L 2006 Geoarchaeology: The Earth-Science approach to Archaeological Interpretation. Yale University Press: Newhaven.

RCAHMS 1994 South-east Perth: an archaeological landscape, HMSO: Edinburgh.

RCAHMS 1999 Catalogue of the Luftwaffe Photographs in the National Monuments Record of Scotland, Edinburgh.

RCAHMS 2000 Catalogue of the RAF World War II Photographs in the National Monuments Record of Scotland, Edinburgh.

RCAHMS 2007 In the Shadow of Bennachie: A Field Archaeology of Donside, Aberdeenshire, RCAHMS/Society of Antiquaries of Scotland: Edinburgh.

Redfern, R C., Hamlin, C and Athfield, N B 2010 'Temporal changes in diet: a stable isotope analysis of late Iron Age and Roman Dorset, Britain', Journal of Archaeological Science 37, 1149-1160.

Reed, S., Bailey, N and Onokpise, O 2000 Soil Science for Archaeologists. Florida Agricultural and Mechanical University/Southeast Archaeological Center, National Park Service: Tallahassee. Also available online at <http://www.cr.nps.gov/seac/soils-index.htm> Accessed 09 December 2011.

Rees, T 2004 (with contributions by Crowley, N., Ellis, C., Heald, A., McCullach, R and McSweeney, K 'Excavation of a post-medieval chapel and graveyard at Cille Bhrea, Lemlair, Highland', PostMedieval Archaeology 38(1), 181-209.

Reimer, P J., Hughen, K A., Guilderson, T P., McCormac, G., Baillie, M G L., Bard, E., Barratt, P., Beck, J W., Buck, C E., Damon, P E., Friedrich, M., Kromer, B., Ramsey, C B., Reimer, R W., Remmele, S., Southon, J R., Stuiver, M and van der Plicht, J 2002 'Preliminary report of the first workshop of the IntCal04 radiocarbon calibration/comparison working group', Radiocarbon 44(3), 653-61.

Reimer, P J., Baillie, M G L., Bard, E., Bayliss, A., Beck, J W., Blackwell, P G., Ramsey, C B., Buck, C E., Burr, G S., Edwards, R L., Friedrich, M., Grootes, P M., Guilderson, T P., Hajdas, I., Heaton, T J., Hogg, A G., Hughen, K A., Kaiser, K F., Kromer, B., McCormac, F G., Manning, S W., Reimer, R W., Richards, D A., Southon, J R., Talamo, S., Turney, C S M., van der Plicht, J and Weyhenmeyer, C E 2004 'IntCal04 terrestrial radiocarbon age calibration, 0-26 cal kyr BP', Radiocarbon 46 (3), 1029-1058.

Reimer, P J., Baillie, M G L., Bard, E., Bayliss, A., Beck, J W., Blackwell, P G., Ramsey, C B., Buck, C E., Burr, G S., Edwards, R L., Friedrich, M., Grootes, P M., Guilderson, T P., Hajdas, I., Heaton, T J., Hogg, A G., Hughen, K A., Kaiser, K F., Kromer, B., McCormac, F G., Manning, S W., Reimer, R W., Richards, D A., Southon, J R., Talamo, S., Turney, C S M., van der Plicht, J and Weyhenmeyer, C E 2009 'IntCal09 and Marine09 radiocarbon age calibration curves, 0 - 50,000 years cal BP', Radiocarbon 51(4), 111150.

Reinhardt, L J., Bishop, P., Hoey, T B., Dempster, T J., Sanderson, D C W 2007 'Quantification of the transient response to base-level fall in a small mountain catchment: Sierra Nevada, Southern Spain', Journal of Geophysical Research- Earth Surface 112, F03S05, doi:10.1029/2006JF000524.

Reitz, E J and Wing, E S 2008 ( $2^{\text {nd }}$ Edition) Zooarchaeology Cambridge University Press: Cambridge. 
Richards, C 1996 'Henges and water: towards an elemental understanding of monumentality and landscape in late Neolithic Britain', Journal of Material Culture 1, 313-336.

Richards, M P 2000 'Human consumption of plant foods in the British Neolithic: Direct evidence from bone stable isotopes', in Fairbairn, A S (ed) Plants in the Neolithic Britain and beyond. Oxbow Books,: Oxford, 123-135.

Richards, M P 2004 'The early Neolithic in Britain; new insights from biomolecular archaeology', in Shepard, I and Barclay, G (eds) Scotland in Ancient Europe. Society of Antiquaries of Scotland: Edinburgh, 83-90.

Richards, M P., Hedges, R E M., Molleson, T.I and Vogel, J.C 1998 'Stable isotope analysis reveals variations in human diet at the Poundbury Camp cemetery site', Journal of Archaeological Science $25,1247-1252$.

Richards, M P and Hedges, R E M 1999 'A Neolithic revolution? New evidence of diet in the British Neolithic', Antiquity 73, 891-897.

Richards, M P., Hedges, R E M., Jacobi, R., Current, A and Stringer, C., 2000 'FOCUS: Gough's Cave and Sun Hole Cave human stable isotope values indicate a high animal protein diet in the British Upper Palaeolithic', Journal of Archaeological Science 27, 1-3.

Richards, M P et al. 2001 'Stable isotope evidence for increasing dietary breadth in the European mid-Upper Paleolithic', Proceedings of the National Academy of Sciences of the United States of America, 98(11), 6528-6532.

Richards, M P., Mays, S and Fuller, B T 2002 'Stable carbon and nitrogen isotope values of bone and teeth reflect weaning age at the Medieval Wharram Percy site, Yorkshire, UK', American Journal of Physical Anthropology 119, 205-210.

Richards, M P., Schulting, R J and Hedges, R E M 2003 'Sharp shift in diet at onset of Neolithic', Nature 425, 366.

Richards, M P., Fuller, B T and Molleson, T I 2006 'Stable isotope palaeodietary study of humans and fauna from the multi-period (Iron Age, Viking and Late Medieval) site of Newark Bay, Orkney', Journal of Archaeological Science 33, 122-131.

Ritchie, W A 1966 'The post-glacial rise in sea-level and coastal changes in the Uists', Transactions of the Institute of British Geographers 39, 79-86.

Ritchie, W A 1979 'Machair development and chronology of the Uists and adjacent islands', Proceedings of the Royal Society of Edinburgh B77, 107-122.

Ritchie, W and Whittington, G 1994 'Non-synchronous aeolian sand movements in the Uists: the evidence of the intertidal organic and sand deposits at Cladach Mór, North Uist', Scottish Geographical Magazine 110, 40-46.

Roberts, C and Cox, M 2003 Health \& disease in Britain: from prehistory to the present day, Sutton Publishing: Gloucester 
Roberts, C., Groves, S., Pearson, G., Nowell, G and MacPherson, C 2010 'Health, diet and mobility at the medieval Bowl-Hole cemetery, Bamburgh, Northumberland, England: A contextual study of skeletal and isotopic data', Poster presented at the $79^{\text {th }}$ Annual Meeting of the American Association of Physical Anthropologists, Albuquerque, New Mexico, April 14-17, 2010.

Roberts, C and Manchester, K 2005 ( $3^{\text {rd }}$ edition) The Archaeology of Disease, Alan Sutton Publishing: Stroud.

Roberts, S J., Hodgson, D A., Bentley, M J., Sanderson, D C W., Milne, G., Smith, J A., Verleyen, E and Balbo, A 2009 'Holocene relative sea-level change and deglaciation on Alexander Island, Antarctic Peninsula, from elevated lake deltas', Geomorphology 112, 122-134.

Robinet, L., Eremin, K., Cobo del Arco, B and Gibson, L T 2004 'A Raman spectroscopic study of pollution-induced glass deterioration', Journal of Raman Spectroscopy 35, 662-670.

Rodwell, J S (ed) 2000 British Plant Communities Volume 5. Maritime communities and vegetation of open habitats. Cambridge University Press: Cambridge

Rogers, J and Waldron, T 1995 A Field Guide to Joint Disease in Archaeology. Wiley-Blackwell: London

Rohl, B and Needham, S 1998 The circulation of metal in the British Bronze Age : the application of lead isotope analysis, British Museum: London.

Romans, J C C and Robertson, L 1975 'Soils and archaeology in Scotland', in Evans, J G., Limbrey, S and Cleere, $\mathrm{H}$ (eds) The Effect of Man on the Landscape: the Highland Zone. CBA Research Report 11: London, 37-39.

Romans, J C C and Robertson, L 1983 'The general effects of early agriculture on the soil', in Maxwell, G S (ed) The Impact of Aerial Reconnaissance on Archaeology. CBA Research Report 49: London, 13641.

Roper, T 1999 'The beetles', in Parker Pearson, M and Sharples, N Between land and sea. Excavations at Dun Vulan, South Uist, Sheffield Academic Press: Sheffield, 290-297.

Rose, J and Smith, M J 2008 'Glacial geomorphic maps of the Glasgow region, western-central Scotland', Journal of Maps 2008, 399-416.

Russell, N., Cook, G T., Ascough, P L and Dugmore, A J 2010 'Spatial variation in the MRE throughout the Scottish Post-Roman to Late Medieval period: North Sea values (500 - 1350BP)', Radiocarbon 52, 1166-1181.

Russell, N., Cook, GT., Ascough, P., Barrett ${ }_{2}$ JH and Dugmore ${ }_{2}$ A 2011a 'Species specific marine radiocarbon reservoir effect: a comparison of $\Delta \mathrm{R}$ values between Patella vulgata (limpet) shell carbonate and Gadus morhua (Atlantic cod) bone collagen'. Journal of Archaeological Science 38, 1008-1015.

Russell, N., Cook, G T., Ascough, P L., Scott, E M., Dugmore, A J. 2011b 'Examining the inherent 
variability in $\Delta R$ : new methods of presenting $\Delta R$ values and implications for MRE studies.' Radiocarbon 53(2), 277-288.

Sadler, J P 1993 'Records of modern and fossil Coleoptera from the Orkney Islands', Entomologist's Monthly Magazine 129, 21-23.

Sadler, J P and Buckland, P C 1998 'The biogeography of the Coleoptera of the Orkney Isles of Britain', Proceedings of the 2nd Symposium, Fauna and Flora of the Atlantic Islands. Boletim do Museu Municipal do Funchal (História Natural) Suppl. 5, 363-398.

Sahlen, D 2011 Ceramic Technology and Technological Practice, Unpublished PhD thesis, University of Glasgow.

Sanderson, D C W 1988a 'Fading of Thermoluminescence in Feldpars: Characteristics And Corrections', Nuclear Tracks 14, 155-161.

Sanderson, D C W 1988b 'Thick Source Beta Counting : A Rapid Method For Measuring Beta Dose Rates', Nuclear Tracks 14, 203-207.

Sanderson, D C W 2006 'Thermoluminescence dating results', in 'Dundonald Castle Excavations 1986-1993', Scottish Archaeological Journal 26 (1-2), 117-122.

Sanderson, D C W., Hunter, J R and Warren S E 1983 'The TL Properties Of Archaeological Glass', PACT, 9, 287-293

Sanderson, D C W and Chambers D A 1985 'An Automatic 90-Sr Irradiator For TL Dating', Ancient TL 3, 26-29.

Sanderson, D C W., Placido, F., Tate J O 1985 'Scottish Vitrified Forts: Background And Potential For Thermoluminescence Dating', Nuclear Tracks 10, 799-810.

Sanderson, D C W., Placido, F., Tate J O 1988 'Scottish Vitrified Forts: TL Dating Results From Six Study Sites', Nuclear Tracks 14, 307-316.

Sanderson, D C W., Clark, P A., Dougans, A B and Spencer, J Q 1989a 'TL Dating Using Alkali Feldspars : Sensitivity Range And Minimum Detectable Doses in Long And Short Range Limits In Luminescence Dating', Papers presented to mark the retirement of Professor Martin Aitken, Research Laboratory for Archaeology and the History of Art, University of Oxford: Oxford, 6.

Sanderson, D C W., Clark, R J., Slater C and Cairns, K J 1989b 'TL Dating Using Alkali Feldspars : High Dose Characteristics And Stability Estimates, Papers presented to mark the retirement of Professor Martin Aitken, Research Laboratory for Archaeology and the History of Art, University of Oxford: Oxford, 5.

Sanderson, D C W and Clark, R J 1994 'Pulsed Photostimulated Luminescence Of Alkali Feldspars', Radiation Measurements 23(2/3), 633-639.

Sanderson, D C W., Bishop, P., Houston, I and Boonsener, M 2001 'Luminescence characterisation of quartz-rich cover sands from NE Thailand', Quaternary Science Reviews 20, 893-900. 
Sanderson, D C W., Bishop, P., Stark, M T., Spencer J Q 2003 'Luminescence dating of Anthropogenically reset sediments from Angkor Borei, Mekong Delta, Cambodia', Quaternary Science Reviews 22 (10-13), 1111-1122.

Sanderson, D C W., Bishop P., Stark, M., Alexander, S and Penney, D 2007 'Luminescence dating of canal sediments from Angkor Borei, Mekong Delta, Southern Cambodia', Quaternary Geochronology, 2(1-4), 322-329.

Sanderson, D C W and Murphy, S 2010 'Using simple portable OSL measurements and laboratory characterisation to help understand complex and heterogeneous sediment sequences for luminescence dating', Quaternary Geochronology 5, 299-305.

Sands, R and Hale, A 2001 'Evidence from marine crannogs of later prehistoric land use of the Firth of Clyde', Journal of Wetland Archaeology 1, 41-54.

Schaefer, M., Black, S and Scheuer, L 2009 Juvenile Osteology: A Laboratory and Field Manual. Elsevier Academic Press.

Schelvis, J 1997 'Mites in the background: Use and origin of remains of mites (Acari) in Quaternary deposits', in Ashworth, A C., Buckland, P C and Sadler, J P (eds) 'Studies in Quaternary Entomology An Inordinate Fondness for Insects', Quaternary Proceedings 5, 233-236.

Schiffer, M B 1987 Formation Processes and the Archaeological Record. Salt Lake City: University of Utah Press.

Schoeninger, M J., DeNiro, M J and Tauber, H 1983 'Stable nitrogen isotope ratios of bone collagen reflect marine and terrestrial components of prehistoric human diet', Science 220, 1381-1383.

School of GeoSciences 2010 Tephrochronology Analytical Unit. http://www.geos.ed.ac.uk/facilities/tephra/.

Schulting, R and Richards, M P 2002a 'Finding the coastal Mesolithic in southwest Britain: AMS dates and stable isotope results on human remains from Caldey Island, south Wales', Antiquity 76, 1011 1125.

Schulting, R J and Richards, M P 2002b Dogs, ducks, deer and diet: 'New stable isotope evidence on Early Mesolithic dogs from the Vale of Pickering, North-East England', Journal of Archaeological Science 29, 327-333.

Schulting, R J and Richards, M P 2002c 'The wet, the wild and the domesticated: The MesolithicNeolithic transition on the West coast of Scotland', European Journal of Archaeology 5, 147-189.

Schulting, R.J., Trinkaus, E., Higham, T., Hedges, R., Richards, M and Cardy, B 2005 'A Mid-Upper Palaeolithic human humerus from eel point, South Wales, UK', Journal of Human Evolution 48, 493505. 
Schwenninger, J L 1999 'The soil micromorphology', in Parker Pearson, M., Sharples, N., Mulville, J and Smith, $\mathrm{H}$ (eds) Between Land and Sea: Excavations at Dun Vulan, South Uist. Academic Press: Sheffield, 336-342.

Scott, D A 1991 Metallography and microstructure of ancient and historic metals. Getty Conservation Institute in association with Archetype Books: Los Angeles.

Scott E M and Sanderson D C W 1988 'Statistics And The Additive Dose Method In TL Dating', Nuclear Tracks 14, 345-354.

Serjeantson, D 2001 'The great auk and the gannet: a prehistoric perspective on the extinction of the great auk', International Journal of Osteoarchaeology, 11 (1-2), 43-55.

Serjeantson, D 2005 'Archaeological records of a gadfly petrel Pterodroma sp. from Scotland in the first millennium A.D. ', Documenta Archaeobiologiae 3, 235-246.

Serjeanstson, D 2009 Birds Cambridge University Press: Cambridge.

Serjeantson, D., Smithson, V and Waldron, T 2005 'Animal husbandry and the environmental context', in Ritchie, A. (ed) Kilellan Farm, Ardnave, Islay: excavations of a prehistoric to early medieval site by Colin Burgess and others 1954-76. Society of Antiquaries of Scotland: Edinburgh, 151-67.

Shahack-Gross, R 2011 'Herbivorous livestock dung: formation, taphonomy, methods for identification, and archaeological significance', Journal of Archaeological Science 38, 205-218.

Shepherd, I A G and Bruce, M F 1986 Powerful pots: Beakers in north-east prehistory. University of Aberdeen, Anthropological Museum: Aberdeen.

Sheridan, A., Davis, M., Clark, I and Redvers-Jones, H 2002 'Investigating jet and jet-like artefacts from prehistoric Scotland: the National Museums of Scotland project', Antiquity 76, 812.

Sheridan, A and Shortland, A 2004 'Faience in Early Bronze Age Ireland', in Shepherd, I A G and Barclay, G J (eds) Scotland in Ancient Europe: The Neolithic and Early Bronze Age of Scotland in their European Context. Society of Antiquaries of Scotland: Edinburgh.

Shiel, R and Askew, G P 1988 'Descriptions of thin sections taken from plaggen layers at lona', Proc Soc Antiq Scot 118, fiche 3: A5-114.

Siame, L L., Bourlès, D L and Brown, E T (eds) 2006 In situ-produced Cosmogenic Nuclides and Quantification of Geological Processes, Geological Society of America Special Paper 415.

Simpson, I A 1985 'Stable carbon isotope analysis of anthropogenic soils and sediments in Orkney', in Fieller, N R J., Gilbertson, D D and Ralph, N G A (eds) Palaeoenvironmental Investigations. British Archaeological Reports, International Series 258: Oxford, 55-65.

Simpson, I and Barrett, J H 1996 'Interpretation of midden formation processes at Robert's Haven, Caithness, Scotland using thin section micromorphology', Journal of Archaeological Science 23, 543556. 
Simpson, I A., Bol, R., Dockrill, S J., Petzke, K J and Evershed, R P 1997 'Compound-specific $\delta^{15} \mathrm{~N}$ amino acid signals in palaeosols as indicators of early land use: a preliminary study', Archaeological Prospection 4, 147-52.

Simpson, I A., Dockrill, S J., Bull, I D and Evershed, R P 1998 'Early anthropogenic soil formation at Tofts Ness, Sanday, Orkney', Journal of Archaeological Science 25, 727-46.

Simpson, I A., van Bergen, P F., Perret, V., Elhmmali, M M., Roberts, D J and Evershed, R P 1999 'Lipid biomarkers of manuring practice in relict anthropogenic soils', The Holocene 9 (2), 223-229.

Simpson, I A and Guttmann, E B 2002 'Transitions in early arable land management in the Northern Isles: the Papar as agricultural innovators?', in Crawford, B (ed) The Papar of the North Atlantic: Environment and History, University of St Andrews: St Andrews (St John's House papers No.10), 5967.

Simpson, I A., Barrett, J H and Milek, K B 2005 'Interpreting the Viking age to Medieval period transition in Norse Orkney through cultural soil and sediment analyses', Geoarchaeology 20, 357379.

Simpson, I A., Dockrill, S J., Guttmann, E., Bull, I D and Evershed, R P 2007 'Soils and the early cultural landscape', in Dockrill. S J (ed) Investigations in Sanday, Orkney Volume 2: Tofts Ness, Sanday. An island landscape through 3,000 years of prehistory. Historic Scotland: Edinburgh, 239-252.

Skidmore, P 1995 'Analysis of fly remains from F23 in the stone-lined pit (F22)', in McCormick, F 'Excavation at Pluscarden Priory, Moray', Proc Soc Antiq Scot 124, 418-419.

Skidmore, P 1996 A Dipterological Perspective on the Holocene History of the North Atlantic Area. Unpublished Ph.D., University of Sheffield.

Skidmore, P 2000 'Diptera analysis', in Crone, A The history of a Scottish lowland crannog: excavations at Buiston, Ayrshire, Scottish Trust for Archaeological Research Monograph 4, Edinburgh, 252-254.

Skinner T, 2010 'Appendix 1' in Strachan, D Carpow in Context Society of Antiquaries of Scotland: Edinburgh, 191-198.

Smith, A B and Epstein, S 1971 'Two categories of 13C/12C ratios for higher plants', Plant Physiology $47,380-384$.

Smith, C 1996 'The animal bone' in Coleman, R J 'Burgage plots of medieval Perth: the evidence from excavations at Canal Street', Proc Soc Antiq Scot 126, 689-732.

Smith, C 1998 'Dogs, cats and horses in the Scottish Mediaeval town', Proc Soc Antiq Scot 128, 859885.

Smith, C 2000 'A grumphie in the sty: an archaeological view of pigs in Scotland, from their earliest domestication to the agricultural revolution', Proc Soc Antiq Scot 130, 705-724. 
Smith, C 2009 'The Animal Bone', in White, R H M and O'Connel, C 'Excavations on the Site of Balmerino House, Constitution Street, Leith', Scottish Archaeological Internet Reports [online] 41. Society of Antiquaries of Scotland: Edinburgh. Available at <http://www.sair.org.uk/sair41/index.html> [Accessed 12 December 2011].

Smith, D N 1996 'Thatch, turves and floor deposits: a survey of Coleoptera in materials from abandoned Hebridean blackhouses and the implications for their visibility in the archaeological record', Journal of Archaeological Science 23, 161-174.

Smith, D 2002 'The insect remains', in Ellis, C 'Excavation of two ditches and a medieval grain-drying kiln, Inverness, Highland', Proc Soc Antiq Scot 132, 430-431.

Smith, H 1996 'An investigation of site formation processes on a traditional Hebridean farmstead using environmental and geoarchaeological techniques', in Gilbertson, D., Kent, M and Grattan, J (eds) The Outer Hebrides: The Last 14,000 Years. Sheffield Academic press: Sheffield, 195-206.

Smith, H., Marshall, P and Parker Pearson, M 2001 'Reconstructing house activity areas', in Albarella, $\mathrm{U}$ (ed) Environmental Archaeology: Meaning and Purpose. Kluwer Academic Publishers: Dordrecht, 249-270.

Smith, I M 1991 'Sprouston, Roxburghshire: an early Anglian centre of the eastern Tweed ', Proc Soc Antiq Scot 121, 261-94.

Smith, M J., Rose, J and Booth, S 2006 'Geomorphological mapping of glacial landforms from remotely-sensed data: an evaluation of the principal data-sources and an assessment of their quality', Geomorphology 76, 148-165.

Smith, M J., Brickley, M B., Leach, S L 2007 'Experimental evidence for lithic projectile injuries: improving identification of an under-recognised phenomenon', Journal of Archaeological Science 34, 540-553.

Smith, M J and Pain, C F 2011 'Geomorphological mapping', in Gregory, K J and Goudie, A S (eds) The SAGE Handbook of Geomorphology. SAGE Publications: London.

Solazzo, C et al. 2008 'Identification of protein remains in archaeological potsherds by proteomics', Analytical Chemistry 80(12), 4590-4597.

Sommerville, A A 2003 Luminescence Dating of Windblown Sands from Archaeological Sites in Northern Scotland., Unpublished PhD Thesis, University of Glasgow

Sommerville, A A., Sanderson, D C W., Hansom, J D and Housley, R A 2001 'Luminescence dating of aeolian sands from archaeological sites in Northern Britain: a preliminary study', Quarternary Science Reviews 20, 913-919.

Sommerville, A A., Hansom, J D., Sanderson, D C W and Housley, R A 2003 'Optically Stimulated Luminescence Dating of Large Storm Events in Northern Scotland', Quaternary Science Reviews 22 (10-13), 1085-1092. 
Sommerville, A A, Hansom, J D., Housley, R A and Sanderson, D C W 2007 'Optically Stimulated Luminescence (OSL) Dating Of Coastal Aeolian Sand Accumulation In Sanday, Orkney Islands, Scotland', The Holocene 17 (5), 1-11.

Spencer, J Q 1996 The development of luminescence methods to measure thermal exposure in Lithic and Ceramic Materials, Unpublished PhD Thesis. University of Glasgow

Spencer, J Q and Sanderson, D C W 1994 'Mapping Thermal Exposure By Luminescence Thermometry', Radiation Measurements 23 (2/3), 465-468.

Spencer, J Q., Sanderson, D C W., Deckers, K and Sommerville, A A 2003 'Assessing mixed dose distributions in young sediments identified using small aliquots and a simple two-step SAR procedure : the F-statistic and a diagnostic tool', Radiation Measurements 37, 425-431.

St Joseph, J K S 1976 'Air Reconnaissance of Roman Scotland, 1939-75', Glasgow Archaeological Journal 4, 1-28.

Stark, M.S., Sanderson, D C W and Bingham, R.G 2006 'Monumentality in the Mekong Delta : Luminescence dating and Implications', Indo-Pacific Prehistory Bulletin 26, 110-120.

Steier, P and Rom, W 2000 'The Use of Bayesian Statistics for1 4C Dates of Chronologically Ordered Samples: A Critical Analysis', Radiocarbon 42(2), 183-198. Also available online at http://homepage.univie.ac.at/peter.steier/Bayes.prn.pdf. Accessed 12 December 2011.

Stell, G and Baillie, M 1993 'The Great Hall and roof of Darnaway Castle, Moray', in Sellar, W D H (ed) Moray: province and people Edinburgh, $163-86$.

Stephens, C., Jones, R E and Gater, J 2008 'Geophysical survey on the Antonine Wall', in Breeze, D and Jilek, S (eds) Frontiers of the Roman Empire Pen \& Sword Military: Edinburgh, 79-93.

Sternberg, R S 1992 'Radiocarbon fluctuations and the geomagnetic field', in Taylor, R E., Long, A and Kra, R S (eds) Radiocarbon After Four Decades, Springer-Verlag: New York, 93-116.

Stevens, R E., Lister, A M and Hedges, R E M 2006 'Predicting diet, trophic level and palaeoecology from bone stable isotope analysis: a comparative study of five red deer populations', Oecologia 149, $12-21$.

Stevens, R E., Jacobi, R M and Higham, T F G 2010 'Reassessing the diet of Upper Palaeolithic humans from Gough's Cave and Sun Hole, Cheddar Gorge, Somerset, UK', Journal of Archaeological Science $37,52-61$.

Stevens et al. 2010 'Evaluation of microwave-assisted enzymatic digestion and tandem mass spectrometry for the identification of protein residues from an inorganic solid matrix: implications in archaeological research', Analytical and Bioanaytical Chemistry 396 (4), 1491-1499.

Stos-Gale, Z A and Gale, N H 2009 'Metal provenancing using isotopes and the Oxford archaeological lead isotope database (OXALID)', Archaeological and Anthropological Sciences 1(3), 195-213. 
Stone, J., Lambeck, K., Fifield, L K., Evans, J M and Cresswell, R G 1996 'A Lateglacial age for the Main Rock Platform, western Scotland', Geology 24, 707-710.

Stroeven, A P., Fabel, D., Codilean, A T., Kleman, J., Clague, J J., Miguens-Rodriguez, M and Xu, S 2010 'Investigating the glacial history of the northern sector of the Cordilleran Ice Sheet with cosmogenic

${ }^{10}$ Be concentrations in quartz'. Quaternary Science Reviews 29, 3630-3643.

Stuiver, M 1961 'Variations in radiocarbon concentration and sunspot activity', Journal of Geophysical Research 66, 273.

Stuiver, M., Reimer, P J and Braziunas, T F 1998 'High-precision radiocarbon age calibration for terrestrial and marine samples', Radiocarbon 40, 1127-1151.

Suess, H E 1953 'Natural radiocarbon and the rate of exchange of carbon dioxide between the atmosphere and the sea', in Aldrich, W (ed) Nuclear Processes in Geologic Settings, University of Chicago Press: Chicago, 52-56.

Suess, H E 1955 'Radiocarbon concentration in modern wood', Science 122, 415-417.

Surowiec, I., Quye, A and Trojanowicz, M 2006 'Liquid chromatography determination of natural dyes in extracts from historic Scottish textiles excavated from peat bogs', Journal of Chromatography A $1112(1-2,209-217$.

Tate, J 1986 'Some problems in analysing museum material by nondestructive surface sensitive techniques', Nuclear Instruments and Methods in Physics Research Section B: Beam Interactions with Materials and Atoms 14(1), 20-23.

Tate, J., Troalen, L and Hunter, F 2008 Investigating the Traprain Law Roman Treasure. Eu-ARTECH experimental report.

Thomas, R and Mainland, I 2005 'Introduction: animal diet and health - current perspectives and future directions', in Davies, J., Fabis, M., Mainland, I., Richards, M and Thomas, R. Diet and Health in past animal populations: current research and future directions. Oxbow: Oxford, 1-7.

Thomas, J., Simpson, I A and Davidson, D A 2007 'GIS mapping of anthropogenic soils in Scotland: Investigating the location and vulnerability of Scottish plaggen-type soils', Atti della Società Toscana di Scienze Naturali. Memorie Serie A. 112, 85-90.

Thórarinsson, S 1944 ‘Tefrokronoliska studier på Island', Geografiska Annaler 26, 1-217.

Thórarinsson, S 1981 'The application of tephrochronology in Iceland', in Self, S and Sparks, R S J (eds) Tephra Studies, Dordrecht: Reidel, 109-134.

Tilley, C 1994 A Phenomenology of Landscape: Places, Paths and Monuments. Berg: Oxford.

Tilley, C., Hamilton, S., Harrison, S and Andersen, E 2000 'Nature, culture, clitter: distinguishing between cultural and geomorphological landscapes: the case of tors in South-west England', Journal of Material Culture V, 197-224. 
Timberlake, S 2001 'Mining and prospection for metals in Early Bronze Age Britain - making claims within the archaeological landscape', in Bruck, J (ed) Bronze Age Landscapes. Tradition and Transformation. Oxbow: Oxford, 179-192.

Timpany, S., Haston, S-J and Scott, L (forthcoming) 'The Environmental Remains' in Jones, E and Sheridan, A (eds) Pots, pits and roundhouses at Meadowend Farm, Clackmannan. Society of Antiquaries of Scotland

Tipping, R 1992 'The determination of cause in the generation of major prehistoric valley fills in the Cheviot Hills, Anglo-Scottish Border', in Needham, S and Macklin, M G (eds) Alluvial Archaeology In Britain. Oxbow: Oxford, 111-121.

Tipping, R 1994 'The form and fate of Scotland's woodlands', Proc Soc Antiq Scot 124, 1-54.

Tipping, R 2010 Bowmont. An environmental history of the Bowmont Valley and the northern Cheviot Hills, $10000 B C-A D$ 2000. Society of Antiquaries of Scotland: Edinburgh.

Tipping, R and Milburn, P 2000 'Mid-Holocene charcoal fall in southern Scotland - temporal and spatial variability', Palaeogeography, Palaeoclimatology, Palaeoecology 164, 177-193.

Tipping, R., Haggart, B A., Milburn, P A and Thomas, J 2004 'Landscape perception in early Bronze Age henge construction at The Pict's Knowe, southern Scotland: a palaeoenvironmental perspective', in Carver, E and Lelong, O (eds) Modern Views - Ancient Lands. New Work and Thought on Cultural Landscapes. Archaeopress: Oxford, 33-40.

Tipping, R., Ashmore, P., Davies, A L., Haggart, B A., Moir, A., Newton, A., Sands, R., Skinner, T and Tisdall, E 2008a 'Prehistoric Pinus woodland dynamics in an upland landscape in northern Scotland: the roles of climate change and human impact', Vegetation History and Archaeobotany 17, 251-267.

Tipping, R., Davies, A., McCulloch, R and Tisdall, E 2008b 'Response to Late Bronze Age climate change of farming communities in north east Scotland', Journal of Archaeological Science 35, 23792386.

Tipping, R., Jones, A P., Carter, S., Holden, T and Cressey, M 2008c 'The chronology and long term dynamics of a low energy river system: the Kelvin Valley, central Scotland', Earth Surface Processes and Landforms 33, 910-922.

Tipping, R., Bunting, M J., Davies, A L., Murray, H., Fraser, S and McCulloch, R 2009 'Modelling land use around an early Neolithic 'timber hall' in north east Scotland from high spatial resolution pollen analyses', Journal of Archaeological Science 36, 140-149.

Topping, P G 1985 The pottery of the later prehistoric period in the western isles of Scotland, Unpublished PhD thesis, University of Edinburgh.

Topping, P G and MacKenzie, A B 1988 'A test of the use of Neutron Activation Analysis for clay source characterisation', Archaeometry 30, 92-101. 
Troalen, L G., Cox, D., Skinner, T., Ramsey, A and Bate, D 2010 'Three-Dimensional Computed Tomography X-Radiographic Investigation of a 17th-Century Watch from the Wreck of the Swan, off Duart Point, Mull, Scotland', International Journal of Nautical Archaeology 39(1), 165-171.

Trouet, V., Esper, J., Graham, N.E. et al. 2009 'Persistent positive North Atlantic Oscillation mode dominated the Medieval Climate Anomaly', Science 324, 78-80.

Turner, V., Chrystall, F., Simpson, I A and Guttmann, E B 2004 'Form and function in Shetland prehistoric field systems', in Housley, R and Coles, G (eds) The North Atlantic: Culture and Environment. Oxbow Monographs: Oxford, 120-127.

Turner, V E., Guttmann-Bond, E B A., Burbidge, C I and Simpson, I A 2010 'Old Scatness: the Viking and Norse anthrosols', in Dockrill, S J., Bond, J M., Turner, V E., Brown, L D., Bashford, D J., Cussans, J E and Nicholson, R A (eds) The Pictish and Viking Settlement. Excavations at Old Scatness, Shetland, Volume 1. Shetland Heritage Publications: Lerwick, 197-203.

Turner, W 1895 'On human and animal bones and flints from a cave at Oban, Argyllshire', Proc Soc Antiq Scot 29, 41-438.

Turney, C S M., Harkness, D D and Lowe, J J 1997 'The use of microtephra horizons to correlate Lateglacial lake sediment successions in Scotland', Journal of Quaternary Science 12(6), 525-531.

Vacca, E and Delfino, V P 2004 'Three-dimensional topographic survey of the human remains in Lamalunga Cave (Altamura, Bari, Southern Italy)', Collegium Antropologicum 28 (1), 113-119.

van Geel, B., Buurman, J., Brinkkemper, O., Schelvis, J., Aptroot, A., van Reenen, G and Hakbijl, T 2003 'Environmental reconstruction of a Roman Period settlement site in Uitgeest (The Netherlands), with special reference to coprophilous fungi', Journal of Archaeological Science 30, 873-883.

Verri, G., Barkai, R., Gopher, A., Hass, M., Kubik, P W., Paul, M., Ronen, A., Weiner, S and Boaretto, E 2005 'Flint procurement strategies in the Late Lower Palaeolithic recorded by in situ produced cosmogenic Be-10 in Tabun and Qesem Caves (Israel)', Journal of Archaeological Science 32, 207213.

Vogel, H et al. 2008 'Fourier transform infrared spectroscopy, a new cost-effective tool for quantitative analysis of biogeochemical properties in long sediment records', Journal of Paleolimnology 40, 689-702.

Waldron, T 2007 Palaeoepidemiology: The Measure of Disease in the Past. Left Coast Press: Walnut Creek, CA.

Waldron, T 2009 Palaeopathology (Cambridge Manuals in Archaeology). Cambridge University Press: Cambridge.

Walker, B and McGregor, C 1996 Earth Structures and Construction in Scotland, Historic Scotland Technical Advice Note 6, Historic Scotland: Edinburgh. 
Walker, M J C 1984 'Pollen analysis and Quaternary research in Scotland', Quaternary Science Reviews 3, 369-404

Walker, P L., Miller, K W P and Richman, R 2008 'Time, temperature and oxygen availability: an experimental study of the effects of environmental conditions on the colour and organic content of cremated bone', in Schmidt, C W and Symes, S A (eds) The Analysis of Burned Human Remains. Academic Press: London, 129-135.

Walsh, J A 2000 Scottish slate quarries. Historic Scotland Technical Advice Note 21. Historic Scotland: Edinburgh.

Warsop, C 2000 'Plants by proxy: plant resources on a Neolithic crannog as indicated by insect remains', in Fairbairn, A S (ed) Plants in Neolithic Britain and beyond. (Neolithic studies group seminar papers 5) Oxbow Books: Oxford, 37-47.

Warsop, C and Skidmore, P 1998 'Insect remains from the rock-cut pit', in Ewart, G and Baker, F 'Carrick Castle: symbol and source of Campbell power in south Argyll from the $14^{\text {th }}$ to the $17^{\text {th }}$ century', Proc Soc Antiq Scot 128, 987-992.

Wells, C E., Hodgkinson, D and Huckerby, E 2000 'Evidence for the role of beaver (Castor fiber L.) in the prehistoric ontogenesis of a mire in northwest England, UK', The Holocene 10, 503-508.

Wells, L H 1952. 'Notes on the human skeletal fragments from the Quoyness Cairn', in Childe, V G 'Re-excavation of the chambered cairn of Quoyness, Sanday, on behalf of the Ministry of Works in 1951-52', Proc Soc Antiq Scot 86, 123-139.

White, T D and Folkens, P A 2005 The Human Bone Manual. Academic Press: San Diego.

Whittington, G and Edwards, K J 1999 'Soil pollen studies at the Biggings', in Crawford, B E and Ballin Smith, B (eds) The Biggings, Papa Stour, Shetland: The History and Excavation of a Royal Norwegian Farm. Society of Antiquaries of Scotland (Monograph Series 15): Edinburgh, 100-104.

Wilkinson, K., Tyler, A., Davidson, D and Grieve, I 2006 'Quantifying the threat to archaeological sites from the erosion of cultivated soil', Antiquity 80(309), 658-670.

Willenbring, J K and von Blanckenburg, F 2010 'Meteoric cosmogenic Beryllium-10 adsorbed to river sediment and soil: Applications for Earth-surface dynamics', Earth-Science Reviews 98, 105-122.

Williams, D 1973 'Flotation at Siraf', Antiquity 47, 198-202.

Williams Thorpe, O and Thorpe, R S 1984 'The Distribution and Sources of Archaeological Pitchstone in Britain', Journal of Archaeological Science 11, 1-34.

Winterbottom, S J and Dawson, T 2005 'Airborne Multi-spectral Prospection For Buried Archaeology in Mobile Sand Dominated Systems'. Archaeological Prospection 12(4), 205-219.

Wilson, C A., Davidson, D A and Cresser, M S 2005 'An evaluation of multi-element analysis of soil contamination to differentiate space use and former function in and around abandoned farms', The Holocene 15, 1094-1099. 
Wilson, C A., Bacon, J R., Cresser, M S and Davidson, D A 2006a 'Lead isotope ratios as a means of sourcing anthropogenic lead in archaeological soils: a pilot study of an abandoned Shetland croft', Archaeometry 48, 501-509.

Wilson, C A., Cresser, M S and Davidson, D A 2006b 'Sequential element extraction of soils from abandoned farms: an investigation of the partitioning of anthropogenic element inputs from historic land use', Journal of Environmental Monitoring 8, 439-444.

Wilson, C A., Davidson, D A and Cresser, M S 2006c 'Evaluating the use of multi-element soil analysis as an aid to archaeological interpretation', in Jones, R E and Sharpe, L (eds) Going over old ground. British Archaeological Reports, British Series 416: Oxford, 143-147.

Wilson, C A., Davidson, D A and Cresser, M S 2007 'Evaluating the use of multi-element soil analysis in archaeology: a study of a post-medieval croft (Olligarth) in Shetland', Atti della Società Toscana di Scienze Naturali. Memorie serie A. 112, 69-77.

Wilson, C A., Davidson, D A., Cowie, J., Cairns, D and Blunn, M 2008a 'Soil Analysis Support System for Archaeologists: developing SASSA', Internet Archaeology [online] 25. Available at <http://intarch.ac.uk/journal/issue25/wilson index.html> [Accessed 12 December 2011].

Wilson, C A., Davidson, D A and Cresser, M S 2008b 'Multi-element soil analysis: an assessment of its potential as an aid to archaeological interpretation', Journal of Archaeological Science 35, 412-424.

Wilson, C A., Davidson, D A and Cresser, M S 2009 'An evaluation of the site specificity of soil elemental signatures for identifying and interpreting former functional areas', Journal of Archaeological Science 36, 2327-2334.

Wilson, C A., Davidson, D A., Cairns, D., Cowie, J and Blunn, M 2010 'SASSA: an open source, Wiki soil based knowledge and decision support tool for archaeologists', in Gilkes, R J and Prakongkep, N (eds) Proceedings of the 19th World Congress of Soil Science: Soil Solutions for a Changing World, Symposium 4.4.1 Delivering soils information to non-agriculture users (published on DVD), 19-22.

Wilson, L A., MacLeod, N and Humphrey, L T 2008 'Morphometric Criteria for Sexing Juvenile Human Skeletons Using the llium', Journal of Forensic Sciences 53 (2), 26-278.

Wilson, L., Mitchell, D S., Davey, A and Pritchard, D 2010 'Digital Documentation of Historic Ferrous Metal Structures: 3D Laser Scanning as a Conservation Tool', in Mardikian, P., Chemello, C., Watters, $\mathrm{C}$ and Hull, $\mathrm{P}$ (eds) Metal 10, International Conference on Metal Conservation. Interim Meeting of the International Council of Museums Committee for Conservation Metal Working Group. October 11-15 2010, Charleston, USA, Clemson University Press: Charleston, 279-286.

Wilson, L., Rawlinson, A., Mitchell, D S., Pritchard, DK and McGregor, H C 2011a'3D Documentation of Global Historic Sites: The 'Scottish Ten' Project and its Applications for Cultural Heritage', Proceedings of 3D-ARCH 2011 Conference, 2-5 March 2011, Trento, Italy. The International Archives of the Photogrammetry, Remote Sensing and Spatial Information Sciences, 38-5, W16. 
Wilson, L A., Cardoso, H F V and Humphrey, L T 2011b 'On the reliability of a geometric morphometric approach to sex determination: a blind test of six criteria of the juvenile ilium', Forensic Science International 206, 35-42.

Wilson, R., Loader, N., Rydval, M., Paton, H., Frith, A., Mills, C., Crone, A., Edwards, C., Larson, L and Gunnarson, B 2011 'Reconstructing Holocene climate from tree rings - the potential for a long chronology from the Scottish Highlands', The Holocene 22(1), 3-11.

Wilthew, P T., Tate, J O and Dalgleish, G R 1988 'An XRF survey of Scottish pewter measures', in Slater, E and Tate, J Science and Archaeology Glasgow 1987 : proceedings of a conference on the application of scientific techniques to archaeology, Glasgow, September, 1987, British Archaeological Reports British Series 196: Oxford, 275-282.

Woodland, W A., Charman, D J and Sims, P C 1998 'Quantitative estimates of water tables and soil moisture in Holocene peatlands from testate amoebae', The Holocene 8, 261-273.

Yalden, D W 2001 'Mammals as climatic indicators', in Brothwell, D R and Pollard, A M (eds) Handbook of Archaeological Sciences. Wiley: Chichester, 147-154.

Young, A 1996 'The skeletal material', in Proudfoot, E 'Excavations at the Long Cist on the Hallow Hill, St Andrews, Fife, 1975-7', Proc Soc Antiq Scot 126, 387-354.

Young, M E, Urquhart, D C M and Laing, R A 2003 Maintenance and repair issues for stone cleaned sandstone and granite building facades, Building and Environment 38, Issues 9-10

Youngblood, E., Fredriksson, B J., Kraut, F and Fredriksson, K 1978 'Celtic vitrified forts: implications for a chemical-petrological study of glasses and source rocks', Journal of Archaeological Science 5, 99-121.

Zananiri, I., Batt, C M., Lanos, P., Tarling, D H and Linford, P 2007 'Archaeomagnetic secular variation in the UK during the past 4000 years and its application to archaeomagnetic dating'. Physics of The Earth and Planetary Interiors 160 (2), 97-107. 